\title{
ESTUDO DO COMPORTAMENTO GEOQUÍMICO DOS METAIS PESADOS NOS SEDIMENTOS DA REGIÃO ESTUARINA DO RIO PARAGUAÇU - BAHIA
}

SUELY SCHUARTZ PACHECO MESTRINHO

Orientador: Prof. Dr. Aldo da Cunha Rebouças

TESE DE DOUTORAMENTO

COMISSÃO JULGADORA

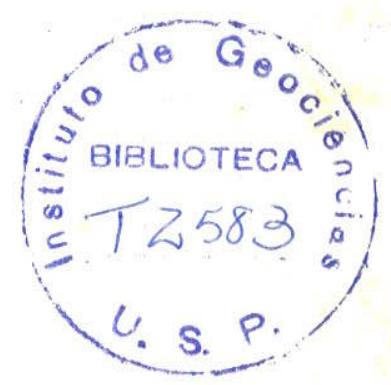

Nome

Presidente:

Examinadores: Prof. Dr. Kenitiro Suguio

Prof. Dr. Luiz Drude de Lacerda

Prof. Dr. Sambasiva Rao Patchineelam

Prof. Dr. Vicente José Fulfaro

Prof. Dr. Aldo da Cunha Rebouças

Assinatura

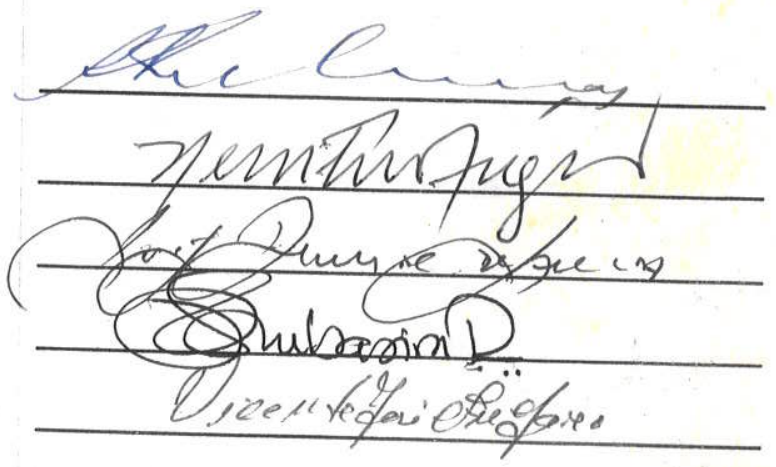

SÃO PAULO

1998 


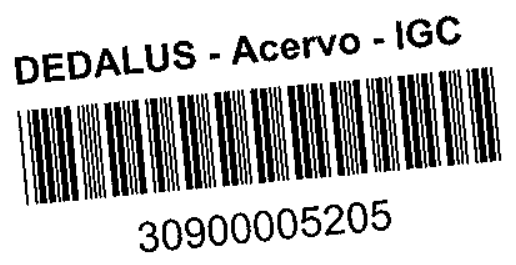

Esta obra começou quando nasci. A todos Aqueles que me ajudaram - tenho certeza, estão cientes o meu coração agradece. 


\section{RESUMO}

Este estudo foi desenvolvido na região estuarina do rio Paraguaçu, caracterizada por um sistema transicional de influências fluvial, controlada pela descarga da barragem de Pedra do Cavalo, e marinha, proveniente das águas da baía de Todos os Santos.

Com o objetivo de verificar a distribuição e o comportamento geoquímico do $\mathrm{Cu}$, $\mathrm{Cd}, \mathrm{Pb}, \mathrm{Cr}, \mathrm{Zn}, \mathrm{Fe}, \mathrm{Al}$ e $\mathrm{Mn}$ no material particulado em suspensão e nos sedimentos de fundo, quinze pontos de amostragem foram investigados ao longo do complexo estuarino, durante oito campanhas planejadas, entre o período 1994-1995, de acordo com a sazonalidade e a dinâmica das marés de sizígia e quadratura. Um ponto fixo foi monitorado para o material particulado em suspensão e parâmetros físico-químicos associados, durante doze horas, em diferentes ciclos de marés enchente e vazante.

Os resultados sugerem que a distribuição dos metais é influenciada pelos efluentes locais e dinâmica das marés. Durante as marés de sizígia os metais são importados da baía de Todos os Santos, junto ao material particulado em suspensão que entra no sistema estuarino. O sedimento de fundo parece estar atuando como reservatório semi-permanente e acumulador de metais no ecossistema. Também nas marés de sizígia, o material fino do sedimento é ressuspenso e incorporado ao material particulado em suspensão, presente na coluna d'água. As variações não são significantes, conforme os fluxos e refluxos diários da maré.

O processo de acumulação resulta em concentrações particularmente elevadas de metais, que se encontram no sedimento de fundo sob formas pouco disponíveis para a biota aquática. Os valores mais altos de $\mathrm{Cu}, \mathrm{Zn}, \mathrm{Cr}$ e Fe são encontrados próximos as cidades de Cachoeira e São Félix e de $\mathrm{Cu}, \mathrm{Cd}, \mathrm{Pb}, \mathrm{Zn}, \mathrm{Cr}$, Fe e $\mathrm{Mn}$ na foz do rio na baía de Todos os Santos, o que sinaliza a influência das ações antrópicas nestas áreas.

Considerando-se a hidrodinâmica do sistema, a metodologia usada mostra-se adequada para 0 monitoramento de zonas estuarinas em ambientes tropicais. Os valores médios registrados para o ano de 1995, são referências importantes para acompanhar as mudanças produzidas por um aumento na contaminação. 


\section{ABSTRACT}

This present study was carried out on Paraguaçu River estuarine area. This area is characterized by having a transitional system of fluvial and marine influences, controlled by discharges come from both Pedra do Cavalo dam and waters from Todos os Santos Bay.

Fifteen sampling sites along the estuarine complex were investigated on eight planned campaigns between 1994 and 1995, in order to verify the distribution and geochemical behavior of $\mathrm{Cu}, \mathrm{Cd}, \mathrm{Pb}, \mathrm{Cr}, \mathrm{Zn}, \mathrm{Fe}, \mathrm{Al}, \mathrm{Mn}$ considering seasonably and dynamics of spring and neap tides. One specific site was monitored for suspended particulate material as well as physical-chemical parameters during twelve hours covering different cycles of flood and ebb tide.

Results indicate that distribution of metals is influenced by local waste and tide dynamics. Metals are imported from Todos os Santos Bay during spring tide along with suspended particulate material flushed into the estuarine system. The bottom sediment apparently acts as a semi-permanent reservoir, accumulating metals in the eco-system. Also, during spring tide, the sediment's fine material is re-suspended and therefore incorporates the suspended particulate material floating in the water. Variations due to daily changes in the flow of tides are not significant.

The accumulation process results in particularly high concentrations of metals lying in bottom sediments under circumstances which make them hardly available for the aquatic biota. Highest values of $\mathrm{Cu}, \mathrm{Zn}, \mathrm{Cr}, \mathrm{Fe}$ were found at sites closest to cities of Cachoeira and São Felix while highest values of $\mathrm{Cu}, \mathrm{Cd}, \mathrm{Pb}, \mathrm{Zn}, \mathrm{Cr}, \mathrm{Fe}, \mathrm{Mn}$ were found by the mouth of the river at Todos os Santos Bay, indicating these areas are influenced by surrounding antropogenic activity.

Considering the system's hydro-dynamics, the methodology applied proves itself adequate for monitoring estuarine zones in tropical environments. Average values registered during the year of 1995 are important references in order to understand changes produced by increase in contamination. 


\section{AGRADECIMENTOS}

A realização deste trabalho somente foi possivel com o decidido apoio de:

Conselho Nacional de Pesquisa - CNPq;

Programa Centro de Pesquisas de Aguas Subterrâneas - CEPAS em convênio com IDRC - Instituto de Geociências da USP;

Programa de Pós-Graduação em Recursos Minerais e Hidrogeologia da USP; Curso de Pós-Graduação em Geoquímica e Meio Ambiente da UFBA;

Direção do Instituto de Geociências da UFBA;

Laboratórios de Geoquímica do Instituto de Geociências da UFBA;

Laboratório de Estatística do Instituto de Matemática da UFBA;

Prefeitura de Maragogipe;

Empresa Baiana de Águas e Saneamento - EMBASA, e

Centro de Recursos Ambientais - CRA.

A estas Instituições, Órgãos e Empresas que entenderam o alcance desta pesquisa para gerações futuras, deixa-se registrado os melhores agradecimentos. 


\section{ÍNDICE}

RESUMO

ABSTRACT

ii

AGRADECIMENTOS

iii

INDICE

iv

INDICE DE FIGURAS

vii

INDICE DE QUADROS

xi

INDICE DE TABELAS

xii

CAPITULOO 1 - INTRODUÇÃO

1. - INTRODUÇÃO

1.1. - METAIS PESADOS NOS SEDIMENTOS AQUATICOS

1.2. - CONTAMINAÇAOO POR METAIS PESADOS EM AMBIENTES COSTEIROS

1.3. - ESCOLHA DA AREA DE ESTUDO

1.4. - OBJETIVOS / PLANO DE TRABALHO

1.5. - APRESENTAÇÃO

CAPITULO 2 - CARACTERIZAÇÁO DA AREA.

2. - CARACTERIZAÇÃO DA AREA.

2.1. - LOCALIZAÇAO GEOGRAFICA E ACESSOS............................................... 12

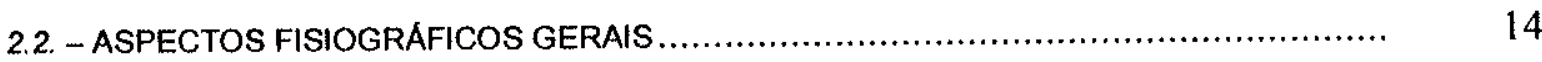

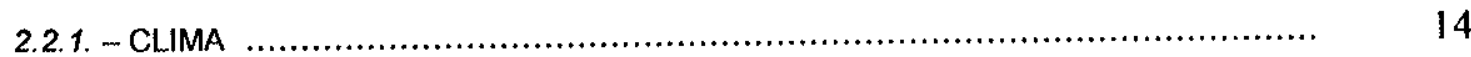

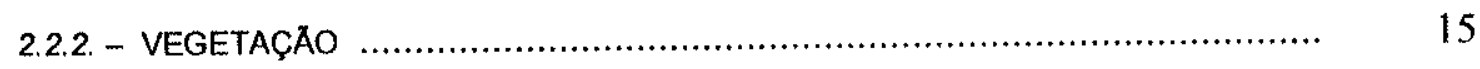

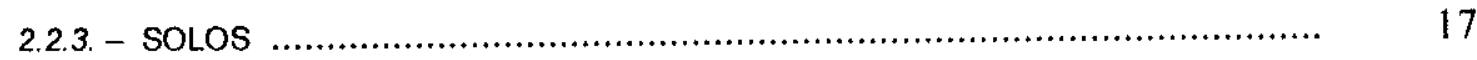

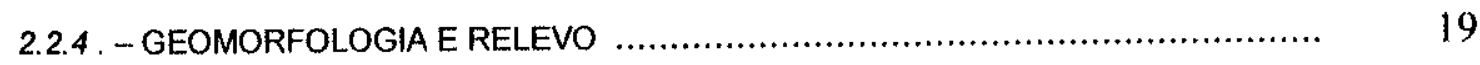

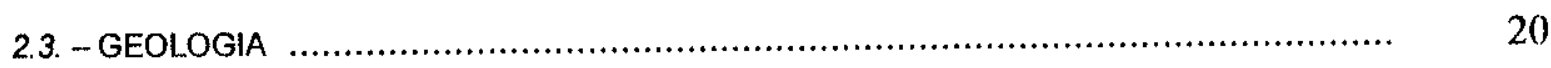

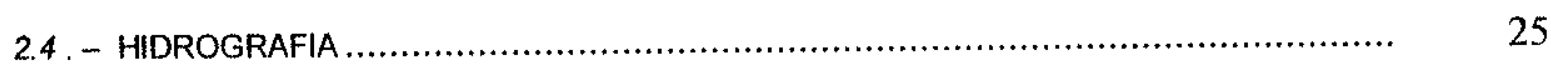

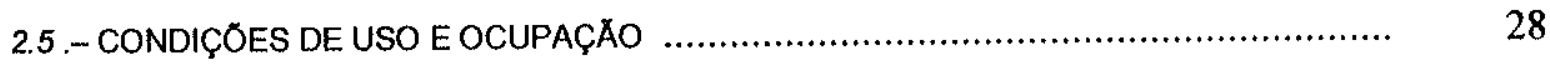


2.5.1. - PRINCIPAIS ATIVIDADES POLUENTES E OS IMPACTOS RESULTANTES SOBRE O MEIO AMBIENTE ......................................................... 30

2.5.2. - QUALIDADE DAS AGUAS .......................................................... 32

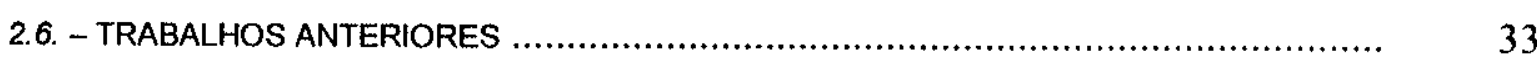

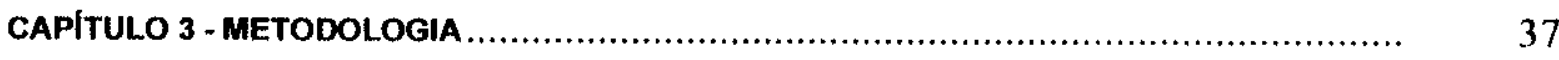

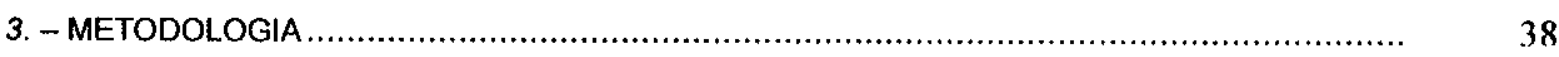

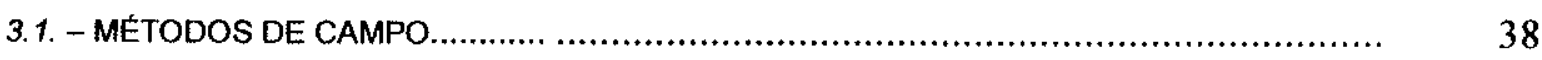

3.1.1. - LOCALIZAÇÃO DAS ESTAÇOES DE AMOSTRAGEM ................................ 38

3.1.2. - FREQÜÊNCIA DAS COLETAS .................................................... 39

3.1.3. - MATERIAIS E MÉTODOS UTILIZADOS NA AMOSTRAGEM .......................... 41

3.1.4. - PARAMMETROS FISICO-QUIMICOS NÃO CONSERVATIVOS ......................... 45

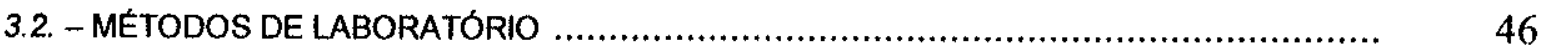

3.2.1. - MATERIAL PARTICULADO EM SUSPENSAO - MPS................................... 46

3.2.2. - SEDIMENTO DE FUNDO ............................................................ 47

3.2.3. - EXTRAÇÃO SEQÜENCIAL DOS METAIS NOS SEDIMENTOS DE FUNDO .... 47

3.3. - CONTROLE DE QUALIDADE E GARANTIA DE QUALIDADE DOS RESULTADOS ...... 49

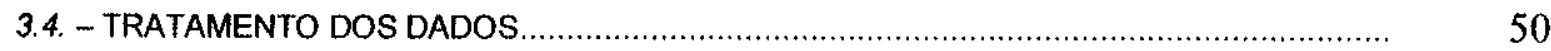

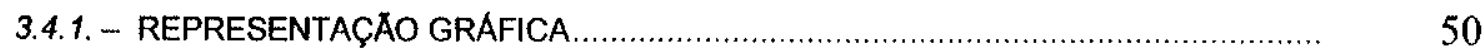

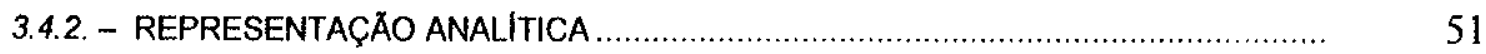

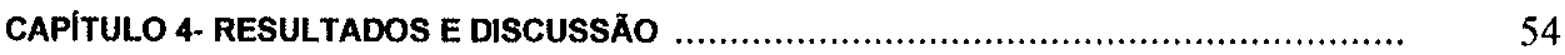

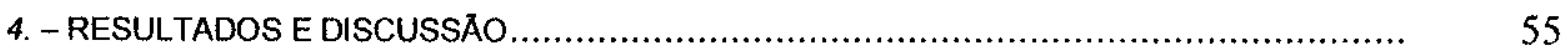

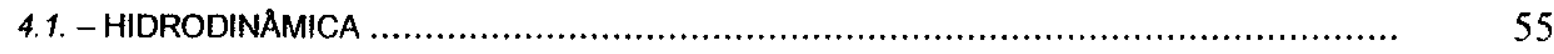

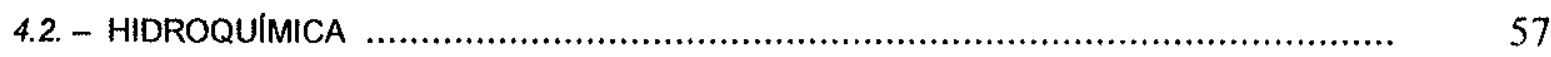

4.2.1. - DISTRIBUIÇÃO DOS PARÅMETROS FISICO-QUIMICOS ............................. 57

4.2.2. - TRATAMENTO ESTATISTICO - ANÁLISE DE VARIÅNCIA ............................. 61

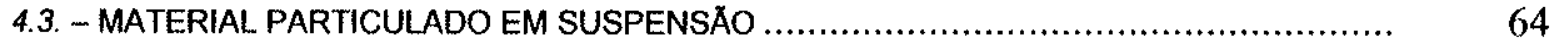

4.3.1. - CONCENTRAÇAOO DOS SOLLIDOS SUSPENSOS TOTAIS (SST), SÓLIDOS SUSPENSOS VOLÁTEIS (SSV) E MATERIAL PARTICULADO EM SUSPENSAO

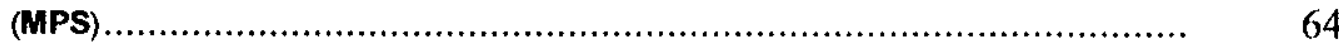

4.3.2. - CONCENTRAÇÃO DE COBRE, CADMIO, CHUMBO, CROMO, ZINCO, FERRO, MANGANES E ALUMINIO ................................................................ 67

4.3.3. - TRATAMENTO ESTATISTICO ....................................................... 71

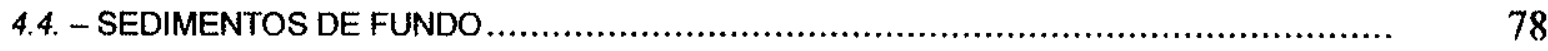


4.4.1. - CARACTERISTICAS GERAIS.

4.4.2. - CONCENTRAÇÃO DE COBRE, CADMIO, CHUMBO, CROMO, ZINCO, FERRO, MANGANES E ALUMINIO

4.4.3. - TRATAMENTO ESTATISTIICO

4.4.4. - ESPECIAÇĀO QUIMICA DOS METAIS ................................................ 90

4.4.5. - COMPARAÇAO DOS DADOS COM SEDIMENTOS DE OUTRAS REGIÖES............ 94

4.5. - INTEGRAÇAOO DOS RESULTADOS ...................................................... $\quad 100$

4.5.1. - CORRELAÇOES ENTRE AS VARIÁVEIS .......................................... 100

4.5.2. - DISTRIBUIÇAXO ESPACIAL E VARIABILIDADE TEMPORAL DOS PARÅMETROS NOS MATERIAIS INVESTIGADOS ......................................................... 104

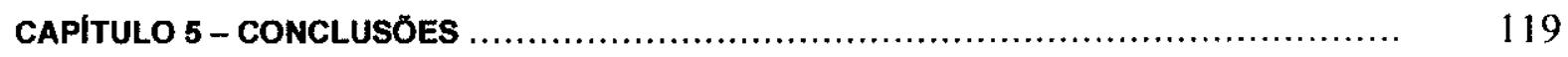

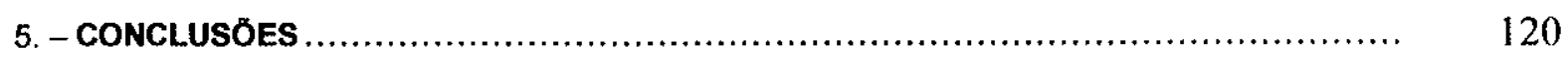

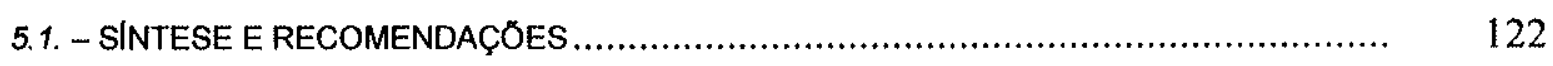

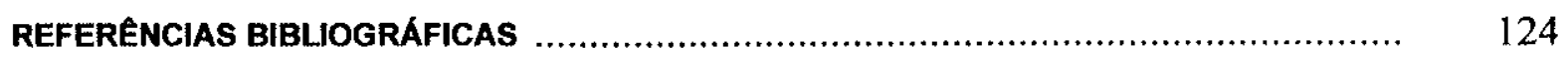

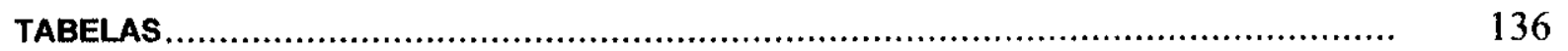




\section{ÍNDICE DE FIGURAS}

Figura

Pág.

01 DIAGRAMA ESQUEMATICO DOS OBJETIVOS E PLANO DE TRABALHO ............... 9

02 MAPA DE LOCALIZAÇÃO E ACESSO DA AREA EM ESTUDO

MAPA DE DISTRIBUIÇÃO DA TIPOLOGIA CLIMÁTICA (KOPPEN), PLUVIOMETRIA

ANUAL (mm) E VEGETAÇAO DA REGIAOO

MAPA DE SOLOS NA REGIÃO

MAPA GEOLOGICO DA AREA

CONDIÇOES DE USO E OCUPAÇÃO NA REGIAOO

DISTRIBUIÇÃO DOS PONTOS DE AMOSTRAGEM

08 CLASSIFICAÇÃO DOS SOLLIDOS DAS AGUAS DE ACORDO COM O TAMANHO E CARACTERISTICAS QUIMICAS

09 FLUXOGRAMA DE PREPARAÇÃo E ANÁLISE DOS SEDIMENTOS EM SUSPENSÃO

FLUXOGRAMA DE PREPARAÇAO E ANÁLISE DOS SEDIMENTOS DE FUNDO ....... (1) 
DIAGRAMAS "BOX PLOT" PARA SST, SSV E MPS NO MATERIAL PARTICULADO EM SUSPENSAO NAS FASES 01-02-03/1995. CAMPANHAS I (SIZIGIA) E \| QUADRATURA

21 DIAGRAMAS "BOX PLOT" PARA Mn, Fe E AI NO MATERIAL PARTICULADO EM SUSPENSAOO NAS FASES 01-02-03/1995. CAMPANHAS I (SIZIGIA) E II QUADRATURA

DIAGRAMAS "BOX PLOT" PARA Zn E Cr, NO MATERIAL PARTICULADO EM SUSPENSAO NAS FASES 01-02-03/1995. CAMPANHAS I (SIZIGIA) E \| QUADRATURA

23 AGRUPAMENTO DAS ESTAÇOES COM AS CARACTERISTICAS DO MATERIAL PARTICULADO EM SUSPENSAO, FASES 01-02-03/95, CAMPANHAS 1 (SIZIGIA) E II QUADRATURA

24 AGRUPAMENTO DAS ESTAÇOES COM AS CARACTERISTICAS DOS SEDIMENTOS EM SUSPENSAO, FASE 03/95, CAMPANHAS I (SIZIGIA) E \| QUADRATURA

25 GRANULOMETRIA DOS SEDIMENTOS DE FUNDO NAS DIFERENTES FASES ESTUDADAS

DISTRIBUIÇÃO DOS METAIS NOS SEDIMENTOS DE FUNDO NAS ESTAÇOES ESTUDAS. FASES 01-02-03/95

27 "BOX PLOT" PARA CU, Pb E Cd NO SEDIMENTO DE FUNDO NAS FASES 01-0203/95. CAMPANHAS I (SIZIGIA) E II QUADRATURA

28 "BOX PLOT" PARA $\mathrm{Zn}, \mathrm{Cr}$ E AI NO SEDIMENTO DE FUNDO NAS FASES 01-0203/95. CAMPANHAS 1 (SIZIGIA) E II QUADRATURA. "BOX PLOT" PARA Mn E Fe NO SEDIMENTO DE FUNDO NAS FASES 01-02-03/95. CAMPANHAS I (SIZIGIA) E II QUADRATURA

30 AGRUPAMENTO DAS ESTAÇOES PARA OS SEDIMENTOS DE FUNDO. FASES 01-02-03/95. CAMPANHAS I (SIZIGIA) E II QUADRATURA. AGRUPAMENTO DAS ESTAÇOES COM AS INTERRELAÇOES DAS CARACTERISTICAS DOS SEDIMENTOS DE FUNDO. FASES 01-03/95. CAMPANHAS I (SIZIGIA) E II QUADRATURA 
32. PARTIÇÃO GEOQUIMICA DOS METAIS NOS SEDIMENTOS DE FUNDO DA REGIÃO ESTUARINA DO RIO PARAGUAÇU. FASE 02/95, CAMPANHAS I (MARE DE SIZIGIA) E II (MARE DE QUADRATURA) DISTRIBUIÇÃO DOS TEORES DE SOLIDOS TOTAIS EM SUSPENSÃO NA REGIÃO ESTUARINA DO RIO PARAGUAÇU DISTRIBUIÇÃO DOS TEORES DE SÓLIDOS EM SUSPENSÃO VOLATEIS NA REGIÃO ESTUARINA DO RIO PARAGUAÇU. DISTRIBUIÇÃO DO MATERIAL PARTICULADO EM SUSPENSÃO (MPS) NA REGIAO ESTUARINA DO RIO PARAGUAÇU... DISTRIBUIÇÃO DO ALUMINIO NO MATERIAL PARTICULADO EM SUSPENSÃO NA REGIÃO ESTUARINA DO RIO PARAGUAÇU DISTRIBUIÇÃO DO FERRO NO MATERIAL. PARTICULADO EM SUSPENSÃO NA REGIÃO ESTUARINA DO RIO PARAGUAÇU DISTRIBUIÇÃO DO MANGANÊS NO MATERIAL PARTICULADO EM SUSPENSÃO NA REGIÃO ESTUARINA DO RIO PARAGUAÇU. DISTRIBUIÇÅO DO CROMO NO MATERIAL PARTICULADO EM SUSPENSÃO NA REGIÃO ESTUARINA DO RIO PARAGUAÇU.

DISTRIBUIÇAOO DA MATÉRIA ORGANICA NO SEDIMENTO DE FUNDO NA REGIAO ESTUARINA DO RIO PARAGUAÇU. DO RIO PARAGUAÇU. DISTRIBUIÇAOO DO SILTE FINO NO SEDIMENTO DE FUNDO NA REGIAOO ESTUARINA DO RIO PARAGUAÇU DISTRIBUIÇÃO DO SILTE GROSSO NO SEDIMENTO DE FUNDO NA REGIÃO ESTUARINA DO RIO PARAGUAÇU. DISTRIBUIÇÃO DA AREIA FINA NO SEDIMENTO DE FUNDO NA REGIÅO ESTUARINA DO RIO PARAGUAÇU. 
46 DISTRIBUIÇÃO DA AREIA GROSSA NO SEDIMENTO DE FUNDO NA REGIÃO

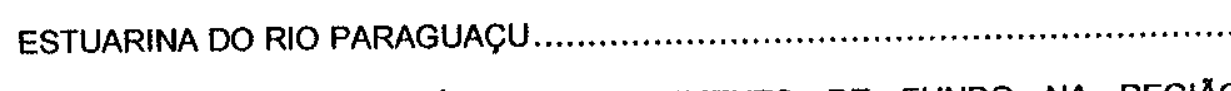

47 DISTRIBUIÇAOO DO ALUMINIO NO SEDIMENTO DE FUNDO NA REGIAOO ESTUARINA DO RIO PARAGUAÇU

48 DISTRIBUIÇAO DO FERRO NO SEDIMENTO DE FUNDO NA REGIAOO ESTUARINA DO RIO PARAGUAÇU

49 DISTRIBUIÇAO DO MANGANES NO SEDIMENTO DE FUNDO NA REGIÅO ESTUARINA DO RIO PARAGUAÇU.

50 DISTRIBUIÇÃO DO ZINCO NO SEDIMENTO DE FUNDO NA REGIÃO ESTUARINA DO RIO PARAGUAÇU .

51 DISTRIBUIÇÃO DO CÁDMIO NO SEDIMENTO DE FUNDO NA REGIÄO ESTUARINA

52 DISTRIBUIÇÃO DO COBRE NO SEDIMENTO DE FUNDO NA REGIÃO ESTUARINA DO RIO PARAGUAÇU

53 DISTRIBUIÇÃO DO CROMO NO SEDIMENTO DE FUNDO NA REGIÅO ESTUARINA DO RIO PARAGUAÇU

54 DISTRIBUIÇÃO DO CHUMBO NO SEDIMENTO DE FUNDO NA REGIAOO ESTUARINA DO RIO PARAGUAÇU 


\section{ÍNDICE DE QUADROS}

Quadro

Pág.

1 PARAMETROS FISICOS REGISTRADOS NA BARRAGEM DE PEDRA DO CAVALO

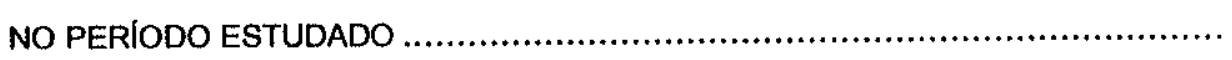

2 FASES, PERIODOS E CONDIÇOES DE MARE CORRESPONDENTES AS CAMPANHAS DE CAMPO REALIZADAS (1994 - 1995) ................................... 41

3 MÉDIAS E DESVIO PADRAO DOS PARÅMETROS FISICO-QUIMICOS DO MONITORAMENTO NA ESTAÇAO 50. FASES 01/94 E 03/95, CAMPANHAS (I)

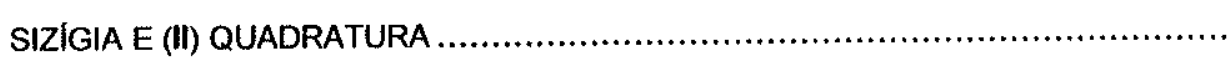

4 COMPARAÇÃO ENTRE OS TEORES MÉDIOS DOS METAIS ENCONTRADOS EM SEDIMENTOS COSTEIROS DE VARIAS REGIÓES

5 TEORES MÉDIOS DE METAIS PESADOS (EM PPM) NOS PRINCIPAIS TIPOS DE

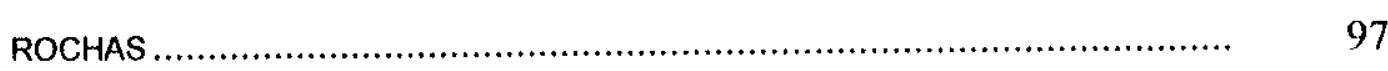

6 METAIS PESADOS ASSOCIADOS AS PRINCIPAIS INDÚSTRIAS ...................... 98

$7 \quad$ MEDIA DE METAIS EM LODO DE ESGOTOS ........................................... 99

8 CORRELAÇOESS ENTRE OS PARÅMETROS NOS SEDIMENTOS DE FUNDO (SF) E NO MATERIAL PARTICULADO EM SUSPENSÃO (MPS) NAS FASES E CAMPANHAS DE 1995 


\section{ÍNDICE DE TABELAS}

Tabela

Pág.

1 PARÅMETROS MEDIDOS "IN SITU". FASE 01/94. CAMPANHAS I (SIZIGIA) E \| (QUADRATURA)

PARÅMETROS MEDIDOS "IN SITU". FASE 01/95, CAMPANHAS I (SIZIGIA) E \| (QUADRATURA).

PARÅMETROS MEDIDOS "IN SITU". FASE 02/95, CAMPANHAS I (SIZIGIA) E II (QUADRATURA).

4 PARÅMETROS MEDIDOS "IN SITU". FASE 03/95 , CAMPANHAS I (QUADRATURA) E II (SIZIGIA)

CONCENTRAÇÃO (mg/L) DE SOLLIDOS SUSPENSOS TOTAIS (SST), SOLLIDOS SUSPENSOS VOLATEIS (SSV), MATERIAL PARTICULADO EM SUSPENSAO (MPS) E METAIS NO MATERIAL PARTICULADO EM SUSPENSAOO . FASE 01/94, CAMPANHAS I (SIZIGIA) E II (QUADRATURA)

CONCENTRAÇAO (mg/L) DE SST, SSV, MPS E METAIS NO MATERIAL PARTICULADO EM SUSPENSÃO NA FASE 01/95, CAMPANHAS I (SIZIGIA) E II (QUADRATURA)

CONCENTRAÇÃO (mg/L) SST, SSV, MPS E METAIS NO MATERIAL. PARTICULADO EM SUSPENSAOO NA FASE 02/95, CAMPANHAS I (SIZIGIA) E ॥ (QUADRATURA)

8 CONCENTRAÇÃO (mg/L) de SST, SSV, MPS E METAIS NO MATERIAL PARTICULADO EM SUSPENSÄO DURANTE A FASE 03/95 CAMPANHAS I (SIZIGIA) EII (QUADRATURA)

9 ANALISE GRANULOMÉTRICA (\%) E DE MATERIA ORGANICA - MO (\%) DOS SEDIMENTOS DE FUNDO. FASE $01 / 95$

10 ANALISE GRANULOMÉTRICA (\%) E DE MO (\%) DOS SEDIMENTOS DE FUNDO. FASE 02/95.

11 ANÁLISE GRANULOMÉTRICA (\%) E DE MO (\%) DOS SEDIMENTOS DE FUNDO DURANTE A FASE 03/95 CAMPANHAS I (SIZIGIA) E II (QUADRATURA).

12 CONCENTRAÇAOO TOTAL DE METAIS NOS SEDIMENTOS DE FUNDO DURANTE A FASE 01/94, CAMPANHAS I (SIZIGIA) E II (QUADRATURA)

13 CONCENTRAÇAO TOTAL DE METAIS NOS SEDIMENTOS DE FUNDO DURANTE A FASE 01/95 CAMPANHAS I (SIZIGIA) E II (QUADRATURA) 
14 CONCENTRAÇÃO TOTAL DE METAIS NOS SEDIMENTOS DE FUNDO DURANTE A FASE 02/95 CAMPANHAS I (SIZIGIA) E II (QUADRATURA)

15 CONCENTRAÇÃO (PPM) TOTAL DE METAIS NOS SEDIMENTOS DE FUNDO DURANTE A FASE 03/95 CAMPANHAS I (SIZIGIA) EII (QUADRATURA) TEORES DOS METAIS (PPM) OBTIDOS POR EXYTRAÇÃO SEQÜENCIAL PARA OS SEDIMENTOS DE FUNDO DA FASE 03/95, CAMPANHAS I (SIZIGIA) E ॥ (QUADRATURA)

17 MATRIZ DE CORRELAÇÃO ENTRE OS PARÅMETROS NO MATERIAL PARTICULADO EM SUSPENSÃO (MPS) E SEDIMENTO DE FUNDO (SF). FASE 01/95 CAMPANHAS IE II

18 MATRIZ DE CORRELAÇÃO ENTRE OS PARÁMETROS NO MATERIAL PARTICULADO EM SUSPENSÃO (MPS) E SEDIMENTO DE FUNDO (SF). FASE 02/95 CAMPANHAS IE II

19 MATRIZ DE CORRELAÇÅO ENTRE OS PARÅMETROS NO MATERIAL. PARTICULADO EM SUSPENSÃO (MPS) E SEDIMENTO DE FUNDO (SF). FASE 03/95 CAMPANHAS IE 11

20 PARAMETROS ESTATISTICOS PARA OS DADOS (mg/L) DO MATERIAL PARTICULADO EM SUSPENSÃO DURANTE AS FASES 01/95, 02/95 E 03/95.....

21 PARÅMETROS ESTATISTICOS PARA OS DADOS DOS SEDIMENTO DE FUNDO NAS FASES 01/95, 02/95 E $03 / 95$ PARÅMETROS ESTATISTICOS PARA A GRANULLMETRIA DOS SEDIMENTOS DE FUNDO EM CADA ESTAÇÃO DURANTE AS FASES 01/95, 02/95 E 03/95 
CAPÍTULO 1 - INTRODUÇÃO 


\section{INTRODUÇÃo}

\subsection{METAIS PESADOS NOS SEDIMENTOS AQUATIICOS}

Os metais pesados săo importantes sob vários aspectos: alguns săo usados na indústria outros são, fisiologicamente, essenciais para as plantas e animais e assim, possuem relação direta com a saúde humana e sua cadeia alimentar e outros, săo poluentes significativos dos ecossistemas. No ambiente aquático, os metais estăo distribuídos na fase aquosa (coluna d'água e água intersticial), na fase sólida suspensa e sedimentada, nas plantas e nos organismos aquáticos. A troca entre os diferentes compartimentos $\dot{e}$ dinåmica e varia de um ecossistema para outro.

Nos últimos anos, os metais pesados em sedimentos, tém despertado particular atenção. Nos sistemas aquáticos, os sedimentos săo representados pelos materiais detríticos que se depositam no fundo dos corpos de água, no caso, o sedimento de fundo e, pelo material insolúvel suspenso na água, também denominado material particulado. Estudos demonstram que, nos sistemas aquáticos, os sedimentos podem funcionar como reservatório ou fonte de metais pesados (SALOMONS \& FÖRSTNER, 1984; LITERATHY et al., 1987; PUCCI, 1988).

Os sedimentos contêm metais pesados de origem natural e antrópica. Os metais de origem natural ocorrem, principalmente, como componentes traços de minerais detriticos. Os metais de origem antrópica, uma vez descarregados em águas superficiais, são associados ao material particulado (complexos argilo-metálicoorgânicos) ou transportados nas formas dissolvida $e$, eventualmente, coloidal (hidróxidos). O tempo de residência dos metais nos sedimentos, depende de vários processos no meio, os quais promovem a sua fixação ou remobilizaçăo (FORSTNER \& WITTMANN, 1981; MOORE \& RAMAMOORTHY, 1984), tais como: processos químicos e fisico-químicos de adsorçăo, coprecipitação e complexação/floculaçăo, que possibilitam a retenção dos metais nos diversos substratos associados aos sedimentos - óxido/hidróxidos de Fe/Mn, carbonatos, sulfetos e matéria orgânica; modificaçőes de $\mathrm{pH}$, Eh, teor orgánico e salinidade, as quais promovem a dessorção parcial ou liberaçăo total das fraçőes metálicas móveis, associadas aos substratos sedimentares e outros. 
O conhecimento da forma que o metal se encontra ligado ao sedimento, informa sobre possibilidade de acumulação e/ou liberação decorrente daqueles processos (FORSTNER, 1982; NAIR et al., 1991). A fraçăo metálica ligada mais fortemente ao retículo cristalino dos minerais (fase residual do sedimento), tem sido considerada como inerte, assim, năo é solubilizável pelos processos físico-químicos comuns entretanto, as formas mais lábeis, retidas por ligaçōes mais fracas, são aquelas mais biodisponiveis ou seja, as mais fáceis de serem repassadas à cadeia trófica. A especiação química dos metais é forma eficiente para a avaliação da biodisponibilidade

No contexto da poluição ambiental, o estudo sobre a distribuição dos metais em sedimentos é de grande importância. Tem sido demonstrado que, como os sedimentos representam um dos melhores meios para concentrar metais nos ambientes aquáticos, eles podem ser usados como indicadores de contaminação.

\subsection{CONTAMINAÇÃO POR METAIS PESADOS EM AMBIENTES COSTEIROS}

$\mathrm{Na}$ "interface" rio/oceano e na plataforma continental, ocorre acumulação natural e antrópica de metais, em especial, nos estuários e balas, onde localizam-se centros urbanos e industriais.

O uso indiscriminado de um largo espectro de substâncias quimicas em atividades humanas, domésticas $\mathrm{e}$ industriais, aliados a direção preferencial deste desenvolvimento em áreas costeiras, têm contribuido para a contaminaçăo ambiental por parte dos metais pesados. Assim, não é surpresa que os ecossistemas costeiros tropicais, estejam ameaçados por impactos ambientais, o que torna imperioso o conhecimento sobre o comportamento e distribuição dos metais pesados nestes ambientes.

A qualidade da água, com relaçăo ao nivel de contaminaçăo por parte dos metais pesados nos sedimentos e, em conseqüéncia, dos organismos marinhos nela existentes (peixes, crustáceos, ostras, microrganismos etc.), ao atingir determinados valores, pode constituir sério problema, năo só ao ecossistema flúvio-marinho local, 
como também ao ser humano, usuário dependente dessa água e dos "frutos marinhos" ai obtidos.

Estuários săo áreas de investigação complexa (LE DAUREC, 1978). Representam ambientes em constante processo evolutivo, constituindo o meio de interação entre mar, rio e atividades antrópicas. Nas regiões estuarinas a abundância, distribuição e especiação de metais nos sedimentos, pode ser afetada por processos hidrodinâmicos, relacionados às variaçőes de litologias, topografia, vegetaçáo, regime de chuvas, fluxos dos rios, "inpuf" de energia das correntes de marés durante os ciclos de enchente e vazante e/ou durante os ciclos das marés de sizígia (luas cheia ou nova) e quadratura (luas quarto crescente ou minguante) e outros. Ademais, quando a água fluvial mistura-se com a água do oceano, ocorrem modificações físico-quimicas que, associadas aos processos hidrodinâmicos particulares, influenciam a distribuiçăo dos metais no material particulado em suspensão e também a composição do sedimento depositado.

E razoável admitir-se que, dada a diversidade destes efeitos, gerenciar, monitorar ou avaliar a poluição por metais pesados em ambientes estuarinos, é assunto intricado e particular para cada regiåo. Por sua vez, o tema ainda năo tem sido suficientemente estudado para regióes de climas tropicais. A resposta do sedimento para as variaçőes no ambiente não é instantânea, devido a dinâmica dos processos de ressuspensão e deposiçăo dos sedimentos, de acordo com os diferentes ciclos de marés atuantes no estuário; tal fato, exige a aplicação de monitoramento contínuo destes ambientes para obtenção de um diagnóstico consistente sobre a distribuição e acumulação dos metais nos sedimentos.

A adequação e padronização dos procedimentos de campo e de laboratório, tais como: escolha dos periodos, fases e número de pontos para amostragem; técnicas de coleta e acondicionamento das amostras; intervalo de tempo para análise; limites de detecção dos métodos analiticos; metodologia para tratamento de dados etc. são aspectos relevantes, a serem considerados para o sucesso de um programa de monitoramento ambiental em sistemas estuarinos. E imperiosa a segurança de que o conjunto de dados produzidos venha refletir as condiçóes reais do ecossistema e, aponte as possíveis correntes de contaminação. 


\subsection{ESCOLHA DA AREA DE ESTUDO}

A bacia do rio Paraguaçu, situada na parte centro-leste do Estado da Bahia, Recôncavo Baiano, representa um dos mais antigos ecossistemas explorados no Brasil. Desde a época do descobrimento, essa exploraçåo tem sido efetivada sob o ponto de vista extrativista, pesqueiro e agropecuário.

No processo de ocupaçăo do território baiano, o rio Paraguaçu desempenhou papel fundamental devido à sua localizaçăo geográfica privilegiada. A partir do seu trecho baixo, que possibilitou o acesso fluvial pela baía de Todos os Santos, foi desenvolvido todo o processo de povoamento do Recôncavo baiano, com a expansăo da cultura de cana-de-açúcar e do fumo e que originou os primeiros municípios: Maragogipe, Cachoeira e Santo Amaro. A maior concentração de população, se encontra na porção ocidental da bacia, nas regióes entre Feira de Santana e a foz do rio na baia de Todos os Santos.

No trecho final da bacia do Paraguaçu, a aproximadamente $40 \mathrm{~km}$ da sua foz na baía de Todos os Santos, foi construida em 1980, a barragem de Pedra do Cavalo cujo reservatório é alimentado, principalmente, pelos rios Paraguaçu e um dos seus tributários, o Jacuípe.

Nas últimas três décadas, o desenvolvimento urbano e industrial do Recôncavo da Bahia, região na qual o trecho inferior do rio Paraguaçu encontra-se em grande parte inserido, bem como o da cidade de Feira de Santana, foi motivado, sobretudo, pela indústria de extração e refino do petróleo, pela indústria química, metalúrgica, de cimento e portuária (complexo portuário de Aratu). Estas industrias vêm deteriorando, pelos seus efeitos, o ecossistema flúvio-marinho estuarino do rio Paraguaçu.

O rio Paraguaçu possui estuário tipo lagunar (baía de lguape), com aproximadamente $80 \mathrm{~km}^{2}$, caracterizado por um sistema transicional de influência fluvial, controlada pela descarga da barragem de Pedra do Cavalo e influência marinha, proveniente das águas da baía de Todos os Santos, que atinge a baia de Iguape, através do Canal de São Roque. 
Fica evidente, que a construção da barragem de Pedra do Cavalo estabeleceu uma ruptura no sistema, diminuindo a influência da parte à montante. Desta forma, é previsível que o trecho final da bacia do rio Paraguaçu e a sua região estuarina, tenham sido submetidos a alteraçŏes, das quais podem ser questionados os seguintes efeitos para as condições ecológicas locais :

(a) a regulaçăo do caudal e conseqüente contenção das cheias determina um ecossistema estuarino com uma menor faixa de variação da salinidade?

(b) os impactos próximos-passados e atuais na baia de Todos os Santos transferem seus efeitos à área estuarina?

(c) as descargas defluentes e os fluxos de maré conjugados impõem um regime dinâmico de pequena variaçăo sazonal?

(d) qual o papel da dinâmica estuarina na circulação dos sedimentos em suspensão?

Atualmente, na região a montante da barragem, são desenvolvidas atividades agrícolas e de exploração mineral e, como atividade industrial, destaca-se o Centro Industrial de Subaé instalado em Feira de Santana, próximo ao rio Jacuipe, tributário do rio Paraguaçu, que deságua no reservatório de Pedra do Cavalo.

A área estuarina encontra-se ainda em estado incipiente de industrialização, sendo a pesca e a agricultura suas principais atividades entretanto, săo criticas as condições de saneamento das cidades vizinhas. Na margem direita do Canal de Săo Roque destaca-se um estaleiro de plataformas submarinas, destinadas a perfuraçăo de poços de petróleo. As atividades industriais (fábricas de cimento, papel, refinarias, terminal de petróleo, estaleiros), urbanas e os principais portos localizam-se na baía de Todos os Santos. Toda a área jusante da barragem recebe, praticamente, forte influência das marés e apresenta-se circundada por exuberantes florestas de manguezais.

A fisiografia do estuário-lagunar e do canal de São Roque reúne estruturas promissoras para pesca e aquacultura, a depender de condições de contaminaçăo ambiental que, de alguma forma, impeçam essas atividades. Em outras palavras, o desenvolvimento da pesca extrativa e extensiva na área estuarina-lagunar e no canal 
de São Roque, carece de prévio diagnóstico de qualidade ambiental e, em especial, de zoneamento das áreas privilegiadas para estas atividades.

Face ao interesse sócio-econômico que a regiåo desperta, e também aos aspectos decorrentes do represamento do rio, tem-se bons fundamentos para o estudo da distribuição e avaliação da contaminação dos metais pesados nos sedimentos. Este fato, requer estudo de diagnóstico, avaliaçăo e, em especial, a definição de uma metodologia de monitoramento, orientada para acompanhar a poluiçåo causada por metais pesados em regiozes estuarinas para ambientes tropicais.

\section{4 - OBJETIVOS / PLANO DE TRABALHO}

Este trabalho propõe-se a estudar a distribuição e o comportamento dos metais pesados nos sedimentos da região estuarina do rio Paraguaçu, com os seguintes objetivos:

(a) Caracterizar a distribuição espacial e temporal da concentração de metais pesados e dos parámetros-suporte representados pelos teores de $\mathrm{Fe}, \mathrm{Al}$, e $\mathrm{Mn}$, nos sedimentos dos sistemas situados à jusante do reservatório Pedra do Cavalo.

(b) Verificar a atuação dos sedimentos como reservatório semi-permanente e acumulador de metais pesados no ecossistema.

(c) Estabelecer metodologia para o monitoramento dos metais pesados na região estuarina do rio Paraguaçu, considerando o seu comportamento geoquímico com as flutuações sazonais e diferentes condiçōes de mares.

Para alcançar estes objetivos, foi estabelecido plano de trabaiho envolvendo as seguintes etapas: avaliação das condiçōes de uso e ocupação da região consideradas as atividades industriais, agriculturais e urbanas; levantamento dos estudos realizados na área, dos dados pluviométricos e fluviométricos do rio Paraguaçu e do controle da vazão afluente e defluente da barragem de Pedra do Cavalo; planejamento dos pontos de amostragem, em mapa cartográfico, aliado a seleção de itinerário racional para amostragem, em conformidade com os ciclos de marés; avaliação da capacidade laboratorial com respeito a quantidade de amostras, o processamento em tempo adequado, aos parâmetros a serem analisados, equipamentos disponiveis e limites de deteç̧åo a serem alcançados; cronograma de desenvolvimento dos trabalhos, 
consideradas todas as atividades envolvidas, sazonalidade e disponibilidade de recursos humanos e materiais, durante a execução do trabalho.

Oito campanhas de campo foram realizadas. Os parâmetros físico-químicos foram medidos "in situ", e as amostras de sedimentos, correspondentes as respectivas estaçōes de amostragem, foram coletadas e tratadas em laboratórios para a determinação da concentração dos metais. Com a aplicação de métodos gráficos e estatisticos, os resultados foram sintetizados para as possiveis conclusões. A Figura 01 apresenta diagrama esquemático dos objetivos e plano de trabalho.

\subsection{APRESENTAÇÃo}

O presente trabalho compreende os seguintes capitulos:

Capitulo 1, intitulado "INTRODUÇÃO", apresenta generalidades sobre o comportamento e contaminação dos metais nos sedimentos em ambientes costeiros, incluídas as citaçōes bibliográficas pertinentes, justificativas para a escolha da área de estudo, objetivos a serem alcançados, plano de trabalho e, por fim, a apresentação deste compêndio.

Capitulo 2, intitulado "CARACTERIZAÇÃO DA AREA" descreve caracteristicas gerais da área, incluindo dados sobre localização geográfica, aspectos litológicos e geomorfológicos, tipos de solos, hidrologia, clima, vegetação condições de uso/ocupação da área e os trabalhos anteriores.

Capítulo 3, intitulado "METODOLOGIA" detalha metodologia utilizada em campo e no tratamento dos dados obtidos.

Capítulo 4, intitulado "RESULTADOS E DISCUSSÃO" apresenta resultados da distribuição dos metais nos sedimentos combinados a análise da dinâmica do sistema e da metodologia utilizada. 


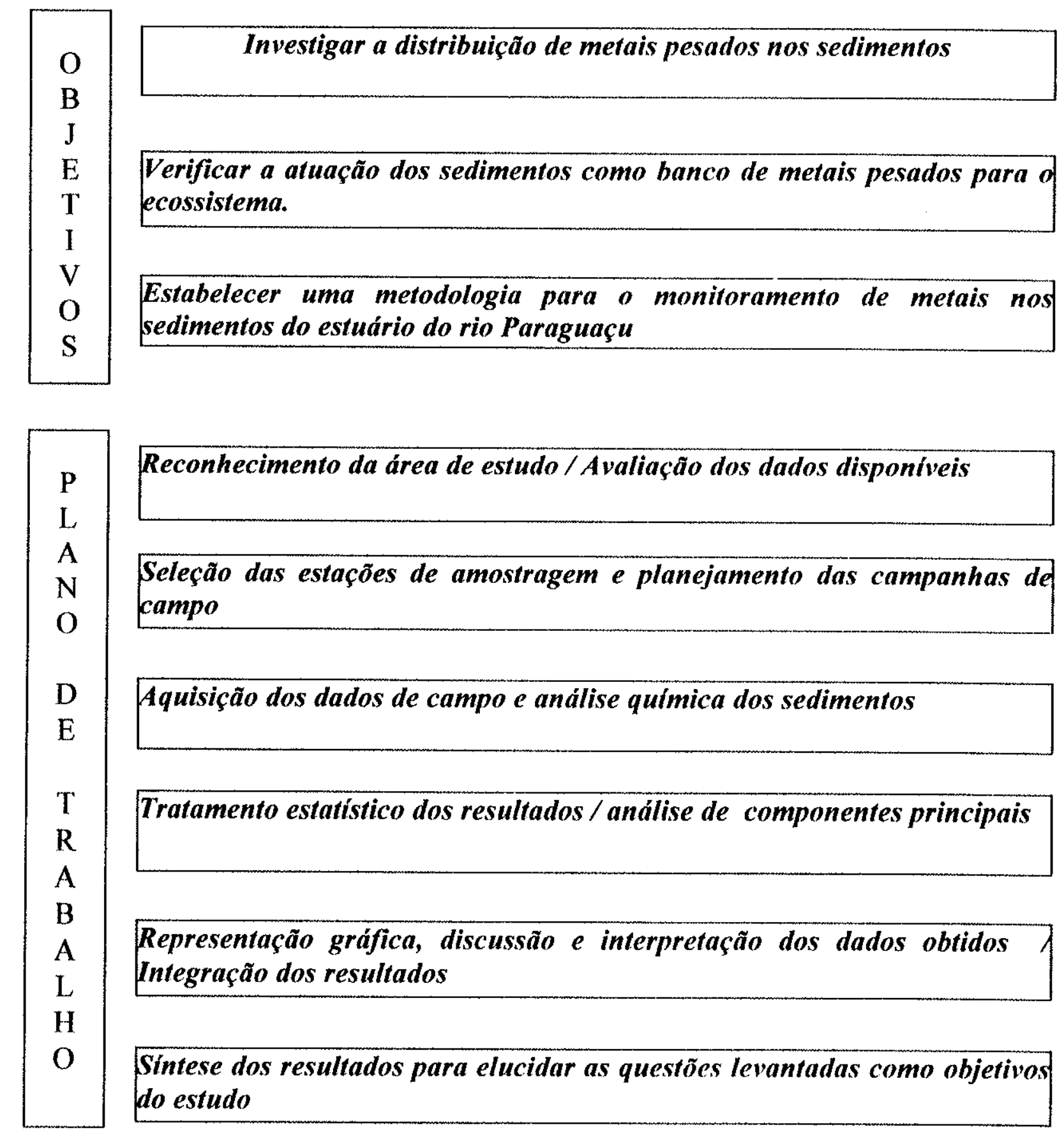

FIGURA 01 - DIAGRAMA ESQUEMÁTICO DOS OBJETIVOS E PLANO DE TRABALHO 
Capitulo 5, intitulado "CONCLUSOES" sumaria e integra resultados do capitulo anterior, salientando as respostas às questões levantadas nos objetivos e, a luz das conclusões alcançadas, apresenta recomendações para estudos posteriores.

Esta apresentação é enriquecida com mapas temáticos, figuras e gráficos que elucidam e detalham o estudo proposto. 
CAPÍTULO 2 - CARACTERIZAÇÃO DA ÁREA 


\section{CARACTERIZACÃO dA ÁREA}

Considerando que os sedimentos estudados, sempre colhidos em drenagem de menor porte, provêm dos setores do médio e baixo curso do rio Paraguaçu, é importante ressaltar, que as caracteristicas da área relacionadas ao contexto geológico e aos aspectos fisiográficos gerais aqui apresentadas, estão restritas a estes setores hidrográficos. As informações apresentadas, foram compiladas do Plano Diretor de Recursos Hídricos da Bacia do Médio e Baixo Paraguaçu - PDRH-BMBP (BAHIA, 1996), realizado pela Secretaria de recursos Hidricos Saneamento e Habitação Superintendência de Recursos Hídricos do Governo da Bahia em 1996, como instrumento de planejamento da gestão e do aproveitamento de recursos hídricos. $\mathrm{O}$ diagnóstico da situação dos sistemas físico e ambiental da região, apresentados no volume VI - Documento Sintese, muito ajudaram na atualização dos dados ora apresentados sobre a área de estudo.

\subsection{LOCALIZAÇÃO GEOGRÁFICA E ACESSOS}

A área considerada para estudo, situa-se entre as latitudes $12^{\circ} 00^{\prime} \mathrm{S}$ e $13^{\circ} 00^{\prime} \mathrm{S}$ e longitude $38^{\circ} 30^{\prime} \mathrm{W}$ e $39^{\circ} 30^{\prime} \mathrm{W}$, englobando os municípios de Cachoeira, São Félix e Maragogipe, perfazendo uma área de, aproximadamente, $80 \mathrm{~km}^{2}$ (Figura 02). Localizada à jusante da barragem de Pedra do Cavalo, compreende o complexo formado pelo estuário-lagunar da baia de Iguape, o canal de São Roque e a baía de Todos os Santos, nas proximidades da desembocadura do rio Paraguaçu.

A região dista cerca de $120 \mathrm{~km}$ da cidade de Salvador e possui duas formas principais de acesso: (i) por via terrestre, a partir de Salvador, através da BR-324 até o entroncamento com a BA-001, seguindo por esta até a cidade de Maragogipe (ii) por via maritima, saindo do porto da cidade de Salvador, atravessando a bala de Todos os Santos em direção oeste-noroeste até a entrada do canal de São Roque, passando pela baia de Iguape até chegar a Maragogipe. A partir desta cidade, o deslocamento para os pontos de amostragem, exige embarcação de pequeno porte para facilitar o acesso em locais de menor profundidade. 


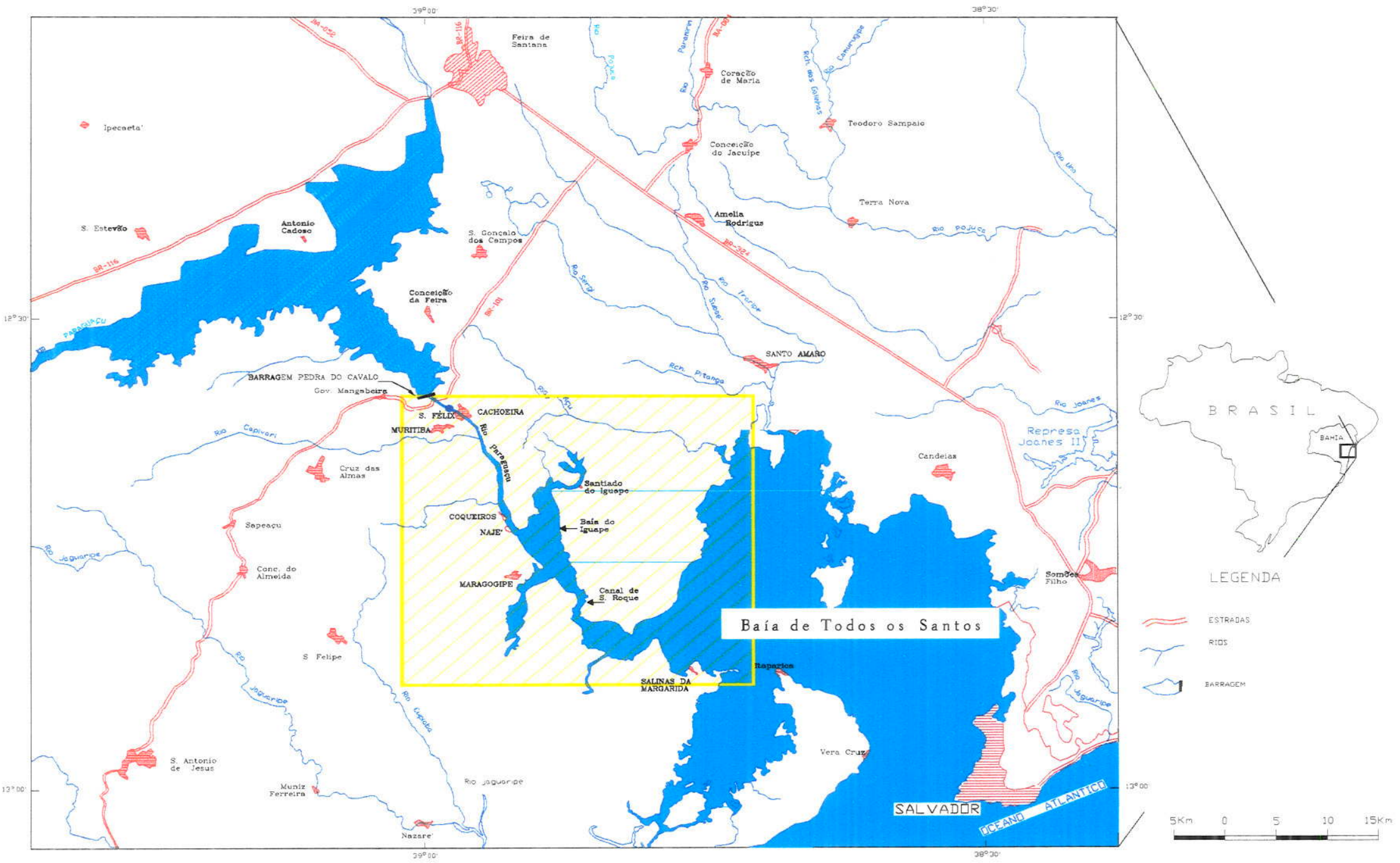

FIGURA 02 - MAPA DE LOCALIZAÇÃO E ACESSO DA ÁREA EM ESTUDO (adaptado de RAMOS, 1993). 


\subsection{ASPECTOS FISIOGRAFICOS GERAIS}

\subsubsection{Clima}

A bacia hidrográfica do médio e baixo Paraguaçu, se estende por regiōes distintas e que the confere variedade de características geoambientais, incluindo domínios de clima semi-árido no seu trecho médio e, de clima úmido na faixa litorânea. Próximo a barragem de Pedra do Cavalo, que corresponde a zona de transição entre estes dois domínios, o clima se torna mais ameno e os indices pluviométricos alcançam até $1200 \mathrm{~mm} / \mathrm{ano}$.

O trimestre mais chuvoso é variável ao longo da bacia, sofrendo um atraso à medida que se aproxima da foz. No alto e médio trecho é de novembro a janeiro e, no litoral, de maio a julho. As maiores cheias do rio Paraguaçu, que afetavam as cidades geminadas de São Félix e Cachoeira eram registradas no verão, de novembro a março, justamente nos periodos com menores índices pluviométricos nesta área. Isto sugere que as cheias do rio Paraguaçu, hoje controladas pela barragem de Pedra do Cavalo, são consequiências das chuvas acumuladas na bacia hidrográfica provenientes do alto e médio curso do rio. Durante o desenvolvimento deste estudo, o período de chuvas mais intensas, registrado na estação pluviométrica da barragem de Pedra do Cavalo, foi de março-julho no ano de 1994 e de abril-julho, em 1995.

$\mathrm{Na}$ classificação climática de Köppen, a área da bacia do médio e baixo Paraguaçu é caracterizada, em toda sua extensão, por climas da categoria A - Tropical chuvoso. Nos setores do alto e médio curso, o clima é do tipo Aw - clima tropical chuvoso com estação de inverno : seca (maio-outubro) e chuvosa (novembro a abril) com precipitações atingindo $750 \mathrm{~mm} / a n o$. No trecho mais baixo da bacia, até a foz do rio, predomina a tipologia Af - clima tropical chuvoso de floresta, sem estação seca, com os totais de indices pluviométricos, variando de 1200 a $1600 \mathrm{~mm} / \mathrm{ano}$ (Figura 03). 
Do médio curso do rio Paraguaçu ao litoral, a temperatura média anual é de $25^{\circ} \mathrm{C}$, com uma amplitude térmica baixa de $5,6^{\circ} \mathrm{C}$, devido ao efeito regulador da maritimidade. Os meses de julho e agosto são os mais frios e janeiro, o mais quente.

\subsubsection{Vegetação}

Ao longo da bacia, a vegetação ocorre em tipos variados (Figura 03), distribuidos de forma zonal, do interior (zonas de floresta estacional decidual) para o litoral (zonas de floresta ombrófila). Tal fato é conseqüência direta, não só do posicionamento próximo ao mar e da direção dos ventos, que levam à diminuição da pluviosidade da costa para o interior, como também, da altitude, litologia e atividade humana.

Nas áreas de Maragogipe, São Félix, Muritiba e próximo à foz do rio, a vegetação primária é do tipo floresta ombrófila densa, constituida de árvores perenefoliadas. Formada predominantemente por fanerófitas, possuem folhagem ampla e sempre verde, com alturas que variam de 20 a $30 \mathrm{~m}$. Este tipo de vegetaçăo pode ser observada em núcleos localizados, em consequeência da devastação antrópica, por efeito do extrativismo vegetal, preparaçăo da terra para a cultura de subsistência e implantação de pastagens.

Nas áreas não cultivadas, desenvolve-se uma mata secundária heterogênea, com destaque para a vegetação típica dos manguezais a bordejar alguns trechos da baia de Iguape. Formações Pioneiras, consideradas como pertencentes ao "complexo vegetacional edáfico de primeira ocupação" são registradas nas áreas de influência flúvio-marinha (manguezal arbóreo). Nas áreas com influência marinha, săo encontradas espécies como "mangue vermelho" (Rhizophora racemosa) e, em particular, nas comunidades aluviais, as paludicolas, psamófilas e palmeiras de áreas alagadiças. 


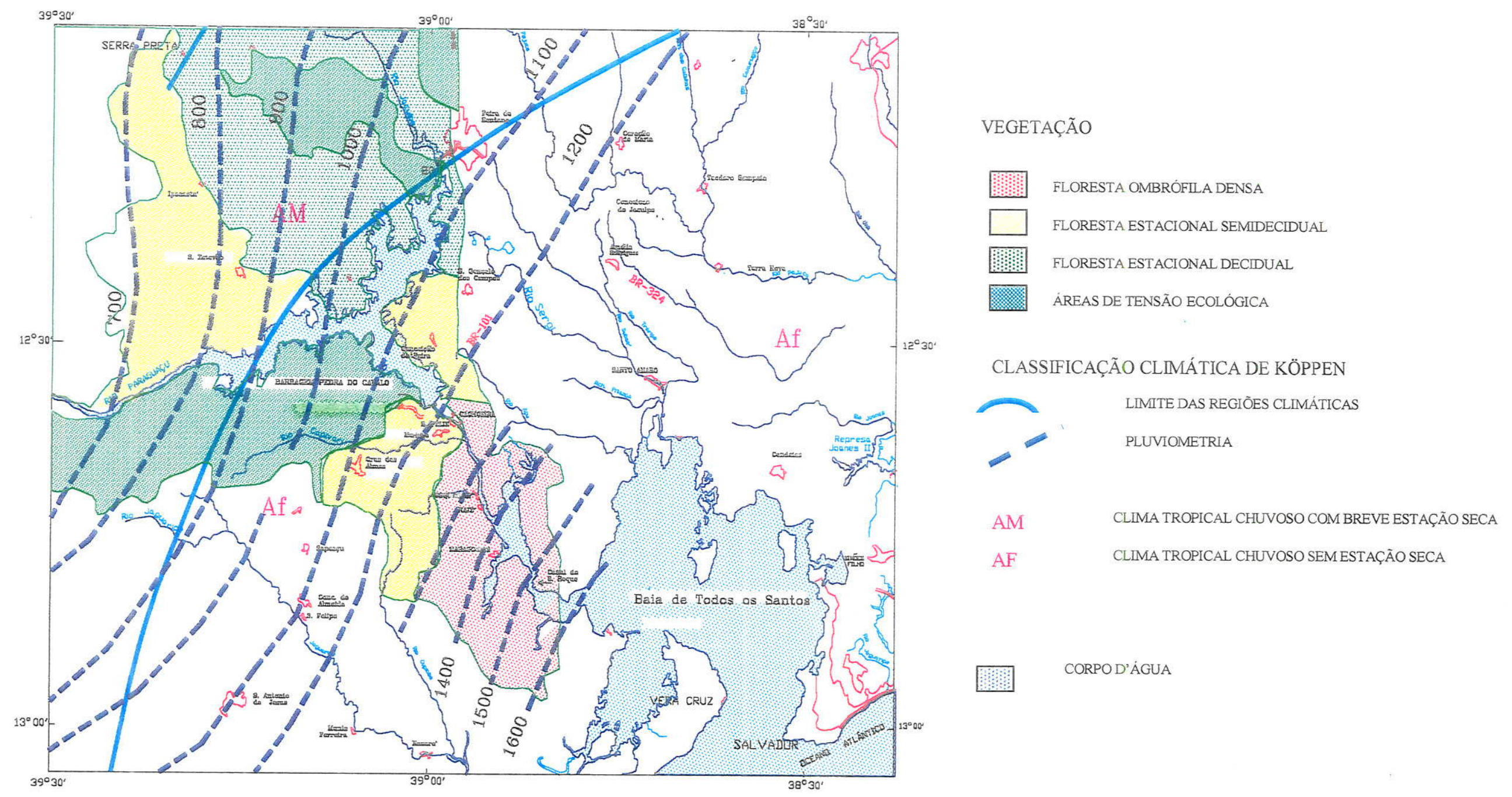

FIGURA 03 - MAPA DE DISTRIBUIÇÃO DA TIPOLOGIA CLIMÁTICA (KÖPPEN), PLUVIOMETRIA ANUAL (mm) E VEGETAÇÃO DA REGIÃO. (adaptado do PDRH-BMBP- BRASIL,1996) 


\subsubsection{Solos}

No conjunto, os solos ocorrem de maneira diversificada (Figura 04), ora oriundos de evoluçăo pedogenética autóctone, ora originados de sedimentos transportados. A leste da falha de Maragogipe são encontrados solos do tipo: arenoquartzozos e podzólicos vermelho-amarelos álicos, listróficos (associados às rochas sieniticas); e, vertissolos (massapê) associados aos sedimentos da bacia do Recôncavo. Expressiva ocorrência de latossolo amarelo álico, correspondendo às coberturas sobre os granulitos, ocorre ao norte do municipio de Cachoeira e nos municípios de São Félix e Muritiba.

Em áreas alagadas, bordejando a bala do Iguape embora com pouca expressividade, såo encontrados solos indiscriminados de mangues, mais considerados como terrenos do que como solos. Ao longo do vale do rio Paraguaçu, predominam os solos do tipo Brunizém Avermelhado, com caráter litólico (de maior importância) vértico e solódico. As principais caraterísticas dos solos identificados săo :

- Areno-Quartzoso : Săo solos minerais pouco desenvolvidos, devido ao material original ser de constituição areno-quartzosa que impede a evolução pedogenética do perfil. Os teores de argila estăo abaixo de $15 \%$. Săo profundos, muito ácidos, de textura grosseira e bastante susceptiveis a erosåo.

- Podzólico Vermelho-Amarelo Álico e Listrófico : Apresenta o horizonte B textural, năo hidromórfico. O horizonte $\mathrm{A}$ pode ter textura arenosa, média e argilosa e o Bt, média, argilosa e muito argilosa. No municipio de São Félix, onde ocorre em grande extensão, apresenta textura argilosa.

- Vertissolo : São solos minerais, argilosos, que apresentam pronunciadas mudanças em volume relacionadas com variações nos teores de umidade.

- Latossolo Amarelo : Săo solos minerais, não hidromórficos, com horizonte B latossólico. Apresentam-se na maioria dos casos, com texturas muito argilosa. Estăo relacionados as fases de relevo plano e suavemente ondulado. 


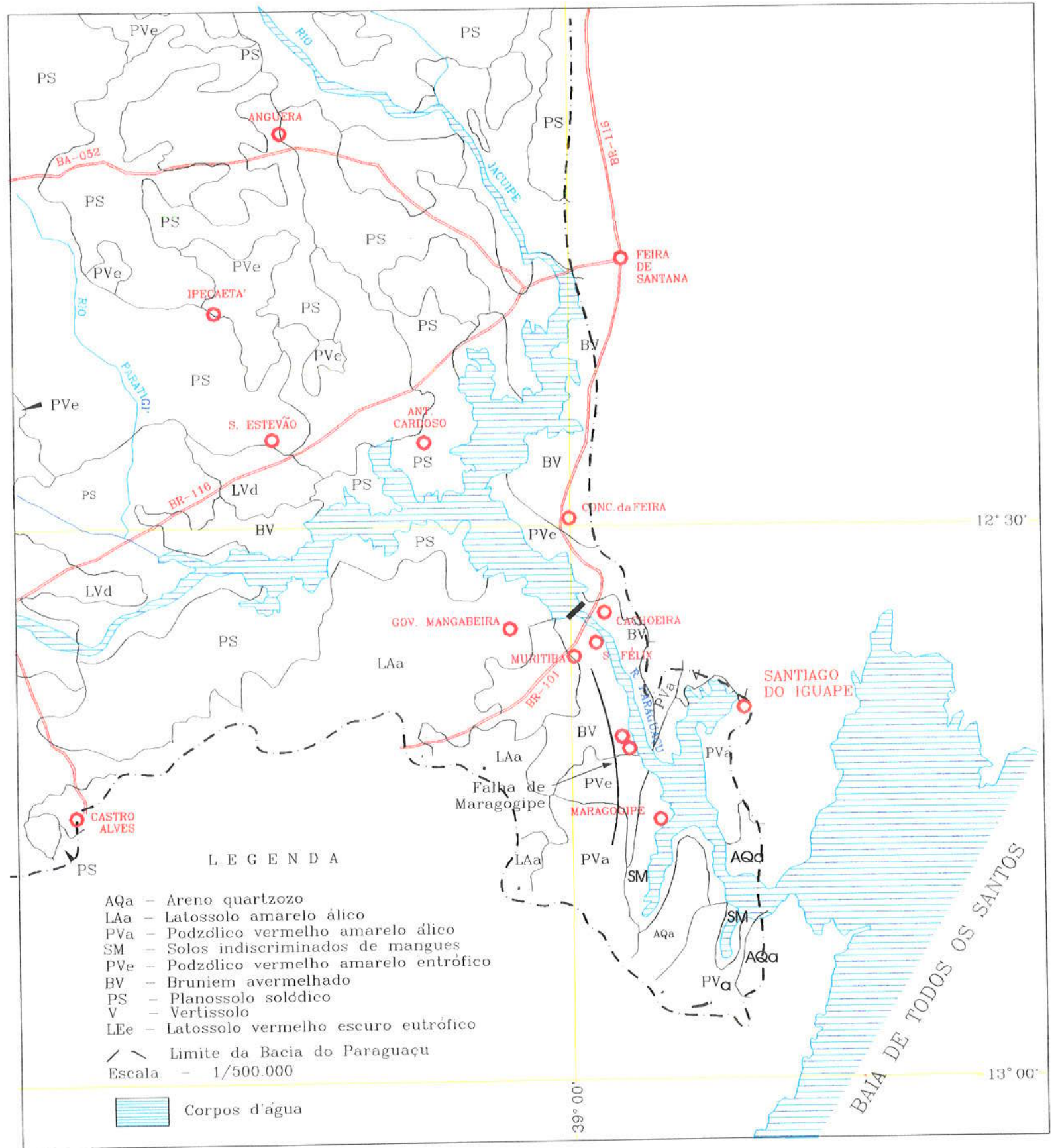

FIGURA 04 - MAPA DE SOLOS NA REGIÃO (adaptado do PDRH-BMBP, op. cit) 
- Solo indiscriminado de Mangues : São solos mal drenados, com alto conteúdo em sais provenientes da água do mar e de compostos de enxofre; se formam em áreas sedimentares baixas e alagadas do litoral, em geral nas proximidades de desembocaduras de rios, com o acúmulo de matéria orgânica.

- Brunizém Avermelhado : são solos derivados de rochas ricas em minerais ferromagnesianos e com elevados níveis de matéria orgânica nos horizontes superficiais. Caracterizam-se por um horizonte B textural, A do tipo chernozémico, argila de atividade alta e valores elevados de bases trocáveis. São, de forma moderada, ácidos ou neutros, com baixos teores de aluminio trocável e boa reserva de minerais facilmente decompostos.

\subsubsection{Geomorfologia e Relevo}

$\mathrm{Na}$ área da bacia do médio e baixo Paraguaçu, se destacam modelados de aplanamento e dissecação diferencial, onde as principais unidades geomorfológicas identificadas são :

- Pediplano Sertanejo : predomina na porção central da bacia onde ocorrem as litologias do embasamento. Corresponde a uma superficie deprimida, com altitudes variando de 200 a 600 metros cercada, em parte, por relevos planálticos. Morros residuais formando pequenas serras e "inselbergs" se destacam no relevo. Grande parte da área encontra-se recoberta por formaçóes superficiais pouco espessas, de natureza predominantemente arenosa, com freqüência mostrando afloramentos e forma de lajedos. É comum a ocorrência de solos Litólicos e Planossolos, em geral pedregosos.

- Tabuleiros Interioranos : ocorrem, de forma acentuada, nas regiöes de Feira de Santana e Santo Estevão. Trata-se de pediplano conservado em parte, com planos inclinados de altitudes em torno de 200 metros. O relevo apresenta cobertura de alteração arenosa, relativamente espessa. 
- Baixada Colinosa Pré-Litorânea: constitui modelado de dissecaçăo diferencial, com forte controle estrutural, abrangendo os domínios das rochas granulíticas e do sienito. Localizada próximo à faixa litorânea, é unidade de topografia rebaixada, de relevo uniforme e com altitudes que variam entre 100 e 200 metros. Os terrenos apresentam espesso manto de alteraçăo recoberto por um material coluvionar vermelho-amarelado, com espessura média de dois metros. A retirada da vegetaçăo original da área, tem ocasionado fenômenos erosivos e de movimentação de massa em vertentes ingremes podendo-se observar, com freqüência, afloramentos de rochas.

Na margem direita, nos limites do municipio de São Félix, desenvolve-se estreita Planicie Fluvial, com altitudes inferiores a 10 metros e estendendo-se até os Tabuleiros Pré-Litorâneos. Bordeando a baía de Iguape, destacam-se os trechos da Baixada Litorânea, entrecortada por um setor da Planície Flúvio-marinha, formada por sedimentos de origem fluvial e maritima.

Caracteristica marcante nas feiçōes geomorfológicas da área da região estuarina lagunar do rio Paraguaçu, é a escarpa da Falha de Maragogipe, que constitui a dorsal ocidental da Fossa do Recôncavo e com grande influência no relevo local. A oeste, os relevos correspondentes as rochas cristalinas sustentam um relevo mais abrupto e de maiores altitudes; à leste, o substrato sedimentar permite maior suavizaçăo, nas formas dos vales e elevaçőes, além de uma dissecaçăo mais intensa na zona de falhas secundárias.

\subsection{GEOLOGIA}

O rio Paraguaçu corre a maior parte do seu percurso no dominio de rochas metamórficas do Pré-Cambriano, na região centro-leste do Estado da Bahia. Seu embasamento cristalino constituido, principalmente, por granitos, gnaisses variados e por rochas metamórficas granulitizadas, integrantes do Complexo Jequié, corresponde aos litotipos predominantes em seu curso médio e porção ocidental do baixo curso. No seu alto curso, ele corta litologias metassedimentares precambrianas dos Supergrupos Espinhaço (Grupo Chapada Diamantina) e São Francisco (Grupo Una), 
respectivamente constituídos predominantemente por metarenitos $e$ rochas carbonatadas. No seu baixo curso, corta rochas sedimentares mesozóicas da Bacia do Recôncavo (Grupo Brotas) e os sedimentos tércio-quaternários das Formações Barreiras e Marizal.

Inúmeros trabalhos têm sido desenvolvidos para caracterização da geologia da região centro-leste do estado da Bahia. Definida no contexto tectonoestratigráfico do Cráton do São Francisco, onde se encontra inserida, a grande variação litológica dessa área e o seu complexo padrão estrutural relacionados aos vários ciclos deformativos tem dificultado, e muito, o estabelecimento de uma seqüência estratigráfica unívoca e comum. As principais informações geológicas apresentadas neste trabalho, foram obtidas do PDRH - BMBP (BRASIL,1996), e dos estudos geológicos na parte oriental da área realizados por CONCEIÇÃO et al. (1991), AlLLON (1992) e ROSA (1994), os quais serviram de suporte para a confecção do mapa geológico da área estudada, apresentado na Figura 05.

As rochas mais antigas, de idade arqueana são representadas, litologicamente, por charnockitos e enderbitos, ortognaisses e granitóides. As coberturas cratônicas estão representadas pelos seguintes dominios: os metassedimentos do Grupo Chapada Diamantina, que incluem as formações Tombador, Caboclo e Morro do Chapéu, enquadradas no contexto do Supergrupo Espinhaço do Proterozóico Médio; o conjunto de rochas carbonático pelíticas do Supergrupo São Francisco, mais especificamente do grupo Una, composto das Formações Bebedouro e Salitre referenciadas ao Proterozóico Superior; e, por fim, pela seqüência basal da bacia sedimentar do Recóncavo, de idade jurássica, representada pelo Grupo Brotas e os depósitos tércio-quaternários detríticos da Formação Barreiras e da formação Marizal, que ocorrem de forma pouco representativa.

A seguir, serão apresentados alguns aspectos referentes à geologia, dando ênfase à sua distribuição espacial e aos tipos litológicos predominantes nos trechos médio e baixo do rio Paraguaçu. 


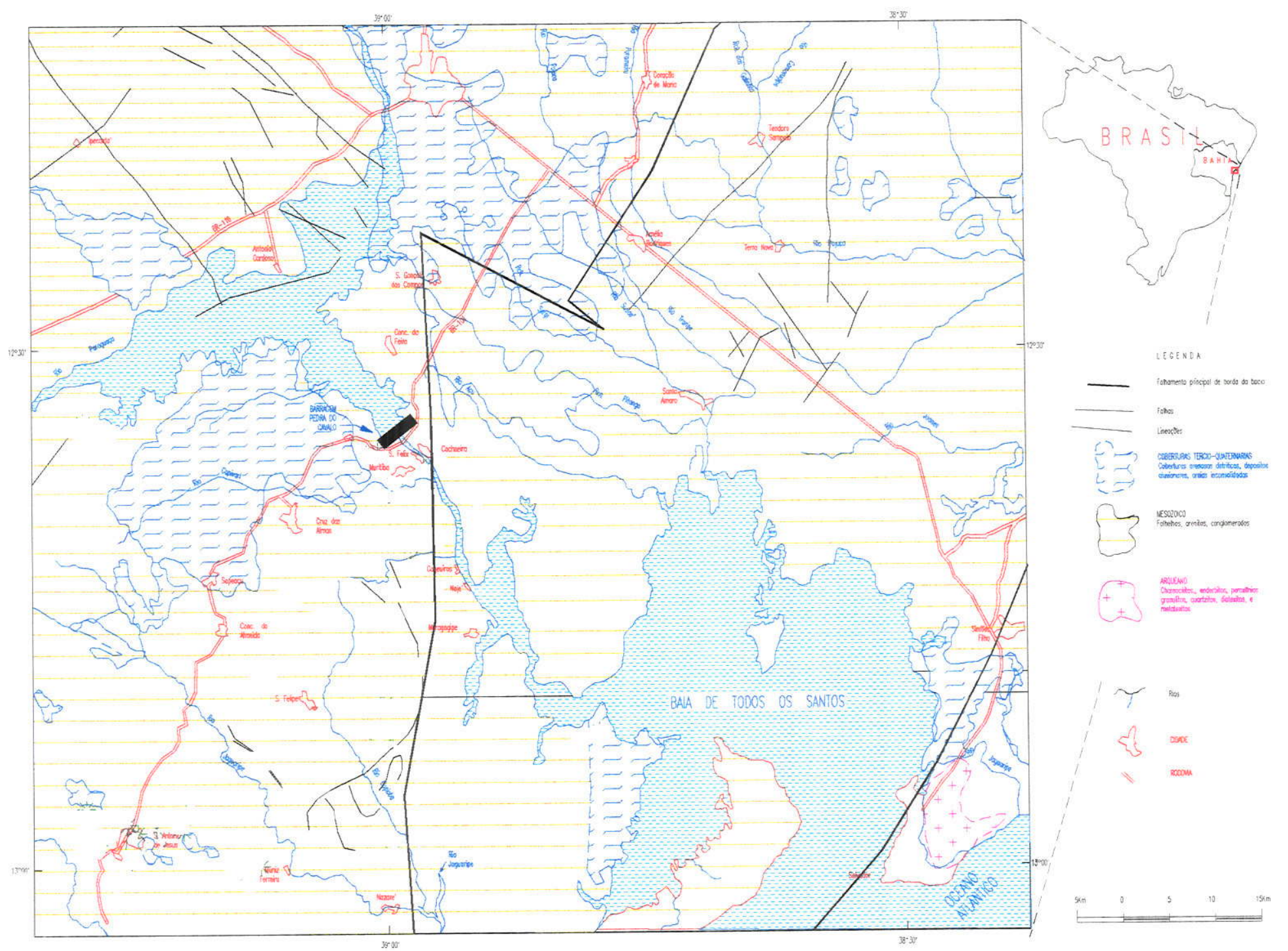

FIGURA 05 - MAPA GEOLÓGICO DA ÁREA (adaptado de AILION, 1992 e ROSA, 1994) 


\section{(a) Embasamento Arqueano}

Em superficie, estende-se desde a falha de Maragogipe a leste, até a porção oriental da região da Chapada Diamantina, a oeste da área correspondente ao curso médio e às porções ocidentais e orientais respectivamente dos cursos inferior e superior da bacia. Afloramentos de granulitos vão ocorrer, também, a leste da falha de Salvador, já fora dos limites da bacia do rio Paraguaçu. Os tipos litológicos a oeste da falha de Maragogipe e incluídos na Figura 05, são representados por charnockitos e enderbitos, ortognaisses da fácies anfibolito, ortognaisses granulitizados e granitóides, com ocorrências descontínuas de granulitos, anfibolitos, gnaisses kinzigíiticos e rochas calcissilicatadas, além de corpos graníticos intrusivos que marcam a consolidação do Cráton do São Francisco, durante o ciclo tectono-magmático Transamazônico (2,0 Ga). Em toda a área de ocorrência, estas litologias se encontram parcialmente recobertas por coberturas tércio-quaternárias detríticas e, em menor proporção, por depósitos terrígenos da Formação Barreiras.

\section{(b) Grupo Chapada Diamantina}

Corresponde à borda oriental da Chapada Diamantina. É formado por um conjunto de rochas metassedimentares que representam as rochas do Proterozóico Médio do Cráton do São Francisco. Da base para o topo, é dividido nas seguintes Formações: Tombador (uma seqüência de arenitos, com niveis conglomeráticos e ferruginosos, intercalada por siltitos e conglomerados); Caboclo (unidade litológica composta por intercalações de niveis de arenitos, siltitos e argilitos, com ocorrências locais de calcário oolíticos silicificado); e Morro do Chapéu (unidade composta por arenitos ortoquartzíticos róseos, associados com lentes de siltitos, argilitos, arenitos síticoargilosos e conglomerados de matriz arenosa).

\section{(c) Grupo Una}

Formação Bebedouro: está representada por sedimentos síltico-argilosos, finamente estratificados, por diamictitos, ardósias laminadas e arenitos. Na porção basal, apresenta niveis de paraconglomerados com seixos mal selecionados, variando de areia até blocos de gnaisses, filitos, quartzitos verdes, quartzo leitoso e dolomitos. 
Formação Salitre: Aflora na porção sudoeste da área da bacia. É unidade composta de calcarenitos bastante fraturados, calcissiltitos e calcilutitos, ocorrendo também margas laminadas e com niveis de calcário e calcários dolomíticos, com detritos e cristais de pirita.

\section{(d) Bacia Sedimentar do Recôncavo}

Os sistemas de falhamento de Salvador (a leste) e de Maragogipe (a oeste) desenvolvidos à partir do final do Paleozóico, geraram regionalmente um ambiente deposicional tipo grabem. Desta forma, já durante o período Jurássico, foram criadas condições para a deposição sobre o Embasamento Cristalino, de sedimentos de origem continental (folhelhos e arenitos), sobre essa vasta depressão, evoluida a um sistema de tipo "rift". Dessa forma, espessos pacotes de sedimentos depositados deram origem à bacia sedimentar do Recôncavo. Na área da bacia hidrográfica do Paraguaçu, os sedimentos estão representados por afloramentos situados próximos à faixa litorânea, à jusante da barragem de Pedra do Cavalo, localizada $4 \mathrm{~km}$ a oeste da cidade de Cachoeira, ou seja, toda a porção oriental da área. O grupo Brotas, depositado antes da implantação do sistema de "rift", constitui a unidade inferior dos sedimentos que compõem a bacia sedimentar do Recôncavo. É constituido de folhelhos, lamitos e siltitos, enquadrados na Formação Aliança que representa a seqüência de base $e$, arenitos quartzosos com interestratificações de camadas de folhelhos e siltitos, conglomerados finos a médios e arenitos com seixos esparsos, da unidade superior denominada de Formação Sergi.

Estas características litológicas, aliadas ao clima que predomina na área, condicionam a formação de um espesso manto de intemperismo e de solos bastante argilosos, do tipo "massapê".

\section{(e) Coberturas Tércio-Quaternárias}

Na área do baixo Paraguaçu distingue-se, genericamente, o complexo granulítico (migmatitos facoidais, granulitos e protomilonitos) sobre 0 qual, distribuem-se 
sedimentos terciários da Formação Barreiras e, de forma restrita, da Formação Marizal e sedimentos recentes, representados pelos aluviões dos cursos d'água.

Formação Barreiras : Ocorre depositada de forma discordante sobre as litologias PréCambrianas do Embasamento Cristalino. $\mathrm{Na}$ área da bacia, ocorre na porção leste, na margem oriental do lago de Pedra do Cavalo e também ao norte. É representada por conglomerados com niveis argilosos, definidos como depósitos continentais formados por material areno-argiloso, com acamamento definido e grande variação lateral e horizontal, apresentando-se intercalados por argilas e siltitos, de coloração variada. Os arenitos são, em geral, quartzosos, grosseiros e mal selecionados.

Coberturas Tércio-Quaternárias detríticas (Formação Marizal) : apresentam-se como sedimentos arenosos, podendo ser, no local, areno-argiloso com niveis cascalhosos ou conglomeráticos na parte basal. Ocorrem em toda a área da bacia sendo mais significativa na margem sul do lago da barragem de Pedra do Cavalo.

Depósitos Quaternários: são representados por sedimentos arenosos distribuídos na forma de aluviões, ao longo do rio Paraguaçu e de seus principais afluentes e como depósitos litorâneos na região costeira. No baixo curso do rio Paraguaçu e no terço inferior do rio Jacuipe, os depósitos aluvionares tornam-se mais representativos, formando uma planície aluvionar relativamente larga. Os depósitos litorâneos são constituidos de sedimentos flúvio-marinhos que, condicionados pela baixa energia do mar no interior da baía de Todos os Santos são representados, de forma predominante, por sedimentos argilosos escuros e ricos em matéria orgânica que formam as zonas de manguezais.

\subsection{HIDROGRAFIA}

Do ponto de vista hidrográfico, a área de estudo faz parte da bacia do Paraguaçu, a qual drena uma área de aproximadamente $56.000 \mathrm{~km}^{2}$ na região centroleste do estado da Bahia, abrangendo 75 municipios. O rio Paraguaçu, principal rio da bacia, nasce na Serra do Sincorá, Chapada Diamantina a, aproximadamente, $1200 \mathrm{~m}$ de altitude e corre de SW para NE. Até sua foz, percorre cerca de $540 \mathrm{~km}$ atravessando dezoito municípios, indo desaguar na Bala de Todos os Santos, através 
do Canal de São Roque. Seus principais afluentes são os rios Paraguaçuzinho, Santo Antônio, Una, Capivari, Peixe e Jaculpe.

Em seu trecho superior, é um rio típico de planalto, cortando os terrenos selvagens da Chapada Diamantina, ricos em diamantes, razão pela qual seu leito tem sido perturbado pelos trabalhos de garimpagem, efetuados de forma predatória. $\mathrm{Na}$ regiåo oriental do municipio de Milagres, o rio atravessa os terrenos metamóficomigmáticos do Complexo de Jequié. Este, é o trecho inferior do rio que, na sua porção final, inclui a área estuarina-lagunar formada pela "baía" do lguape, com uma área aproximada de $80 \mathrm{~km}^{2}$.

No leito do rio Paraguaçu, $30 \mathrm{~km}$ à montante do estuário, foi construída, nos anos 60, a barragem de Bananeiras (359 $\mathrm{m}$ de extensão por $35 \mathrm{~m}$ de altura), cujo reservatório encontra-se hoje incorporado ao da barragem de Pedra do Cavalo (1210 $\mathrm{m}$ de extensão por $143 \mathrm{~m}$ de altura), levantada em 1980, $40 \mathrm{~km}$ da foz do rio. Este reservatório, com uma cota máxima de $124 \mathrm{~m}$ acima do nivel do mar, forma um lago com um volume de 4066 bilhöes de $\mathrm{m}^{3}$ de água, ocupando uma área de $147 \mathrm{~km}^{2}$. A vazão defluente para a região à jusante, corresponde a uma descarga pelo sistema de comportas (liberaçăo de água pelo topo ou crista) abertas na cota máxima de transbordamento, que é de $108 \mathrm{~m}$.

O aproveitamento de Pedra do Cavalo teve, como principais objetivos, a regularização do rio para controle das enchentes e o abastecimento de água da região metropolitana, denominada Grande Salvador, da regiåo fumageira de Cruz das Almas e do município de Feira de Santana, além da irrigaçăo agrícola. Este aproveitamento, vem contribuindo para o desenvolvimento regional, sobretudo mediante o uso da água para fins domiciliar, irrigar áreas cultivadas, incrementar a pesca, desenvolver turismo e o lazer.

O Paraguaçu é um rio de regime torrencial muito variado, dado a enchentes, cujos períodos de altas descargas correspondem aos periodos de chuvas nas regióes de seus trechos superior e médio. Este regime complexo, decorre do escoamento das bacias secundárias, função não somente da variaçăo sazonal das chuvas, como do relevo movimentado que imprime fortes inclinações no seu perfil como também, da 
baixa retenção do solo, que facilita o rápido escoamento. A drenagem média do rio corresponde a $120 \mathrm{~m}^{3} / \mathrm{s}$.

Em Pedra do Cavalo, nos últimos cinco anos, a vazão média diária máxima registrada foi de $2.300 \mathrm{~m}^{3} / \mathrm{s}$, enquanto a média mínima, foi apenas de $50 \mathrm{~m}^{3} / \mathrm{s}$. O Quadro 01 relaciona outros parâmetros registrados da estaçăo hidrográfica em Pedra do Cavalo, no periodo estudado. Os dados foram fornecidos pela EMBASA - Empresa de Aguas e Saneamento do Estado da Bahia. Valores máximos e minimos, respectivos à precipitação e vazão defluente média mensal, são destacados em negrito.

QUADRO 01 - PARÃMETROS FÍSICOS REGISTRADOS NA BARRAGEM DE PEDRA DO CAVALO NO PERIODO ESTUDADO (dados fomecidos pela EMBASA)

\begin{tabular}{|c|c|c|c|c|c|c|}
\hline Mês / ano & \multicolumn{3}{|c|}{1994} & \multicolumn{3}{|c|}{1995} \\
\hline & $V A\left(m^{3} / s\right)$ & $V D\left(m^{3} / s\right)$ & $P(m m)$ & $V A\left(m^{3} / s\right)$ & $V D\left(m^{3} / s\right)$ & $P(m m)$ \\
\hline Janeiro & 16 & 0 & 12 & 5 & 6 & 3 \\
\hline Fevereiro & 23 & 0 & 30 & 5 & 5 & 25 \\
\hline Março & 275 & 19 & 182 & 17 & 4 & 52 \\
\hline Abril & 115 & 48 & 216 & 83 & 3 & 124 \\
\hline Maio & 76 & 14 & 160 & 100 & 6 & 145 \\
\hline Junho & 22 & 45 & 113 & 18 & 6 & 97 \\
\hline Julho & 30 & 13 & 238 & 42 & 3 & 103 \\
\hline Agosto & 26 & 15 & 71 & 30 & 11 & 78 \\
\hline Setembro & 19 & 15 & 89 & 7 & 12 & 77 \\
\hline Outubro & 10 & 15 & 55 & 4 & 10 & 18 \\
\hline Novembro & 5 & 42 & 29 & 117 & 126 & 235 \\
\hline Dezembro & 16 & 8 & 15 & 191 & 167 & 58 \\
\hline
\end{tabular}

VA - Vazão afluente média; VD - Vazão defluente média; P - Precipitação.

Na região estuarina-lagunar, as oscilações de maré atuantes são perceptiveis até as cidades de São Félix e Cachoeira e, na época de estiagem, a altura das águas é comandada, sobretudo, pelo regime das marés. Em toda a área a jusante da barragem, o rio Paraguaçu recebe a influência da cunha salina da Baía de Todos os Santos, que acompanha o ciclo semidiurno de marés, com amplitudes variando entre 2,0 $\mathrm{m}$ na preamar, 0,0 na baixa-mar e amplitude média em torno de 1,6. 
O rio Jacuipe, um dos principais tributários do Paraguaçu na região do reservatório percorre, aproximadamente, $250 \mathrm{~km}$ passando de um clima quente e seco no seu alto e médio curso, para outro, quente e úmido, perto do reservatório. Feira de Santana é a cidade mais importante na sua bacia, com aproximadamente 500.000 habitantes e onde o Centro Industrial de Subaé - CIS é locado.

\subsection{CONDIÇÕES DE USO E OCUPAÇÃO}

Com base em estudos de impactos ambientais, tem sido verificado que as principais fontes de poluição dos corpos d'água, estăo relacionadas as atividades econômicas e urbanas. Atividades industriais, na maioria dos casos, geram efluentes que săo lançados nos cursos d'água sem adequado tratamento. Nas atividades agrosilvopastoris, os agrotóxicos usados nos cultivos, ao serem dissolvidos e carregados pela ação das águas de irrigaçăo, provocam o progressivo aumento do nivel de poluição dos mananciais. Entretanto, uma das maiores fontes de poluição é a provocada pelo lançamento dos despejos domésticos sem tratamento.

O principal uso das terras na região estudada, (Figura 06) se dá através de atividades agropecuárias, normalmente associadas a agricultura e ao extrativismo. A área ocupada pelas atividades agropecuárias tem crescido sobremaneira nas últimas décadas, em detrimento das atividades puramente agrícolas.

As atividades extrativistas são representadas pela pesca artesanal e pela extração de mariscos, crustáceos e camarões. A atividade extrativa de mariscos e crustáceos, que se desenvolve em todas as áreas de mangue e áreas estuarinas destaca-se, com mais clareza, nos municipios de Maragogipe e Cachoeira. É uma atividade utilizada pela população de menor renda para o seu próprio sustento. Nos próximos itens são enfatizadas as principais atividades poluentes e os impactos ambientais resultantes na região, a qualidade das águas, seguidos de uma bibliografia referencial sobre os trabalhos anteriores desenvolvidos com respeito aos estudos sobre o uso e ocupação da terra, seus recursos hidricos e a qualidade ambiental. 


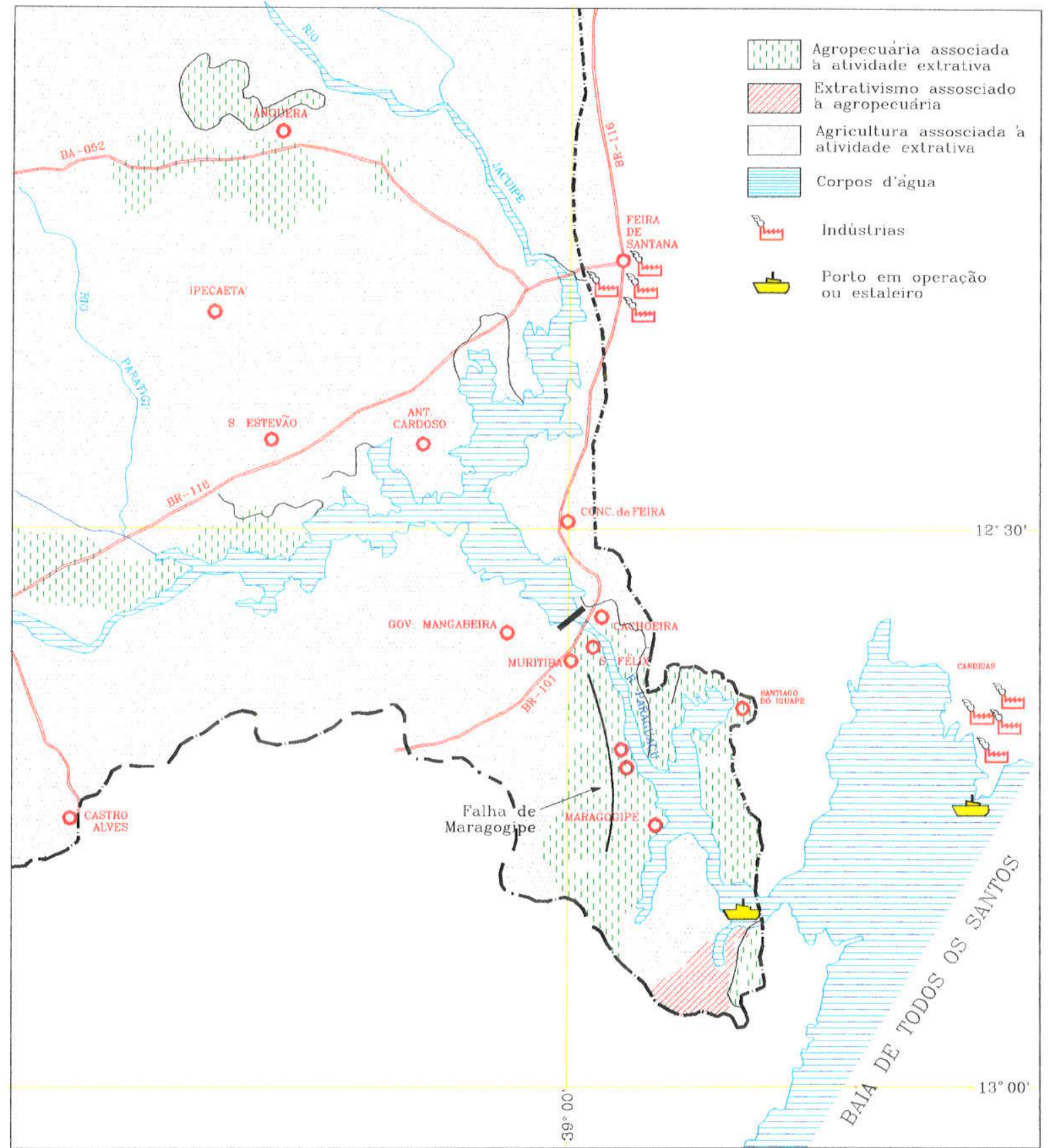

FIGURA 06 - CONDIÇÕES DE USO E OCUPAÇÃO NA REGIÃO (adaptado do PDRH-BMBP op. cit.) 


\subsubsection{Principais Atividades Poluentes e os Impactos Resultantes sobre o Meio Ambiente}

Com base nos dados da literatura e dos levantamentos efetuados, cinco (05) são os fatores que têm sido computados como agentes impactantes do ecossistema flúvio-deltáico estudado. São eles:

\section{a) Disposição de Esgotos urbanos}

$\mathrm{Na}$ maioria dos municípios integrantes da região, os serviços de coleta $e$ tratamento dos esgotos sanitários são ausentes. As condições de saneamento básico das populações urbanas ainda deixam muito a desejar. Os mananciais superficiais são utilizados como corpos receptores das águas residuárias e para afastamento dos despejos o que, quase sempre, ocasiona impacto ambiental.

A exemplo, cerca de $70 \%$ dos efluentes urbanos da cidade de Feira de Santana, município mais populoso situado à montante da barragem de Pedra do Cavalo é lançado, "in natura", direto nos corpos d'água, via canais de drenagem da cidade. As cidades localizadas à jusante e no entorno da baía de Todos os Santos estão sendo contempladas, recentemente, com projetos de sistemas de esgotamento sanitário, dentro do programa de despoluição da Baía de Todos os Santos.

De acordo com os dados publicados pelo PDRH-BMBP (BAHIA, 1996), as amostras de água do alto rio Jacuipe, à montante de Feira de Santana, indicaram alteração na qualidade da água por despejos sanitários, com valores de coliformes fecais acima dos limites. No trecho onde se inicia a formação do lago da barragem de Pedra do Cavalo, os parâmetros se encontram dentro dos padrões.

\section{b) Disposição de Resíduos Sólidos}

A disposição de lixo em todos os municípios, ocorre em lixões nas ruas, nas margens das estradas, nas margens dos corpos d'água ou, até mesmo, com o descarte direto nos mananciais. Tal fato, além de contribuir para a erosão das margens 
e obstrução das seções de escoamento, pode causar alterações significativas na qualidade da água.

\section{c) Agropecuária}

A agropecuária associada a agricultura e ao extrativismo vegetal, constitui conjunto de atividades sem o necessário controle, que inclui: desmatamento da vegetação original para a implantação de pastagens e cultivos agrícolas; limpeza do solo através de queimadas; manipulação do solo para o plantio, alterando suas características físicas e estruturais; manipulação de maiores quantidades de água sobre o solo, nas áreas de irrigação; utilização de fertilizantes e agro-tóxicos. Tudo se caracteriza como atividade impactante que contribui para a aceleração dos processos de erosão do solo, assoreamento dos mananciais e degradação da qualidade das águas.

\section{d) Atividades Industriais}

O Centro Industrial do Subaé, localizado a leste da cidade de Feira de Santana, e formado por 39 empresas, constitui o principal parque industrial à montante da barragem de Pedra do Cavalo. Nos municipios de Maragogipe, São Félix e Cachoeira, a indústria do fumo e da extração de minerais não metálicos são as atividades industriais que se destacam.

\section{e) Atividades de Mineração}

A região próxima à foz do rio Paraguaçu, se encontra totalmente descaracterizada pelas atividades antrópicas, inclusive de mineração. A PETROBRÁS e a companhia de Mineração Quimica do Nordeste S/A, que já vêm explorando a região, têm intensificado estudos de prospecção para óleo, gás e sal-gema.

As ocorrências de mineração nos municipios de Maragogipe, Cachoeira e outros, são de argilas, areias e pedras para construção, exploradas de forma descontrolada. 
Quanto as indústrias mineradoras, duas empresas de extração e tratamento de minerais em Feira de Santana são consideradas como alto potencial poluidor, por serem indústrias de extração de granito, mármore, sais minerais e pedras.

\subsubsection{QUALIDADE DAS AGUAS}

No que diz respeito a qualidade das águas, além dos problemas de assoreamento, a mineração e irrigação, como efetivados na região, têm sido admitidos como os principais fatores que contribuem para a contaminação das águas do Paraguaçu, muito embora a maior preocupação, atualmente, venha recair sobre o esgotamento sanitário dos núcleos urbanos, em especial, daquele de Feira de Santana. Com uma população estimada em mais de 500.000 habitantes, essa pequena metrópole possui um sistema de esgotamento sanitário incompleto, no que diz respeito a sua rede coletora, ainda parcialmente executada. Assim, o tratamento dos efluentes domésticos não atende a vazão (produzida pela cidade), induzindo a contaminação das águas do rio Jacuípe, seu principal canal de drenagem. Este, por sua vez, deságua no Paraguaçu, logo na entrada do lago de Pedra do Cavalo. Outro fator relevante, é o aumento da salinidade das águas à jusante, na região estuarina, sempre que ocorre diminuição da vazão normal do rio, em função da operação de barramento de Pedra do Cavalo.

De acordo com dados apresentados no PDRH-BMBP (BRASIL, 1996), a qualidade das águas da bacia do Paraguaçu, à montante da barragem de Pedra do Cavalo, está enquadrada na Classe 2 da Resolução CONAMA 20/86 (BRASIL, 1994a). Portanto, são águas adequadas para abastecimento doméstico após tratamento convencional, e à proteção de comunidades aquáticas, à recreação de contato primário (natação, mergulho e esqui aquático), à irrigação de hortaliças e plantas frutiferas e à criação natural ou intensiva (aquicultura) de espécies destinadas à alimentação humana.

$\mathrm{Na}$ regiấo estuarina do trecho do baixo curso do rio Paraguaçu, entre a barragem Pedra do Cavalo e a desembocadura da baía de Todos os Santos, a influência da intrusão da cunha salina com as variações de marés, condicionam o enquadramento diferenciado destas águas, do restante da bacia. A salinidade é 
dependente da oscilação das marés e da vazão efluente da barragem Pedra do Cavalo. Tem sido proposto enquadramento preliminar destas águas na classe 5 , ou seja, são consideradas águas salinas destinadas à recreação de contato primário, à proteção das comunidades aquáticas e à criação natural e/ou intensiva (aquicultura) de espécies destinadas à alimentaçăo humana.

Para o enquadramento definitivo e melhor avaliação da qualidade das águas tem sido indicada a adoção das seguintes providências: o monitoramento da salinidade durante pelo menos um ano hidrológico; investigações específicas nas áreas onde existe suspeita ou informaçăo da presença de substâncias prejudiciais; vistoria e controle das atividades antrópicas potencialmente prejudiciais à qualidade das águas.

\subsection{TRABALHOS ANTERIORES}

A partir da década de 60 , foram realizados pelos órgãos governamentais estudos hidrológicos que objetivaram: aproveitamento das águas do rio Paraguaçu, através da implantação de barramentos; controle das enchentes e da dinâmica fluvial para identificar a contribuição das bacias afluentes, nas inundaçőes catastróficas que atingiam o baixo curso do rio; e diagnóstico das potencialidades e problemas para a definição de alternativas de usos adequados dirigidos à ordenaçăo territorial da bacia do Paraguaçu. Estes documentos tratam dos seguintes aspectos:

- Do Plano de Valorização dos Recursos Hídricos da bacia do rio Paraguaçu, elaborado em 1974, pela Secretaria de Saneamento e Recursos Hídricos do Estado da Bahia, que resultou num relatório em dois volumes incluindo diagnóstico da área, estudos detalhados sobre os locais para irrigação e possiveis barramentos, objetivando a implantação da barragem de Pedra do Cavalo.

- Estudo de impacto em torno da área hoje ocupada pelo Reservatório de Pedra do Cavalo, compreendendo aspectos de Climatologia, Geomorfologia, Sismologia, Pedologia, Biologia e Limnologia, realizado pelo Centro de Pesquisa e Desenvolvimento - CEPED (BAHIA, 1980), antes da construção da barragem. A publicação, foi editada pela Companhia de Desenvolvimento do Vale do Paraguaçu - DESENVALE (BAHIA, 1984). Os estudos específicos de limnologia resultaram em 
dois trabalhos publicados pela Universidade de Hamburgo (PAREDES et al.,1983 e PAREDES et al., 1993). Assim, tais estudos dizem respeito a situação anterior à qual ora se propõe examinar.

- Controle da qualidade das águas, principalmente através da fiscalização das fontes potenciais de poluição, considerando o fechamento/enchimento do reservatório de Pedra do Cavalo, realizado pelo Centro de Recursos Ambientais da Bahia - CRA (BAHIA, 1982). As águas da Bacia Hidrográfica do rio Paraguaçu, para o ano de 1985, foram enquadradas na classe 2, de acordo com os resultados de monitoramento, realizado na área de Feira de Santana e, em especial, na área de influência do Centro Industrial de Subaé (CIS).

- "Diagnóstico Geoambiental e Sócio-Econômico da Bacia do rio Paraguaçu" (BRASIL, 1993) com o objetivo de orientar a seleção de áreas prioritárias, para ações governamentais, no âmbito do Programa de Irrigação do Nordeste. O estudo foi divulgado em 1993 pela IBGE - Fundação Instituto Brasileiro de Geografia e Estatistica.

- Plano Diretor de Recursos Hídricos da Bacia do Médio e Baixo Paraguaçu, realizado em 1996 pela Secretaria de Recursos Hidricos Saneamento e Habitação Superintendência de Recursos Hidricos tendo como objetivo, servir de instrumento de planejamento da gestão e do aproveitamento dos recursos hídricos, no âmbito espacial e em setores de atividades econômicas, mais diretamente relacionadas com o uso destes recursos.

- Estudo da presença e influência dos metais pesados em várias áreas da baía de Todos os Santos realizado pelo Centro de Estatística e Informações do Estado da Bahia - CEI (BAHIA, 1994).

Em outras pesquisas, desenvolvidas na região nos últimos quinze anos, são abordados aspectos de caráter específicos, mesmo quando posteriores a construção da barragem. Destacam-se: 
- Os sedimentos de fundo do rio e do interior da baía, na área da desembocadura do rio Paraguaçu na baia de Todos os Santos, foram classificados por BRICHTA (1977) em quatro tipos faciológicos: arenoso, areno-argiloso, argiloso e conchifero. $O$ estudo revela que, a distribuição é semelhante nos dois setores estudados embora o teor de carbonato, apresente-se inferior a $5 \%$ nos sedimentos de fundo do rio Paraguaçu e de $5 \%-15 \%$, nas amostras coletados no interior da baía.

- Estudando a relação do Carbono Orgânico Particulado e Nitrogênio na zona estuarina, PAREDES et al. (1983) sugerem que, o alto teor de matéria orgânica em suspensão e a baixa produtividade primária, são provenientes dos detritos das vegetação.

- Avaliando a influência antrópica no ecossistema de manguezal instalado no rio Jacuipe, QUEIROZ (1989) relaciona a deposição dos metais com a dos sedimentos finos. O mesmo autor, em estudo posterior, datado de 1992, sobre abordagem sedimentológica, mineralógica e geoquímica dos sedimentos, destaca a influência antrópica nos mangues das regiões de Maragogipe e Santo Amaro.

- Os estudos desenvolvidos por PAREDES et al. (1993), referenciam dados para comparações posteriores, sobre os componentes orgânicos e inorgânicos transportados pelos rios Paraguaçu e Jacuipe e transferidos para 0 antigo reservatório de Bananeiras, hoje incorporado ao Complexo de Pedra do Cavalo.

- Estudos realizados por LINHARES et al. (1995) nos sedimentos do lago de Pedra do Cavalo, do rio Paraguaçu, à montante do reservatório e do rio Jacuipe, revelam que os teores de Fe-Al-Mn-Cu-Pb-Zn-Cd são relativamente mais altos, nos sedimentos de fundo do rio Jacuipe. Entretanto os teores de Fe-Al-Mn-Zn são mais altos nos sedimentos em suspensão do rio Paraguaçu. A especiação química dos metais pesados nos sedimentos de fundo do rio Jacuipe, apresentada por LINHARES et al. (1996), usando extração seqüencial, mostra que $\mathrm{Zn}, \mathrm{Cr}$ e, principalmente, $\mathrm{Pb}$ estão biodisponiveis enquanto $\mathrm{Cu}$ e $\mathrm{Cd}$, estăo associados à fase residual. 
- Várias pesquisas, desenvolvidas à jusante da barragem de Pedra do Cavalo, acusam altas concentrações de $\mathrm{Pb}-\mathrm{Cd}-\mathrm{Zn}-\mathrm{Hg}$ nos sedimentos da baía de Todos os Santos (PFEIFER et al., 1988) e nos manguezais (QUEIROZ et al., 1993). Teores elevados de $\mathrm{Cu}-\mathrm{Pb}-\mathrm{Zn}$ também foram encontrados nos sedimentos de fundo do estuário lagunar da baia de lguape (RAMOS, 1993; PAREDES et al., 1993).

- Estudo geoquímico desenvolvido por RAMOS (1993), no estuário do rio Paraguaçu, conclui que a concentração dos metais nos sedimentos de fundo, está relacionada à grande quantidade de matéria orgânica, presente nos sedimentos e resultante de uma intensa atividade biológica no estuário, além dos fatores antrópicos que afetam a região.

- MESTRINHO (1995), estudando influência da dinâmica das marés, na distribuição dos metais nos sedimentos de fundo da região estuarina sugere que, durante as marés de menor amplitude, a composição dos sedimentos de fundo, por parte de metais pesados, parece ser mais representativa para avaliar a qualidade ambiental. Outro estudo desenvolvido sobre os sedimentos em suspensão, ainda por MESTRINHO et al. (1995), demonstra que a concentração dos metais nos sedimentos em suspensão, também é influenciada pelo tipo de maré.

- Os resultados preliminares sobre a distribuição dos metais, nos sedimentos de fundo do baixo Paraguaçu e de seu ambiente estuarino, apresentados por MESTRINHO et al. (1996), indica a necessidade de um monitoramento contínuo da região decorrente do fato de que, a presença dos metais, pode estar associada aos efluentes locais e a circulação de água no sistema estuarino. 
CAPÍTULO 3 - METODOLOGIA 


\section{METODOLOGIA}

A metodologia desenvolvida neste trabalho, buscou uma caracterização da distribuição espacial e temporal da concentração dos metais, nos sedimentos do complexo estudado, associada a influência das variáveis fisicas na fase de coleta das amostras, tais como: tipo de sedimentos (material particulado em suspensão e de fundo); diferentes condições de marés; variaçōes sazonais; número e distribuição dos pontos de amostragem. Dentro deste propósito, as seguintes atividades foram consideradas primordiais para nortear a metodologia apresentada: planejamento das campanhas de campo, de acordo com as diferentes condiçőes de maré no porto de Salvador, acompanhadas pela Tábua de Marés (BRASIL, 1994 e 1995); seleção de pontos para medidas "in situ" e coleta das amostras de sedimentos de fundo e de material particulado em suspensão; escolha dos métodos de análise quimica para determinação dos teores dos metais; e utilização de métodos gráficos e estatísticos para interpretação dos resultados obtidos.

As técnicas utilizadas em campo e laboratório, seguiram a orientação de textos especializados mais recentes, tais como: Standard Methods for the Examinations of Water and Wastewaters - 19a ed. (AMERICAN, 1995) e do Guia de Coleta e Preservação de Amostras (CETESB, 1988). As análises químicas e mineralógicas, foram realizadas no Laboratório de Geoquímica da Universidade Federal da Bahia. Todos métodos foram previamente testados e adaptados antes da sua aplicação direta.

\section{1- MÉTODOS DE CAMPO}

\subsection{1 - Localização das estações de amostragem}

Em geral, em um mesmo ponto, os corpos de águas superficiais apresentam variações ao longo do tempo, em função das contribuições recebidas ou das variáveis meteorológicas. Na área estuarina, em particular, a influência das marés provoca profundas alterações nas características da água e dos sedimentos, já que se trata de área de confluência e mistura entre água salgada e doce, provocando ressuspensão do sedimento de fundo durante a penetração da cunha salina, com maior densidade. No sentido de se obter caracterização média, em vários pontos, as estações de 
amostragem foram selecionadas tomando-se por base estes aspectos e, também, aqueles relacionados à ocupação demográfica da área, bem como às principais atividades impactantes, do trecho à jusante da barragem de Pedra do Cavalo até a foz do rio Paraguaçu, na baia de Todos os Santos.

Na primeira fase de campo, em março de 1994, foram considerados 9 pontos de amostragem, objetivando o reconhecimento preliminar da faixa de teores dos metais nos sedimentos da área e a adequação da metodologia de campo e de laboratório. Nas fases subsequentes, a rede de amostragem foi redimensionada e outros pontos foram escolhidos, pretendendo-se maior representatividade amostral nos diferentes sistemas. Quinze (15) estações foram investigadas ao longo do complexo, de acordo com a seguinte distribuição e numeração correspondente (Figura 07) : 31 - 32 próximas a São Félix; 40 - 50 - 51 - 52 - 53 - 54 na baía de Iguape; 60 - 70 no canal de São Roque; 80 81 - 90 - 100 - 101 na baía de Todos os Santos, na foz do rio Paraguaçu.

\subsection{2 - Freqüência das coletas}

A freqüência da coleta foi definida em se considerando as variações sazonais e a dinâmica das marés. Foram realizadas quatro fases distintas de amostragem, cada qual com duas campanhas, correspondentes as marés de sizigia, durante a campanha (I), e quadratura, durante a campanha (II), respectivamente, marés de maior e menor amplitude. O Quadro 02 apresenta as principais caracteristicas das oito campanhas. Nas fases 01/94 e 03/95, a estação 50, localizada na boca do estuário, foi monitorada durante doze horas, acompanhando as condições hidrodinâmicas de fluxo e refluxo de maré. Nas campanhas (I) e (II) e nas duas fases, a cada hora, os parâmetros físicoquímicos eram medidos e coletadas amostras de água para a separação do material particulado.

Para todas as campanhas, a amostragem era feita da estação 101 para a 31, durante a maré vazante, e no sentido inverso das correntes, para evitar a coleta de águas com as mesmas características do ponto anterior. 


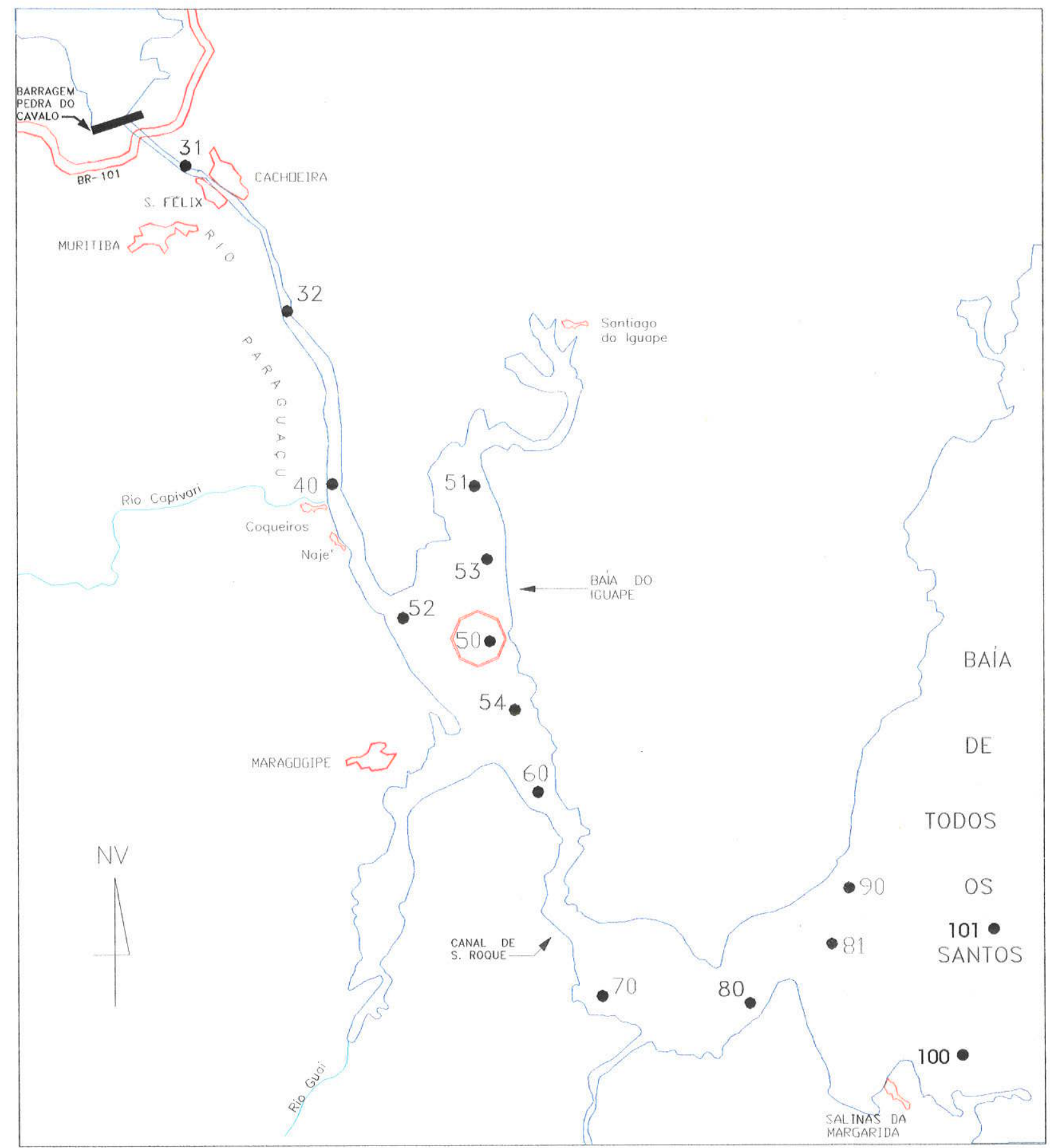

- pontos de amostragem

50) ponto de monitoramento

FIGURA 07 - DISTRIBUIÇÃO DOS PONTOS DE AMOSTRAGEM. 
Para fixação e retorno em nova fase, a locação das estações foi feita por triangulação, utilizando-se bússola ou seja, amarração por segmentação de três pontos capazes de serem reconhecidos na costa e identificados em mapa.

Algumas dificuldades como, a segurança da equipe no deslocamento do barco em condições de preamar na baía de Todos os Santos, na região da desembocadura do rio e/ou a ocorrência de fortes pancadas de chuvas durante os trabalhos de campo impossibilitaram, em algumas campanhas, uma amostragem completa de todas as estações. Como consequeência, as informações para essas fases estão incompletas.

QUADRO 02 - FASES, PERIODOS E CONDIÇŐES DE MARÉ CORRESPONDENTES AS CAMPANHAS DE CAMPO REALIZADAS (1994 - 1995)

\begin{tabular}{|c|c|c|c|c|}
\hline Fase & Campanha & Periodo & Tipo de maré & $\begin{array}{c}\text { Amplitude média } \\
\text { da maré (m) }\end{array}$ \\
\hline $01 / 94$ & I & $26-29 / 03 / 94$ & sizigia $^{\left({ }^{*}\right.}$ & 2,5 \\
& II & $18-21 / 03 / 94$ & quadratura $^{(*)}$ & 1,2 \\
\hline $01 / 95$ & I & $30 / 01-01 / 02 / 95$ & sizigia & 2,4 \\
& II & $07-08 / 02 / 95$ & quadratura & 0,8 \\
\hline $02 / 95$ & I & $12-14 / 06 / 95$ & sizigia & 2,4 \\
& II & $20-21 / 06 / 95$ & quadratura & 1,1 \\
\hline $03 / 95$ & I & $23-25 / 09 / 95$ & sizigia & 2,4 \\
& II & $16-18 / 09 / 95$ & quadratura & 0,8 \\
\hline
\end{tabular}

(*) maré de luas nova e cheia

$\left({ }^{\star *}\right)$ maré de luas quarto minguante e crescente

\subsection{3 - Materiais e métodos utilizados na amostragem}

Os materiais de estudo, foram escolhidos com o objetivo de verificar o equilibrio entre material particulado e sedimento de fundo. Para cada campanha e estação, amostra de água, para separação do material particulado em suspensão e de sedimento de fundo, eram recolhidas. A coleta próxima as margens foi evitada no sentido de se obter amostra representativa de maior volume de água e, também, para 
prevenir a contaminação por materiais que se depositam nas áreas marginais (CETESB, 1988). Todo o trabalho foi realizado em barco a motor de popa.

Lista dos tipos de equipamentos e materiais necessários aos trabalhos foi previamente elaborada. Para se evitar qualquer tipo de contaminação, os materiais eram lavados com detergente neutro, isento de fosfatos, a seguir, por solução preparada pela mistura de ácidos $1: 1 \mathrm{HCl}+1: 1 \mathrm{HNO}_{3} \mathrm{e}$, finalmente, com água deionizada, conforme recomendação determinada nos textos citados no início deste capitulo. Antes de cada viagem de campo, os equipamentos de medida eram calibrados. Todas as informações de campo, respectivas a cada estação e amostra, foram registradas em fichas de coleta.

Para minimizar possiveis alterações com relação as interferências microbiológicas, mudanças no estado de oxidação de cátions e ânions ou dissolução e volatilização de alguns constituintes, as amostras foram acondicionadas em frascos de polietileno, mantidas em caixas de isopor com gelo, a temperatura de $\pm 4^{\circ} \mathrm{C}$, até sua chegada ao laboratório.

A seguir, são apresentadas algumas particularidades dos materiais e métodos utilizados durante a coleta:

\section{(a) Água / Material particulado em suspensão}

Os sólidos presentes em uma determinada solução aquosa natural podem ser classificados de acordo com o seu tamanho e características químicas. Em se seguindo esses parâmetros, uma preposição de classificação, apresentada em PORTO et al. (1991), é mostrada na Figura 08. Neste trabalho, considera-se como material particulado em suspensão (MPS), a fração retida após filtração da amostra, em filtros

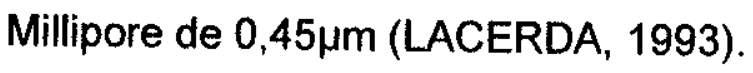

Quanto à temperatura de volatilização, os sólidos podem ser classificados em fixos, quando quantitativamente se mantêm inalterados em temperaturas maiores que $500^{\circ} \mathrm{C}$ e, voláteis ao inverso $\left(<500^{\circ} \mathrm{C}\right)$. 


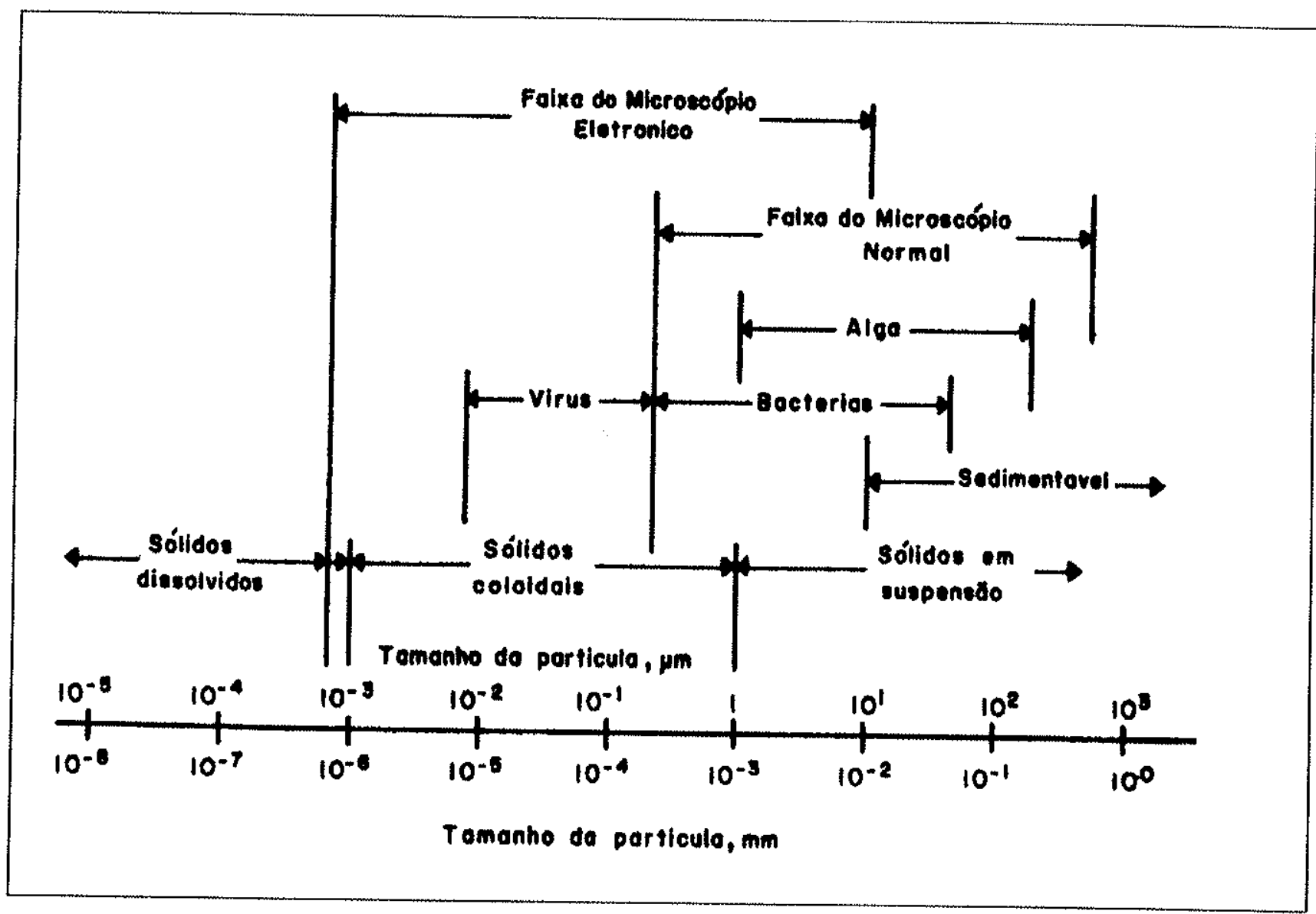

FIGURA 08 - CLASSIFICAÇÃO DOS SÓlIDOS DAS AGUAS DE ACORDO COM O TAMANHO E CARACTERISTICAS QUIMICAS (PORTO et al., 1991)

A escolha do material particulado em suspensão para estudo, foi baseada em três fatores:

- Transportador de Contaminantes

Metais pesados e micro-nutrientes estão associados, de preferência, ao material particulado. Segundo vários autores, (dentre outros, FORSTNER \& WITTMAN, 1981; LORING, 1982; SALOMONS \& FORSTNER, 1984) entre 20 a $90 \%$ de metais pesados são transportados, via material particulado, dependendo da quantidade $\mathrm{e}$ tipo de material.

- Acumulador de Contaminantes:

Quando a matéria particulada está depositada, constitui um reservatório de contaminantes que pode prejudicar a biota, seja através do contato direto, seja por 
liberação de contaminantes para o corpo d'água, por mudanças nas condições físico-químicas.

- Indicadores Sensiveis à Contaminação

Como os contaminantes estão, em geral, concentrados na matéria particulada, mesmo a baixos níveis, este material pode ser usado para detecção de contaminação ambiental.

Para separação do MPS em cada estação, amostras de água foram retiradas a 2 metros de profundidade utilizando-se uma garrafa de PVC, tipo "bailer", de 2 litros e, em seguida, armazenadas em frascos de plástico de $1000 \mathrm{ml}$, sob refrigeração, até a filtração. Cada meio litro de amostra era filtrado, "in situ", com conjunto Millipore em vidro e bomba de vácuo manual; foram usadas membranas Millipore de diâmetro $0,45 \mu \mathrm{m}$, do tipo (HA) para determinação dos metais e, GF Glassfiber Filter (GF) para os Sólidos Totais Suspensos (SST) e Sólidos Totais Voláteis (SSV). Os filtrados e membranas filtrantes até a análise, foram mantidos sob refrigeração. Quando possivel, as membranas eram secas em estufa solar e armazenadas em placa de Petri, à temperatura ambiente, até o processamento em laboratório.

\section{(b) Sedimento de Fundo}

Como o sedimento de fundo desempenha um tipo de reservatório de metais, deve existir um fluxo destes na "interface" água-sedimento, nas duas direções, a depender das condições de ambiente e de tempo. Assim, a análise do sedimento de fundo, pode fornecer informações quanto aos processos em atuação no estuário e mudanças ambientais ocorridas. Geralmente, os sedimentos de interesse ambiental, são aqueles que permanecem nas camadas superficiais e cujas amostras podem ser obtidas por meio de dragas.

Neste estudo, em cada estação foi retirado cerca de $1 \mathrm{~kg}$ de sedimento de fundo (0-30 cm), usando-se uma draga do tipo van Veen, em profundidades de lâmina d'água variando de 7 a 30 metros. Esta profundidade era avaliada diretamente no cabo da draga, demarcado a cada $0,5 \mathrm{~m}$. Os sedimentos foram acondicionados em sacos plásticos e mantidos sob refrigeração, até a preparação para análise. 


\subsection{4 - Parâmetros físico-químicos não conservativos}

Os parâmetros fisico-quimicos nåo conservativos, ou seja aqueles que, temporalmente, podem variar de forma rápida e significativa, foram medidos "in situ" para indicaçăo das eventuais alterações periódicas na qualidade da água, em cada ponto e fase. As principais caracteristicas de cada parâmetro e método de medida utilizado săo apresentados a seguir:

- Temperatura do ar e da água : influencia nos processos biológicos, reaçøes químicas e bioquimicas e na solubilidade dos gases dissolvidos. Termômetro com precisão de $\pm 0,1^{\circ} \mathrm{C}$, foi usado para a medida da temperatura da água retirada a $2 \mathrm{~m}$ de profundidade e colocada num becker; a temperatura do ar foi tirada $a \pm 1 \mathrm{~m}$ acima da superfície da água.

- $p H$ : regula a precipitação dos metais além de ser fator importante para a vida aquática. Em pH $\leq 5$ as águas são mais tóxicas. A medida foi feita da mesma maneira como descrito para a temperatura da água, usando-se medidor de $\mathrm{pH}$ Digital Portátil, de marca CORNING e modelo PS-30, com precisão de 0,01 unidades de $\mathrm{pH}$.

- Condutividade Elétrica : indica maior ou menor presença de espécies iônicas. Usou-se termo-condutivimetro digital, da DIST/HANNA modelo PS 17, com correçăo de temperatura para $25^{\circ} \mathrm{C}$, resolução de $10 \mu \mathrm{S} / \mathrm{cm}$ e exatidão $\pm 2 \%$. A medida era feita junto ao $\mathrm{pH}$ e a temperatura da água.

- Salinidade : representa a quantidade total de sais dissolvidos em um determinado volume de água. Sua medida foi realizada com um salinómetro digital portátil com precisão de $\pm 5 \%$, marca ATAGO, modelo F- mill.

- Indice Fótico : avalia a transparência no corpo d'água e a facilidade de penetraçăo de luz para a fotossintese. Foi medido (em metros) através do disco de SECCHI, 
mergulhado na água, até năo ser mais possivel enxergá-lo; é a profundidade denominada de SECCHI.

Em cada estaçăo, procurou-se medir a velocidade instantånea e direçăo da corrente liquida, através de um Correntômetro da ABISSAL TECNOLOGIA (CO 2000), submerso a dois metros, por um periodo de \pm 15 minutos com leitura por minuto. $O$ equipamento disponivel, com freqüência, apresentou problemas técnicos, inviabilizando o registro completo dos dados em todas as campanhas. Somente foram obtidos dados na fase $03 / 95$.

\section{2 - MÉTODOS DE LABORATÓRIO}

\subsection{1 - Material particulado em suspensão - MPS (>0,45 $\mu \mathrm{m})$}

No MPS foram feitas as seguintes determinações, cujos procedimentos são mostrados na Figura 09 :

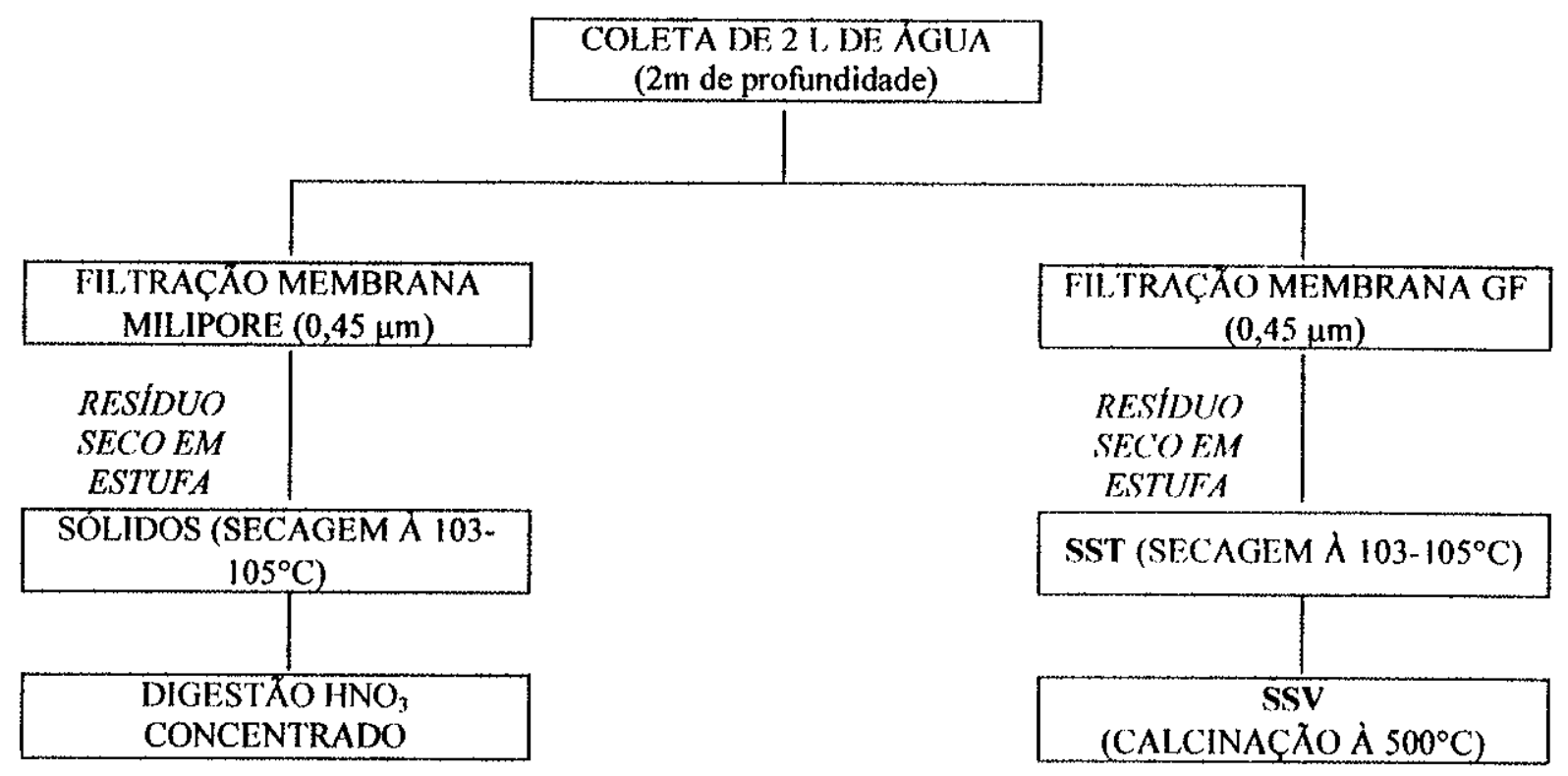

ANÁLISE DE Cu-Pb-Zn-Cr-Cd-Fe-Mn POR EAA (CHAMA)

FIGURA 09 - FLUXOGRAMA DE PREPARAÇÄO E ANÁLISE DOS SEDIMENTOS EM SUSPENSÄO. 
- Sólidos Suspensos Totais : para avaliar as impurezas da água que contribuem para a carga de sólidos transportados.

- Sólidos Suspensos Voláteis : para caracterizar a possibilidade de degradação anaeróbia dos sólidos em suspensão.

- Metais pesados ( $C d, P b, Z n, C u, C r)$ e parámetros de suporte $(F e, A l, M n)$ : para avaliar a faixa de concentração dos metais no material.

\subsection{2 - Sedimento de fundo}

Conforme mostra a Figura 10, as amostras de sedimento de fundo foram preparadas por secagem ao ar, desagregação, peneiramento e quarteamento; porçōes distintas do sedimento foram utilizadas para as seguintes etapas :

- Descrição macroscópica com auxilio de lupa binocular.

- Decomposição ácida total utilizando-se: $\mathrm{HF}-\mathrm{HClO}_{4}-\mathrm{HNO}_{3}$ para a análise de $\mathrm{Cu}-\mathrm{Cr}$ $\mathrm{Ni}-\mathrm{Cd}-\mathrm{Pb}-\mathrm{Zn}-\mathrm{Mn}-\mathrm{Fe}-\mathrm{Al}$ por Espectrofotometria de Absorção Atômica com chama usando o aparelho PERKIN ELMER, modelo 403.

- Análise granulométrica (por peneiramento para a separação das frações de diâmetro maior que silte, o através de pipetagem para as frações inferiores). Para separação da fração argila, usou-se hidróxido de amônia como dispersante e ácido clorídrico como floculante.

- Determinação da Matéria Orgânica (calcinação à $550^{\circ} \mathrm{C}$ até peso constante).

- Identificação dos argilo-minerais com o Difratômetro de Raios-X PHILIPIS PW 1730

\subsubsection{Extração Seqüencial dos Metais nos Sedimentos de Fundo}

É esperado que, a mobilização dos metais adsorvidos pelos sedimentos e, sua posterior liberação para água e/ou retirada biológica, ocorra da fração não residual do sedimento que se comporta de forma diversa, de acordo com suas diferentes estabilidades e condições ambientais. A avaliação da fração biodisponivel, com o uso da especiação dos metais por extração seqüencial, tem se revelado ferramenta útil na pesquisa de metais em sedimentos de áreas poluídas (SOUZA et al., 1986; PESTANA \& LACERDA, 1989; LACERDA et al., 1992). 


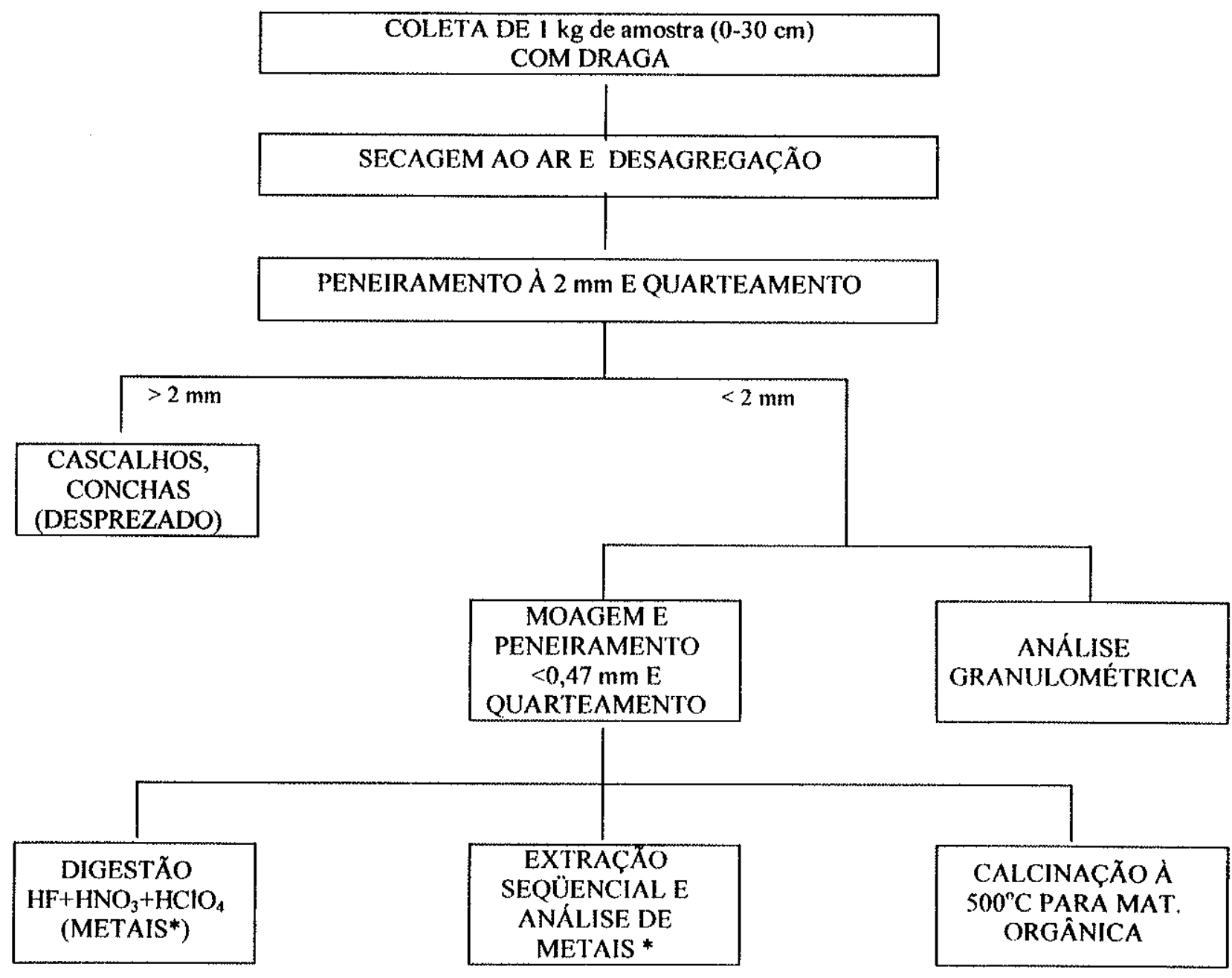

*ANÁLISE DE Cu-Pb-Zn-Cr-Cd-Fe-Mn - EAA

FIGURA 10 - FLUXOGRAMA DE PREPARAÇÃO E ANALISE DOS SEDIMENTOS DE FUNDO

Para a extração seqüencial dos metais, nos sedimentos de fundo da região estudada, foram escolhidas as amostras da fase 02/95, por ser uma das fases que apresentaram menores dificuldades nos trabalhos de campo e, portanto, com maior número de pontos amostrados. A Figura 11 mostra o procedimento de extração seqüencial utilizado (modificado de NAIR \& BALCHAND, 1993 por LINHARES et al., 1995). A concentração dos metais nas fases finais de extração, foram determinadas por Espectrofotometria de Absorção Atômica com chama, utilizando aparelho PERKIN ELMER, modelo 403. 


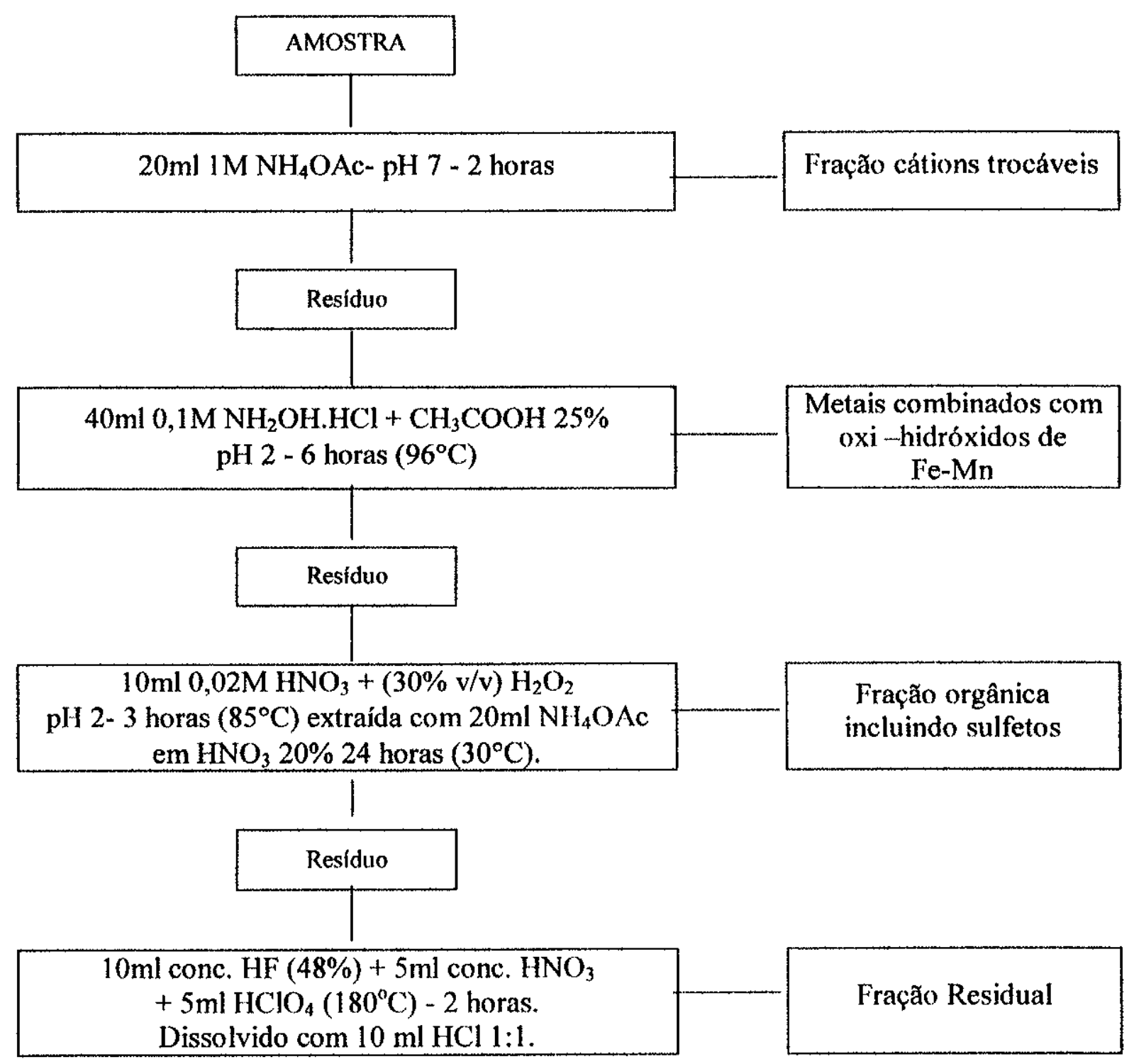

FIGURA 11 - FLUXOGRAMA PARA A EXTRAÇÃO SEQÜENCIAL DOS METAIS NOS SEDIMENTOS DE FUNDO

\subsection{CONTROLE DE QUALIDADE E GARANTIA DE QUALIDADE DOS RESULTADOS}

Para o Controle de Qualidade (CQ) dos resultados, foram utilizadas amostras replicatas, duplicadas e a corrida do branco de analise, correspondente aos reagentes utilizados. Para se contornar as principais fontes de erro, causadas por componentes sistemáticos e aleatórios, requisitos para a Garantia de Qualidade (GQ) foram seguidos, rigorosamente, para se manter a uniformidade dos dados obtidos em cada campanha. Alguns dos procedimentos utilizados, foram os seguintes: 
- Em todas as campanhas, foram utilizados os mesmos procedimentos de coleta e análises.

- No laboratório, todas as análises foram realizadas dentro dos prazos recomendados, obedecidos os limites de detecção especificados.

- Todos procedimentos utilizados foram escritos e acompanhados de formulários padronizados.

- Todos os Instrumentos / Equipamentos, de campo ou de laboratório, foram calibrados / aferidos a intervalos convenientes.

\subsection{TRATAMENTO DOS DADOS}

Para auxiliar na organização, descrição, análise e interpretação, os dados obtidos foram tabelados e tratados por técnicas de representaçőes gráfica e analítica.

\subsubsection{Representação gráfica}

O mapa base de configuração da área foi elaborado usando-se a folha SD-24-XA-IV do IBGE (BRASIL, 1972), em escala 1/100.000, e o mapa de Assentamento Industrial e Potencial Poluidor das Indústrias com escala 1/500.000, elaborado pelo Centro de Estatística e Informação - CEI (BAHIA, 1987). Estes mapas foram digitalizados em uma mesa Genius para o software AUTOCAD, release 12, considerando-se como elementos básicos : estradas, cidades, linha do litoral, ithas, coordenadas, portos, estaleiros e fábricas. O mapa geológico foi confeccionado a partir dos mapas apresentados no Plano Diretor da Bacia do Médio e Baixo Paraguaçu (BAHIA, 1996), AILLON (1992) e ROSA (1994), digitalizados e adaptados para a base citada. O mesmo procedimento foi utilizado para os mapas de solos, vegetaçăo, uso e ocupação da terra, e índices pluviométricos, usando-se como fonte os mapas apresentados no Plano Diretor da Bacia do Médio e Baixo Paraguaçu (BAHIA, 1996).

Para ilustrar as variações e enfatizar diferenças ou similaridades relativas a dinâmica do sistema, os dados obtidos para os parâmetros físico-químicos e material particulado em suspensão foram agrupados em cada fase e campanha, e representados em gráficos de linhas e colunas. 
A fase 01/94 além de representar a única fase do ano de 1994, corresponde a um período atípico. Não ocorreu qualquer repasse de água fluvial para o sistema estuarino, nos dois meses que antecederam os trabalhos de campo. Assim para ressaltar a dispersão ou variabilidade dos parâmetros no sistema estudado, considerou-se para análise exploratória dos dados, o conjunto de valores obtidos nas fases desenvolvidas no ano de 1995. A fase 01/94 é usada, em algumas situações, como uma referência para comparação dos dados entre dois anos consecutivos.

Partindo-se do mapa base foi elaborado um desenho, mostrado na Figura 07 (item 3.1.2.), com destaques (a) para os limites da linha d'água - desde a barragem de Pedra do Cavalo, passando pela baía de Iguape, até a baia de Todos os Santos - e (b) para a posição das estações de amostragem. Deste desenho, através do sofware SURFER, usando-se o Gridding Method Triangulation w/inear Interpolation, para interpolação das curvas de nivel, foram gerados mapas de isoteores, destinados a descrever a distribuição espacial dos valores médios de cada parâmetro investigado no material particulado em suspensão e no sedimento de fundo das diferentes estações durante o ano de 1995. A edição final desses mapas foi feita no software AUTOCAD. Para caracterizar a dispersão ou variabilidade dos dados, em termos relativos ao seu valor médio, ou seja, para qualificar a dispersão temporal, os respectivos coeficientes de variação foram obtidos no software EXCEL e associados aos mapas correspondentes.

\subsubsection{Representação analítica}

Os parâmetros estatísticos convencionais como, médias aritméticas, desvio padrão e coeficiente de variação foram calculados para todos os dados obtidos em cada estação. Todos os procedimentos estatísticos usados neste trabalho foram realizados no Laboratório de Estatística do Instituto de Matemática da UFBA.

Para testar a extensão das variações diurnas e sazonais das variáveis físicoquímicas, medidas na água durante 12 horas de monitoramento na estação 50 , foi feita uma análise de variância, para os dados entre as fases e campanhas. $O$ método de "Scheffé" foi aplicado para as comparações múltiplas, avaliando-se as médias duas a 
duas. Para todos os cálculos foi utilizado o software Statistical Analysis System - SAS (PROC GLM).

A análise comparativa da variabilidade entre as estações e campanhas no periodo (1995), foi conduzida por meio de diagramas do tipo box plot (Figura 12), cuja interpretação é baseada nas seguintes observações (TUKEY, 1977): linhas horizontais, representam a mediana (linha central) e os quartis $\left(Q_{1}\right.$ e $\left.Q_{3}\right)$; linhas verticais, que se estendem acima e abaixo, ligam os quartis aos pontos mais altos e mais baixos do conjunto de observações que ainda estão dentro dos limites $Q_{1}-1,5$ $\left(Q_{3}-Q_{1}\right) \in Q_{3}+1,5\left(Q_{3}-Q_{1}\right)$. A distancia entre os quartis reflete a variabilidade, ou seja, quanto menor a distância, menor a variabilidade ou maior a homogeneidade das observações. Qualquer valor mais extremo é marcado com um zero, se estiver dentro do intervalo $3\left(Q_{3}-Q_{1}\right)$. Pontos aberrantes ou mais extremos (outliers) dentro do conjunto de dados são marcados por asterisco. Para a estística descritiva e construção dos diagramas box plot também foi usado o software SAS (PROC UNIVARIATE).

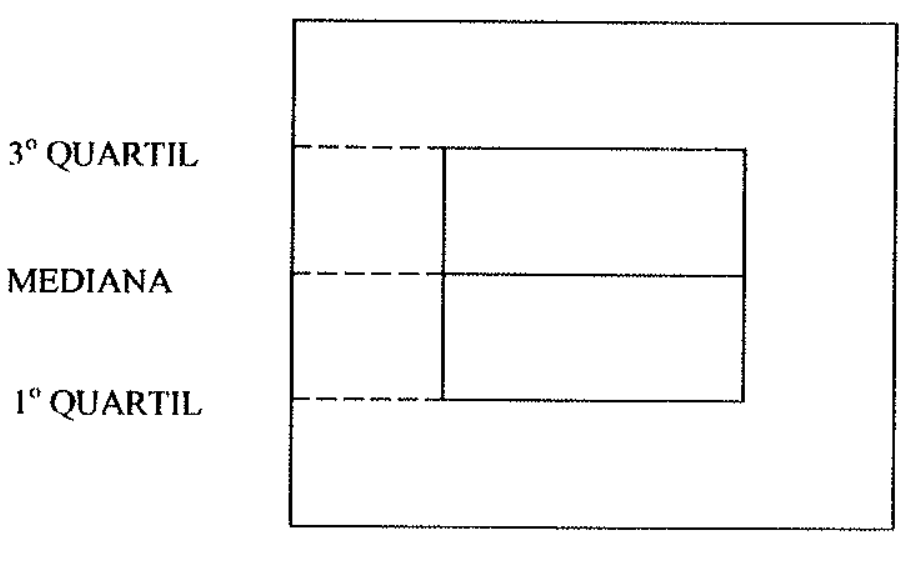

FIGURA 12 - LEITURA DO "BOXPLOT"

Com o intuito de verificar a similaridade e/ou o agrupamento entre os parâmetros investigados nos sedimentos das diferentes estações de amostragem, utilizou-se a análise de agrupamentos (Cluster Analysis), pelo método da ligação simples (single linkage), representada graficamente na forma de dendogramas e obtida com ajuda do software MINITAB. 
Para verificar a dependência linear entre as variáveis estudadas no material particulado e nos sedimentos de fundo, foi calculada a matriz de correlação.

$E$ importante assinalar que diversos métodos estatísticos foram utilizados para verificar situações de similaridades neste estudo, entretanto, a Inferência Estatística é uma ferramenta para auxiliar a tomada de decisão diante de situações de incerteza e não para provar diferenças ou igualdades de parâmetros populacionais baseando-se em amostras. 
CAPÍTULO 4- RESULTADOS E DISCUSSÃO 


\section{4 - RESULTADOS E DISCUSSÃO}

\section{1 - HIDRODINÂMICA}

A distribuição mensal das chuvas e dos parâmetros físicos, registrados na barragem de Pedra do Cavalo durante o período de estudo, são apresentados na Figura 13. Em 1994, os mais baixos índices de precipitação média mensal (12-30 mm), correspondem aos meses de janeiro e fevereiro, quando não houve repasse de água através dos vertedouros (vazão defluente da barragem igual a zero). Isto significa que, nos dois meses que antecederam a fase 01/94, o sistema estuarino teve maior influência do aporte de água da baía de Todos os Santos, embora, no mês de março (período da coleta), a precipitação média atingiu $182 \mathrm{~mm}$.

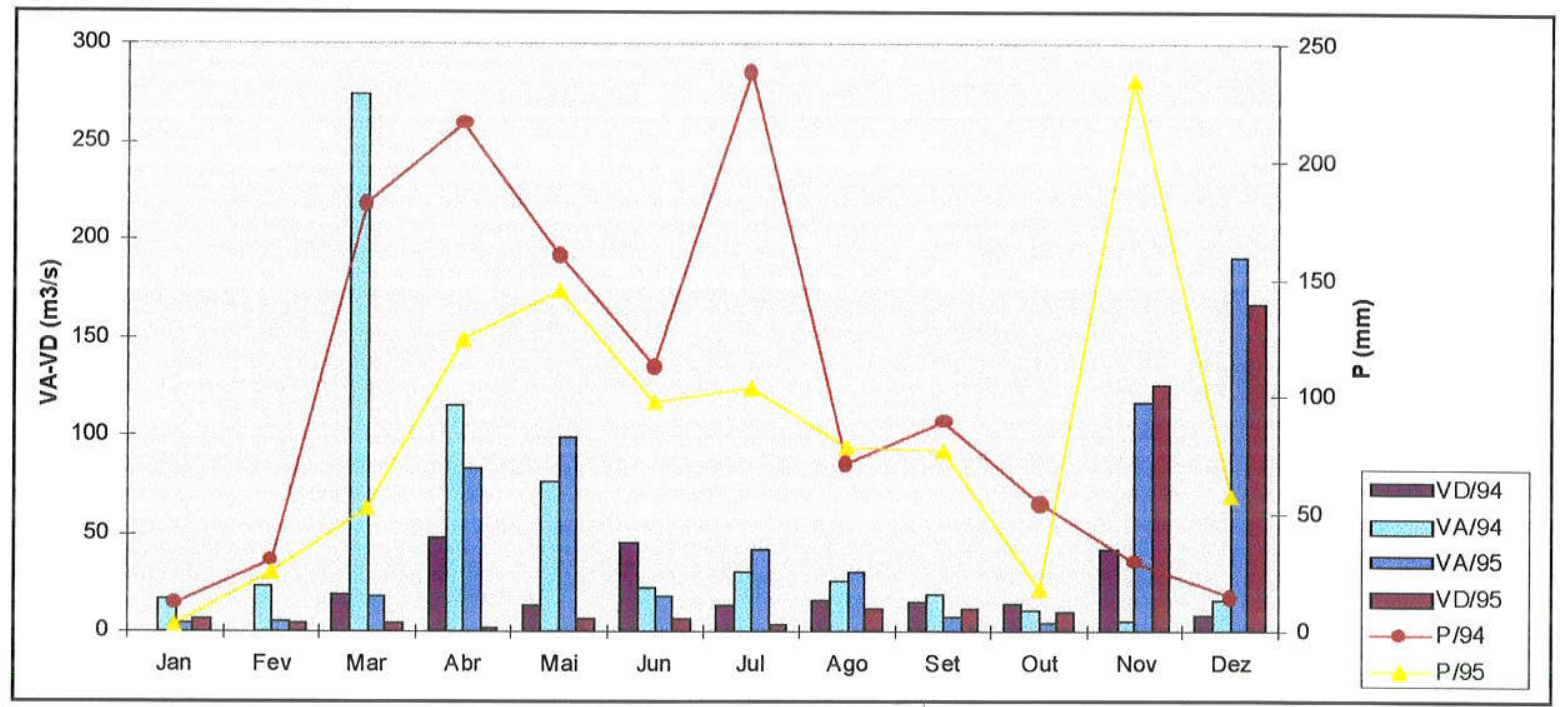

FIGURA 13 - VARIAÇÕES NA VAZÃO AFLUENTE (VA), VAZÃO DEFLUENTE (VD) E PRECIPTAÇÃO (P) NO RESERVATÓRIO DE PEDRA DO CAVALO (19941995). (Dados fornecidos pela EMBASA).

Durante os trabalhos correspondentes às fases de 1995, os maiores índices de precipitação média mensal $(97-145 \mathrm{~mm})$ ocorreram entre abril-julho e a descarga máxima mensal não excedeu $12 \mathrm{~m}^{3} / \mathrm{s}$. 
O input total de água fluvial, para a região estuarina não é totalmente conhecido, e a informação é restrita aos valores da descarga defluente da barragem. A contribuição adicional, através de descargas pequenas, não reguladas, dos rio Guaí e Capivara para a região estuarina podem, a principio, também influir no aporte de água fluvial para a baía de Iguape, principalmente, na ausência ou durante o período de baixa vazão defluente.

Em estuários, o volume de água "estoque oscilante" varia em função da amplitude de maré e da vazão fluvial (FREIRE et al., 1991) portanto, volumes de águas marinhas introduzidos terão maiores contribuições no periodo de estiagem $e$, os de águas doces, no periodo de maior precipitação.

No estuário do Paraguaçu, com a barragem de Pedra do Cavalo controlando a vazão afluente do rio, é de se esperar que, nas condições de baixa descarga defluente da barragem, a intensidade de chuvas é o fator predominante no aporte de águas doces.

$\mathrm{Na}$ média, o período menos chuvoso, com índices pluviais mensais inferiores a $60 \mathrm{~mm}$, foi de dezembro/94 a fevereiro/95. De acordo com a classificação de Köppen, é o indice pluvial mensal limite para definiçăo do mês seco. Os indices totais anuais atingiram $1210 \mathrm{~mm}$ em 1994 e 1015 mm em 1995.

Nos dois anos estudados, comparando as precipitações mensais e os valores de descarga defluente durante as fases de campo conclui-se que : Na fase 01/94 ocorreu maior incidência de chuvas na região, mas a contribuição fluvial através do sistema de comportas da barragem foi muito baixa no mês da coleta $\left(19 \mathrm{~m}^{3} / \mathrm{s}\right)$. Nas fases de 1995 , os valores da descarga defluente foram ainda mais baixos e, de acordo com os índices de precipitação registrados, a fase $01 / 95$ antecedeu ao periodo de maior estiagem, a fase $02 / 95$ ao período mais chuvoso e a fase $03 / 95$, correspondeu a um periodo intermediário, com índices médios mensais em torno de $77 \mathrm{~mm}$. 


\subsection{HIDROQUIMICA}

\subsubsection{Distribuição dos Parâmetros Físico-Químicos}

Além da precipitação acumulada antes do periodo da amostragem, entre as principais variáveis capazes de afetar o transporte dos metais nos sistemas aquáticos, estão o pH, salinidade (S), condutividade (C), indice fótico (IF) e a quantidade e origem do material particulado em suspensão (Tabelas 1, 2, 3 e 4). A Figura 14 ilustra a variação destes parâmetros entre as condições hidrodinâmicas e fases investigadas.

Convém observar que, devido a falhas instrumentais, os dados não são completos, isso faz com que as discussões, em algumas situações, sejam limitadas. Este é o caso, por exemplo, dos valores de condutividade e salinidade. Os mesmos, poderiam ser correlacionados à pluviometria, se fossem registrados para todas as fases. Essa correlação poderia ser significativa no periodo de estiagem, quando a diminuição de aportes fluviais pode promover alterações de salinidade e condutividade. Com os dados obtidos, algumas considerações são assinaladas a seguir.

$\mathrm{Na}$ fase $01 / 94$ a salinidade e condutividade mostram-se concordantes e os mais baixos valores $(24,4 \% ; 24 \mathrm{mS} / \mathrm{cm})$, aparecem na estação 40 . Entre as estações da baía de lguape e da foz, a variação é pequena $(32,0-34,3 \% ; 51,3-56,0 \mathrm{mS} / \mathrm{cm})$. A menor faixa de salinidade, refere-se à maré de sizigia $\left(33,2-34,3 \%_{0}\right)$ e para a condutividade à maré de quadratura $(41,8-57,8 \mathrm{mS} / \mathrm{cm})$.

Segundo WOLANSKI (1986), os estuários em regiões tropicais podem apresentar uma zona de salinidade máxima à montante da foz do rio, o que não foi verificado neste trabalho. Também por FREIRE (1989), estudando o estuário do rio Pacoti no Ceará, onde foram encontrados valores ( $1 \%$ a $38 \%$ ), variando de forma longitudinal, segundo os parâmetros fluviais e marinhos, regidos pela pluviometria. 

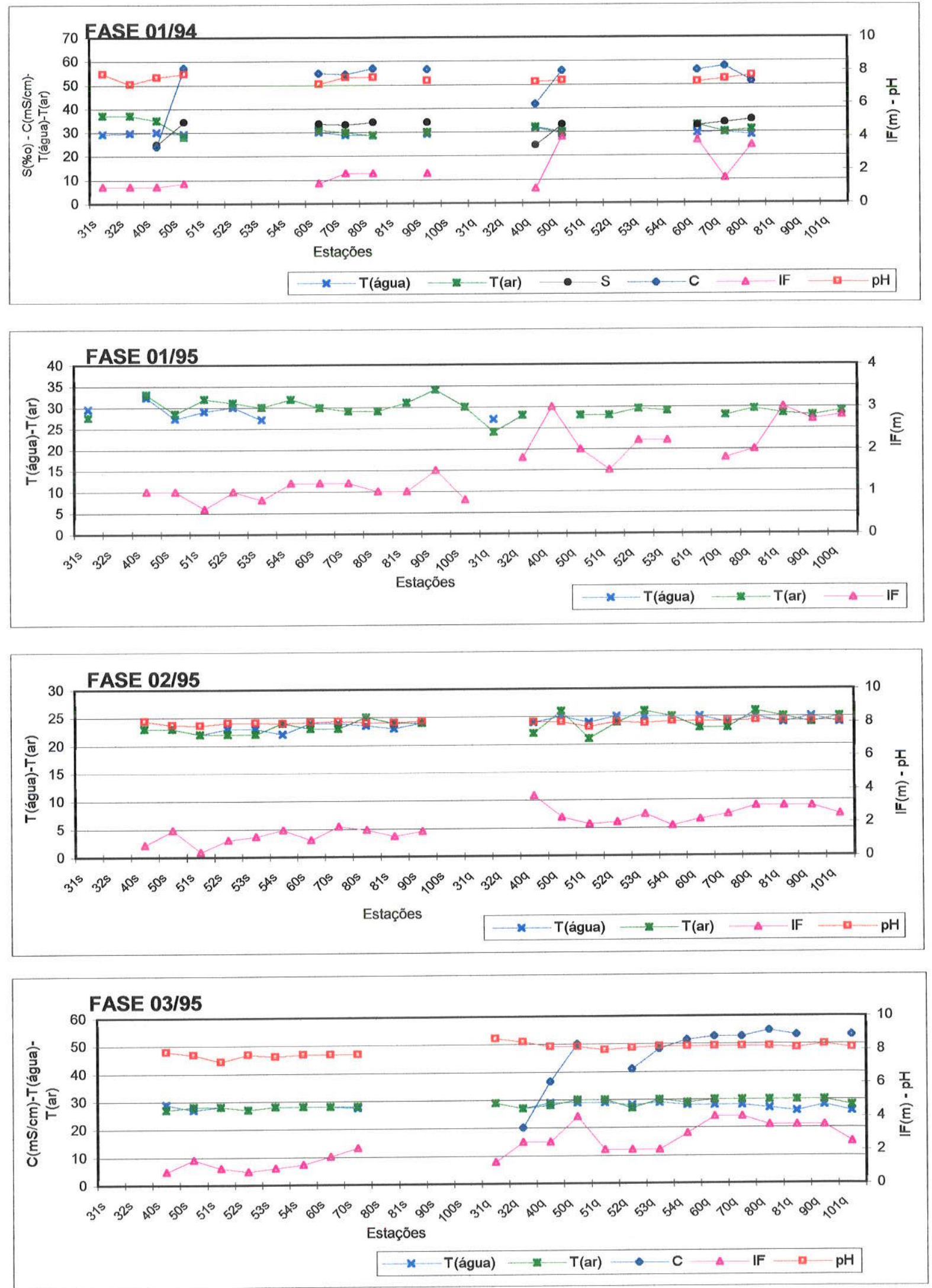

FIGURA 14 - PARÂMETROS MEDIDOS “IN SITU (1994-1995). S - MARÉ DE SIZÍGIA; Q - MARÉ DE QUADRATURA. 
$\mathrm{Na}$ fase 03/95 a faixa de condutividade na maré de quadratura é, ao inverso, ampla $(20,1-54,8 \mathrm{mS} / \mathrm{cm})$, e os mais baixos valores são registrados nas estações 32 $(20,1 \mathrm{mS} / \mathrm{cm})$ e também na $40(36,5 \mathrm{mS} / \mathrm{cm})$.

A alta condutividade registrada pode ser atribuida a constituintes dissolvidos de origem natural e àqueles de origem antrópica, provenientes de contaminação industrial ou urbana. O menor volume de lâmina d'água associado à maré de quadratura năo favorece o efeito de diluição dos constituintes dissolvidos na água.

Os valores mais altos do índice fótico $(1,3-4,0 \mathrm{~m})$ e de $\mathrm{pH}(8,1-8,7)$ também são registrados na maré de quadratura da fase $03 / 95$. O indice fótico mede a transparência da água, portanto é um valor relativo para a turbidez, e se correlaciona inversamente com à quantidade de matéria orgânica dissolvida e aos sólidos em suspensão (RAMOS, 1993). Os valores de $\mathrm{pH}$ situam-se acima de 8,0 , e denotam influência marinha, enquanto mais baixos $(6,9-7,4)$, como registrados para a fase $01 / 94$, podem refletir decomposição de matéria orgânica na região estuarina.

A temperatura da água está diretamente relacionada à temperatura do ar. Dessa forma, as temperaturas mais baixas da água $\left(22-26^{\circ} \mathrm{C}\right)$ tiveram lugar na fase $02 / 95$, em junho, período mais frio da área, enquanto as mais altas $\left(27-32^{\circ} \mathrm{C}\right)$ corresponderam as fases 01/94 e 01/95, durante janeiro e março, período mais quente.

Como se observa na Figura 15, durante o monitoramento da estação 50 (fases $01 / 94$ e 03/95), as flutuações dos parâmetros não são significativas entre os ciclos de marés enchente e vazante. As variações de condutividade $(39,7-56 \mathrm{mS} / \mathrm{cm})$ e salinidade $(26,9-33,1 \%$ são amplas na maré de quadratura da fase 01/94. Também, o índice fótico, exibe valores mais elevados neste ciclo de maré, em ambas as fases monitoradas. 

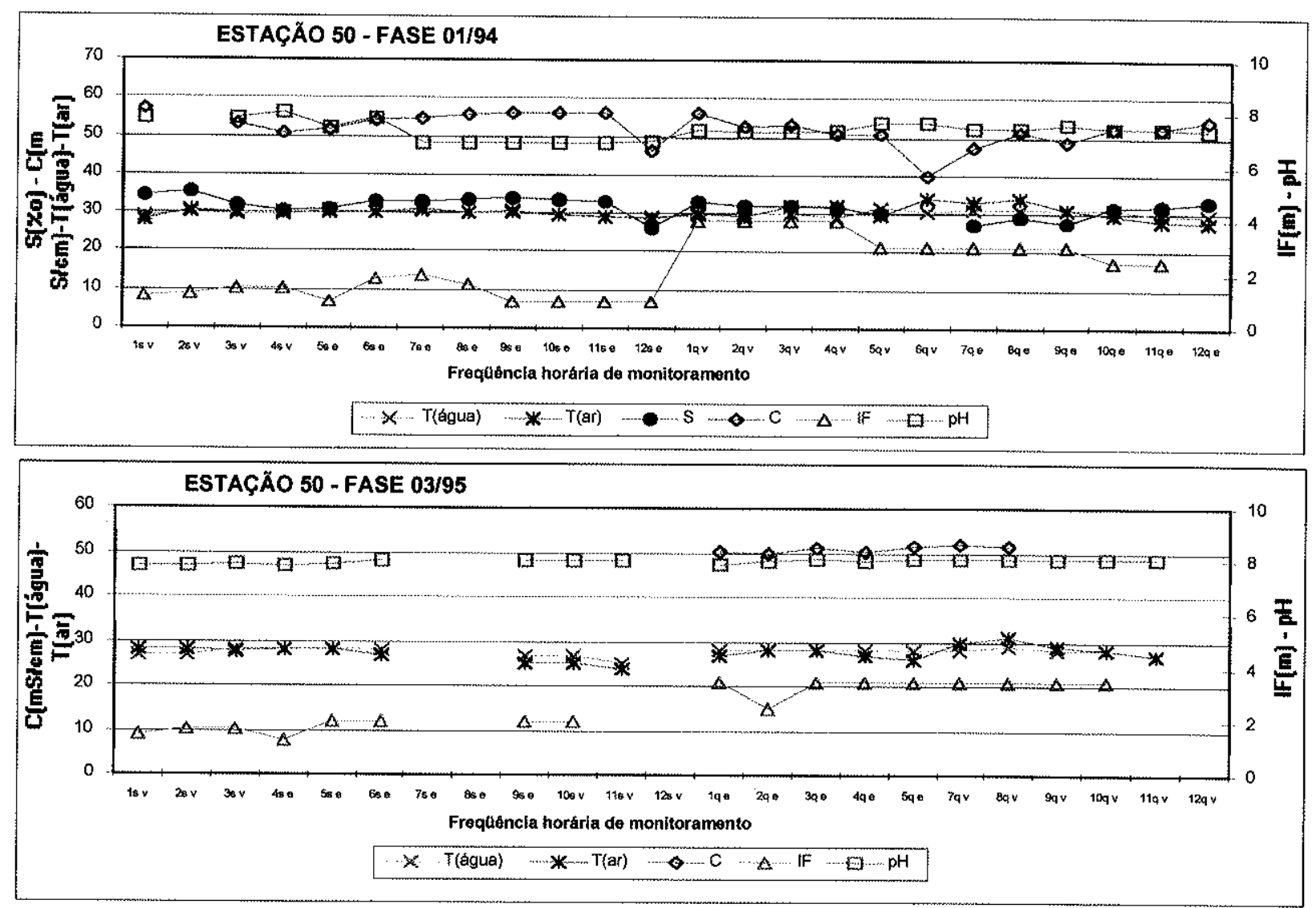

FIGURA 15 - VARIAÇÃO DOS PARÂMETROS FÍSICO-QUÍMICOS NO MONITORAMENTO DA ESTAÇÃO 50 (FASES 01/94 E 03/95). s - MARÉ DE SIZÍGIA; q - MARÉ DE QUADRATURA; e - ENCHENTE; v - VAZANTE.

$\mathrm{Na}$ fase de 1994, mesmo não havendo repasse de água fluvial através dos vertedouros da barragem, a hidroquímica do estuário não difere, de forma significativa, do período monitorado em 1995 durante o qual, embora pequena, havia descarga defluente ao nível da barragem. Nas subidas ou descidas diárias do nível da maré, ao que parece, o sistema não apresenta maiores modificações. Caso contrário, a condutividade e/ou $\circ \mathrm{pH}$ como exemplos, poderiam refletir estas mudanças, na ausência dos dados de salinidade.

A discussão dos parâmetros físico-químicos avaliados, mostra que as principais variações ocorrem conforme a dinâmica das marés (sizígia e quadratura) e os diferentes períodos amostrados. Supõe-se então, que o aporte de água da baía de Todos os Santos e o regime de chuvas são os fatores predominantes que influenciam tanto a hidrodinâmica como a hidroquímica do sistema estudado. 


\subsubsection{Tratamento Estatístico - Análise de Variância}

Os parâmetros estatísticos convencionais, calculados para as variáveis físicoquímicas medidas durante 12 horas na estação $\mathbf{5 0}$, foram agrupados de acordo com as fases e marés (Quadro 03). De modo geral, a média dos valores e o desvio padrão não exibem grande variabilidade entre as condições investigadas. Assinala-se, apenas, que os valores médios do $\mathrm{pH}$ e índice fótico são mais altos, respectivamente, na fase 03/95 e maré de sizigia, confirmando as observações anteriores verificadas na representação gráfica.

QUADRO 03 - MÉDIAS E DESVIO PADRÃO DOS PARÂMETROS FISICO-QUIMICOS DO MONITORAMENTO NA ESTAÇÃO 50. FASES 01/94 E 03/95, CAMPANHAS (I) SIZÍGIA E (II) QUADRATURA.

\begin{tabular}{|l|l|l|l|l|}
\hline & $\begin{array}{l}\text { Fase 01/94 } \\
(n=23)\end{array}$ & $\begin{array}{l}\text { Fase 03/95 } \\
(n=17)\end{array}$ & $\begin{array}{l}\text { Campanha I } \\
(n=21)\end{array}$ & $\begin{array}{l}\text { Campanha II } \\
(n=19)\end{array}$ \\
\hline T água $\left({ }^{\circ} \mathrm{C}\right)$ & $30,08 \pm 0,71$ & $27,67 \pm 0,84$ & $29,28 \pm 1,37$ & $28,78 \pm 1,47$ \\
\hline $\operatorname{Tar}\left({ }^{\circ} \mathrm{C}\right)$ & $30,28 \pm 1,73$ & $27,42 \pm 1,72$ & $29,57 \pm 2,34$ & $28,49 \pm 2,01$ \\
\hline $\begin{array}{l}\text { Cond. } \\
(\mathbf{m S} / \mathrm{cm})\end{array}$ & $52,21 \pm 3,96$ & $50,93 \pm 0,72$ & $50,81 \pm 3,29$ & $53,83 \pm 3,14$ \\
\hline IF (m) & $2,26 \pm 1,10$ & $3,02 \pm 1,55$ & $3,55 \pm 1,15$ & $1,51 \pm 0,40$ \\
\hline pH (água) & $7,40 \pm 0,34$ & $7,99 \pm 0,09$ & $7,73 \pm 0,31$ & $7,57 \pm 0,47$ \\
\hline
\end{tabular}

Para testar, estatisticamente, a igualdade das médias obtidas em cada etapa, usou-se a análise de variância. Foram considerados os quatro grupos (tratamentos), onde as médias de cada variável em estudo na fase i (01/04 e 03/95) e na campanha j (I -maré de sizígia e II - maré quadratura) são denotadas por $\mu_{\mathrm{i} \text {. }}$.

A hipótese testada como hipótese nula $\left(\mathrm{H}_{0}\right)$, foi a de igualdade da média nos diferentes grupos ou :

$\left.H_{0}\right) \quad \mu_{11}=\mu_{111}=\mu_{31}=\mu_{311}$ 
contra a hipótese alternativa

$H_{1}$ ) existe pelo menos um $\mu_{\mathrm{ij}}$ diferente das demais

A aceitação de $\mathrm{H}_{0}$ significa que, os dados não evidenciam diferença significativa entre as fases e campanhas para aquela variável em estudo. Para testar estas hipóteses foi calculada a estatística F e o p-valor correspondente (NETER et al., 1990), obtendo-se, assim, a significância estatística do resultado.

Assinala-se que, não rejeitar uma hipótese sobre igualdade de dois parâmetros, não significa provar que os parâmetros são iguais, mas com aquela amostra ou pelo fato dos valores numéricos dos parâmetros serem muito próximos, não foi possível rejeitar a hipótese de igualdade dos parâmetros.

Adotando-se o nível de $5 \%$ de significancia, a hipótese nula foi rejeitada para o p-valor menor que 0,05. Neste caso, usando-se o método de Scheffé (NETER, op. cit.) foram feitas comparações múltiplas entre os grupos (dois a dois) para se detectar entre quais grupos (ij), estariam as principais diferenças.

Conforme os resultados obtidos, foram confirmadas ou rejeitadas, com $95 \%$ de probabilidade, as seguintes diferenças estatisticas :

(a) Temperaturas (T) da Água e Ar

$F_{\text {água }}=46.07 ; p_{\text {água }}=0.0001<0.05$

$F_{\text {ar }}=12.55 ; p_{a r}=0.0001<0.05$

O valor de $\mathrm{F}$ é considerado significante, tanto para a temperatura da água como para a do ar assim, rejeita-se a hipótese nula e existe, pelo menos uma temperatura da água e do ar diferente das demais. O método de Scheffé demonstra que, não há diferença significativa destes parâmetros entre as campanhas realizadas em uma mesma fase. As comparações entre as fases resultaram em diferenças significativas embora, para a temperatura do ar, a diferença entre a segunda campanha da fase 01/94 e a primeira campanha da fase $03 / 95$ não foi significativa. 


\section{(b) Condutividade (C)}

$F=2.94 ; p$-valor $=0.0701>0.05$

$O$ valor de $F$ não é significante, desta forma, não foi rejeitada a hipótese nula. Isto quer dizer que, não há evidência de que as médias da condutividade nas fases e campanhas sejam diferentes. Válido assinalar que, para esta variável, não existem dados da fase 03/95 na maré de sizígia, portanto, o grupo $\mu_{3}$ ॥ não está incluído.

\section{(c) Índice Fótico (IF)}

$F=63.58 ; p$-valor $=0.0001<0.05$

$O$ valor de $F$ é significante portanto, rejeita-se a hipótese nula ou seja, existe pelo menos uma fase/campanha diferente das demais quanto a média do IF. O resultado do método Scheffé (95\%) mostra que não há diferença significativa entre as fases 01/94 e 03/95 na campanha I $\left(\mu_{11}=\mu_{31}\right)$ e, entre as fases 01/94 e 03/95 na campanha II $\left(\mu_{11}=\mu_{3 \prime \prime}\right)$. As demais comparações (entre as campanhas I e II, numa mesma fase) resultaram em diferenças significativas.

(d) $\mathrm{pH}$

$F=20.12 ; p$-valor $=0.0001<0.05$

Verifica-se que, o valor de $\mathrm{F}$ é significante e conduz a rejeição da hipótese nula. Existe, pelo menos, uma fase/campanha diferente das demais quanto a média da variável $\mathrm{pH}$. As comparações múltiplas revelam que, não há diferença significativa nas médias de $\mathrm{pH}$ entre campanhas realizadas na mesma fase. Entretanto, entre fases, as diferenças são significativas.

(e) Salinidade (S)

$F=3.14 ; p$-valor $=0.0907>0.05$

F não é significante, portanto, decide-se pela rejeição da hipótese nula. Há evidéncia estatistica de que, as médias da variável salinidade nas diferentes campanhas da fase $01 / 94$ são iguais. Não existem dados da fase $03 / 95$ portanto, os grupos $\mu_{31}$ \& $\mu_{3}$ ॥ não estão incluídos nesta avaliação. 
A luz dos resultados discutidos conclui-se que, não existem diferenças estatísticas entre os parâmetros físico-químicos medidos na estação 50 , durante os ciclos de marés enchente e vazante e, também, entre as marés de sizígia e quadratura. Contudo, entre as fases (01/04 e 03/95) as diferenças são significativas.

\subsection{MATERIAL PARTICULADO EM SUSPENSÃO}

\subsubsection{Concentração dos Sólidos Suspensos Totais (SST), Sólidos Suspensos Voláteis ( SSV) e Material Particulado em Suspensão (MPS)}

Os resultados (Tabelas 7, 8, 9 e 10) ilustrados na Figura 16, mostram que os parâmetros são mais altos nas marés de sizigia e, em especial, na fase 01/95. Os teores mais baixos aparecem na estação 31 sobretudo, na fase 01/94 (com maior indice pluviométrico). $O$ ponto 31 , o mais distante da foz, provavelmente é o que tem menor contribuição da corrente marinha.

Ainda na maré de sizigia, as maiores concentrações aparecem, em especial, nas estações 70, 80, 81 e 100, do canal de São Roque, em direção à baia de Todos os Santos, área com maior influência das correntes de maré. Como a energia associada a estas correntes é controlada pela morfologia do estuário, em locais mais estreitos e menos profundos nas áreas marginais, a "onda" de maré pode ser freada com maior intensidade e, sua energia dissipada pelo atrito do fundo. Nas marés de maior amplitude e energia (marés de sizigia), este atrito no fundo é maior e, pode promover intensa ressuspensão do material fino e solto do sedimento de fundo.

Como a vazão defluente da barragem é pequena no período estudado presumese que, a amplitude das marés defronte a foz do rio não se modifica, de forma significativa, por influência do aporte fluvial do rio Paraguaçu Tais resultados ressaltam a importância do controle da dinâmica das marés, no transporte do material particulado em suspensão na região estuarina em estudo. 

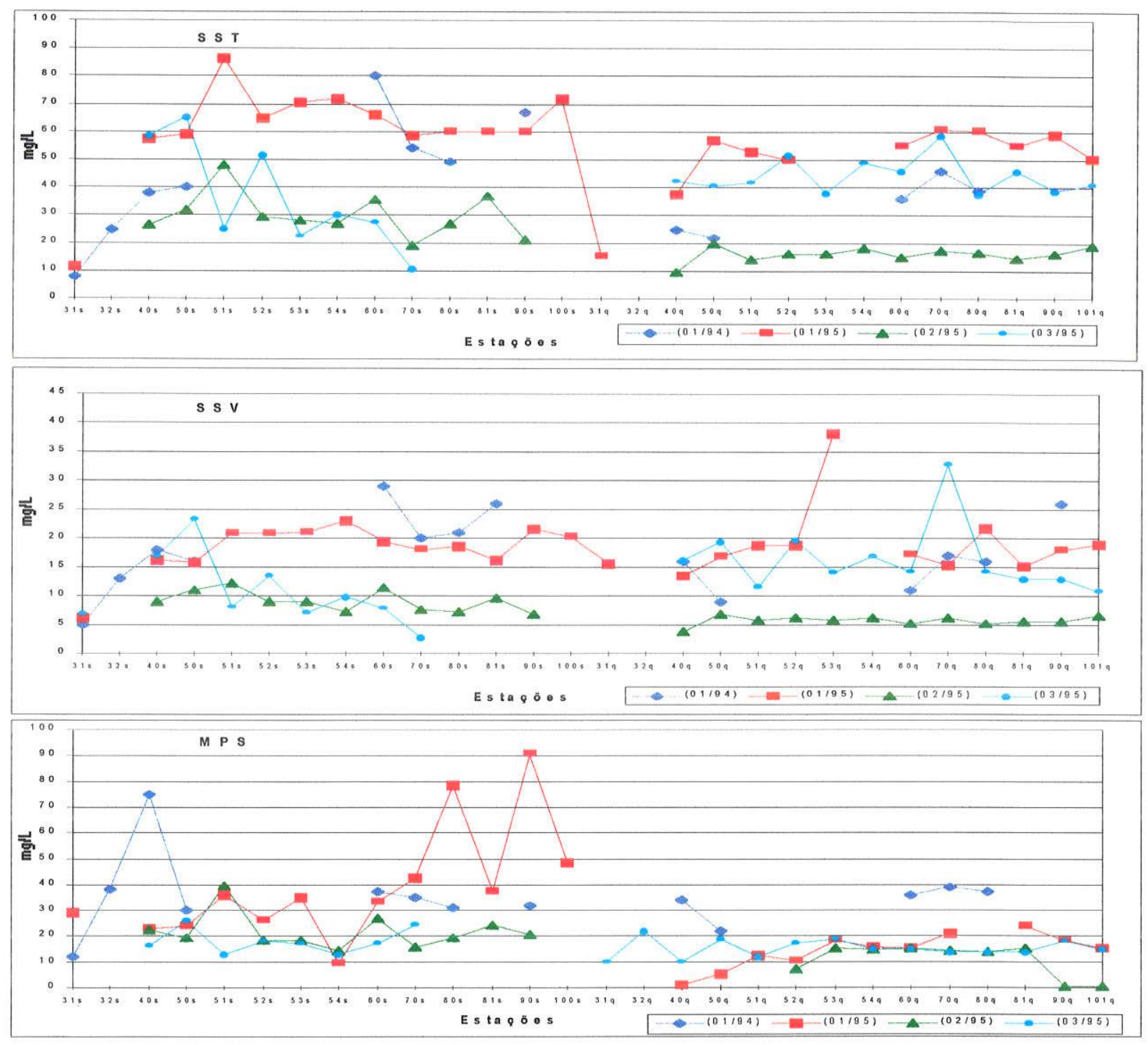

FIGURA 16 - TEORES DE SÓLIDOS EM SUSPENSÃO TOTAIS (SST), SÓLIDOS EM SUSPENSÃO VOLÁTEIS (SSV) E MATERIAL PARTICULADO (MPS) (1994 1995) s - MARÉ DE SIZÍGIA; q - MARÉ DE QUADRATURA.

O valor do índice fótico, parâmetro relacionado, de maneira inversa, ao material em suspensão confirma bem a hipótese apresentada : os menores valores estão associados aos ciclos das marés de sizígia quando, em geral, a penetração da luz não ultrapassa dois metros. Isto significa uma maior quantidade de material em suspensão. Nos ciclos de marés de quadratura o valor alcança até quatro metros, sugestivo de que, existe menor quantidade de matéria orgânica e sólidos em suspensão. 
No monitoramento da estação 50 (Figura 17), entre os diferentes ciclos de marés enchente e vazante, as variações não são expressivas, mas também nas marés de sizigia os valores são mais altos de SST (43-65 mg/L), SSV (15-25 mg/L) e MPS (15-36 mg/L), em excepcional, na fase 01/94. Este fato, mais uma vez, corrobora a hipótese anterior de ressuspensão do material fino de fundo, decorrente da maior energia que acompanha a maré de maior amplitude. BARUA (1990), estudando o sistema estuarino do rio Ganges-Brahmaputra-Meghna em Bangladesh faz considerações semelhantes, registrando valores na maré de sizígia, até duas vezes, maiores do que na maré de quadratura.

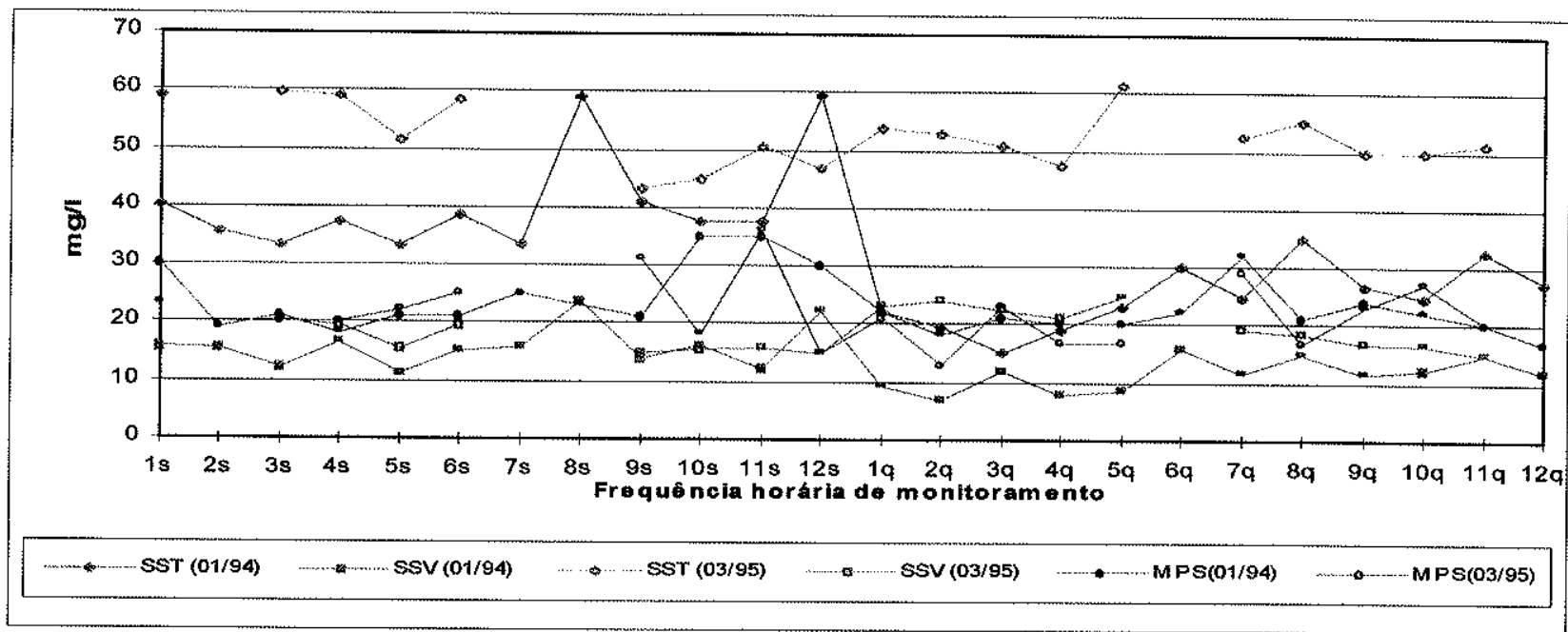

FIGURA 17 - TEORES DE SST, SSV E MPS NO MONITORAMENTO NA ESTAÇÃO 50 (FASES 01/94 E 03/95). s - MARÉ DE SIZIGIA; q - MARÉ DE QUADRATURA.

Uma associação mais estreita entre, o regime hidrodinâmico vigente na região estuarina e as características do material particulado em suspensão é de difícil conclusão. Seria aspectos dos mais interessantes a ser observado pois, a partir das interações entre o aporte fluvial e as correntes de marés, poderiam ser determinados os volumes líquidos e sólidos oscilantes e localizadas zonas de erosão e deposição que poderiam, desta forma, apontar a dispersão de eventuais poluentes. Assim, este estudo poderia ser acompanhado de levantamentos correntométricos e batimétricos no estuário. No primeiro caso, embora tenha-se obtido registros de velocidade e direção 
de corrente com o uso do correntômetro, na fase 03/95 (Tabela - 4), os resultados foram diversificados de tal forma que, sua análise seria passivel de dúvidas quanto a falha instrumental. No segundo, não se dispunha de ecobatimetro pontual para o estudo da morfologia do estuário. Válido ainda, ressaltar a não existência de carta batimétrica atualizada de detalhe da área de trabalho.

Considerando-se que a contribuição de água fluvial é pequena e o presente estudo não se propõe a avaliar a taxa de sedimentação no sistema estuarino, acreditase que, os objetivos aqui propostos não estão comprometidos. Fica a sugestão para estudos posteriores.

\subsubsection{Concentração de cobre, cádmio, chumbo, cromo, zinco, manganês, ferro e alumínio.}

Os resultados encontrados para $\mathrm{Cd}, \mathrm{Cr}$, $\mathrm{Cu}$ e $\mathrm{Pb}$ (Tabelas 7 a 10), apresentamse inferiores aos limites de detecção do método usado ( $\mathrm{Cu}$ e $\mathrm{Cr}=10 \mathrm{mg} / \mathrm{L} ; \mathrm{Cd}=2 \mathrm{mg} / \mathrm{L}$ e $\mathrm{Pb}=40 \mathrm{mg} / \mathrm{L}$ ). Como observa-se na Figura 18, na maré de sizígia da fase 01/95, nas estações 31 (40 mg/L), 40 (45 mg/L) e 70 (39 mg/L), o material particulado em suspensão é rico em $\mathrm{Cr}$. $E$ interessante assinalar que, os dois primeiros pontos têm influência do lançamentos de esgotos urbanos das cidades de São Félix e Cachoeira e, o último está nas imediações do estaleiro no Canal de São Roque.

Na fase 02/95 o Mn apresenta-se em concentração inferior ao limite de detecção (4 mg/L). De modo geral, os elementos $\mathrm{Fe}, \mathrm{Al} \mathrm{e}$, de forma menos acentuada, o $\mathrm{Zn}$, mostram padrão de distribuiçăo similar entre os pontos amostrados e diferentes fases investigadas. De forma concordante, como observado para o material particulado em suspensão (MPS) e a condutividade, todos os metais apresentaram maior concentração na maré de sizigia, em especial na fase 01/95.

As mais altas concentrações de $\mathrm{Fe}$ e $\mathrm{Zn}$ são registradas nos pontos próximos à desembocadura do rio Paraguaçu (70 - 80 - 90- 100), durante as fases 01/94 e 01/95, anteriores a periodos de maior estiagem. Em geral, os metais são mais elevados no MPS das marés de sizígia. Assim, a origem destes pode está na ressuspensão do material fino do sedimento de fundo, durante as marés de maior amplitude, rico em $\mathrm{Fe}$ - 
Mn e metais associados, ou no fluxo de material particulado em suspensão, oriundo da baia de Todos os Santos em direção ao estuário.

HARBINSON (1986) considera uma das fontes principais do ferro oxidável em solução e, em conseqüência, no MPS, é a sua remobilização da água intersticial do sedimento de fundo. A explicação reside no fato de que partículas mais grosseiras se depositam no fundo formando uma estrutura rígida, e as finas, em especial os floculados, formam um "banco" frouxo, com alta porosidade e permeabilidade. A consolidação dos sedimentos, sob seu próprio peso, expulsa a água intersticial dos outros já depositados. Quando a cunha salina (maior densidade), associada as fortes marés de sizígia, penetram na região estuarina, promovem um atrito no fundo arrastando as partículas finas liberando ferro para condições oxidantes. Sua precipitação, pode incorporar metais que são carreados junto ao MPS. O Mn, em geral, exibe o mesmo comportamento, entretanto, sendo menos abundante que o Fe, pode estar sujeito ao efeito diluição num maior volume de água.

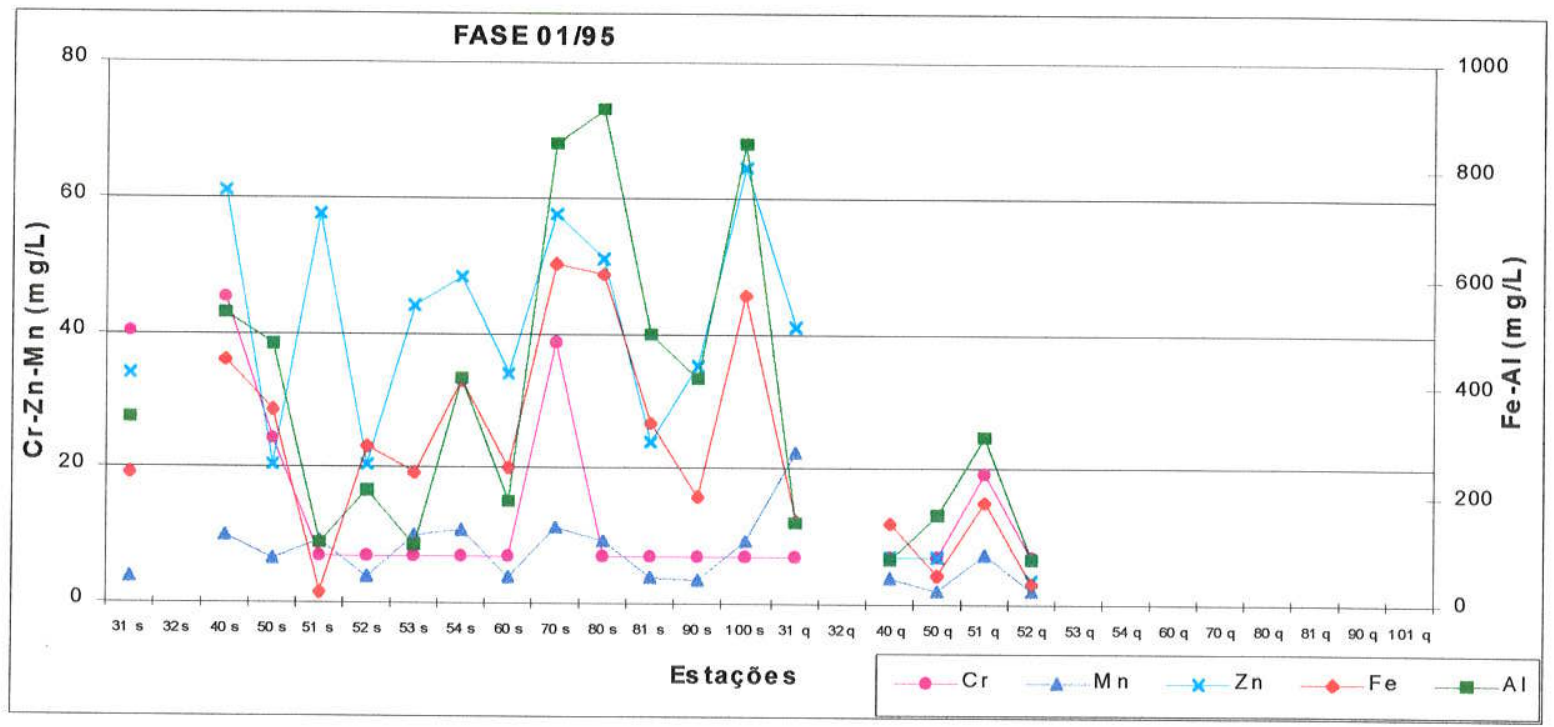

FIGURA 18 - METAIS NO MATERIAL PARTICULADO EM SUSPENSÃO (1994 -1995). s MARÉ DE SIZÍGIA; q - MARÉ DE QUADRATURA. 

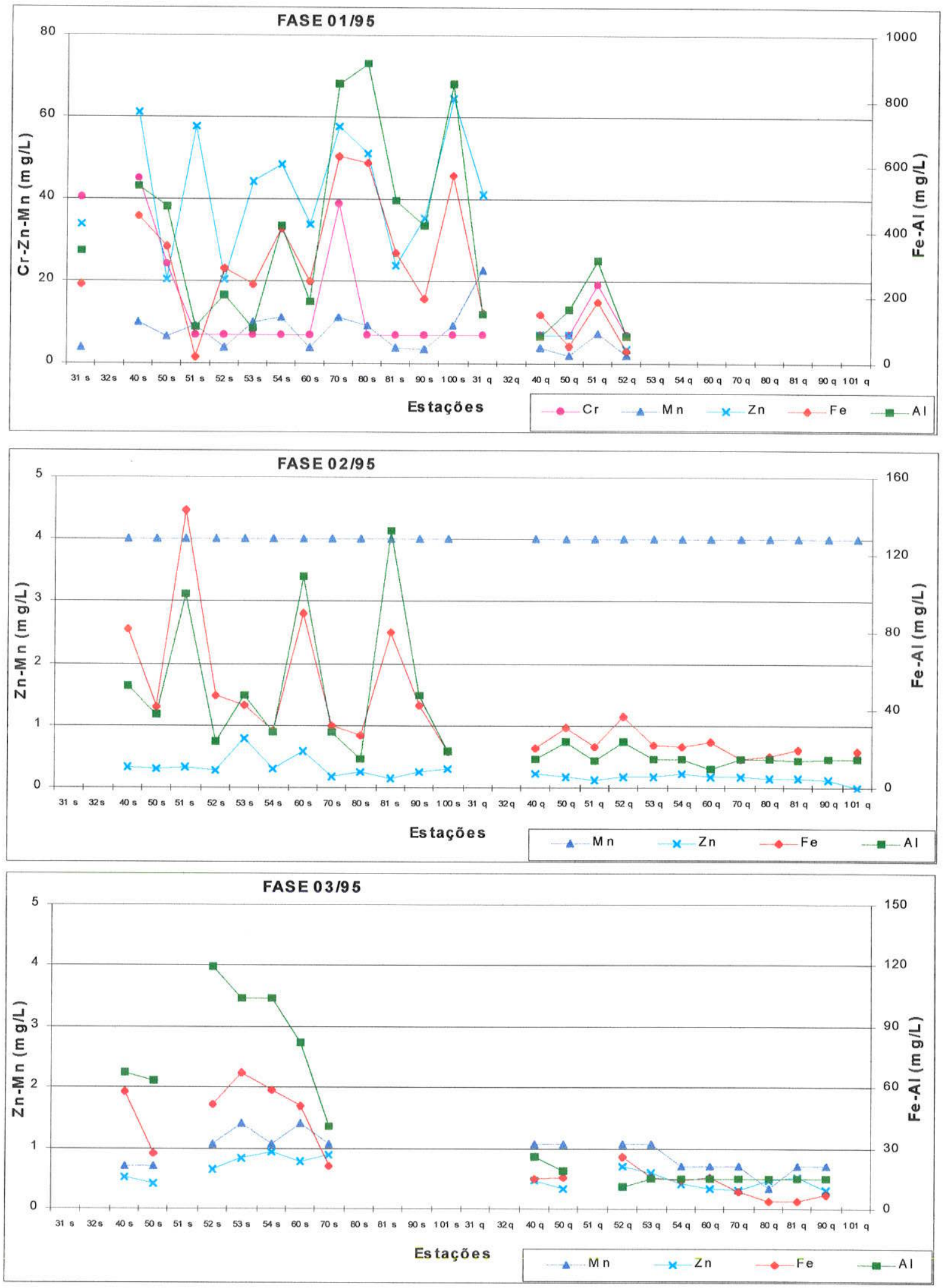

FIGURA 18 - (CONTINUAÇÃO) METAIS NO MATERIAL PARTICULADO EM SUSPENSÃO (1994 -1995). s - MARÉ DE SIZÍGIA; q - MARÉ DE QUADRATURA. 
A Figura 19, mostra a variação dos metais no material particulado em suspensão, durante as enchentes e vazantes das marés de sizígia e quadratura na estação 50. Os teores mais altos de metais, sobretudo Fe (67-620 mg/L) e Al (86-585 $\mathrm{mg} / \mathrm{L})$, mais uma vez, estão associados às marés de maior energia, ou seja, às enchentes das marés de sizígia.
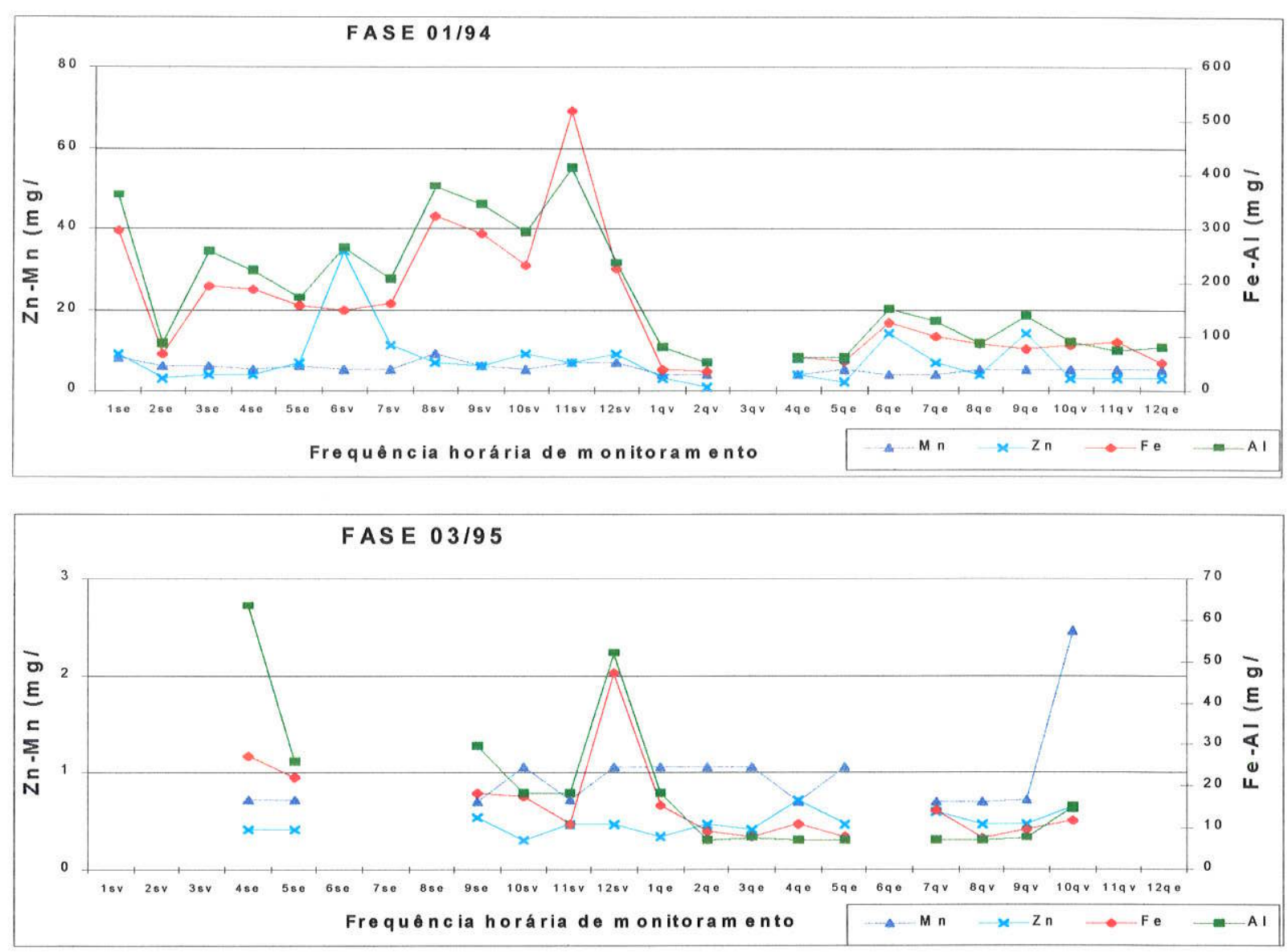

FIGURA 19 -VARIAÇÃO NOS TEORES DE METAIS NO MATERIAL PARTICULADO EM SUSPENSÃO NO MONITORAMENTO DA ESTAÇÃO 50: (FASES 01/94 E 03/95). e - ENCHENTE; v - VAZANTE; s - MARÉ DE SIZÍGIA; q - MARÉ DE QUADRATURA.

Os elementos $\mathrm{Fe}, \mathrm{Al}$ e $\mathrm{Mn}$, com freqüência referidos como parâmetros de suporte, são importantes para o estudo do comportamento dos metais pesados em 
regiões estuarinas pois, junto a matéria orgânica, estão correlacionados com a agregação ou remoção dos metais às partículas suspensas.

Diante o exposto, os resultados indicam que o MPS parece ser o principal carreador de metais. Os metais que entram no sistema estuarino, junto às fortes marés de sizigia, podem ter suas origens na baía de Todos os Santos ou estarem associados aos oxi-hidróxidos de Fe-Al, substrato dominante do MPS. Situação semelhante é encontrada por BARCELOS \& LACERDA (1993) na bala de Sepetiba, no Rio de Janeiro. O padrão de ocorrência do metal no MPS, tende a se correlacionar com o material natural original ou a fontes antrópicas, que lançam os metais às correntes.

\subsubsection{Tratamento estatístico}

As Figuras 20, 21 e 22 apresentam diagramas, do tipo box plot, que ilustram a variabilidade dos parâmetros no material particulado em suspensão entre as fases 01/95, 02/95 e 03/95 e respectivas campanhas, nas marés de sizígia (I) e quadratura (II). Os valores de MPS para a fase 03/95 nåo foram processados devido a problemas operacionais,

Os pontos que aparecem como $(0)$ e $\left(^{*}\right)$ representam valores discrepantes na população, e que podem forçar, inclusive, a maior intervalo na escala de concentração do diagrama correspondente. Como consequéncia, pode dificultar a avaliação das flutuações.

Os valores discrepantes (outliers) se destacam nas marés de quadratura, em especial para SSV, Mn, Al e Cr na fase 01/95 e, para SSV, Al e Zn na fase 03/95. A maior variabilidade e os valores médios mais altos de todos os parâmetros são registrados, principalmente, na maré de sizígia da fase 01/95 a qual, inclusive, não apresenta outliers. Este fato já vem sendo argumentado nos itens anteriores.

Ressalta-se ainda que, a fase 01/95 corresponde ao periodo de maior estiagem, o que influencia os processos de acumulaçăo e/ou menor efeito diluição do MPS e metais associados. Como na maior parte dos dados, a mediana está próxima da média da população, a distribuição pode ser considerada simétrica. 
SST
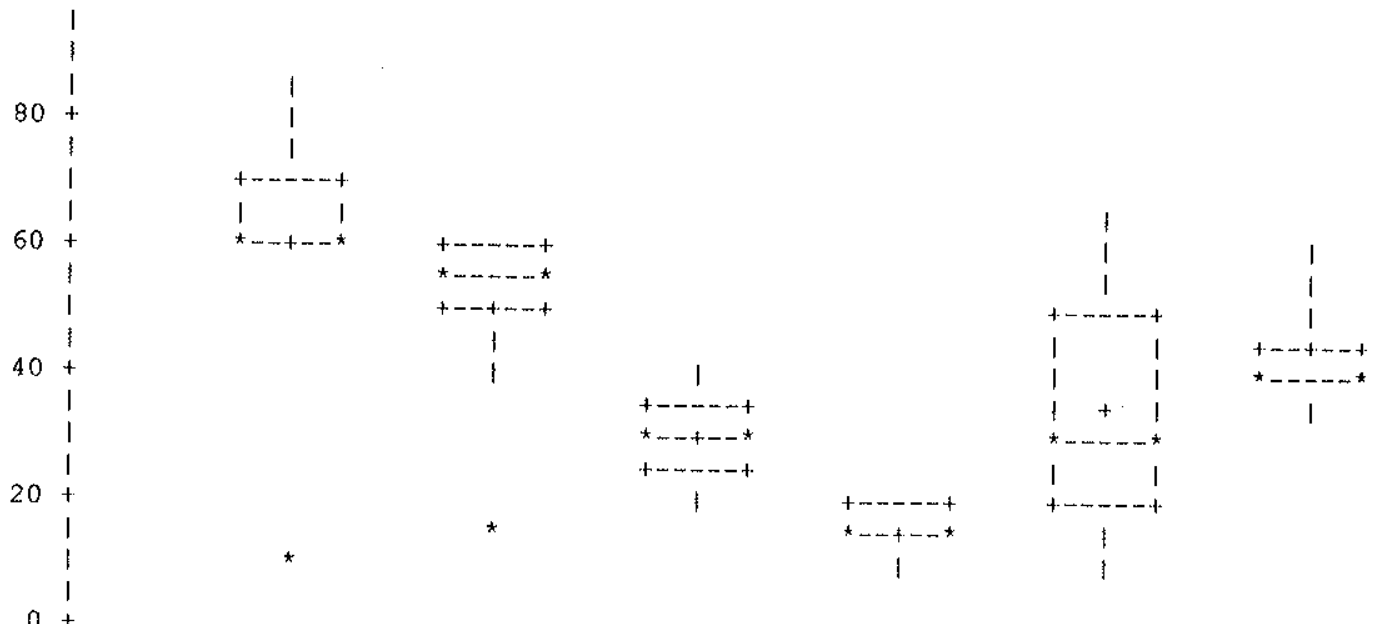

SSV

(1)

$40+$

30
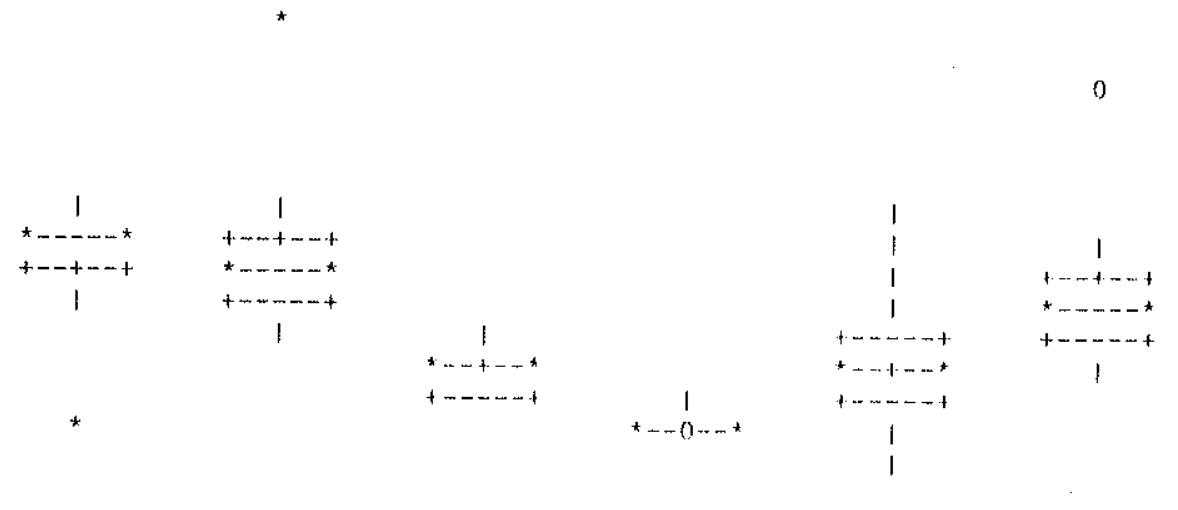

MPS
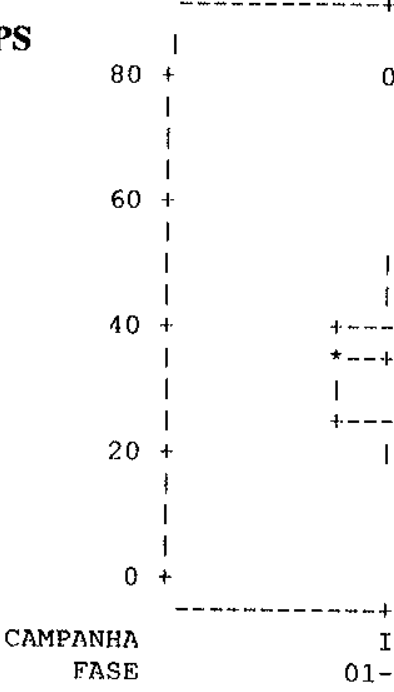

0

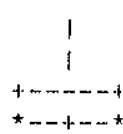

0

I
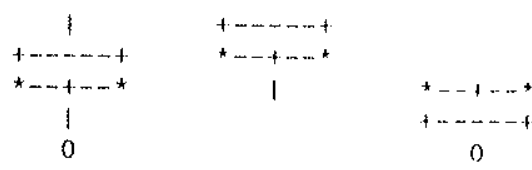

$0+$

FASE
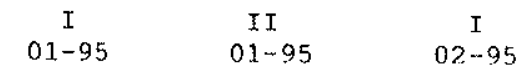

T.T. $02-95$

$I$
$03-95$

II

FIGURA 20 - DIAGRAMAS BOX-PLOT PARA SST, SSV E MPS NO MATERIAL PARTICULADO EM SUSPENSÃO NAS FASES 01-02-03/1995. CAMPANHAS I (SIZIGIA) E II (QUADRATURA). 


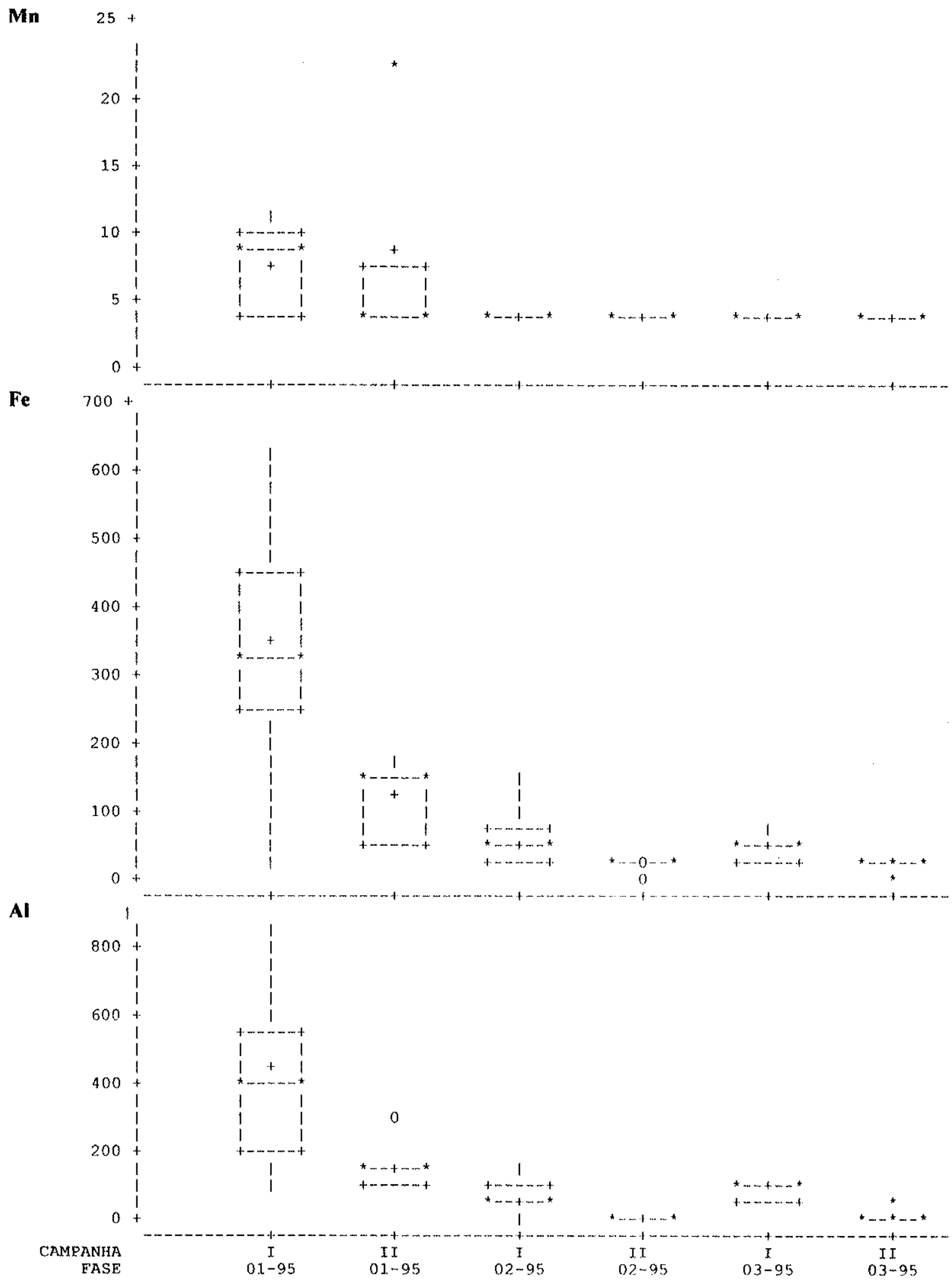

FIGURA 21 - DIAGRAMAS BOX-PLOT PARA Mn, Fe e AI NO MATERIAL PARTICULADO EM SUSPENSÃO NAS FASES 01-02-03/1995. CAMPANHAS I (SIZIGIA) E II (QUADRATURA). 


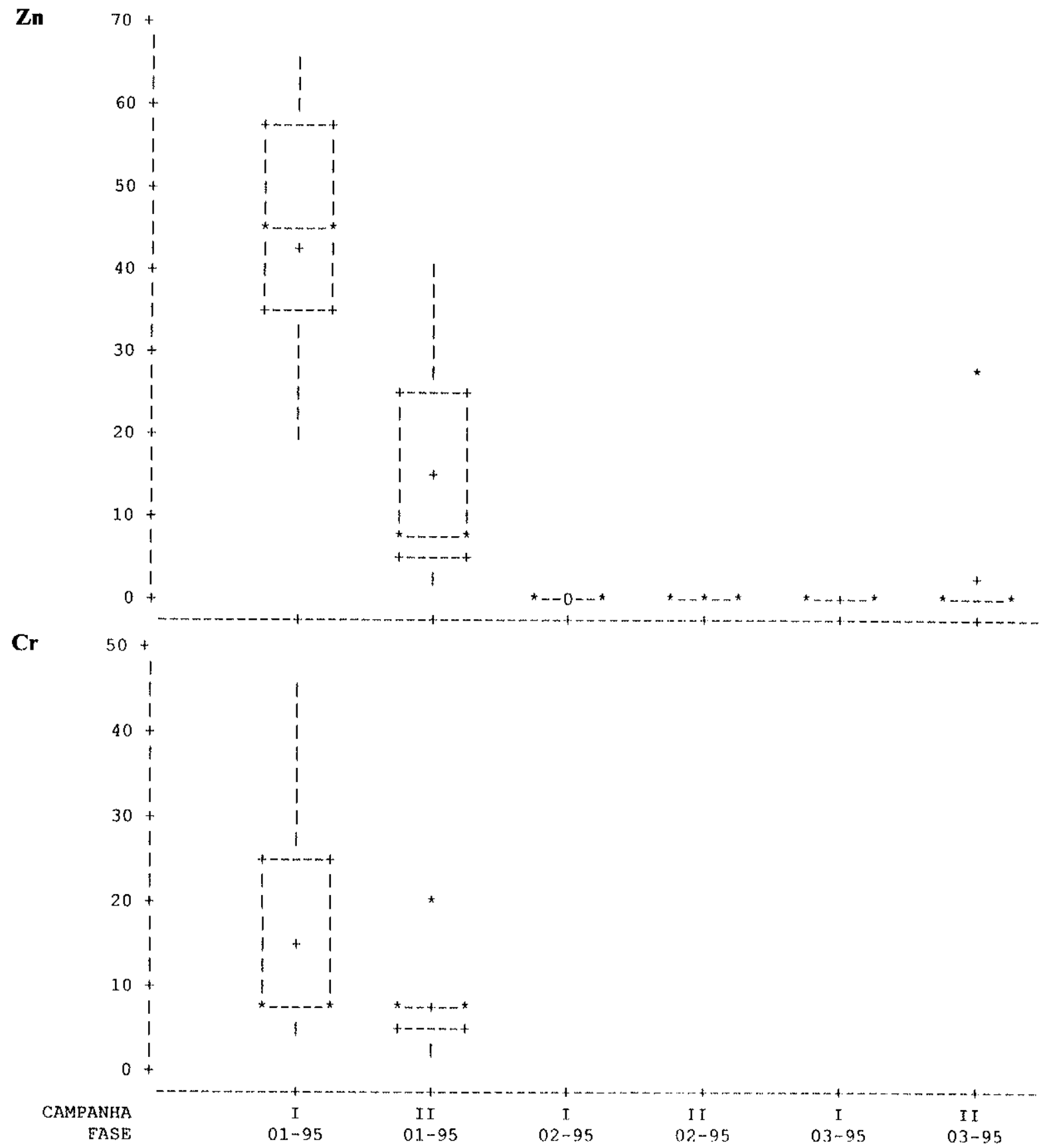

FIGURA 22 - DIAGRAMAS DE BOX-PLOT PARA Zn e Cr NO MATERIAL PARTICULADO EM SUSPENSÃO NAS FASES 01-02-03/1995. CAMPANHAS I (SIZIGIA) E \| (QUADRATURA). 
Para auxiliar a compreensão das complexas relações multivariadas entre os dados obtidos em cada estação nas respectivas fases, ou ainda, a formulação de hipóteses concernentes a essas relações, foi aplicado o procedimento estatístico exploratório por análise de agrupamentos, cluster analysis (BUSSAB et al., 1990; JOHNSON et al., 1992). É um método considerado adequado para estas situações, onde não se conhece ou compreende bem as causas fundamentais da correlação entre variáveis, mas é possivel agrupá-las de acordo com relações mútuas.

Para verificar a existência de agrupamentos entre as estações, fixadas as fases e campanhas, foi utilizado o método da Ligação Simples ou do vizinho mais próximo (Single Linkage), usando a distância Euclidiana entre as diferentes estações de modo a agrupá-las, considerando os resultados obtidos para SST, SSV, MPS e metais no MPS. Para cada estação, as variáveis foram padronizadas, evitando maior influência de alguma variável na medida de distância entre as observações. Esta padronização, consiste em subtrair a média de cada observação e dividir pelo respectivo desvio padrăo. Assim, as variáveis săo colocadas em uma escala comum, adimensional.

Os agrupamentos resultantes são representados, graficamente, na forma de dendogramas ou diagrama de árvore. Nestes gráficos, a escala vertical à esquerda indica o nível de similaridade (distância). Na escala horizontal são marcadas as estações, numa ordem conveniente ao agrupamento. As linhas verticais partindo de cada estação tem altura correspondente ao nivel em que as estações são consideradas semelhantes. Os dendogramas obtidos para os dados do MPS, nas diferentes estações são apresentados nas Figuras 23 e 24.

Como se pode observar, as maiores distâncias que representam menor similaridade entre as estações, são registradas nas marés de sizigia, com destaque para as estações 31,70 e 101. E situação coerente com as considerações já assinaladas : o ponto 31 é o mais próximo da área urbana dos municípios de São Félix e Cachoeira, o ponto $\mathbf{7 0}$ está no canal de São Roque, nas proximidades do estaleiro e, o 101, na foz do rio na baía de Todos os Santos, historicamente, com registros de altos teores de metais. Nas marés de quadratura os agrupamentos mais comuns entre as fases aparecem para os pontos 52-54-80-50-51-53-70-90. 


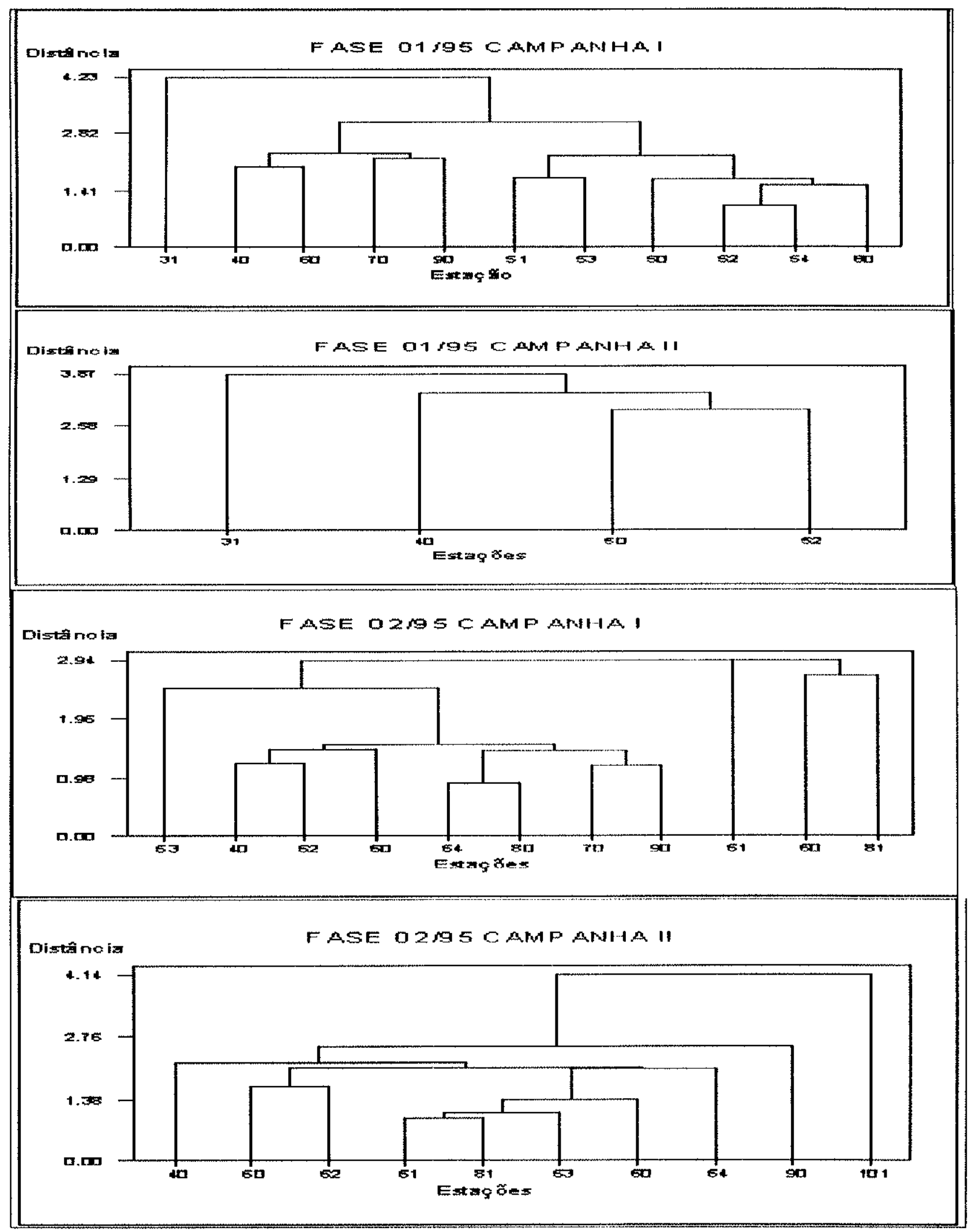

FIGURA 23 - AGRUPAMENTO DAS ESTAÇÕES COM AS CARACTERISTICAS DO MATERIAL PARTICULADO EM SUSPENSÃO, FASES 01-02/95 CAMPANHAS I (SIZIGIA) E II (QUADRATURA). 

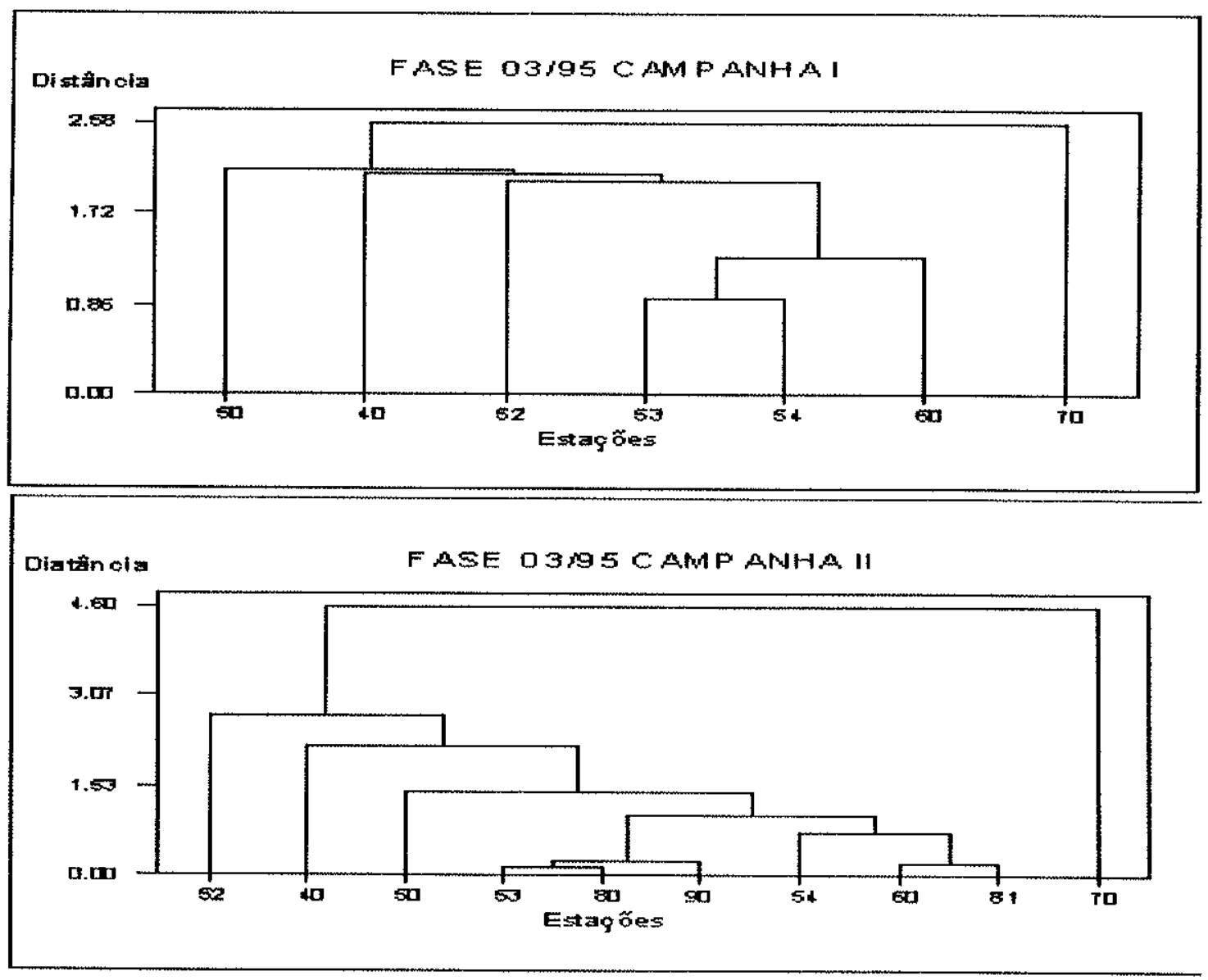

FIGURA 24 - AGRUPAMENTO DAS ESTAÇŐES COM AS CARACTERISTICAS DOS SEDIMENTOS EM SUSPENSÃO. FASE 03/95, CAMPANHAS I (SIZÍGIA) E || (QUADRATURA).

Embora não exista critério definido para escolher a distância que representa o ponto de corte para os agrupamentos, a análise de componentes principais com o uso de dendogramas é um método que permite, com boa aproximação, verificar similaridades ou diferenças entre os pontos de amostragem na área investigada. $E$ método de representação visual, sem incluir probabilidade, entretanto é provável que a tendência encontrada para a população seja bem próxima da situação real na área estudada. Como o box plot, também é uma análise descritiva e não inferencial. 


\subsection{SEDIMENTOS DE FUNDO}

\subsubsection{Características gerais}

Quando descritos macroscopicamente, usando-se lupa binocular, os sedimentos de fundo podem ser classificados, de forma genérica, desde areias muito finas a lamas, com predominância de silte. A fração grosseira, apresenta grãos de quartzo, micas e aglomerados de material fino ferruginoso de natureza diversa e com opacos, fragmentos de conchas e, na maioria das amostras, restos de vegetais.

$O$ estudo mineralógico por difratometria de Raios $X$ indica que, os sedimentos são, principalmente, compostos de quartzo, goethita e minerais argilosos, em especial, a caulinita.

Nas diferentes fases de 1995, em cada estação, a fração granulométrica predominante e o teor de matéria orgânica - MO - (Tabelas 9 a 11), podem ser comparados, conforme se verifica na Figura 25, juntos a profundidade da lâmina d'água durante a retirada da amostra. Neste caso, percebe-se que a matéria orgânica decresce, da fase 01/95 para as fases 02/95 e 03/95 e, o caráter textural do sedimento, é variado nas diferentes fases e estações. Na maré de sizígia, com exceção da fase 03/95, observa-se que a fração argila - ARG - predomina em quase todas as estaçס̄es $e$, em particular, nos sedimentos da baia de Iguape e proximidades da baia de Todos os Santos.

Nas estações 40-52-53, a fração areia (areia fina - AF e areia grossa - AG) é dominante na fase $01 / 95$. Tem sido demonstrado, que as frações silte ( silte fino - SF e silte grosso - SG) e argila não somente estão presentes em alta proporção no sedimento de fundo mas também, são as frações principais, onde os metais pesados e poluentes orgânicos estão incorporados (LITERATHY et al., 1987).

A profundidade da lâmina d'água, na retirada da amostra é variável entre as diferentes etapas de coleta, sinalizando mudanças na morfologia do fundo, devido ao movimento e transporte de massa, associados a dinâmica das correntes de marés na região estuarina. Esta dinâmica, pode ainda ser influenciada pela presença de canais e 
bancos de areia. Deste modo, o padrão de transporte e deposição de sedimentos em estuários é muito particular e, difere caso a caso. Em geral, estuários são geologicamente jovens ou seja, são áreas de crescimento com zonas de rápida deposição.

No escoamento usual de rios e estuários, areia e gravetos movem-se na camada fina ao longo do fundo. $\mathrm{Na}$ variação vertical, partículas pequenas (silte e argila), são transportadas ao longo do corpo de água. Este movimento vertical alcança toda a profundidade da água $e$, as partículas em suspensão, movem-se lentamente e permanecem em suspensão por um longo tempo, viajando maiores distâncias. Portanto, é difícil distinguir o material fino associado ao sedimento de fundo, daquele que está em suspensão no estuário, enfim, o material fino que está depositado num determinado ciclo de maré, poderá estar ressuspenso no outro ciclo (ASTON \& CHESTER, 1973).

4.4.2. Concentração de cobre, cádmio, chumbo, cromo, zinco, manganês, ferro e alumínio.

Na Figura 26 nota-se que, as flutuações entre os teores de $\mathrm{Cu}-\mathrm{Cr}-\mathrm{Cd}-\mathrm{Pb}-\mathrm{Zn}$-FeMn nos sedimentos de fundo (Tabelas 13 a 15) observadas, em 1995, são significativas entre as diferentes etapas de campo investigadas. Na estação 100, os dados estão incompletos para as fases 02 e 03/95. $\mathrm{Na}$ fase 01/95, os valores encontrados para Cd estão abaixo do limite de detecção do método usado (<1 ppm).

Com exceção da estação 60 , os teores de $\mathrm{Cr}-\mathrm{Pb}-\mathrm{Zn}-\mathrm{Mn}$ exibem tendência acumulativa nos sedimentos, amostrados da fase 01 para a 03/95. Tal fato, pode estar relacionado a acumulação gradativa de metais nos sedimentos de fundo, decorrente de lançamentos de residuos portadores destes metais. Em geral, os valores de $\mathrm{Cr}$ (160236 ppm), Pb (30-50 ppm), Zn (70-90 ppm), Mn (361-731 ppm) e Fe (4-11 \%) săo maiores na maré de quadratura, com menor energia para não provocar intensa ressuspensão de material fino do sedimento de fundo. Como foi discutido em 4.2.2., os valores registrados para os metais no MPS também são mais baixos neste tipo maré. 
Teores mais altos de $\mathrm{Cu}-\mathrm{Cr}$ - Zn aparecem nas estações 90 e 31, e representam, respectivamente, pontos com maior influência de despejos industriais e de esgotos urbanos. Na estação 31, próxima a cidade de São Félix e Cachoeira, é possivel que a acumulação dos metais nos sedimentos de fundo, seja decorrente do fato de que o pequeno aporte de água fluvial para o sistema (o máximo de $12 \mathrm{~m}^{3} / \mathrm{s}$ ), aliado ao menor alcance do influxo das correntes de maré até o local, permitem maior taxa de sedimentação e menor ressuspensão do material fino, associado ao residuos domésticos que são lançados no rio. Os baixos valores de SST, SSV e MPS registrados no ponto 31 , confirmam este fato.

As estações 40 e 52 , na fase 01/95, exibem os mais baixos valores de metais e uma grande proporção de areia nos sedimentos de fundo. Em excepcional, nesta fase - Mn tem valores mais altos. Aquelas estações, são pontos próximos a confluéncia do sistema estuarino-lagunar, desta forma sujeitos a maiores renovação e circulação de água. Maior proporção de quartzo no sedimento, associada as frações silte e areia, pode conduzir a um efeito de diluição significativo sobre o teor de metais, no sedimento de fundo.

E curioso ainda que, de modo genérico, da fase 01 para a 03/95, o teor matéria orgânica decresce nos sedimento de fundo enquanto os metais, a exceção do $\mathrm{Mn}$, exibem tendência acumulativa. Assim, tem-se uma relaçăo inversa entre o comportamento da matéria orgânica, junto ao $\mathrm{Mn}$ e os metais. É possivel, que a matéria orgânica associada a fração fina do sedimento de fundo seja, gradativamente, remobilizada e oxidada nas mais camadas superficiais do corpo d'água. Os metais associados, então liberados, são coprecipitados principalmente junto aos óxidos de ferro hidratados. LUOMA \& DAVIS (1983), sugerem que óxidos de Fe amorfos e matéria orgânica, apresentam grande capacidade de retenção dos metais em sedimentos estuarinos oxidados.

Devido a sua menor abundância, a capacidade dos óxidos de Mn é geralmente baixa, desta forma, os óxidos de $\mathrm{Fe}$ e $\mathrm{Mn}$ e a matéria orgânica, diferem na concentração de metais, de acordo com os processos que afetam sua acumulação, precipitação ou remobilização. 

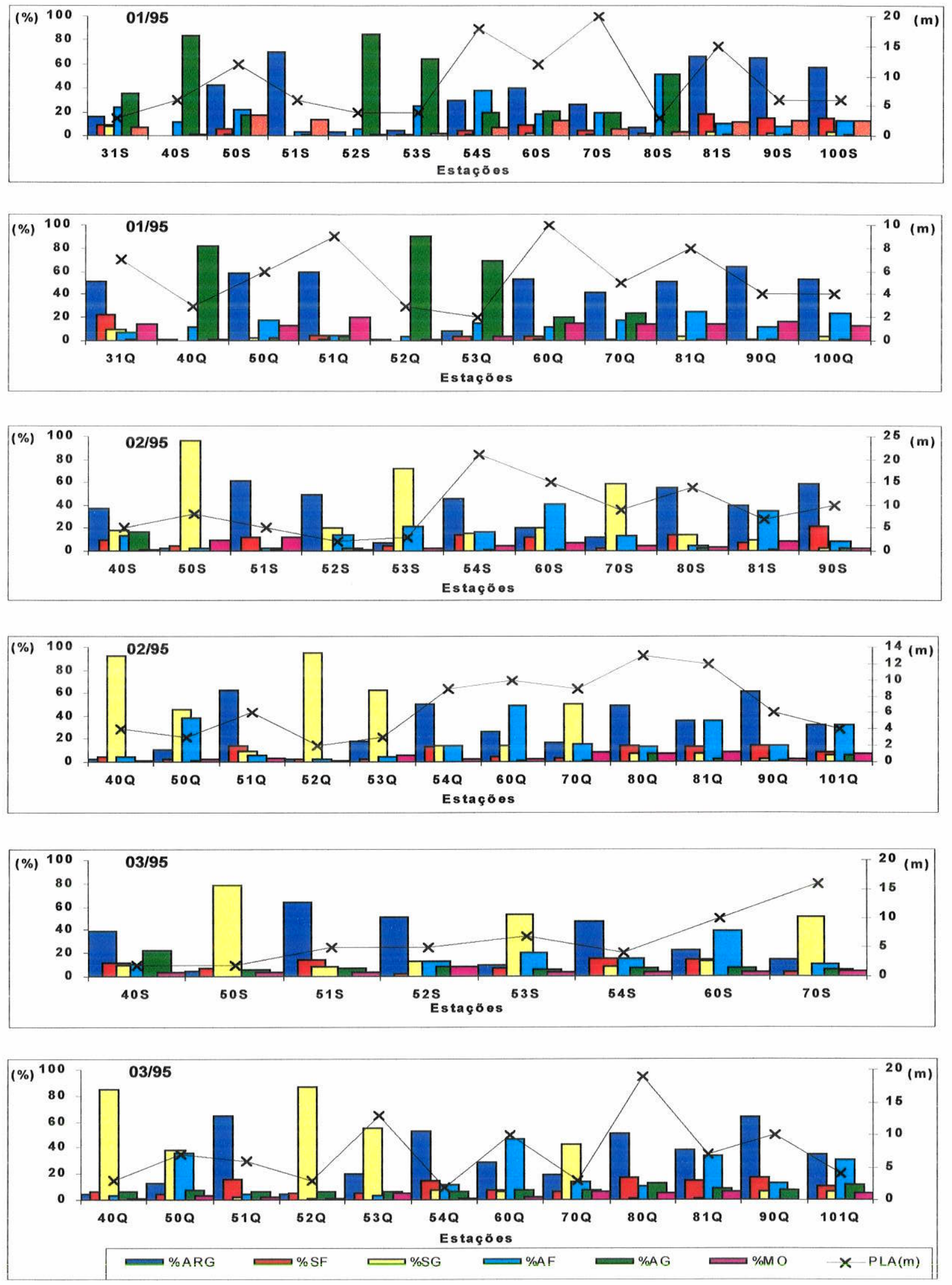

FIGURA 25 - GRANULOMETRIA DOS SEDIMENTOS DE FUNDO NAS DIFERENTES FASES ESTUDADAS. S (SIZÍGIA) E Q (QUADRATURA). 

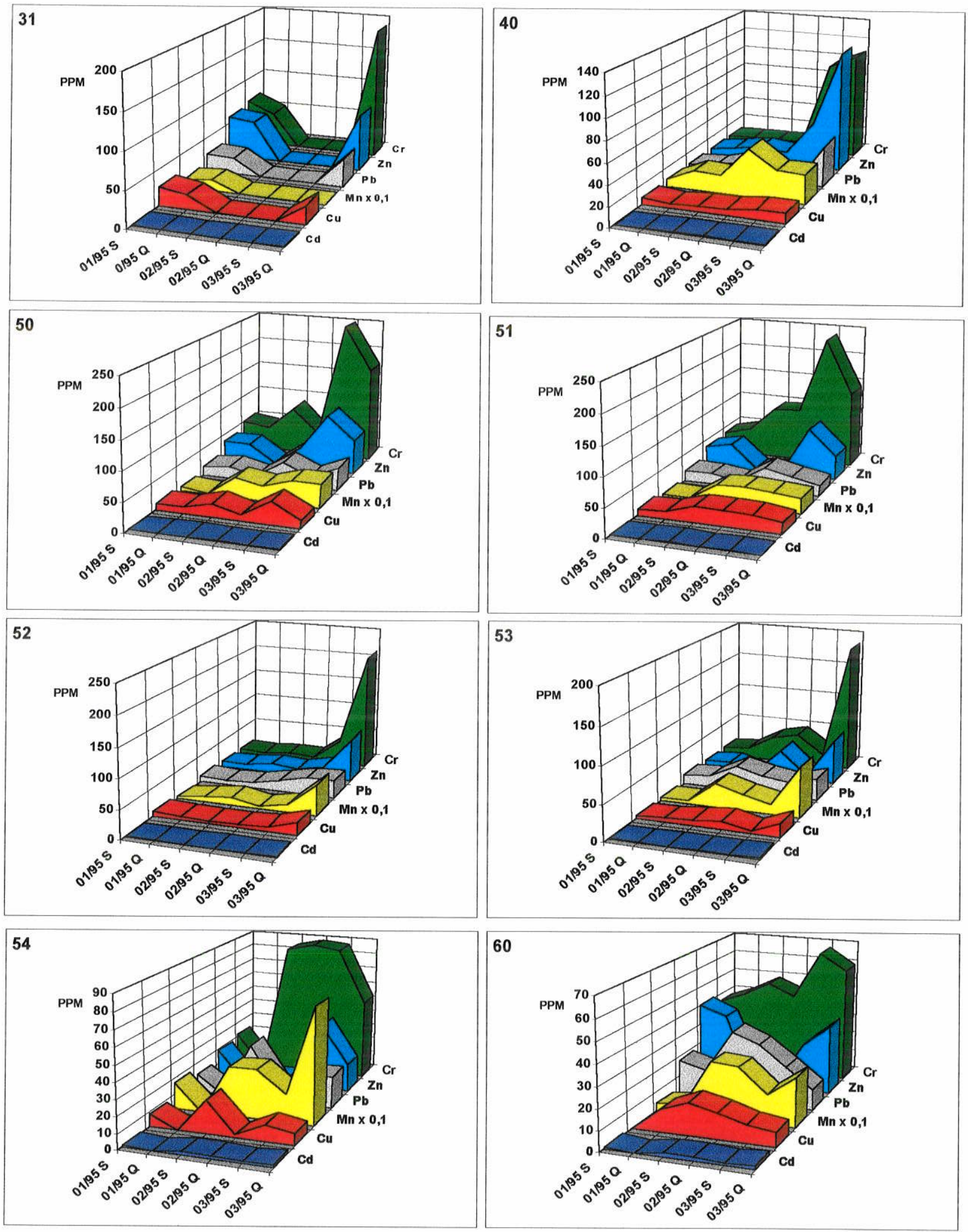

FIGURA 26 - DISTRIBUIÇÃO DOS METAIS NOS SEDIMENTOS DE FUNDO NAS ESTAÇÕES ESTUDADAS. FASES 01-02-03/95, MARÉS DE SIZÍGIA (S) E QUADRATURA (Q). 

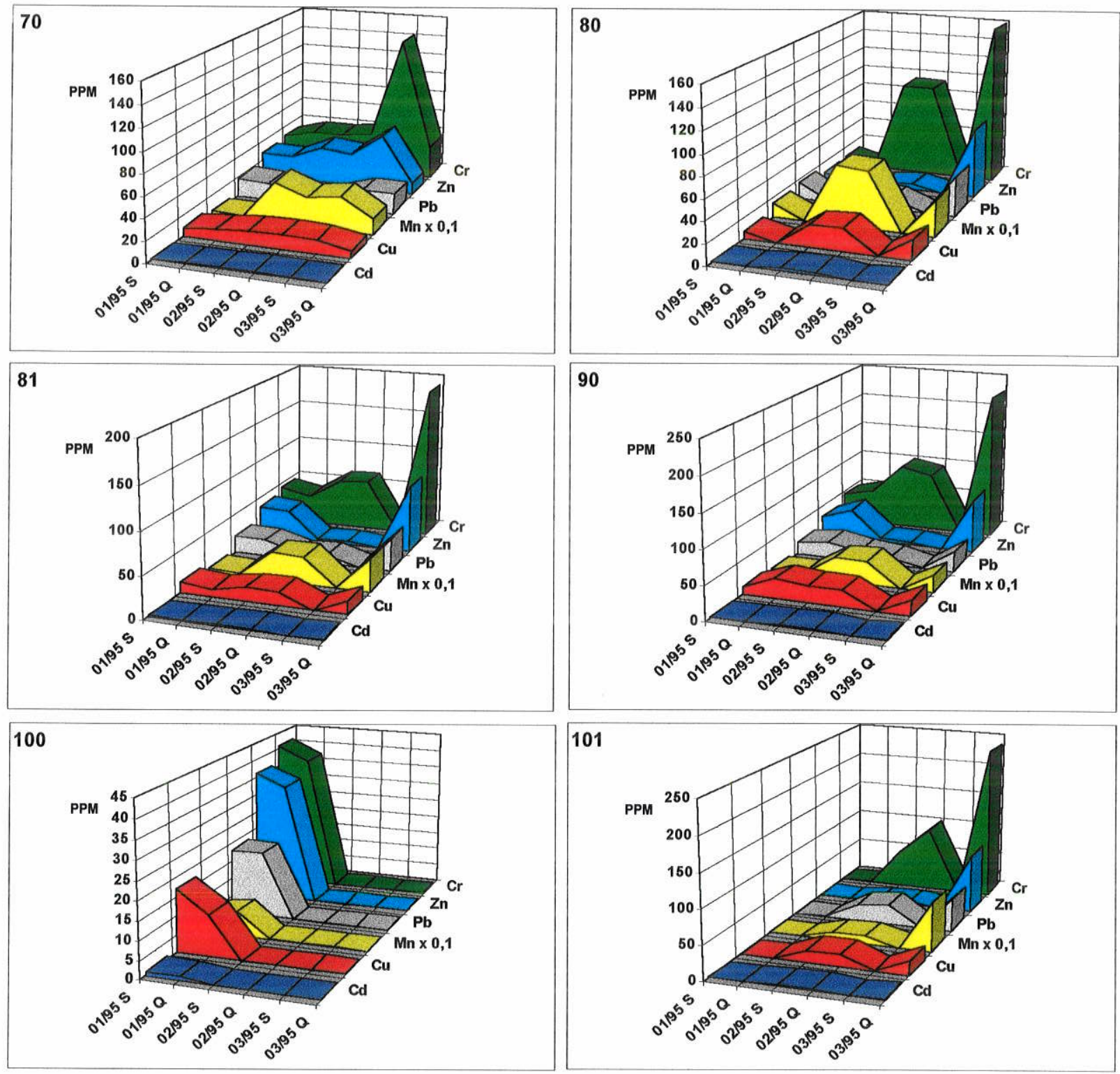

FIGURA 26 - (CONTINUAÇÃO) DISTRIBUIÇÃO DOS METAIS NOS SEDIMENTOS DE FUNDO NAS ESTAÇÕES ESTUDADAS. FASES 01-02-03/95, MARÉS DE SIZÍGIA (S) E QUADRATURA (Q). 
Percebe-se que, entre as diferentes fases não existe tendência regular de distribuição para os metais nos sedimentos de fundo. Tal comportamento, pode ser sugestivo de interferência antrópica, com lançamento irregular destes metais no sistema, a curto ou médio prazo.

\subsubsection{Tratamento estatistico}

Em cada fase e campanha correspondentes, para o conjunto dos pontos estudados na região estuarina, a flutuação dos valores em torno da média obtida pode ser acompanhada pelos diagramas Box plot, mostrados nas Figuras 27 e 28.

É visivel que, para $\mathrm{Pb}, \mathrm{Zn}, \mathrm{Cr}, \mathrm{Mn}$ e $\mathrm{Fe}$ os teores médios săo mais elevados na maré de quadratura da fase 03/95 enquanto que, para $\mathrm{Cu}$ e $\mathrm{C} d$ são na maré de sizígia da fase 02/95. Exceto para $\mathrm{Pb}$ e $\mathrm{Cd}$, a maior variabilidade em torno dos valores médios se observa, em particular, na fase $03 / 95$.

Os pontos discrepantes (outliers), são menos freqüentes quando comparados aos registrados para o material particulado. Destacam-se para $\mathrm{Zn}$ e $\mathrm{Mn}$, na fase 02/95, o que demonstra a maior homogeneidade dos dados nos sedimento de fundo das diferentes estações.

A análise multivariada com o uso de dendogramas (Figuras 30 e 31) sugere os possiveis agrupamentos das estações de acordo com as características dos sedimentos de fundo das estações estudadas. Observa-se que, a exemplo do que foi verificado para o material particulado, os pontos que exibem maior distância são os 3170-90-101. 
$\mathrm{Cu}$

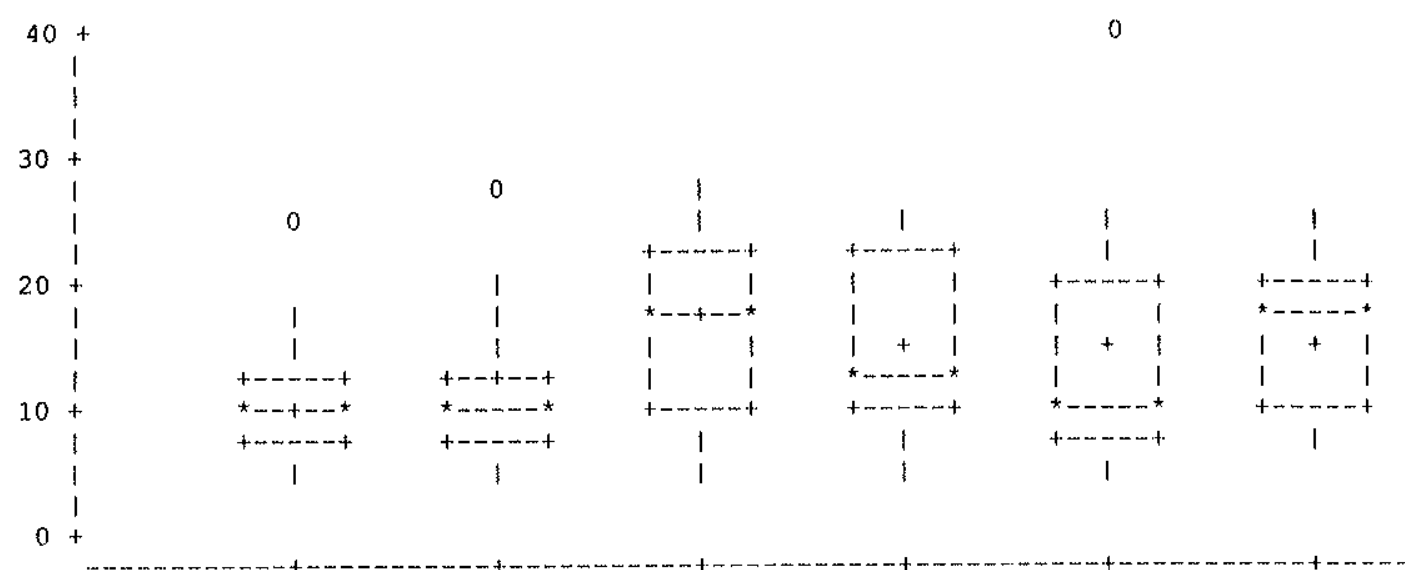

$\mathbf{P b}$
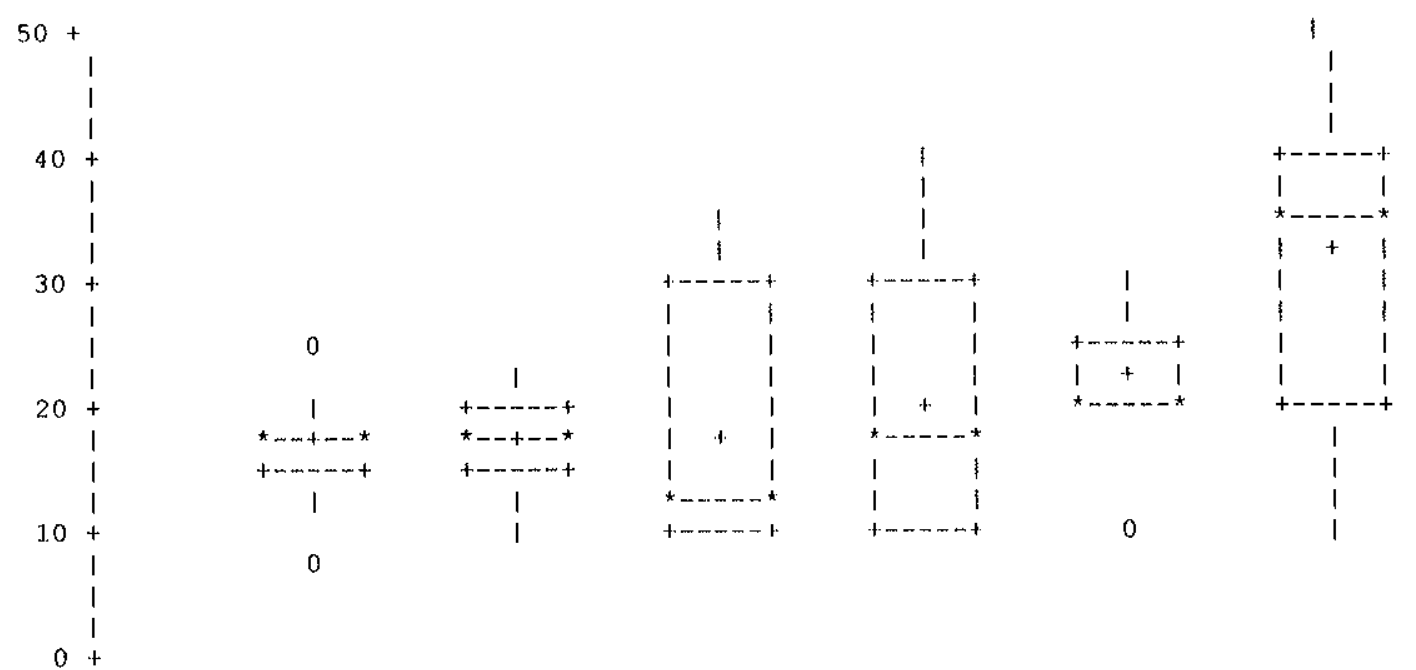

cd
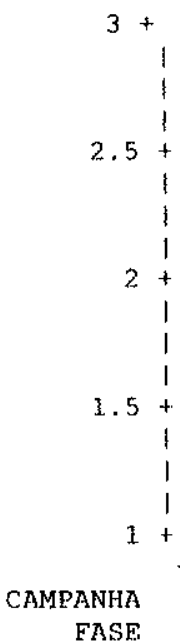

1
+
+
1
+
1
+
1
+
+
+
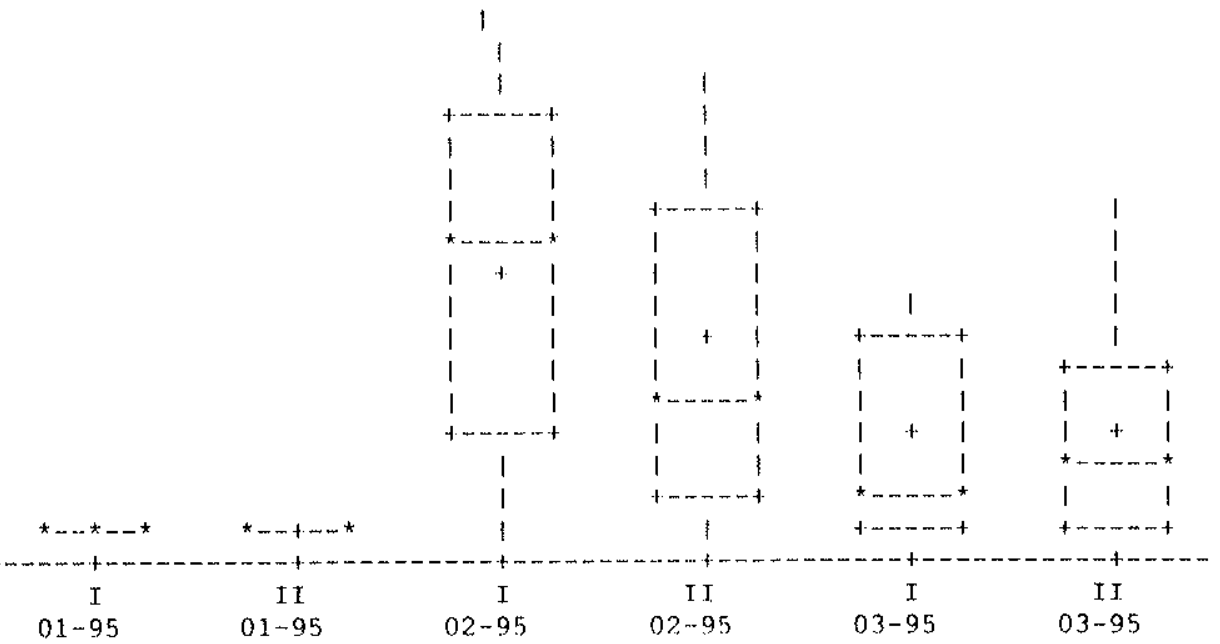

FIGURA 27 - BOX PLOT PARA Cu, Pb e Cd NO SEDIMENTO DE FUNDO NAS FASES 0102-03/1995. CAMPANHAS I (SIZIGIA) E II (QUADRATURA). 
$\mathrm{Zn} \quad 140+$

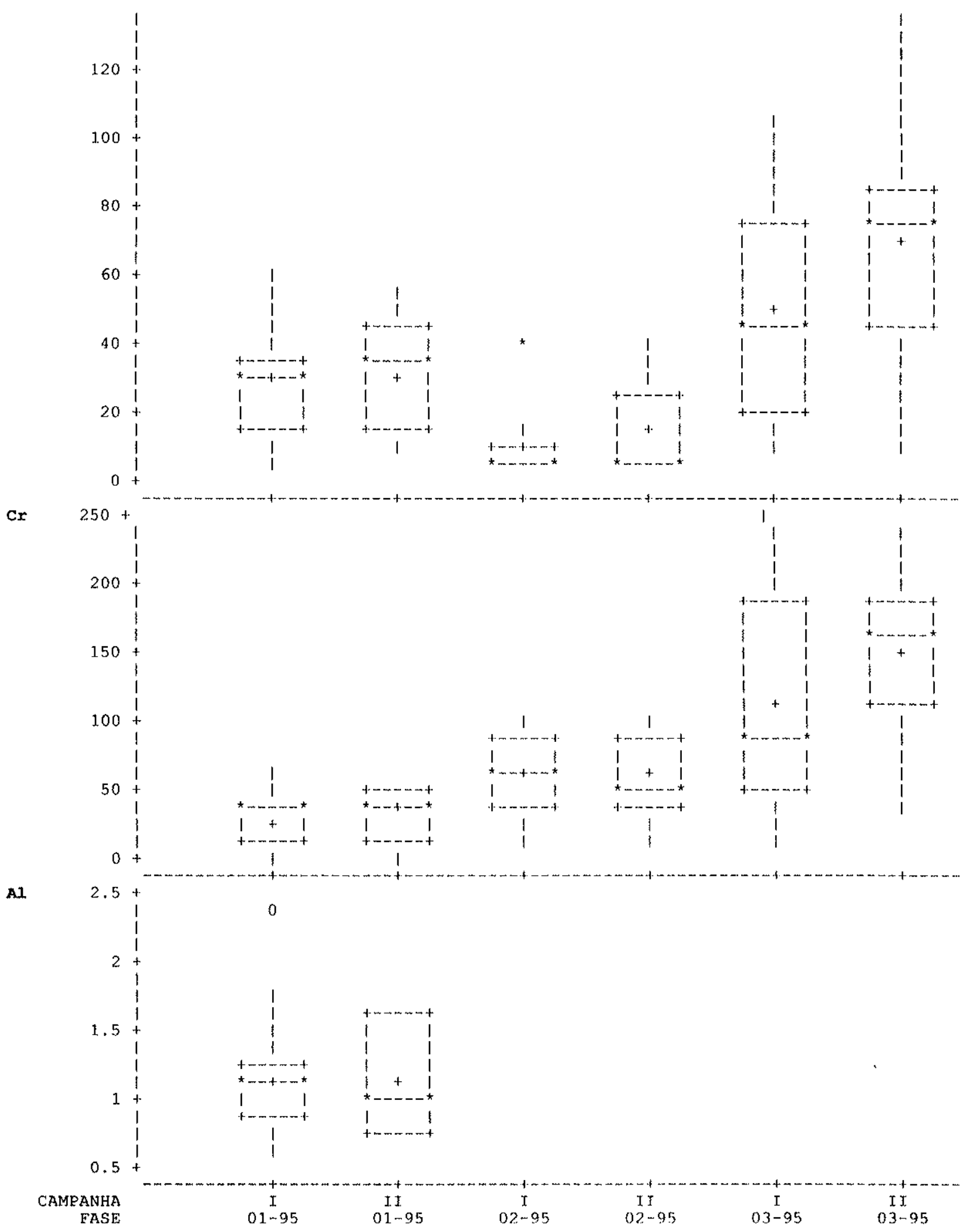

FIGURA 28 - BOX-PLOT PARA $\mathrm{Zn}, \mathrm{Cr}$ e AI NO SEDIMENTO DE FUNDO NAS FASES 01-0203/1995. CAMPANHAS I (SIZIGIA) E II (QUADRATURA). 

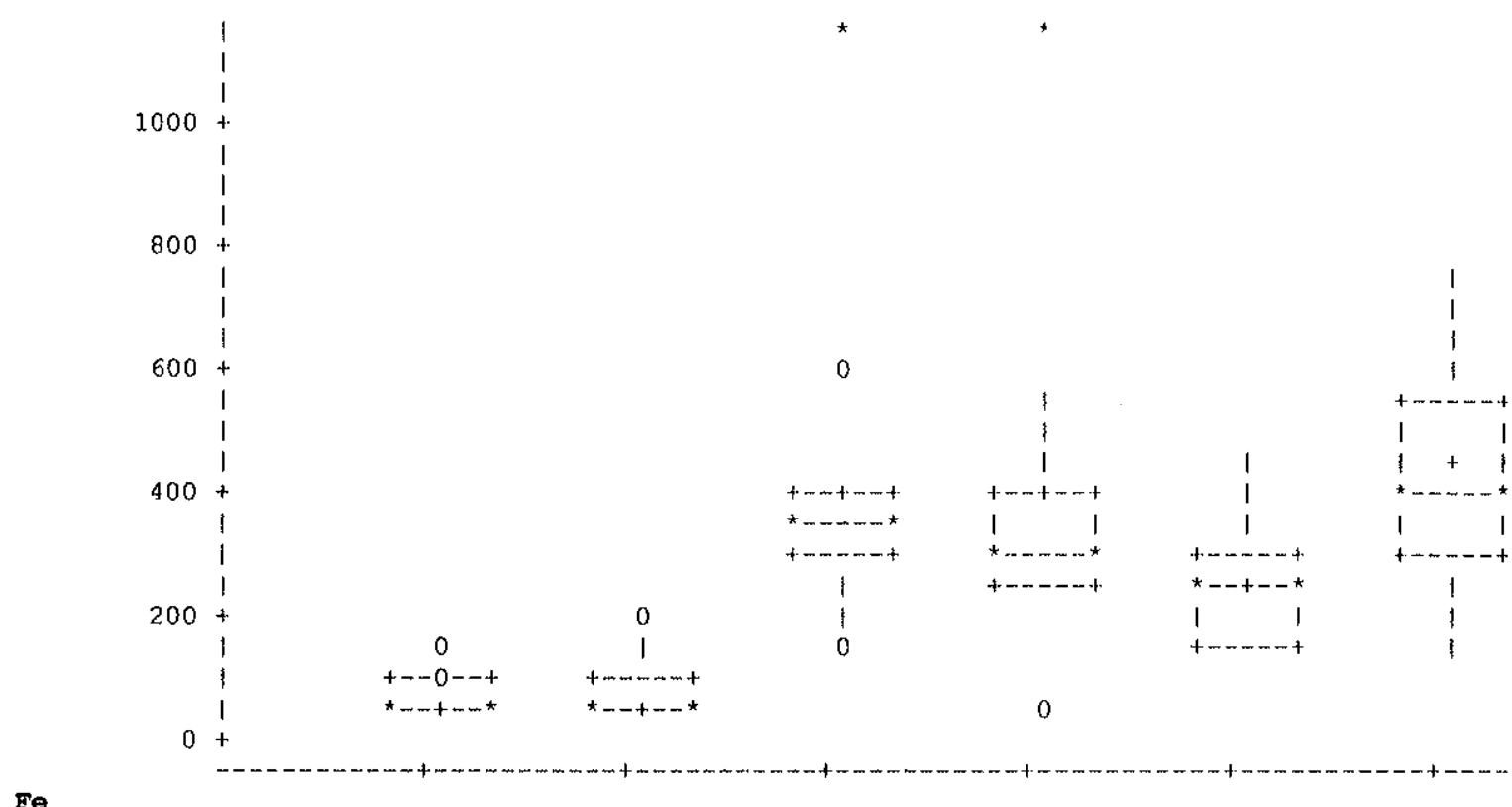

Ie

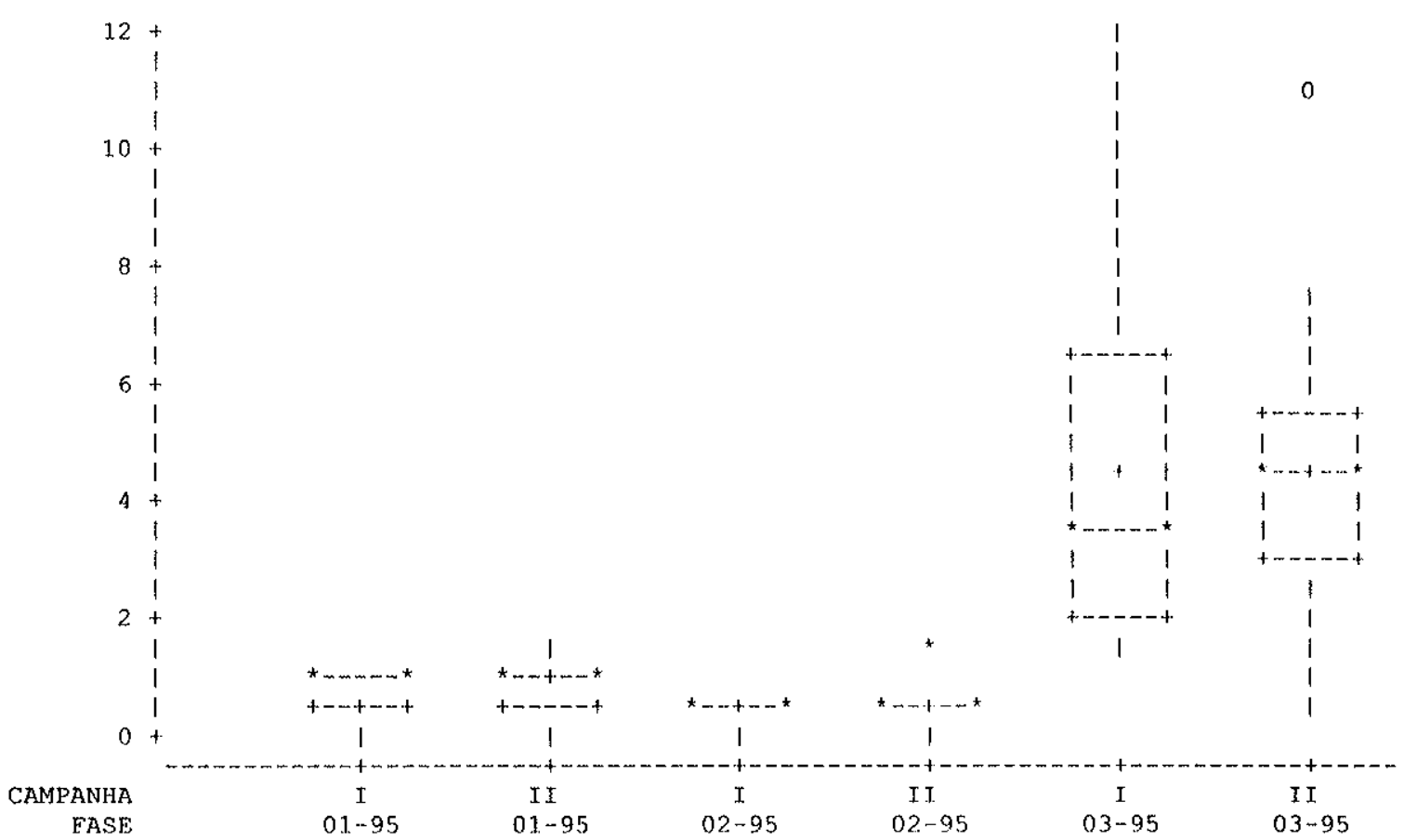

FIGURA 29 - DIAGRAMAS DE BOX-PLOT PARA Mn e Fe NO SEDIMENTO DE FUNDO NAS FASES 01-02-03/1995. CAMPANHAS I (SIZIGIA) E II (QUADRATURA). 

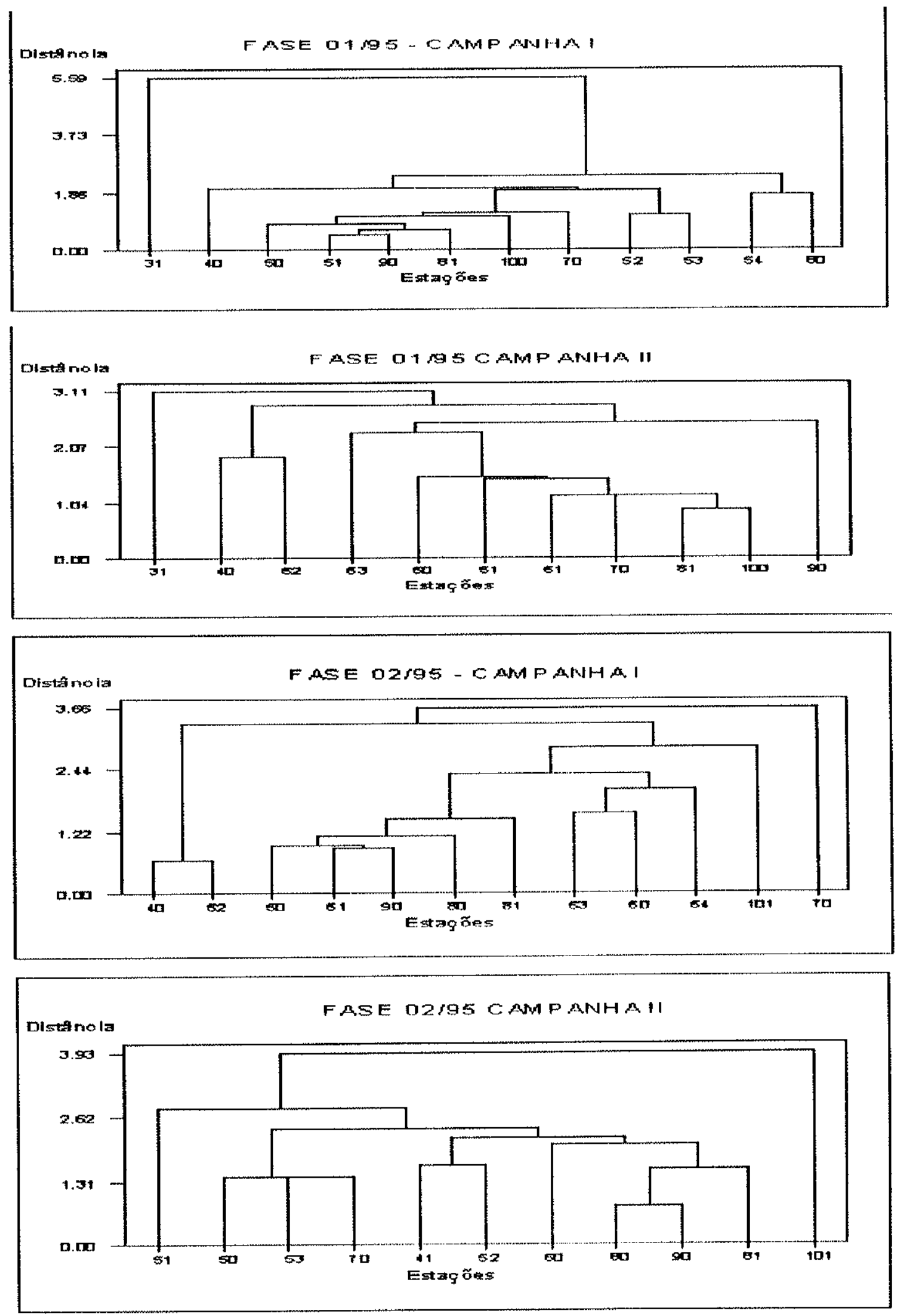

FIGURA 30 - AGRUPAMENTO DAS ESTAÇŌES PARA OS SEDIMENTOS DE FUNDO. FASES 01-02-195, CAMPANHAS I (SIZIGIA) E II (QUADRATURA). 

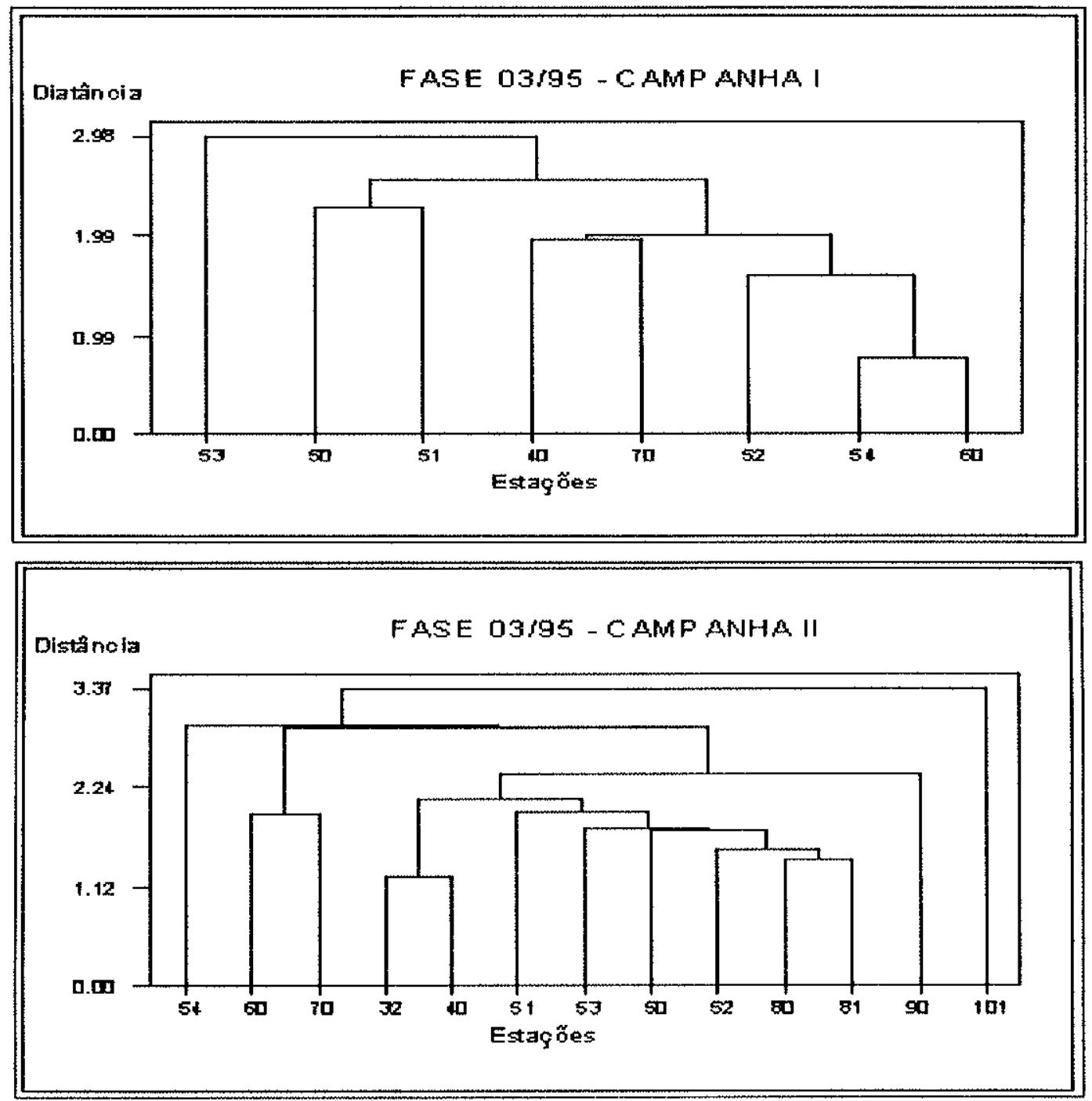

FIGURA 31 - AGRUPAMENTO DAS ESTAÇŐES COM AS INTERRELAÇŐES DAS CARACTERISTICAS DOS SEDIMENTOS DE FUNDO. FASES 01-03/95, CAMPANHAS I (SIZIGGIA) E II (QUADRATURA).

Exceto para a fase 01/95, os maiores valores das distâncias Euclidianas que representam menor similaridade entre as estações, estão na maré de quadratura. Isto pode significar menor mobilização do material fino, associado a camada superficial do sedimento de fundo e cuja deposição acompanha as variações hidrodinâmicas associada ainda a morfologia do estuário. O material pode refletir uma composição mais diversa, com características do material retrabalhado e depositado, próprio da energia que acompanha em cada ponto, a corrente de maré. Na maré de sizígia, este material é remobilizado mais facilmente, e os resultados para os parâmetros dos 
sedimentos de fundo de cada estação, apresentam-se mais próximos. Considerações semelhantes são extrapoladas para o material particulado em suspensão. Em outras palavras, isto pode confirmar a estreita correlação entre os dois materiais estudados. A movimentação do material particulado no sedimento de fundo, depende da energia que acompanha o fluxo de água salgada e dos tamanhos dos grãos que são transportados. Para a erosão do sedimento fino, é necessária uma forte corrente enquanto sua deposição requer condições mais calmas.

Os agrupamentos encontrados, podem refletir as correlações entre as estações estudadas. Desta forma é de se esperar que, nesta condição e quando os valores médios das variáveis são plotados em um mapa de distribuição de teores e, comparados, deve-se notar forte similaridade entre os padrões de dispersão nas estações agrupadas. De forma análoga, menor similaridade é esperada no mapa para as estações que não podem ser agrupadas (LEVINSON, 1982).

\subsubsection{ESPECIAÇÃO QUIMICA DOS METAIS}

Já foi enfatizado que, nos sedimentos de fundo os metais podem estar presentes em: minerais detríticos, associados a compostos discretos (carbonatos, hidróxidos, sulfetos), como lons retidos nas argilas, ligados aos óxidos e hidróxidos de $\mathrm{Fe}$ ou $\mathrm{Mn}$ e, quelatados por substâncias húmicas solúveis. Os metais de origem antrópica ocorrem, no sedimento, nas formas mais lábeis. É esperado que, a mobilização dos metais e sua posterior liberação para água e/ou para a retirada biológica ocorram, principalmente das frações não residuais do sedimento, que comportam-se de forma diversa sob certas condições ambientais, e de acordo com suas diferentes estabilidades.

A biodisponibilidade, bem como as interações entre os reservatórios abióticos, têm sido determinadas por especiação dos metais. Este método, consiste na diferenciação dos metais nas diversas fases, usando processos de extração sequencial com simples passos de lixiviação que não atacam, significativamente, a matriz silicática. O emprego destas técnicas para monitoramento de sedimentos, tem sido 
forte instrumento para a avaliação das correntes de poluentes, disponibilidade biológica e remobilização geoquímica de metais.

$\mathrm{Na}$ partição química dos metais nos sedimentos, a contribuição detrítica representa a concentração do metal, nos minerais distintos ou minerais insolúveis autigênicos. Esta fração não é facilmente disponivel para biota mas, parte dela pode tornar-se, através de processos de oxidação-redução. A contribuição não detrítica, representa a parte do elemento liberado na forma dissolvida, lixiviado da rocha original ou associado a fonte antrópica, que é incorporado, transportado e/ou depositado no sedimento.

Outras contribuições não detriticas podem também, ser derivadas de lons liberados durante alterações diagenéticas, presos em minerais solúveis e/ou, presos nas posições superficial e intersticial dos constituintes orgânicos e inorgânicos dos sedimentos. Na fração não detrítica, o arraste dos metais depende da sua inclusão ou associação com compostos fracamente cristalinos e amorfos, carbonatos e matéria orgânica.

Nos sedimentos de fundo da região estuarina do rio Paraguaçu, a especiação de $\mathrm{Cu}, \mathrm{Pb}, \mathrm{Cr}, \mathrm{Zn}, \mathrm{Fe}$ e $\mathrm{Mn}$ nos diversos substratos geoquímicos, foi estudada nas amostras da fase 02/95. Os teores de $\mathrm{Cu}(<3 \mathrm{ppm}), \mathrm{Cd}(<1 \mathrm{ppm}), \mathrm{Cr}(<4 \mathrm{ppm})$ e $\mathrm{Zn}$ ( $<5$ ppm), nas frações trocável e carbonatos, estão abaixo do limite de detecção para o método usado. $\mathrm{O}$ mesmo acontece para $\mathrm{Cu}$ e $\mathrm{Cd}$, nas fases redutivel (oxi-hidróxidos de Fe e $\mathrm{Mn}$ ) e oxidável (matéria orgânica e sulfetos) e, para Cd na matriz residual (Tabela 16).

Como mostra a Figura 32 os metais, em geral, têm um percentual mais alto na fase residual do sedimento em todas as estaçōes: $\mathrm{Cu}(70-95 \%)$; $\mathrm{Pb}(30-100 \%)$; $\mathrm{Cr}$ (75$90 \%)$ e $\mathrm{Zn}(60-80 \%)$. O Mn é o único metal que tem associação, embora baixa, com as frações carbonática $( \pm 5 \%)$ e trocável $( \pm 5 \%)$.

Dentre as frações mais lábeis que os metais apresentam-se associados parece que, em grande parte dos pontos, a fase redutivel (oxi-hidróxidos de Fe-Mn) é o principal banco de $\mathrm{Pb}(20-40 \%), \mathrm{Zn}(20-30 \%) \mathrm{Fe}(15-40 \%)$ e $\mathrm{Mn}$ (15-50\%). E provável 
que este fato, seja o reflexo das condições oxidantes na parte superficial do estuário, devido a turbulência que acompanha a penetração da água salgada e, conduz a precipitação e posterior deposição dos hidróxidos de Fe/Mn, carreadores efetivos dos metais. Estes resultados, podem explicar a distribuição restrita de áreas com valores mais elevados (contaminadas?) uma vez que, as fraçöes residual e redutivel, sob condições oxidantes, tornaria mais dificeis a remobilização do metal e transporte no sedimento (BAISH et al., 1988).

O efeito dos resíduos urbanos na região, em particular, nas estações 31, 50, 40 e 80, pode estar vinculado ao expressivo percentual que relaciona os metais a fração oxidável (matéria orgânica e sulfetos) : $\mathrm{Cu}(2-20 \%), \mathrm{Pb}(10-35 \%), \mathrm{Cr}(5-15 \%)$ e $\mathrm{Mn}(12-$ 40\%). Entretanto, os metais incorporados aos resíduos orgânicos (fração oxidável) das cidades localizadas nos arredores da área estuarina, ou até transportados da baía de Todos os Santos, poderiam estar sendo remobilizados quando entrassem no ambiente oxidante estuarino (SOUZA et al., 1986). Desta forma, seria de se esperar uma associação menos significativa do metal com a fração oxidável do sedimento, em especial, nas áreas de maior mistura de águas oxigenadas. Portanto, a depender das modificações químicas que ocorrem no meio e atingem os sedimentos, os metais poderão, a médio e longo prazo, serem incorporados nos processos biológicos, caso os sedimentos estejam atuando como banco armazenador dos metais.

Apesar do $\mathrm{Cr}$ apresentar valores relativamente altos $(60-100 \mathrm{ppm})$, cerca de 70 $95 \%$ do $\mathrm{Cr}$ ocorre na fração residual do sedimento, o que implica em baixa disponibilidade e mobilidade deste metal no estuário.

Algumas situações excepcionais se destacam nos sedimentos das estações mais distantes da foz. Na estação 40 , os sedimentos retirados na maré de quadratura apresentam-se com cerca de $55 \%$ do $\mathrm{Fe}$ associado à fração oxidável (orgânica) e, $45 \%$ à fração redutivel (óxidos de $\mathrm{Fe}-\mathrm{Mn}$ ) enquanto o $\mathrm{Cr}$, se encontra com até $90 \%$ na fração residual. 

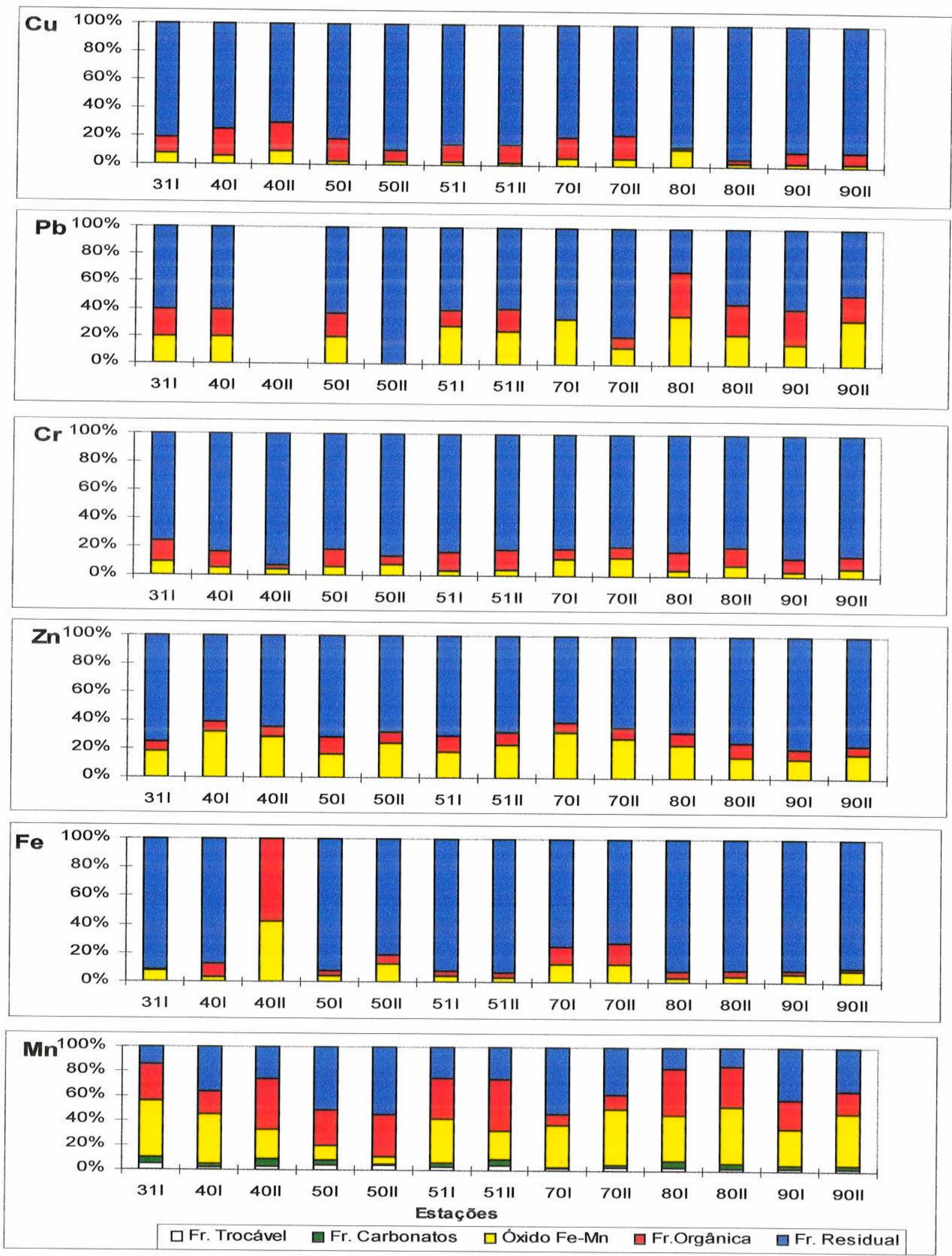

FIGURA 32 - PARTIÇÃO GEOQUÍMICA DOS METAIS NOS SEDIMENTOS DE FUNDO DA REGIÃO ESTUARINA DO RIO PARAGUAÇU. FASE 02/95, CAMPANHAS I (MARÉ DE SIZÍGIA) E II (MARÉ DE QUADRATURA) 
$\mathrm{Na}$ estação 31, próxima ao centro urbano mais populoso na área marginal estuarina (cidades geminadas de São Félix e Cachoeira), o Mn apresenta-se $35 \%$ associado à fração oxidável e o Fe não tem qualquer associação. Isto pode sugerir que, a baixa vazão defluente da barragem, $4 \mathrm{~km}$ à montante permite, embora pequena, uma renovação de água, o que aumenta as condições de oxidação. De um lado, isto dificulta a acumulação do substrato oxidável no sedimento depositado, mas, do outro, aumenta a do redutível (formaçăo de oxi-hidróxidos de Fe-Mn).

$\mathrm{Na}$ estação 50, também na maré de quadratura, $\mathrm{OPb}$ encontra-se somente na fase residual do sedimento mas, nos pontos 70,80 e 90, próximos à foz, encontra-se de forma razoável (20-40\%) associado aos óxidos de $\mathrm{Fe}-\mathrm{Mn}$. Nos dois últimos pontos, o mesmo metal relaciona-se também à fração orgânica (20-40\%). Na estaçăo 70 , próxima a um estaleiro o $\mathrm{Fe}$, de forma particular, apresenta uma associação com a fase residual $(60 \%)$, orgânica $(15 \%)$ e óxidos de Fe-Mn (15\%). Não existem outras diferenças marcantes entre as condições de marés estudadas.

Como os metais se distribuem de maneira mais diversa nas frações oxidável e redutível admite-se que, entre os pontos de amostragem, existem mudanças no ambiente quimico de sedimentação. A análise dos dendogramas no item anterior, confirma as similaridades apontadas, especialmente entre os pontos 31-70-90-101.

Resultados encontrados por MONGOLÓN et al. (1995), estudando os sedimentos do rio Tropical, na Venezuela, concordam em grande parte com o comportamento descrito para os elementos estudados nos sedimentos de fundo da região estuarina do Paraguaçu. Indutivamente, podemos supor que no nosso sistema, Fe e $\mathrm{Mn}$ são oxidados e precipitados como insolúveis, incorporando $\mathrm{Zn}, \mathrm{Pb}, \mathrm{Cr}$ e $\mathrm{Cu}$.

\subsubsection{Comparação dos dados com sedimentos de outras regiōes}

Apesar da grande atenção que vem sendo dada para a geoquímica de sedimentos estuarinos, a relação entre o background ou valores médios dos metais nos sedimentos, e os efeitos dos fatores naturais (litologia, vegetação, hidrodinâmica etc.) ou de fontes antrópicas de lançamentos de metais, não são compreendidos o suficiente para permitir uma segura e estreita comparação entre valores num mesmo sistema ou 
até de diferentes áreas. Adicionalmente, as drenagens tropicais têm sido estudadas com menor freqüência do que aquelas dos sistemas temperados. Portanto, existe ainda muito para se conhecer sobre a composiçäo química e o comportamento dos elementos traços associados a sedimentos estuarinos.

Uma completa investigação dos dados geoquímicos obtidos em ambientes estuarinos tropicais, requer o conhecimento da variação espacial, relacionada aos limites do background e aos valores anômalos. Como a variação dos dados tem inúmeras causas, a habilidade para discriminar as tendências reais é muito diffcil. Assim, como a variabilidade natural é conseqüência da heterogeneidade dos materiais geológicos a antrópica por sua vez, é de diversas fontes associadas as atividades poluentes na regiăo.

A concentração natural dos metais nos sedimentos, vem sendo avaliada pela análise de sedimentos de áreas não poluidas, camadas de sedimentos profundos, e de padrőes sedimentares não poluidos citados na literatura. A composição média do folhelho, reportada por TUREKIAN \& WEDEPOHL (1961) tem sido usada com frequeéncia como base global para comparação de sedimentos contaminados. Para alguns metais ( $\mathrm{Mn}, \mathrm{Zn}$ e $\mathrm{Pb}$ ), o folhelho concorda com a média encontrada em sedimentos de regióes menos poluidas entretanto, para $\mathrm{Cr} e \mathrm{Ni}$, os quais são associados a rochas básicas, o valor do folhelho parece ser alto para comparação com sedimentos aquáticos (SALOMONS \& FORSTNER, 1984). A média de concentraçăo do folhelho tem 11 vezes o teor de $\mathrm{Cu}$, e 8 vezes o de $\mathrm{Cr}$ mais alto do que os registrados para os carbonatos! Assim, um enriquecimento desta magnitude seria negligenciável se valores do folhelho são usados como referência para sedimentos com alto carbonato (MONGOLLÓN \& BIFANO, 1994).

Em 1994, o Governo da Holanda editou normas que estabelecem o C - valor para metais em solos/sedimentos, que vêm a ser a concentração crítica correspondente ao nivel de risco potencial em solos/sedimentos contaminados. THEELEN \& NIJHOF (comunicação verbal) discutem uma emenda para estas normas, incluindo outros critérios ou valores para o julgamento da qualidade ambiental para estes materiais. Esta referência, conhecida como Dutch List ou lista holandesa, tem 
sido delineada e aplicada para solos e sedimentos aquáticos. São três os valores de referência :

(a) S-value que indica o nivel de qualidade ambiental de solo limpo;

(b) I-value que indica o valor para intervenção ou remediação do solo;

(c) T-value que representa o valor médio entre os dois primeiros, ou seja, é o valor que indica a necessidade de investigação.

O Quadro 04, apresenta a concentração média de metais nos sedimentos de fundo da região estuarina do rio Paraguaçu, encontrados neste trabalho e em estudos anteriores, assim como os valores registrados na literatura para outras áreas estuarinas no território nacional e no Globo, situadas na faixa intertropical e temperada. Săo também incluídos os valores médios do folhelho usado como padrăo e os respectivos valores da lista holandesa.

QUADRO 04 - COMPARAÇÃO ENTRE OS TEORES MÉDIOS DOS METAIS ENCONTRADOS EM SEDIMENTOS COSTEIROS DE VARIAS REGIŐES.

\begin{tabular}{|c|c|c|c|c|c|c|c|}
\hline \multirow[b]{2}{*}{ Local } & \multicolumn{7}{|c|}{ Metais } \\
\hline & $\begin{array}{c}\mathrm{Cu} \\
(\mathrm{ppm})\end{array}$ & $\begin{array}{c}\text { Cd } \\
(\mathrm{ppm})\end{array}$ & $\begin{array}{c}\mathbf{P b} \\
(\mathrm{ppm})\end{array}$ & $\underset{(p p m)}{Z n n}$ & $\begin{array}{c}\mathbf{C r} \\
(\mathrm{ppm})\end{array}$ & $\begin{array}{c}\mathrm{Mn} \\
(\mathrm{ppm})\end{array}$ & Fe $(\%)$ \\
\hline $\begin{array}{l}\text { Estuário do rio Paraguaçu } \\
\text { - BA (1994) }\end{array}$ & 20 & 2 & 45 & 56 & 52 & 279 & 2,9 \\
\hline $\begin{array}{l}\text { Estuário dó rio Paraguaçu } \\
\text { - BA (1995) }\end{array}$ & 14 & 1,5 & 21 & 35 & 75 & 256 & 1,9 \\
\hline $\begin{array}{l}\text { Baía de lguape - BA } \\
(1992)^{c}\end{array}$ & 41 & $<1$ & 51 & 45 & n.a. & 267 & 0,1 \\
\hline $\begin{array}{l}\text { Estuário do rio Paraguaçu } \\
-B A(1987)^{d}\end{array}$ & 17 & 0,4 & 12 & 37 & n.a & 333 & - \\
\hline $\begin{array}{l}\text { Estuário do rio do Frade - } \\
\text { RJ }(1989)^{\ominus}\end{array}$ & 45 & $<1$ & 48 & 95 & - & - & - \\
\hline $\begin{array}{l}\text { Estuário do rio Ganges - } \\
\text { India (1988) }\end{array}$ & 26 & - & 29 & 71 & 67 & 553 & 3,1 \\
\hline Folhelho (1961) ${ }^{g}$ & 42 & 0,3 & 25 & 100 & 90 & 850 & 4,7 \\
\hline S-value (Holandês) ${ }^{h}$ & 15 & 0,4 & 50 & 50 & 50 & - & - \\
\hline T-value (Holandês) ${ }^{h}$ & 47 & 3,3 & 181 & 154 & 120 & - & - \\
\hline I-value (Holandês) ${ }^{h}$ & 59 & 6,1 & 312 & 190 & 190 & - & - \\
\hline
\end{tabular}

a,b (Este trabalho); ' (RAMOS, 1993); " (BAHIA, 1987); - (LACERDA \& PESTANA,1989); '(SUBRAMANIAN et al., 1988); ${ }^{9}$ (TUREKIAN \& WEDEPOHL, 1961); ${ }^{\text {h }}$ (THEELEN \& NIJHOF, op. cit.). 
Exceto para $\mathrm{Cr}$ e Cd, os niveis de metais na fase de 1994 e os valores médios das fases do ano de 1995 encontrados neste trabalho, em geral, podem ser considerados menores que aqueles encontrados em estuários e baias de outras regiőes geográficas. Levando-se em conta os valores da lista holandesa, os teores de $\mathrm{Cu}, \mathrm{Cd}, \mathrm{Cr}$ e $\mathrm{Zn}$ estão superiores ao S-value, limite para o solo/sedimento ser considerado limpo.

Chama-se atenção de que existem algumas limitações quando compara-se dados de diversos estudos, em que são usados diferentes procedimentos de amostragem, tratamento e análise das amostras.

Os tipos litológicos predominantes na região são rochas sedimentares, do tipo argilitos, folhelhos e conglomerados que têm altas concentrações de alguns metais, como é o caso de $\mathrm{Cd}, \mathrm{Pb}$ e $\mathrm{Zn}$ no folhetho, devido a sua facilidade em adsorver íons metálicos. O Quadro 05 apresenta a média de concentração dos metais estudados nos principais tipos de rochas.

QUADRO 05 - TEORES MÉDIOS DE METAIS PESADOS (EM PPM) NOS PRINCIPAIS TIPOS DE ROCHAS (Adaptada de ALLOWAY, 1990)

\begin{tabular}{|l|c|c|c|c|c|c|c|}
\hline \multicolumn{3}{|c|}{} & \multicolumn{3}{|c|}{ Rochas ígneas } & \multicolumn{3}{c|}{ Rochas Sedimentares } \\
\hline \hline & $\begin{array}{c}\text { Crosta } \\
\text { terrestre }\end{array}$ & Ultramáfica & Máfica & Granito & Argilito & Arenito & Folhelho \\
\hline $\mathbf{C d}$ & 0,1 & 0,12 & 0,13 & 0,09 & 0,028 & 0,05 & 0,22 \\
$\mathbf{C r}$ & 100 & 2980 & 200 & 4 & 11 & 35 & 90 \\
$\mathbf{C u}$ & 50 & 42 & 90 & 13 & 5,5 & 30 & 39 \\
$\mathbf{M n}$ & 950 & 1040 & 1500 & 400 & 620 & 460 & 850 \\
$\mathbf{P b}$ & 14 & 14 & 3 & 24 & 5,7 & 10 & 23 \\
$\mathbf{Z n}$ & 75 & 58 & 100 & 52 & 20 & 30 & 120 \\
\hline
\end{tabular}

Como o intemperismo geológico é a fonte dos niveis de background ou teores médios em determinadas áreas, o problema maior reside em como se distinguir entre o intemperismo geológico natural e o enriquecimento do metal devido às atividades humanas. 
Algumas fontes antrópicas de metais podem ser importantes tais como: Processos industriais de minérios e metais; uso de metais e componentes de metais; lixiviação de metais do lixo e resíduos sólidos do escoamento continental, e a excreção animal e humana que também contém metais pesados. A disposição de resíduos industriais, com freqüência, é conduzida sem um controle efetivo com respeito ao impacto ambiental deletérico no corpo d'água receptor. Existem numerosas correntes de efluentes industriais, promovendo enriquecimento de metais pesados no ambiente aquático. Os principais processos industriais e alguns metais associados, são compilados no Quadro 06.

QUADRO 06 - METAIS PESADOS ASSOCIADOS AS PRINCIPAIS INDÚSTRIAS (Adaptada de FÖRSTNER, 1981)

\begin{tabular}{|c|c|c|c|c|c|c|c|}
\hline Indústrias & $\mathbf{C d}$ & $\mathrm{Cr}$ & $\mathrm{Cu}$ & $P b$ & $Z n$ & $\mathrm{Fe}$ & $M n$ \\
\hline Papéis & & $\mathrm{X}$ & $\mathrm{X}$ & $\mathrm{X}$ & $x$ & & \\
\hline Petroquímica & $x$ & $\mathrm{x}$ & & $x$ & $x$ & $x$ & \\
\hline Fertilizantes & $\mathrm{X}$ & $x$ & $x$ & $x$ & $x$ & $X$ & $X$ \\
\hline Fundição de & $x$ & $x$ & $x$ & $\mathrm{X}$ & $X$ & $x$ & \\
\hline $\begin{array}{l}\text { Refinamento } \\
\text { de Petróleo } \\
\text { Cimento } \\
\text { Curtumes }\end{array}$ & $x$ & $\begin{array}{l}x \\
x \\
x\end{array}$ & $x$ & $x$ & $X$ & $x$ & \\
\hline
\end{tabular}

O exame do quadro demonstra que os metais pesados, pesquisados neste trabalho, são utilizados em campos diversos como refinamento de petróleo, aço, produção de fertilizantes, etc. Este uso multidirecionado pode provocar dificuldades ao se pontuar a corrente original de poluição.

Em áreas urbanas, o enriquecimento dos metais como resultado de efluentes domésticos e do escoamento das águas de chuvas torrenciais, pode ainda representar algumas das mais importantes correntes de metais não pontuais na água. Particulas de resíduos sólidos podem causar um enriquecimento apreciável do material em suspensão na água. Uma estimativa da magnitude destes efeitos, pode ser avaliada pelos dados apresentados no Quadro 07, onde são comparados os valores 
normais para lodo de esgotos com o correspondente nivel do metal nas rochas crustais.

QUADRO 07 - MÉDIA DE METAIS EM LODO DE ESGOTOS (Adaptada de FÖRSTNER, 1981)

\begin{tabular}{|l|c|c|c|}
\hline Metais & $\begin{array}{c}\text { Média no lodo de } \\
\text { esgotos (ppm) }\end{array}$ & $\begin{array}{c}\text { Média nas rochas } \\
\text { crustais }(p p m)\end{array}$ & Razão (a)/(b) \\
\hline Cromo & 240 & 200 & 1,2 \\
Cobre & 700 & 45 & 15 \\
Chumbo & 450 & 15 & 30 \\
Zinco & 2600 & 65 & 40 \\
Cádmio & 10 & 0,2 & 50 \\
\hline
\end{tabular}

O uso de detergentes também afetam significativamente a qualidade da água. Tem sido encontrado que a maior parte dos detergentes enzimáticos contém As, Fe, $\mathrm{Mn}, \mathrm{Cr}, \mathrm{Ni}, \mathrm{Co}, \mathrm{Zn}, \mathrm{Sr}$ e B.

O imput de metais em áreas rurais também constitui corrente importante, năo pontual, de contribuição antrópica. Os sedimentos resultantes de erosão no solo de áreas cultivadas e do desflorestamento, são altamente poluidos pelo uso de fertilizantes fosfatados e pesticidas e que possuem metais associados.

A poluição atmosférica dos metais ocorre, principalmente, durante os processos metalúrgicos que causam a emissão de particulado, e a queima de combustiveis fósseis como carvão e óleo.

Em sintese, o fato de que as diversas camadas do sedimento de fundo podem revelar gravações históricas dos niveis naturais de "background" e da acumulação de metais induzida pelo homem, a maior dificuldade que aparece nestes estudos, está na diferenciação entre os metais associados aos componentes naturais e não naturais do sedimento. Assim sendo, cada área deve ser estudada com relação as suas interferências particulares. Não pode se considerar muito adequado, extrapolar dados sobre o comportamento dos metais para diferentes áreas, onde diversos sistemas geológicos, geoquímicos e antrópicos estão atuando. 
A carga natural do metal, na maioria dos sedimentos aquáticos, está na fração fina que contém também, produtos ou metais retidos de origem não natural. A ocorrência do metal no material particulado/suspensão em águas não poluídas, relaciona-se com o material original do sedimento. Anomalias aparecem em águas poluídas, onde fontes antrópicas aumentam consideravelmente a concentração de metais no sistema aquático, e por conseqüência, sua acumulação nos sedimentos.

\subsection{INTEGRAÇÃO DOS RESULTADOS}

A discussão sobre a distribuição espacial e temporal e o comportamento das variáveis, nas diferentes condições investigadas neste estudo, embora exaustiva, foi importante para mostrar a não existência de um padrão característico para uma situação particular e que, o comportamento dos metais é influenciado pelas condições hidrodinâmicas do sistema. Algumas tentativas de correlação e integração dos resultados, obtidos para o material particulado em suspensão e os sedimentos de fundo da região estuarina do rio Paraguaçu, são delineadas nos próximos itens.

\subsubsection{Correlações entre as variáveis}

Durante as discussões, tem sido observado que alguns elementos respondem de maneira similar a determinadas condições temporais ou espaciais e, porque não dizer, ambientais. Então correlações mútuas entre estes elementos, devem servir para identificar as variações presentes ou até, conduzir às fontes prováveis destes elementos no sistema.

Para avaliação das intercorrelações, entre as variáveis nos MPS e sedimentos de fundos da região estuarina para cada fase e campanha de 1995, foi calculada a matriz de correlação simples, entre pares de todos parâmetros considerados. Os valores do coeficiente de correlação acima de $\mathbf{0 , 7}$, foram considerados significantes, baseado no teste $\boldsymbol{t}$ ao nível de $\mathbf{0 , 0 5}$. Estes valores, são destacados em negrito nas Tabelas 17 a 19 . 
Embora em algumas situaçōes deste trabalho, existam limitações entre os dados amostrais para $\mathrm{Fe}, \mathrm{Al}$ e $\mathrm{Cr}$, os resultados das correlações observadas revelam uma boa coeréncia geoquímica podendo-se afirmar que, realmente, elas ocorrem dentro dos limites verificados. O Quadro 08, reúne as principais correlações positivas e negativas (inversas) encontradas.

As correlações positivas mais freqüentes, em todas as fases e campanhas, são sólidos totais em suspensão (SST) - sólidos em suspensão voláteis (SSV), (Almps $\left.\mathrm{Fe}_{\mathrm{mps}}\right)$ e $\left(\mathrm{Cr}_{\mathrm{sf}}-\mathrm{Cu}_{\mathrm{sf}}\right)$; as negativas aparecem entre areia - argila e silte - argila. Outras correlações significativas se repetem entre as marés de quadratura, principalmente para $\left(\mathrm{Pb}_{\mathrm{sf}}-\mathrm{Zn}_{\mathrm{sf}}\right)$ e $\left(\mathrm{Cr}_{\mathrm{sf}}-\mathrm{Fe}_{\mathrm{sf}}\right)$.

A fase 01/95 que antecede período de maior estiagem, exibe maior número de correlações entre pares, ou até entre três ou mais variáveis. A exemplo, o material fino do sedimento de fundo apresenta boa correlação entre a fração argila ou silte, matéria orgânica e os metais $\mathrm{Cr}, \mathrm{Cu}, \mathrm{Pb}, \mathrm{Zn}$ e Fe. No MPS apenas (Mn-Zn) e (Al-Fe) são correlacionados. Correlações inversas entre areia com argila, matéria orgânica e, com $\mathrm{Cr}_{\text {sf }}$ e $\mathrm{Fe}_{\text {sf }}$ também são evidentes. Na maré de quadratura desta mesma fase, estas correlações negativas se repetem, acompanhadas de outras, tais como: Areia - $\mathrm{Pb}_{\text {sff }}$; (SST $\left.-M n_{s f}-M n_{m p s}\right)$ e (MPS $-Z n_{m p s}$ ).

Correlações entre os metais e o MPS, quando altas, indica ressuspensão dos sedimentos, contribuindo com metais. A fração suspensa de Fe e Mn com correlação positiva entre os metais mostra o papel dos oxi-hidróxidos ou óxidos hidratados na coprecipitação ou adsorção dos metais. É claro que o material silicatado, matéria orgânica e carbonatos podem também competir para coprecipitação, adsorção e troca iônica de metais (VILLA, 1988).

Com exceção da maré de quadratura na fase 03/95, na qual se correlaciona com - $\mathrm{Cr}$ no sedimento de fundo, o Cd não se correlaciona com qualquer outro parâmetro, nem mesmo com o $\mathrm{Zn}$, que é uma associação geoquímica comum. Isto pode ser sugestivo de uma descarga única pontual. 
QUADRO 08 - CORRELAÇŐES ENTRE OS PARÂMETROS NOS SEDIMENTOS DE FUNDO (SF) E NO MATERIAL PARTICULADO EM SUSPENSÃO (MPS) NAS FASES E CAMPANHAS DE 1995.

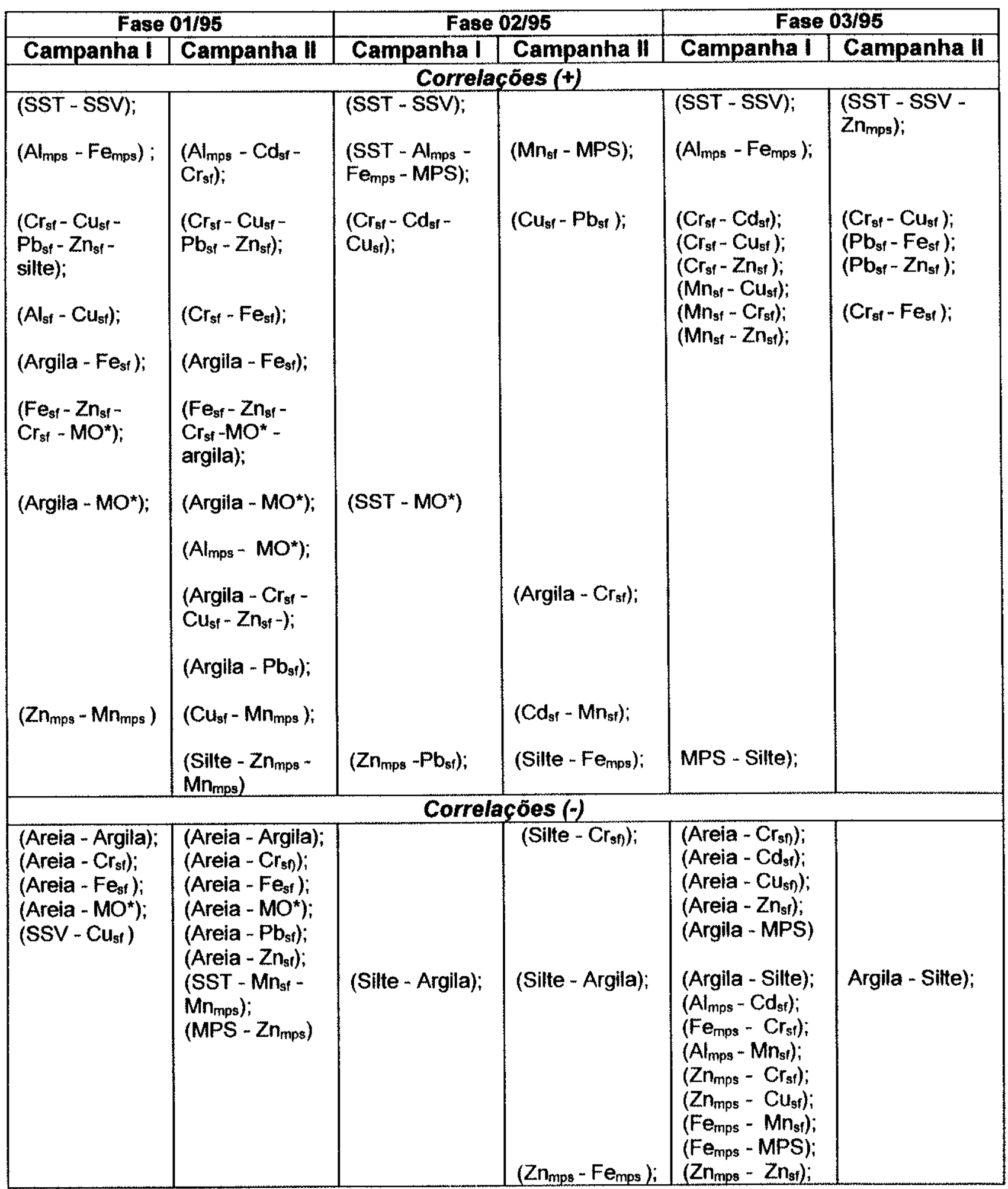

(*) MO - Matéria Orgânica mps - material particulado em suspensão sf - sedimento de fundo 
$\mathrm{Na}$ fase 03/95, as correlações positivas e negativas entre as variáveis são mais expressivas nas maré de sizigia e acontece em pares, sem agrupamentos correlacionados como se observa em 01/95. Da mesma forma, na maré de sizígia daquela fase, as correlações inversas entre areia e metais nos sedimentos de fundo e, entre os metais no material particulado em suspensão e nos sedimentos de fundo são mais freqüentes. As associações são menos evidentes na fase 02/95 que corresponde ao periodo mais chuvoso.

Diante do exposto, temos duas alternativas para explicar o comportamento geoquímico dos metais no sistema:

(a) Como foi discutido no item 4.3.2. os metais nos sedimentos de fundo, estão mostrando uma tendência acumulativa da fase 01 para 03/95 e, os maiores teores são encontrados nas marés de quadratura. Isto significa que, os sedimentos podem estar atuando, gradativamente, como banco armazenadores dos metais associados com o MPS transportado ao longo do corpo d'água. Este material fino encontra melhor condição de deposição e, se incorpora ao material fino do sedimento de fundo durante o ciclo de maré com menor energia ou seja, a maré de quadratura. A medida que a camada de material mais fino é removida pela força da maré de sizigia, a quantidade de areia incorporada ao substrato adjacente do sedimento de fundo, torna-se mais significativa e, proporcionalmente, induz a diluição dos teores de metais associados ao sedimentos finos ainda presentes.

(b) Conforme discutido nos itens 4.2.1 e 4.2.2. a quantidade de MPS e metais associados são mais elevadas na fase 01/95. Desta forma, da fase 01 para a 03/95, o teor de metais no sedimento de fundo está aumentando à medida que no MPS diminui e, este comportamento, também está associado à dinâmica das marés. Isto é sugestivo de que o fator dominante no transporte, distribuição e acumulação de metais para região estuarina é, sem dúvida, a penetração das correntes de marés. Os metais, estão sendo acumulados nos sedimentos de fundo associados ao material fino depositado, que é ressuspenso durante a maré de maior energia e, incorporado ao MPS transportado pelo fluxo de água. 
Ambos os fatos, podem ser acompanhados e deduzidos através das correlações negativas observadas entre $\mathrm{Al}, \mathrm{Fe}, \mathrm{Mn}$ e $\mathrm{Zn}$ e $\mathrm{Cd}$ no material particulado em suspensão e, os metais $\mathrm{Cr}, \mathrm{Mn}, \mathrm{Cu}$ e $\mathrm{Zn}$, no sedimento de fundo na maré de sizigia da fase 03/95.

Portanto o MPS, de um modo geral, está associado a fração fina do sedimento de fundo e ao material transportado pela corrente e, a interpretação dos resultados observados é algumas vezes dificil, mesmo considerando-se o caráter textural do sedimento. A exemplo, em baía Blanca, Argentina (SERICANO \& PUCCl, 1982), Cu e Zn são altamente correlacionados em sedimentos com baixa concentração de argila. No estuário do Ganges, na India (SUBRAMANIAN et al., 1988) não se encontra nenhuma correlação entre a matéria orgânica e a concentração de metais.

Quando as correlações são altas e os niveis dos metais são uniformes (proporções iguais nas estações) ocorre a sugestão de uma fonte comum. Correlação negativa entre $\mathrm{Fe}$ e Mn com outros metais, por sua vez, sugere um decréscimo substancial na concentração do metal onde Mn ocorre com abundância e vice-versa. $\mathrm{Fe}, \mathrm{Al}, \mathrm{Pb}, \mathrm{Zn}, \mathrm{Cu}$ e $\mathrm{Cr}$ podem ser fixados nos sedimentos, enquanto o $\mathrm{Mn}$ pode ser diageneticamente ciclado, como seria de se esperar, tomando-se por base o seu campo de estabilidade entre as fases sólidas/solução como função do pH-Eh (requer ambiente redutor básico para se acumular). Assim, o $\mathrm{Mn}$ perdido do sedimento deve estar numa forma mais lábil (BIFANO \& MONGOLLÓN, 1995).

\subsubsection{Distribuição espacial e variabilidade temporal dos parâmetros nos materiais investigados}

Os valores médios $(\bar{X})$, máximo e mínimo, desvio padrão (S) e coeficiente de variação (CV), foram calculados para os dados em cada estação, durante o ano de 1995 (Tabelas 20, 21 e 22). Os valores médios foram lançados na forma de mapas de isoteores, plotados sobre o mapa base da área, caracterizando a distribuição espacial dos parâmetros investigados no material particulado em suspensão e, no sedimento de fundo da região estuarina do rio Paraguaçu (Figuras 33 a 54).

A variabilidade dos resultados pode ser acompanhada nos gráficos associados aos respectivos mapas, que correlacionam o coeficiente de variação em cada estação. 
Os dados, com certeza, serão úteis como referencia para estudos ambientais e de exploração geoquímica, tanto para esta e, como para outras regiões tropicais.

O exame das figuras, mostra que a distribuição das variáveis é dinâmica, no espaço e no tempo. No material particulado em suspensão, os niveis médios mais altos de SST (35-55 mg/L), MPS (29-44 mg/L), Al (30-80 mg/L), são encontrados na desembocadura do rio logo na baía de Todos os Santos e, os de SSV (13-17 mg/L), na baia de Iguape. Al (70-80 mg/L), mostra uma distribuição concordante com o sentido da corrente marinha da foz para a estação 40. O Fe, por sua vez, apresenta uma dispersão heterogênea, na qual valores altos e baixos se alternam entre estações relativamente próximas. O Mn é pouco abundante (4-12 $\mathrm{mg} / \mathrm{L})$ na maioria do pontos no sistema. Os maiores valores de $\mathrm{Cr}(19-34 \mathrm{mg} / \mathrm{L})$ se distribuem nos arredores do canal de São Roque e em direção as cidades de Cachoeira e São Félix. O Zn só aparece com teores mais altos (30-50 mg/L) nas imediações da foz.

Nos sedimentos de fundo a variação espacial também é diversificada. A matéria orgânica alcança o máximo de $12 \%$ no canal de São Roque e perto das cidades de Coqueiros e Nagé. As fraçōes argila (40-60\%) e silte fino (10-15\%) predominam na região à montante da área estuarina e também na foz. Para silte grosso, o comportamento é mais homogêneo e o valor mais baixo, aparece nas proximidades de Cachoeira e São Félix, onde o $\mathrm{Zn}$ é particularmente alto. A areia, por sua vez, se distribui de forma diversa por quase todas as estações. Al é mais alto $(1,45-1,95 \%)$ no canal e próximo a São Félix, enquanto $\mathrm{Fe}$ e $\mathrm{Mn}$ apresentam valores mais altos $(1,8$ $3,8 \%)$ na foz.

A distribuiçăo da concentração média de metais pesados, é comparada aos limites do valor-S holandês estabelecido para solos/sedimentos aquáticos. Os valores de $C d(1,4-1,8 \mathrm{ppm})$, em excepcional, são superiores em quase em toda a regiåo estuarina. $\mathrm{Cu}$ (16-24 ppm) e $\mathrm{Cr}$ (70-120 ppm) também têm valores excedentes na foz e nas proximidades de Cachoeira - São Félix. Assim, a variação espacial na concentraçăo dos metais nos sedimentos de fundo, é particularmente importante nas estações próximas às áreas com maior influência de efluentes urbanos ou industriais. 
As frações granulométricas mais finas (argila e silte), também acompanham os teores médios mais altos. Isto indica a influência de duas fontes de contaminantes na região estuarina: o resíduo de esgoto municipal das cidades mais próximas e, a transferência dos efeitos de impactos próximos-passados e atuais, das atividades industriais e urbanas da baía de Todos os Santos.

$O$ coeficiente de variação da concentração dos metais $(C V=100 \times \mathbf{S} / \mathbf{X}$, onde $\mathbf{S}$ é o desvio padrão e $X$ o valor médio) em cada estação, é uma estimativa da variabilidade na amostragem durante o ano de 1995, ao longo do trecho investigado. Nota-se que o CV varia de forma muito ampla. Os valores mais altos, são sugestivos de que existem diferenças químicas entre as fases de amostragem na estação.

No MPS, os valores de CV são mais altos (>60\%), para $\mathrm{Cr}, \mathrm{Zn}, \mathrm{Fe}$ e $\mathrm{Al}$, em grande parte das estações. Esta consideração para $\mathrm{Cr}$, é restrita aos pontos com mais de duas determinações (31- 40 - 50 - 51). Nos sedimentos de fundo, CV mais alto é observado para $\mathrm{Cr}, \mathrm{Zn}, \mathrm{Mn}$ e $\mathrm{Fe}$; de forma excepcional na estação 31, isto acontece somente para $\mathrm{Cr}$ e $\mathrm{Fe}$. O CV elevado pode indicar poluição, atribuida a inputs com diferentes correntes, ou rochas de composição química incomum (MOGOLLÓN \& BIFANO, 1994). Na região estuarina do Paraguaçu, não existe grande variação litológica e os pontos amostrados estão próximos um dos outros.

Um menor CV observado significa que não existe variação suficiente, para mascarar as diferenças químicas que existem entre as fases amostradas naquele ponto. Como conseqüência, a metodologia é apropriada, para identificar as tendéncias espaciais e temporais relacionadas as causas antrópicas.

Diante das discussões pode-se sugerir que, a distribuiçăo dos metais nos sedimentos de fundo da região estudada é influenciada por efluentes locais e pela circulação de água no sistema estuarino. Os valores mais altos de $\mathrm{Zn}-\mathrm{Cr}$ - $\mathrm{Pb}-\mathrm{Cu}$ e $\mathrm{Fe}$, são encontrados próximos as cidades de Cachoeira e São Félix e na bala de Todos os Santos, sinalizando a influência das ações antrópicas nestas áreas.

Estudos recentes realizados por LINHARES et al. (1995), com relação a presença de metais pesados nos baixos cursos dos rios Jacuipe e Paraguaçu, à 
montante do reservatório, apresentam conclusões interessantes que podem ser relacionadas ao presente estudo tais como: as contribuiçōes do Rio Paraguaçu de SST, SSV, Fe-Al-Mn-Zn associadas ao material particulado em suspensão são mais altas que as do rio Jacuipe e, são proporcionais ao material transportado dos rios para o reservatório.

Os sedimentos de fundo do rio Jacuipe, por sua vez, apresentam concentraçס̃es de $\mathrm{Fe}, \mathrm{Mn}, \mathrm{Cu}, \mathrm{Cr}, \mathrm{Zn}, \mathrm{Pb}$ e $\mathrm{Cd}$ até 3 vezes maiores que as do rio Paraguaçu, devido a influência das áreas industriais localizadas nos arredores. Entretanto, foi sugerido que, pelo menos $30-60 \%$ desses elementos săo originados de fontes naturais. $A$ acumulação dos metais nos sedimentos, mostra-se comandada pela deposição de oxidos-hidróxidos de $\mathrm{Fe}$ e matéria orgânica os quais, são significativamente mais altos no rio Jacuípe e no reservatório, quando comparados ao rio Paraguaçu.

Diante destas considerações fica evidente que, quando no caso de maior descarga defluente da barragem alguns aspectos aqui discutidos devem ser questionados com respeito ao aporte de MPS e metais associados do rio Paraguaçu, oriundos do trecho à montante do reservatório de Pedra do Cavalo para a região estuarina. Os resultados deste trabalho se remetem a uma situação particular, e poderão servir como base para estudos posteriores em diferentes condições hidrodinâmicas. 

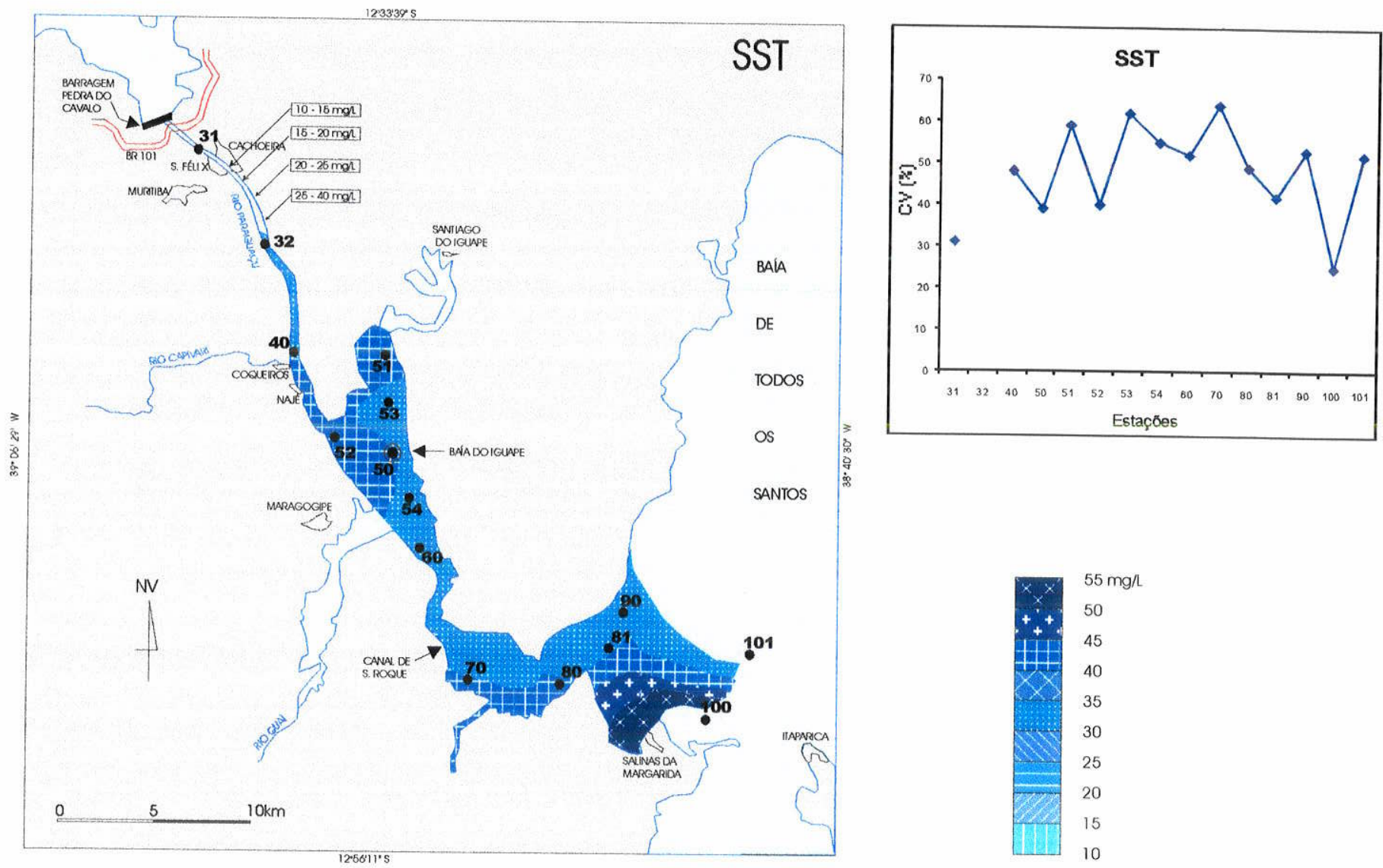

FIGURA 33 - DISTRIBUIÇÃO DOS TEORES DE SÓLIDOS TOTAIS EM SUSPENSÃO NA REGIÃO ESTUARINADORIO PARAGUAÇU.
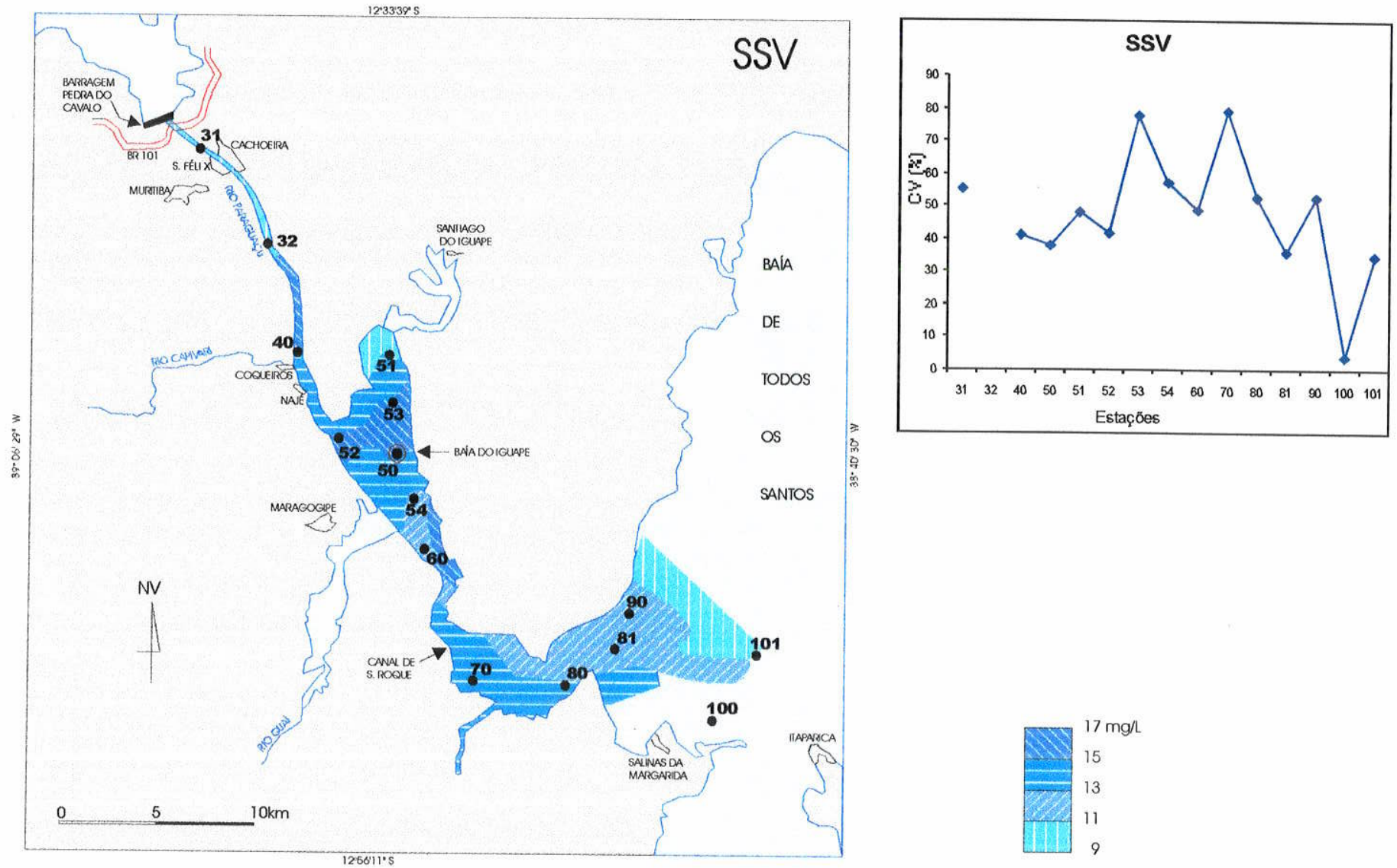

FIGURA 34 - DISTRIBUIÇÃO DOS TEORES DE SÓLIDOS EM SUSPENSÃO VOLÁTEIS NA REGIÄOESTUARINA DORIO PARAGUAÇU. 

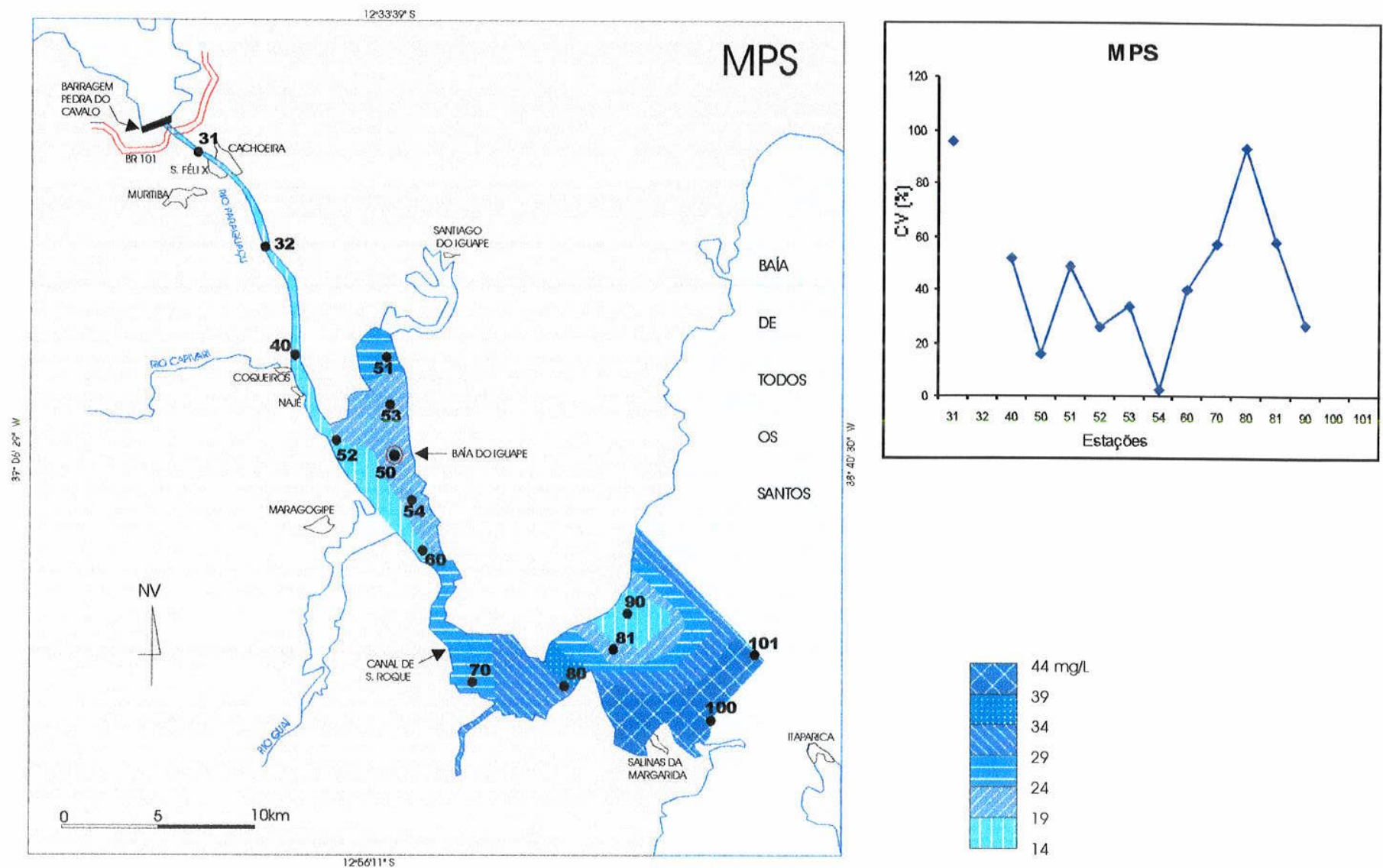

FIGURA 35 - DISTRIBUIÇÃO DO MATERIAL PARTICULADO EM SUSPENSÃO (MPS) NA REGIÃO ESTUARINA DO RIO PARAGUAÇU.
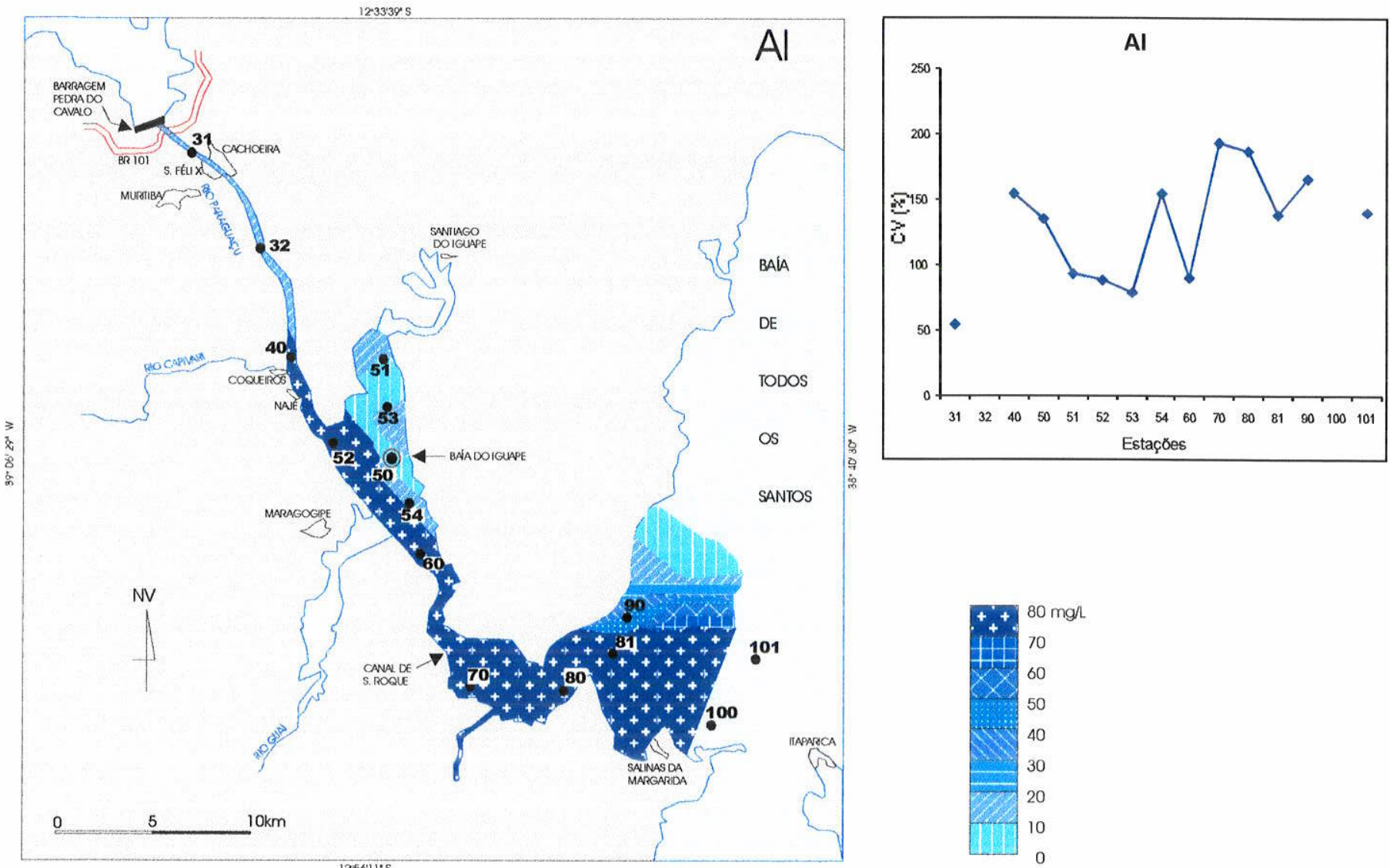

FIGURA 36 - DISTRIBUIÇÃ̃O DO ALUMÍNIO NO MATERIAL PARTICULADO EM SUSPENSÃO NA REGIÃO ESTUARINADO RIO PARAGUAÇU. 

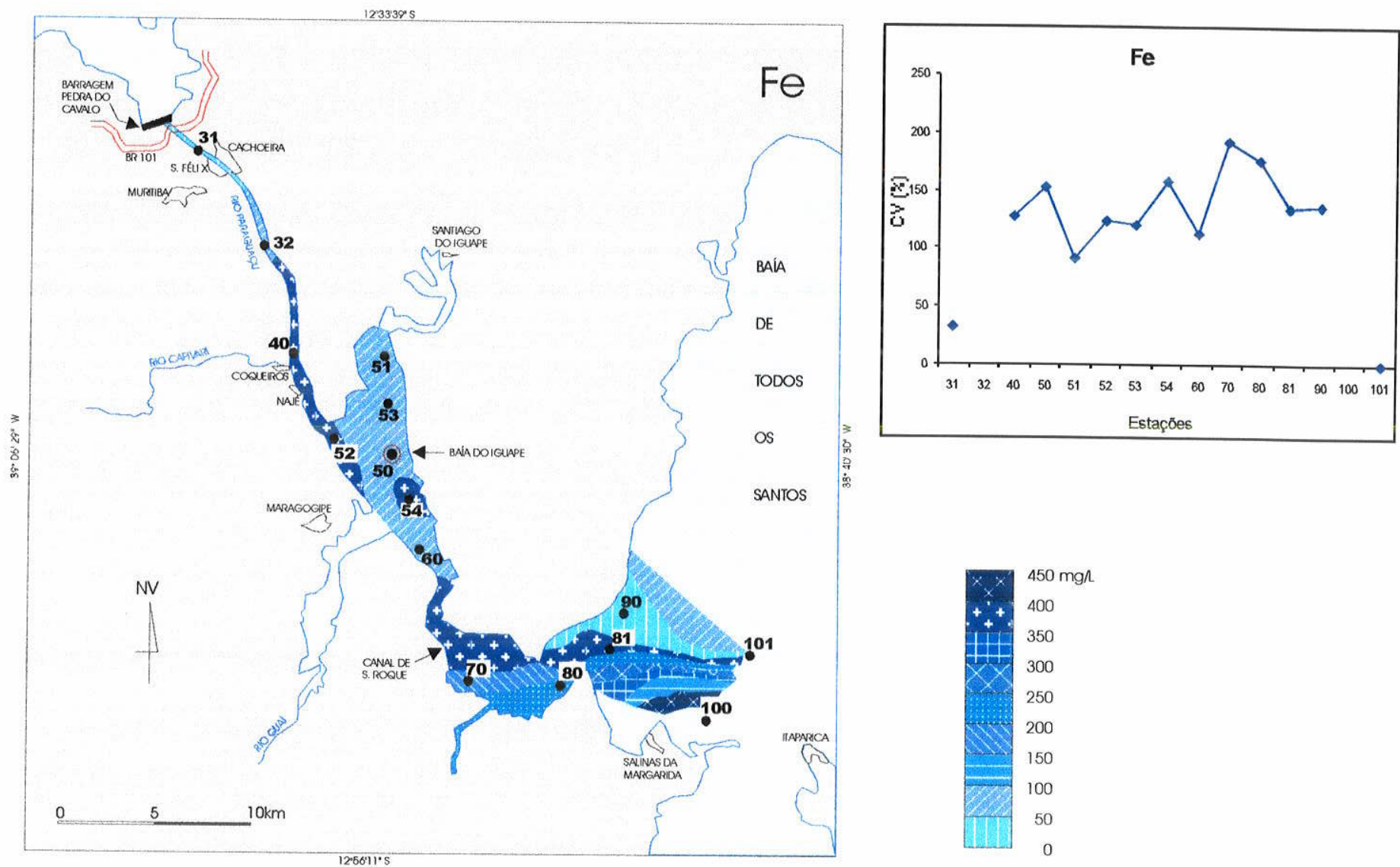

\section{FIGURA 37 - DISTRIBUIÇÃO DO FERRO NO MATERIAL PARTICULADO EM SUSPENSÃO NA REGIÃO ESTUARINA DO RIO PARAGUAÇU.}
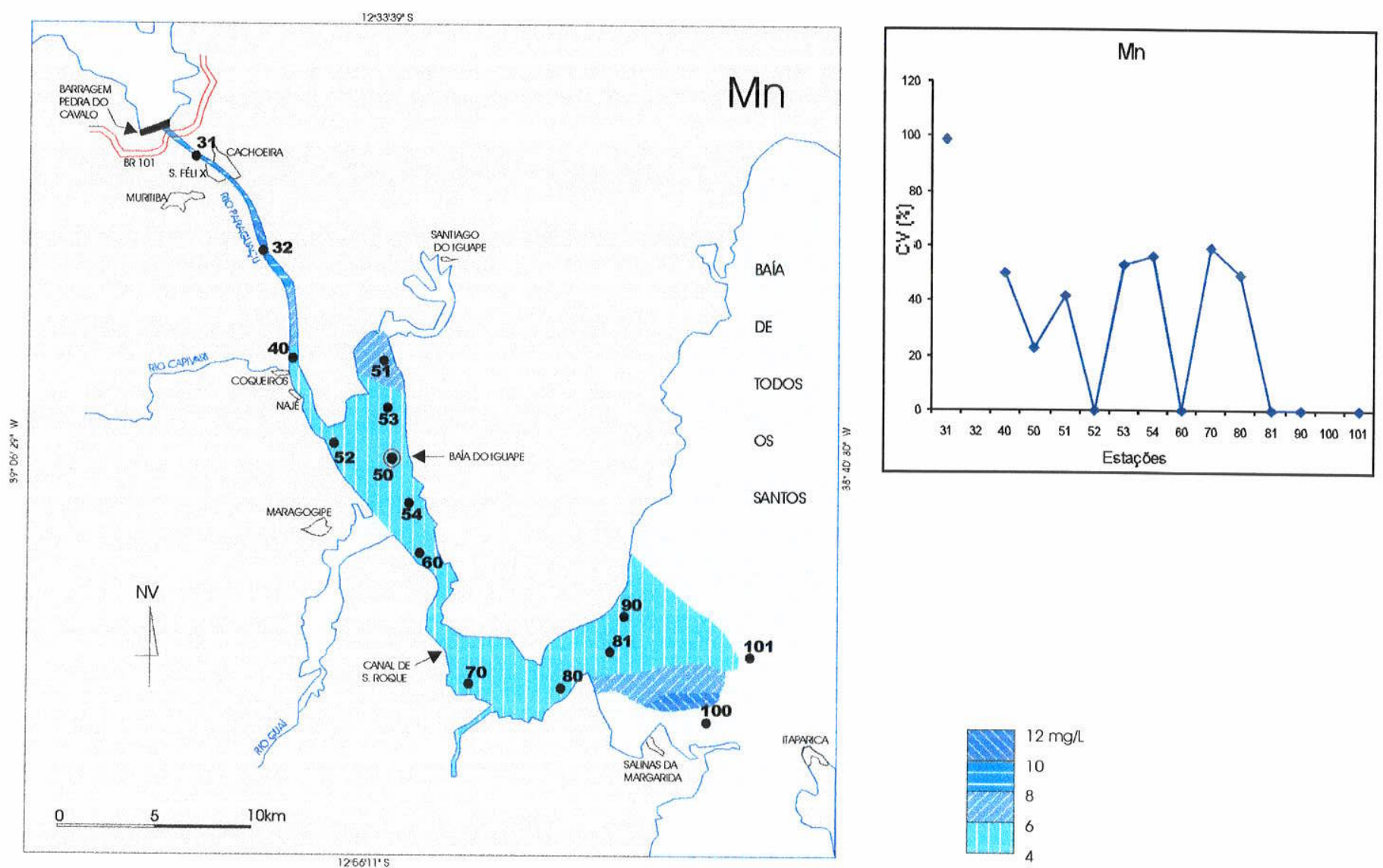

FIGURA 38 - DISTRIBUIÇÃO DO MANGANÊS NO MATERIAL PARTICULADO EM SUSPENSÃO NA REGIÃO ESTUARINA DO RIO PARAGUAÇU. 

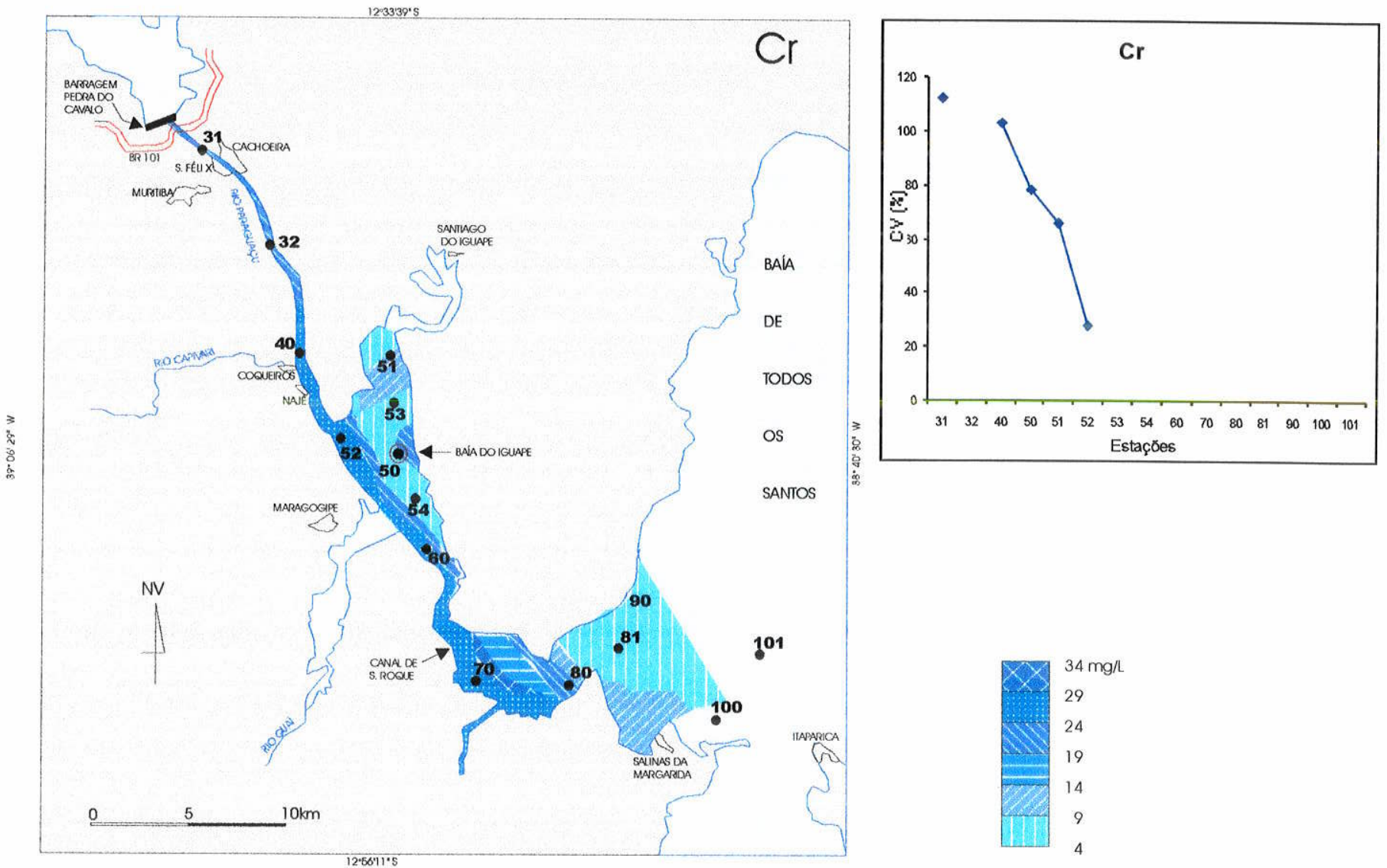

FIGURA 39 - DISTRIBUIÇÃO DO CROMO NO MATERIAL PARTICULADO EM SUSPENSÃO NAREGIÃO ESTUARINADO RIO PARAGUAÇU.
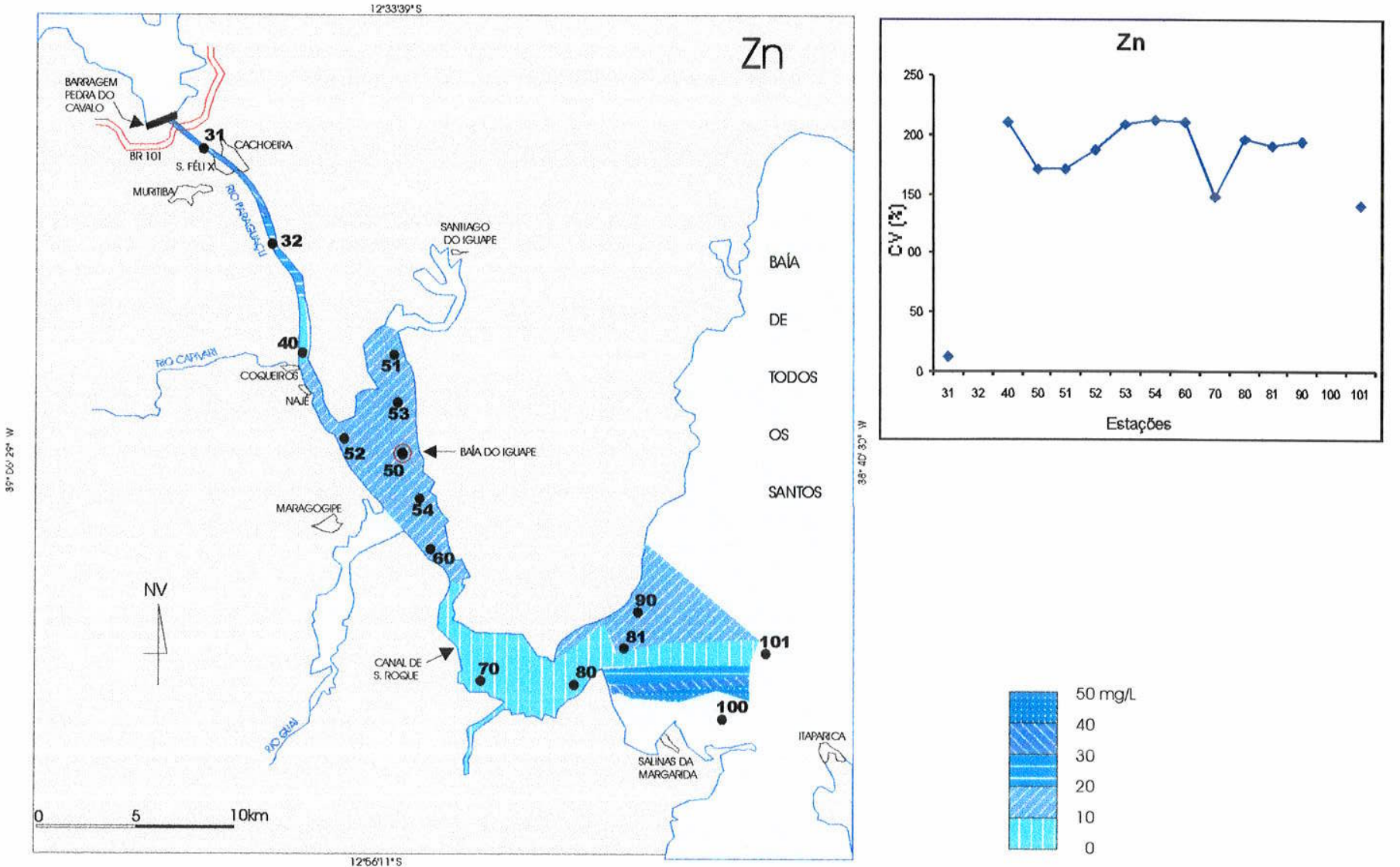

FIGURA 40 - DISTRIBUIÇÃO DO ZINCO NO MATERIAL PARTICULADO EM SUSPENSÃO NA REGIÃOESTUARINADO RIO PARAGUAÇU. 


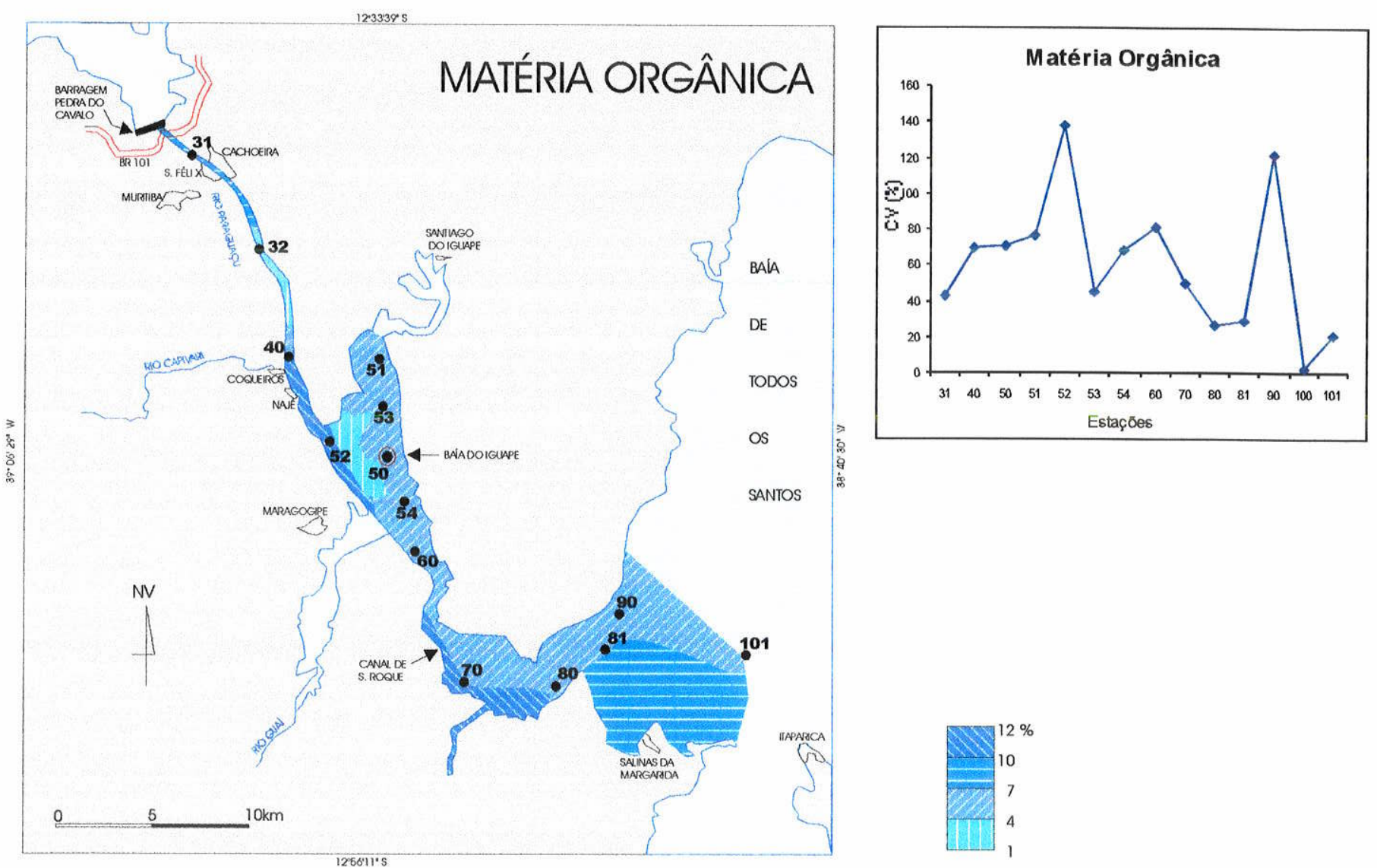

FIGURA 41 - DISTRIBUIÇÃO DA MATÉRIA ORGÂNICA NO SEDIMENTO DE FUNDO NA REGIÃO ESTUARINADO RIOPARAGUAÇU.
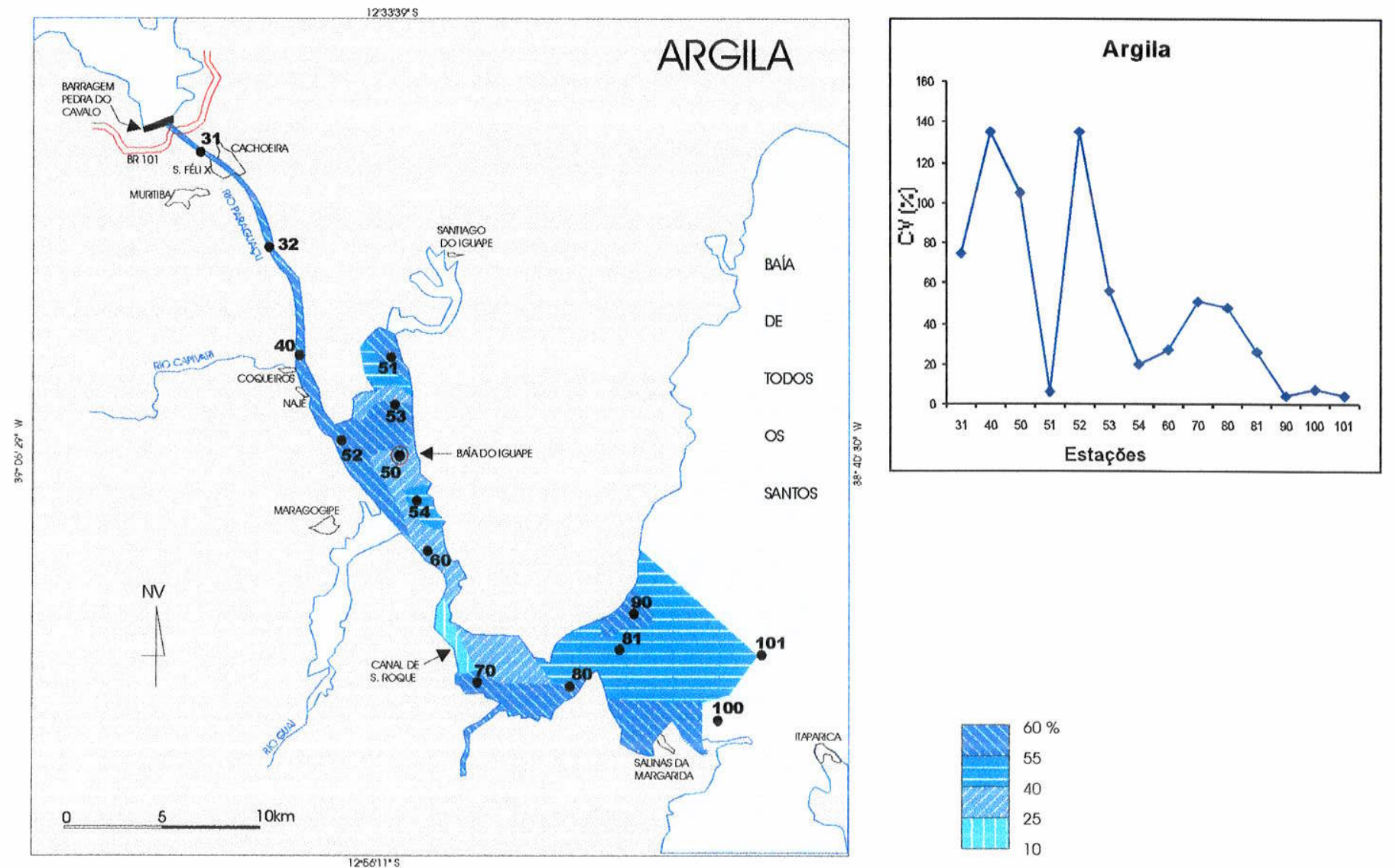

FIGURA 42 - DISTRIBUIÇÃO DA ARGILA NO SEDIMENTO DE FUNDO NA REGIÃO ESTUARINA DORIOPARAGUAÇU. 

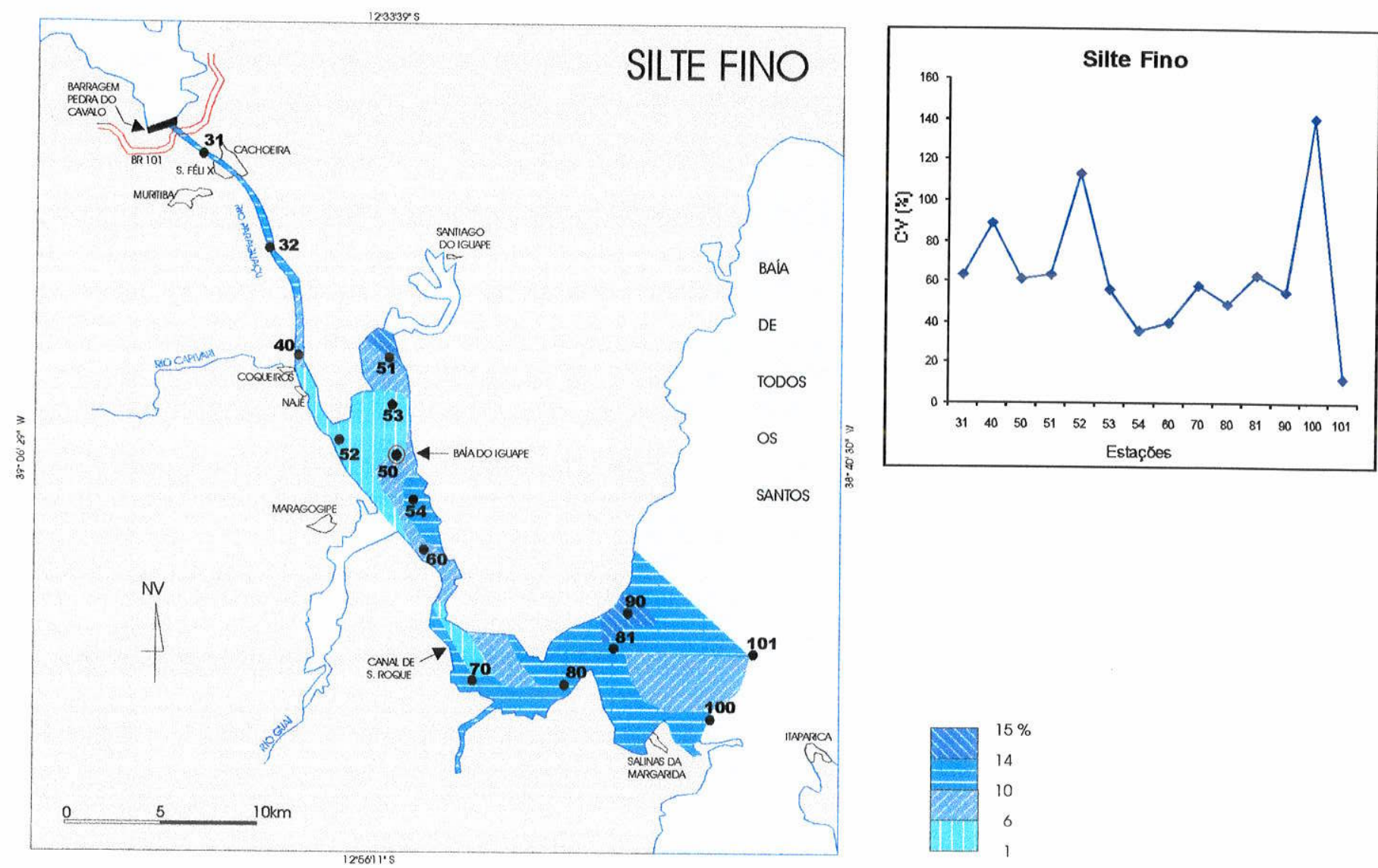

FIGURA 43 - DISTRIBUIÇÃO DO SILTE FINO NO SEDIMENTO DE FUNDO NA REGIÃO ESTUARINA DORIO PARAGUAÇU.
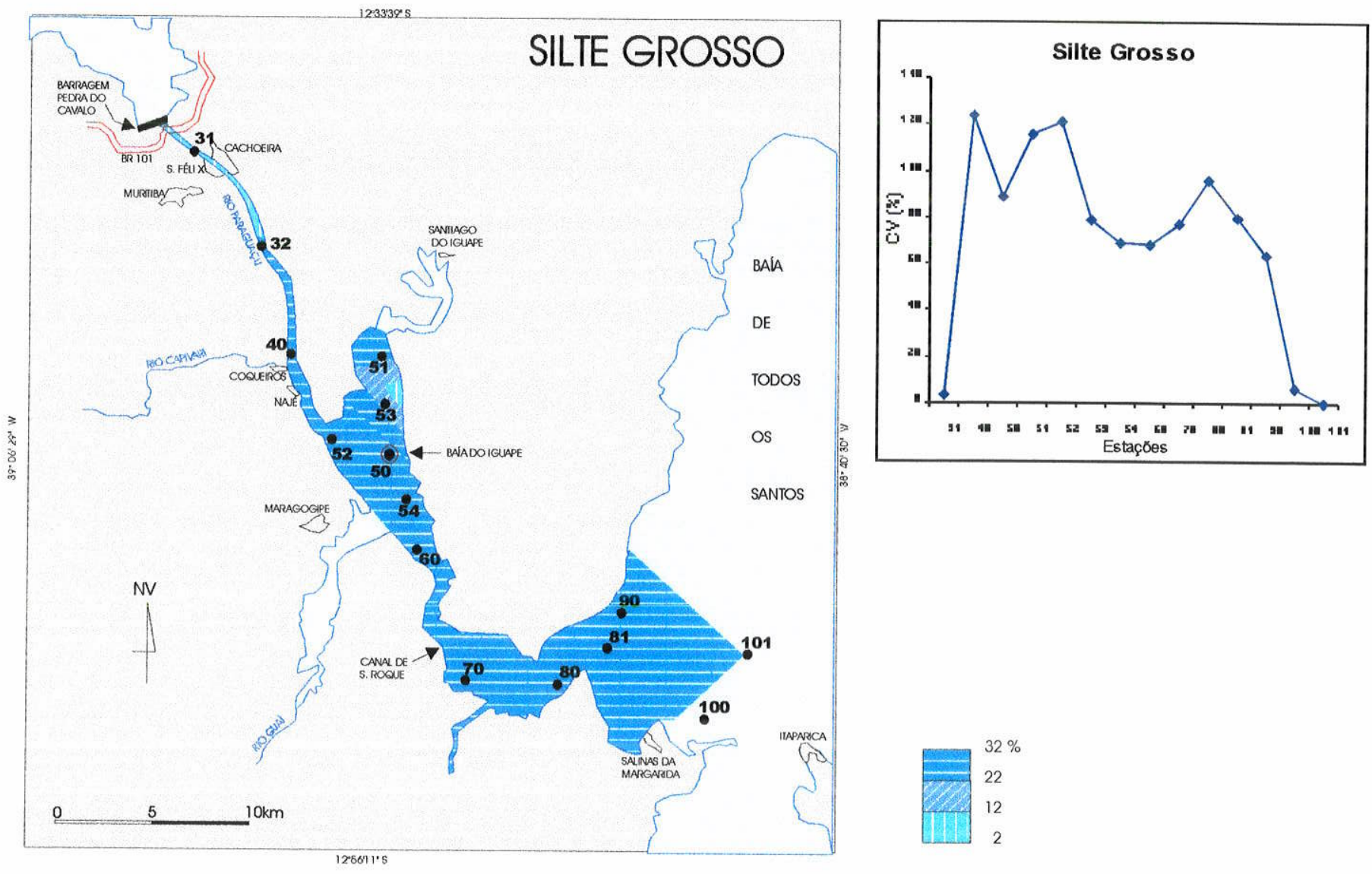

FIGURA 44 - DISTRIBUIÇÃO DO SILTE GROSSO NO SEDIMENTO DE FUNDO NA REGIÃO ESTUARINADO RIO PARAGUAÇU. 

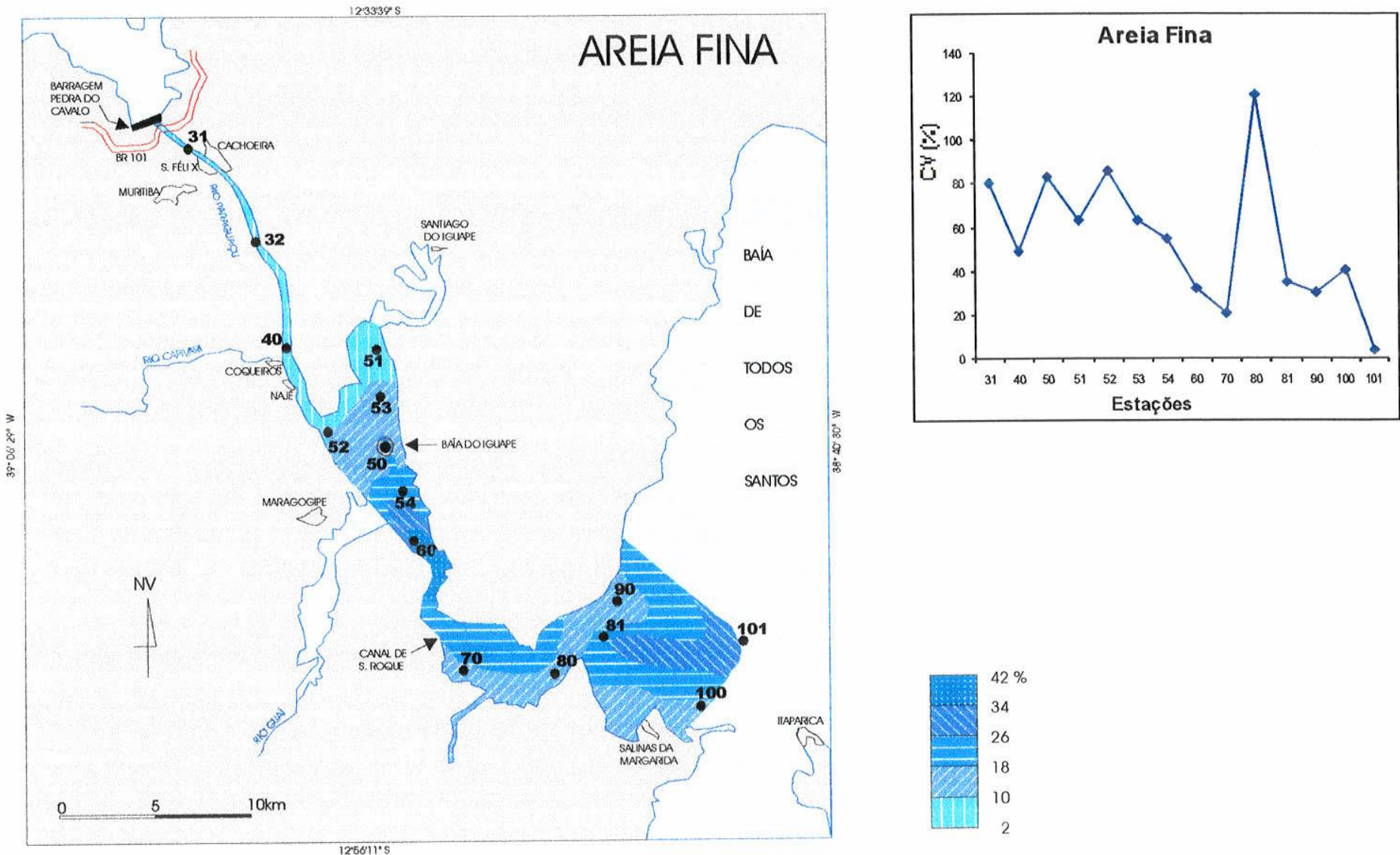

FIGURA 45 - DISTRIBUIÇÃO DA AREIA FINA NO SEDIMENTO DE FUNDO NA REGIÃO ESTUARINA DO RIO PARAGUAÇU.
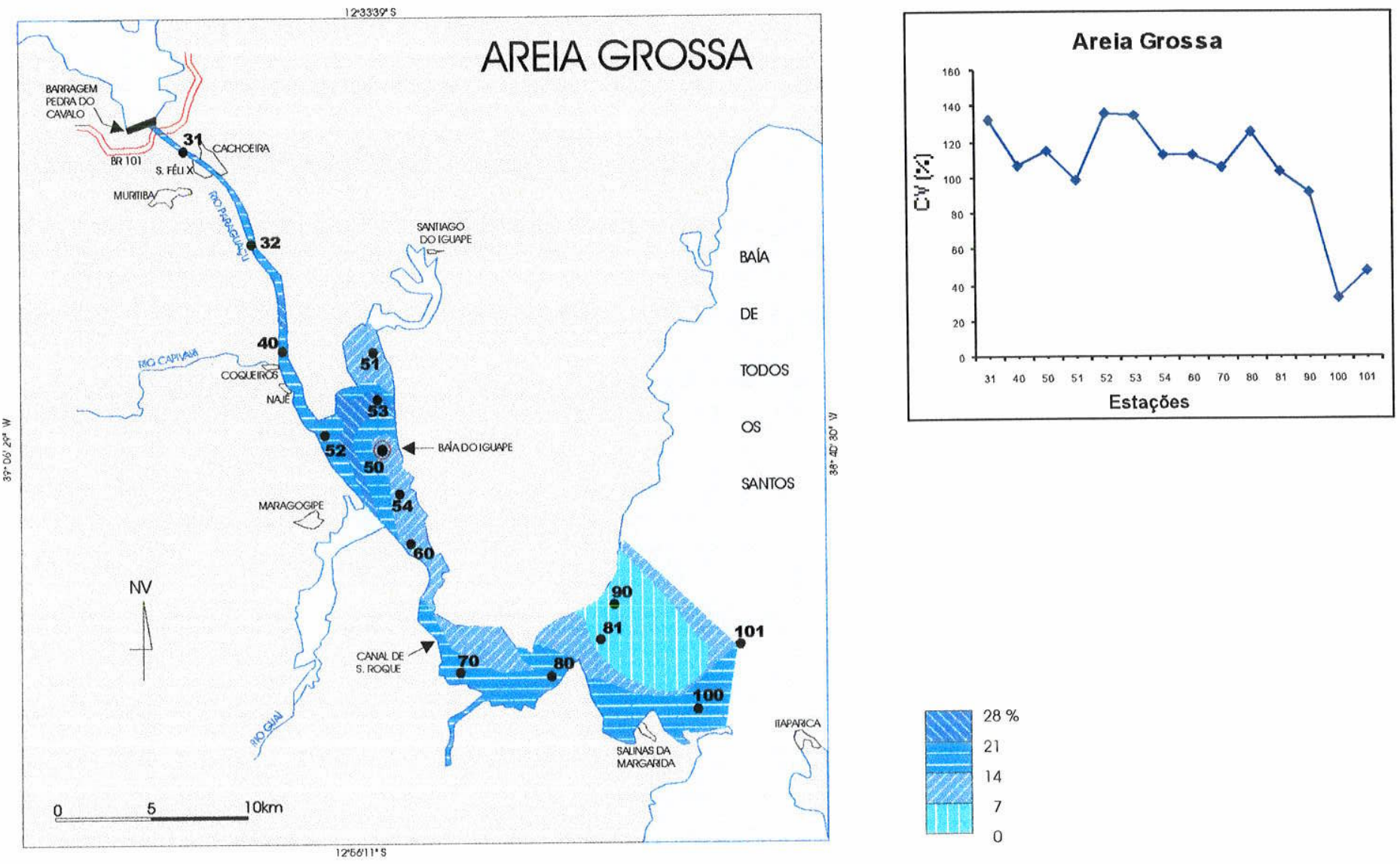

FIGURA 46- DISTRIBUIÇÃO DA AREIA GROSSA NO SEDIMENTO DE FUNDO NA REGIÃO ESTUARINA DO RIO PARAGUAÇU. 

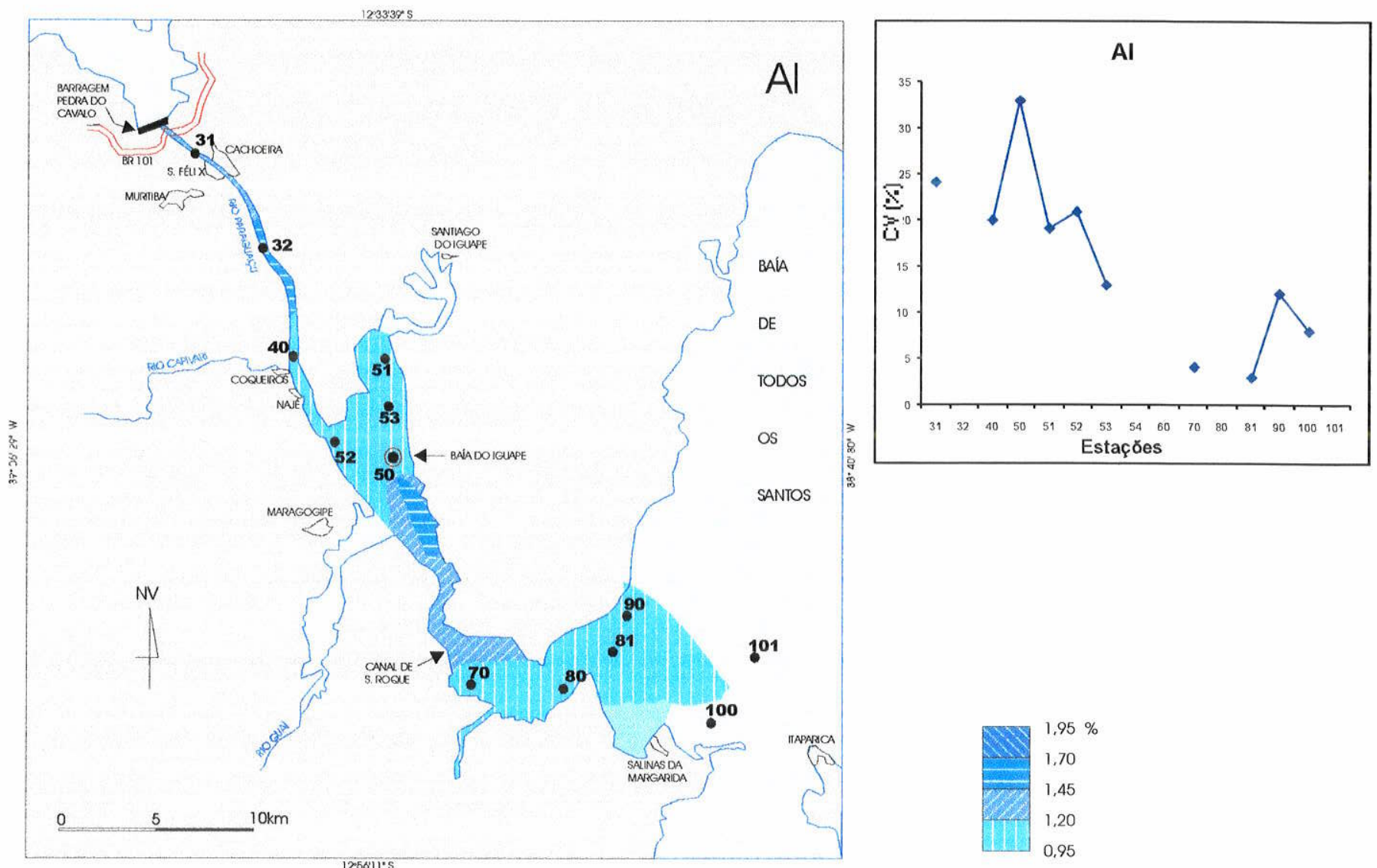

FIGURA 47 - DISTRIBUIÇÃO DO ALUMÍNIO NO SEDIMENTO DE FUNDO NA REGIÃO ESTUARINA DO RIO PARAGUAÇU.
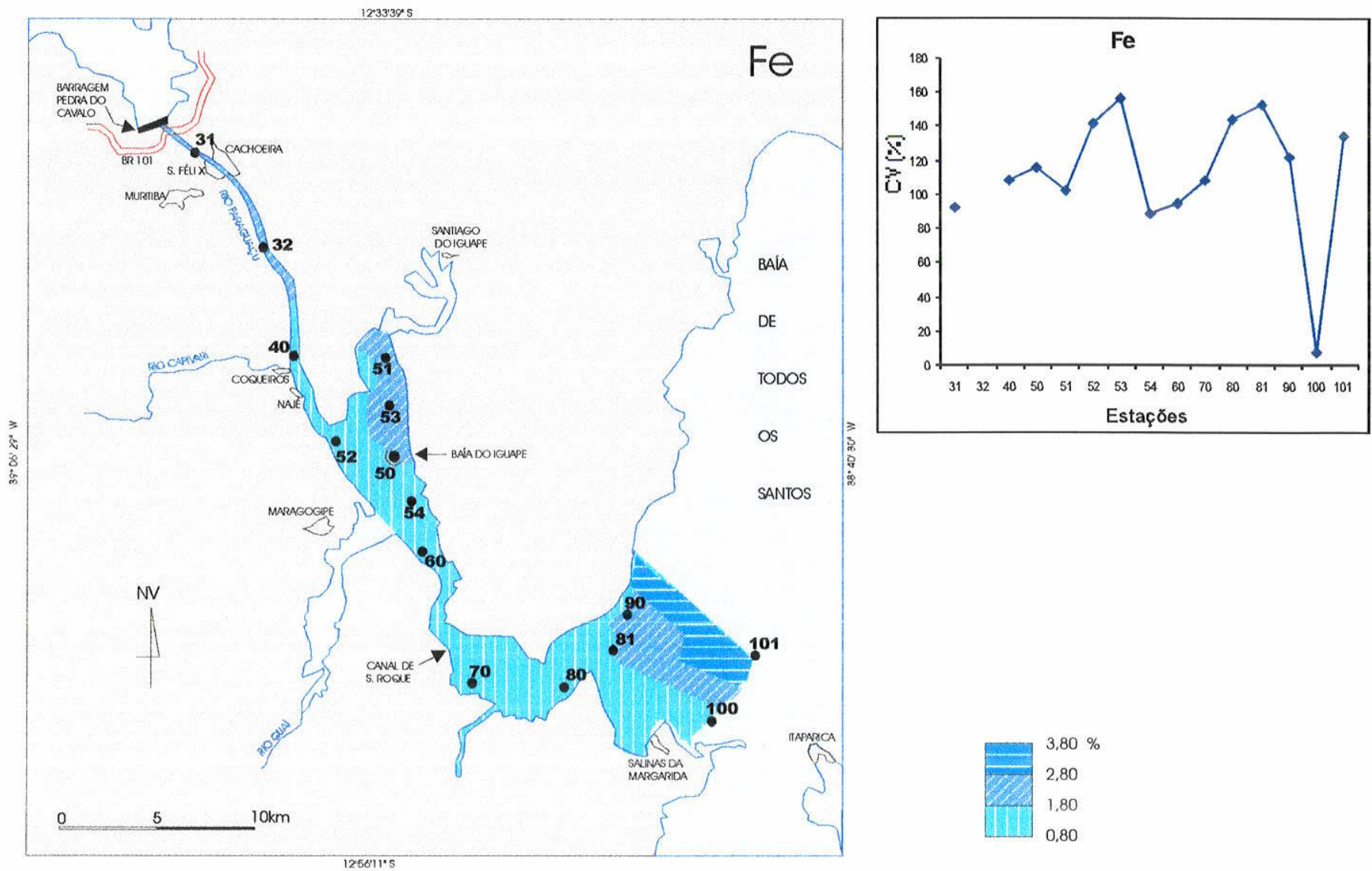

FIGURA 48 - DISTRIBUIÇÃO DO FERRO NO SEDIMENTO DE FUNDO NA REGIÃO ESTUARINA DO RIO PARAGUAÇU. 

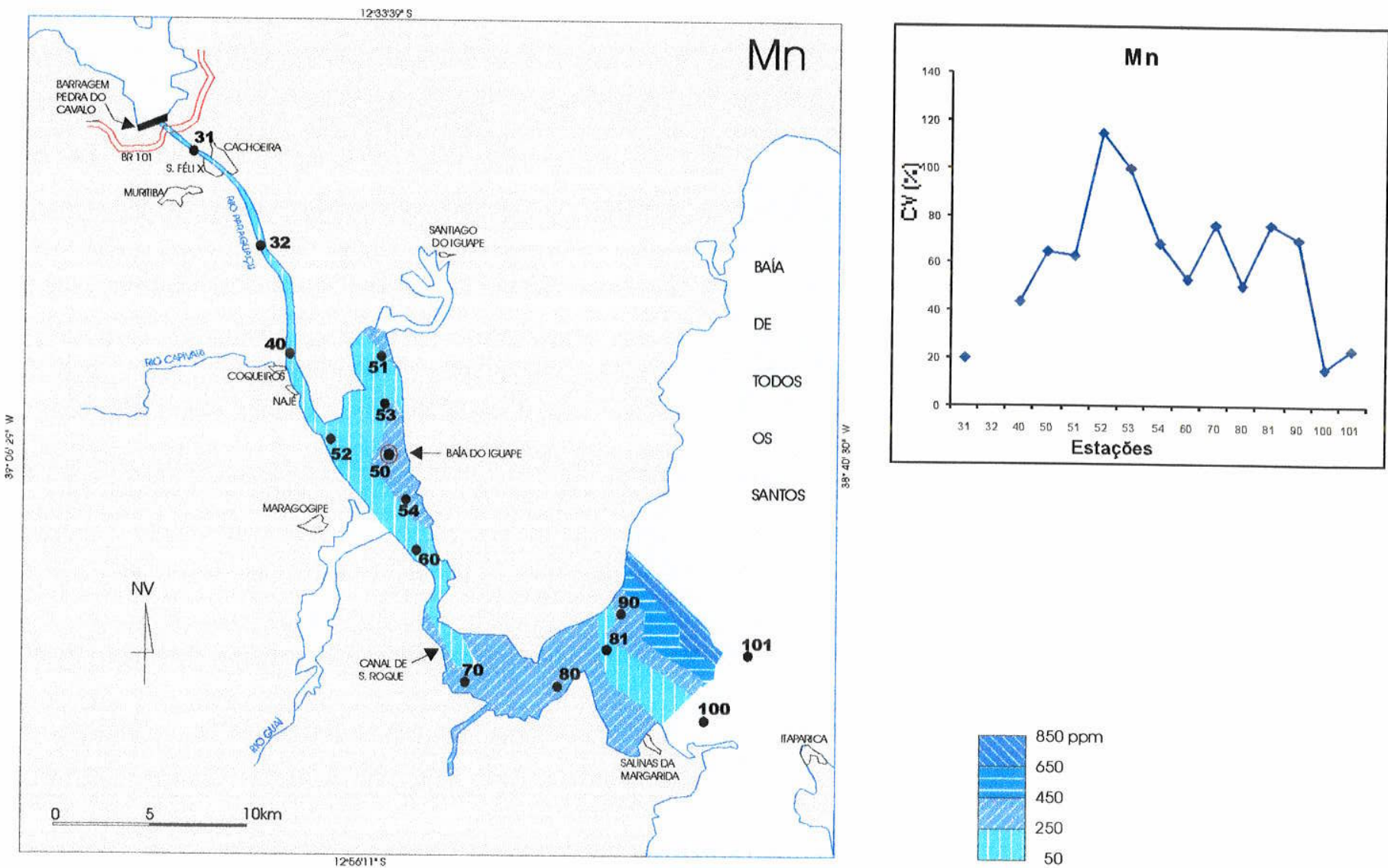

FIGURA 49 - DISTRIBUIÇÃO DO MANGANÊS NO SEDIMENTO DE FUNDO NA REGIÃO ESTUARINA DORIOPARAGUAÇU.
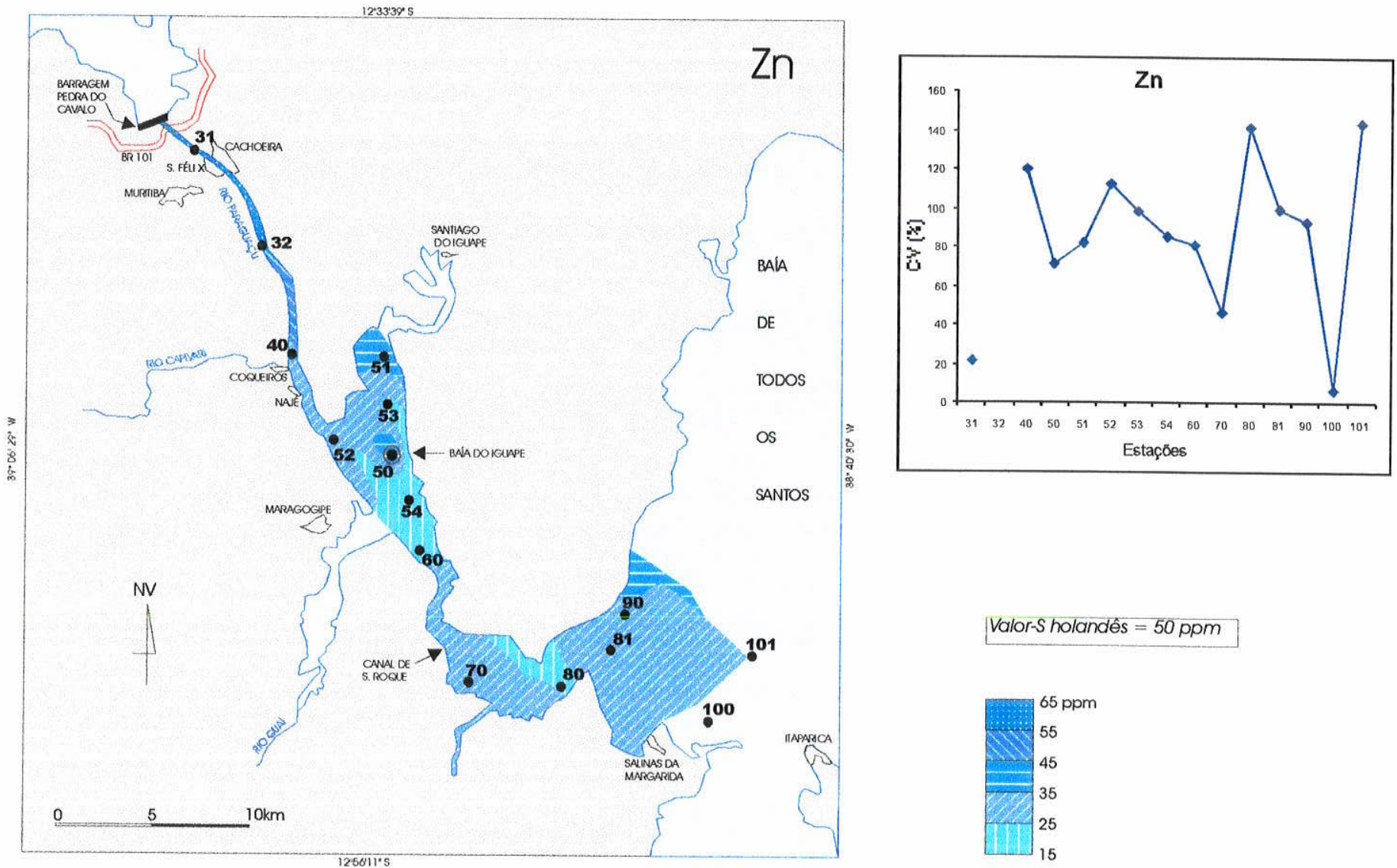

Valor-s holandês $=50 \mathrm{ppm}$

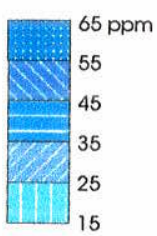




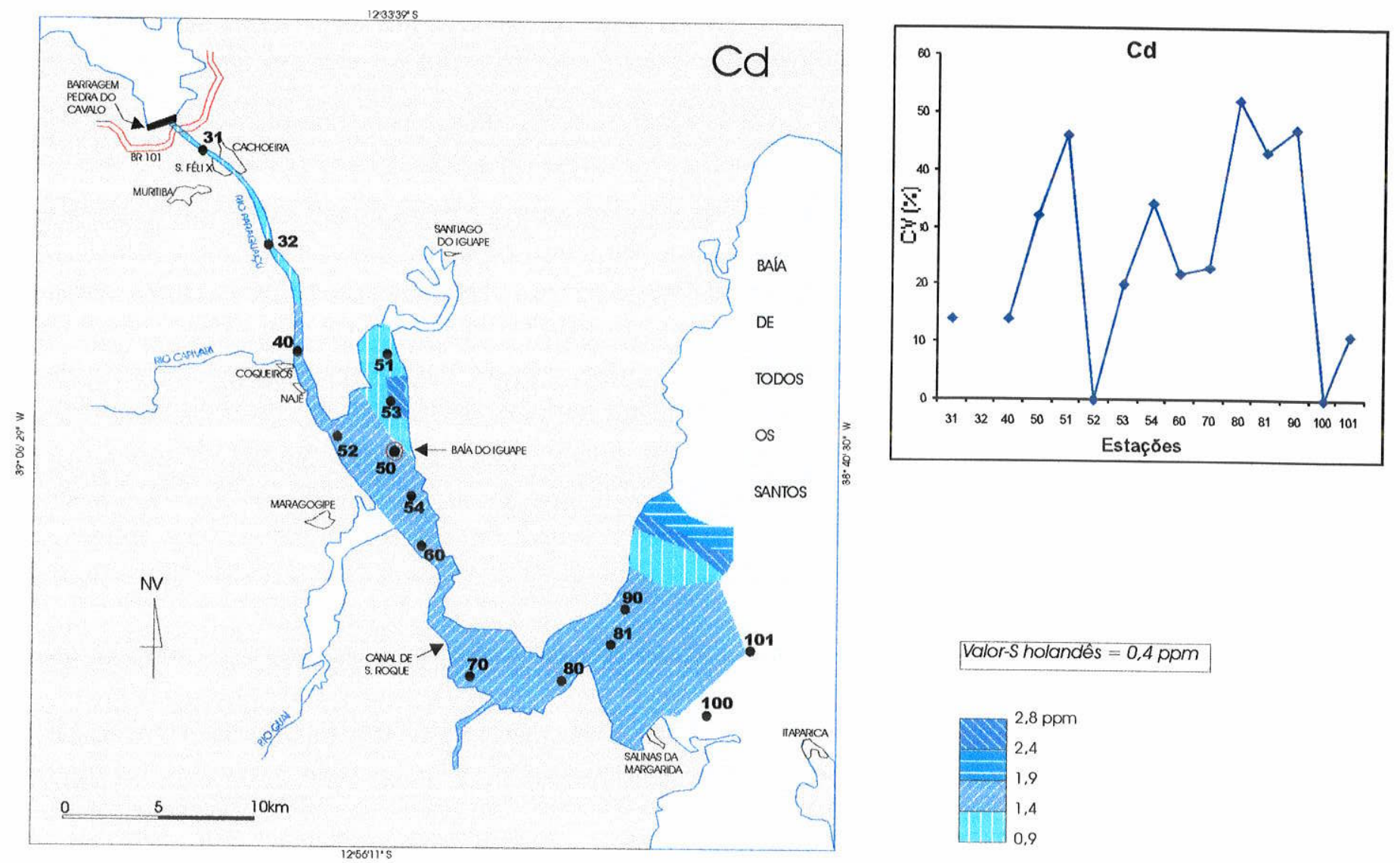

FIGURA 51 - DISTRIBUIÇÃO DO CÁDMIO NO SEDIMENTO DE FUNDO NA REGIÃO ESTUARINA DO RIO PARAGUAÇU.
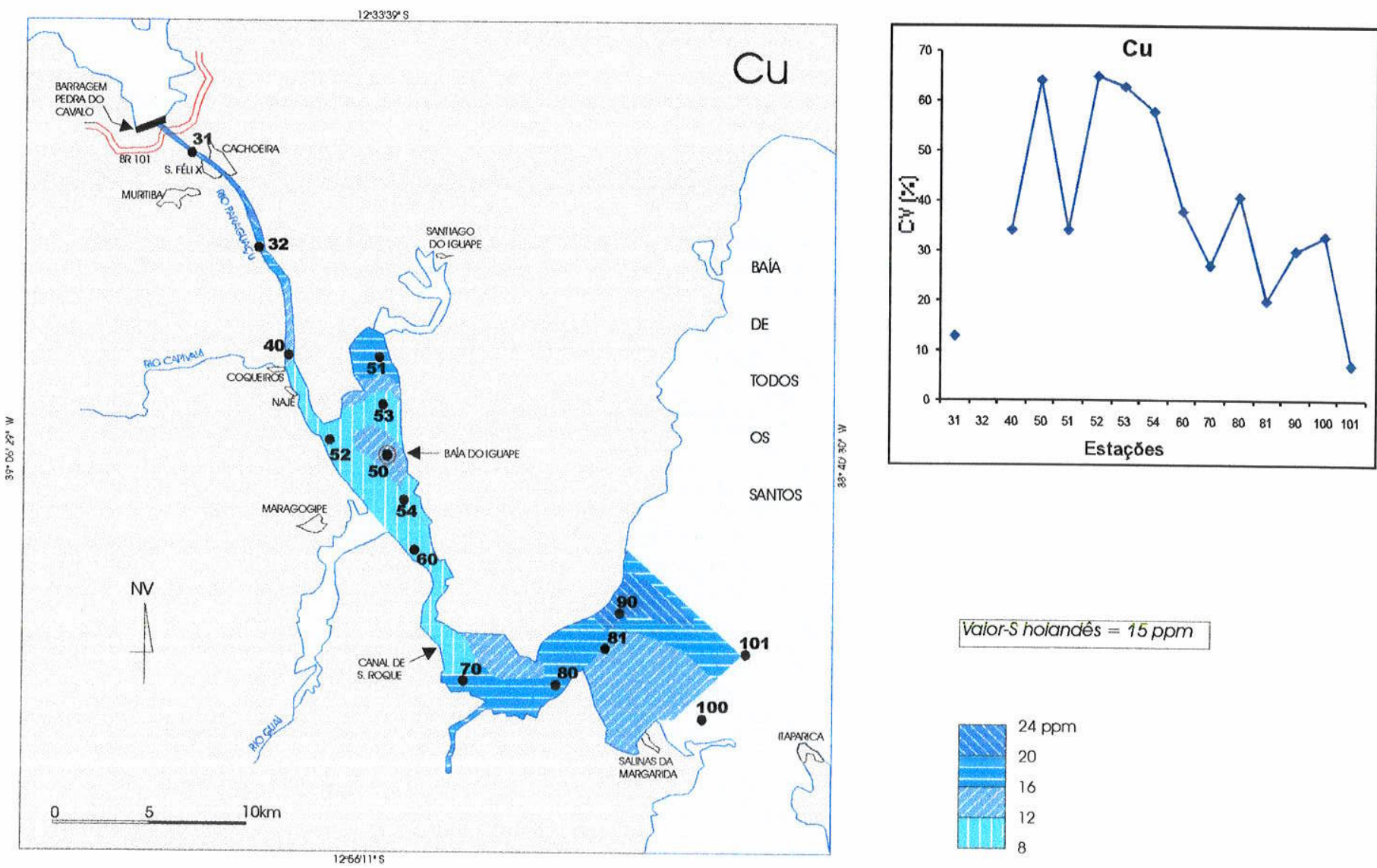

Vaior-S holandês $=15 \mathrm{ppm}$

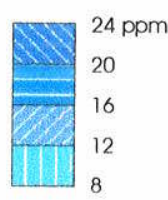

FIGURA 52 - DISTRIBUIÇÃO DO COBRE NO SEDIMENTO DE FUNDO NA REGIÃO ESTUARINA DO RIO PARAGUAÇU. 

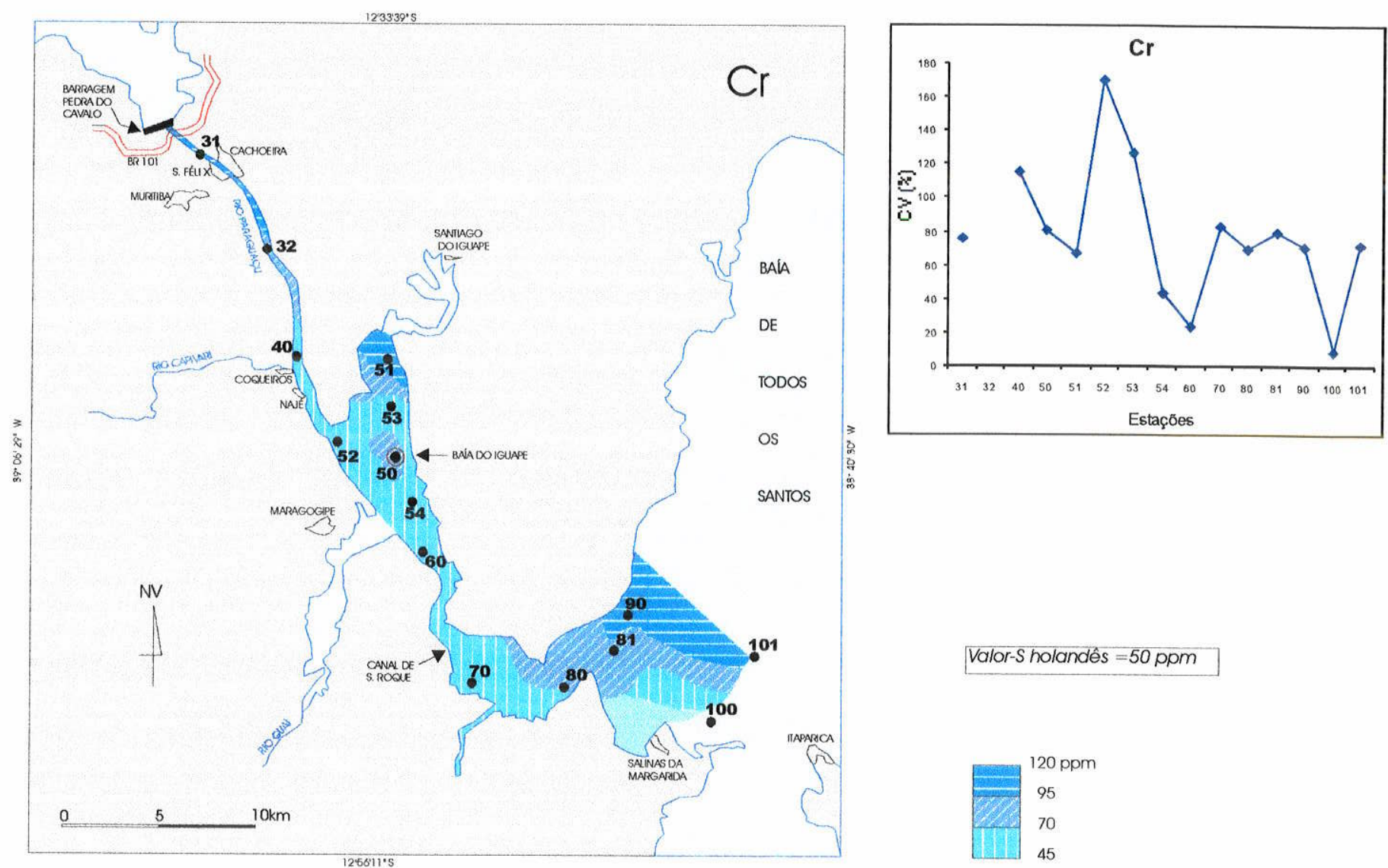

Valor-S holandês $=50 \mathrm{ppm}$

FIGURA 53 - DISTRIBUIÇÃO DO CROMO NO SEDIMENTO DE FUNDO NA REGIÃO ESTUARINA DO RIOPARAGUAÇU.
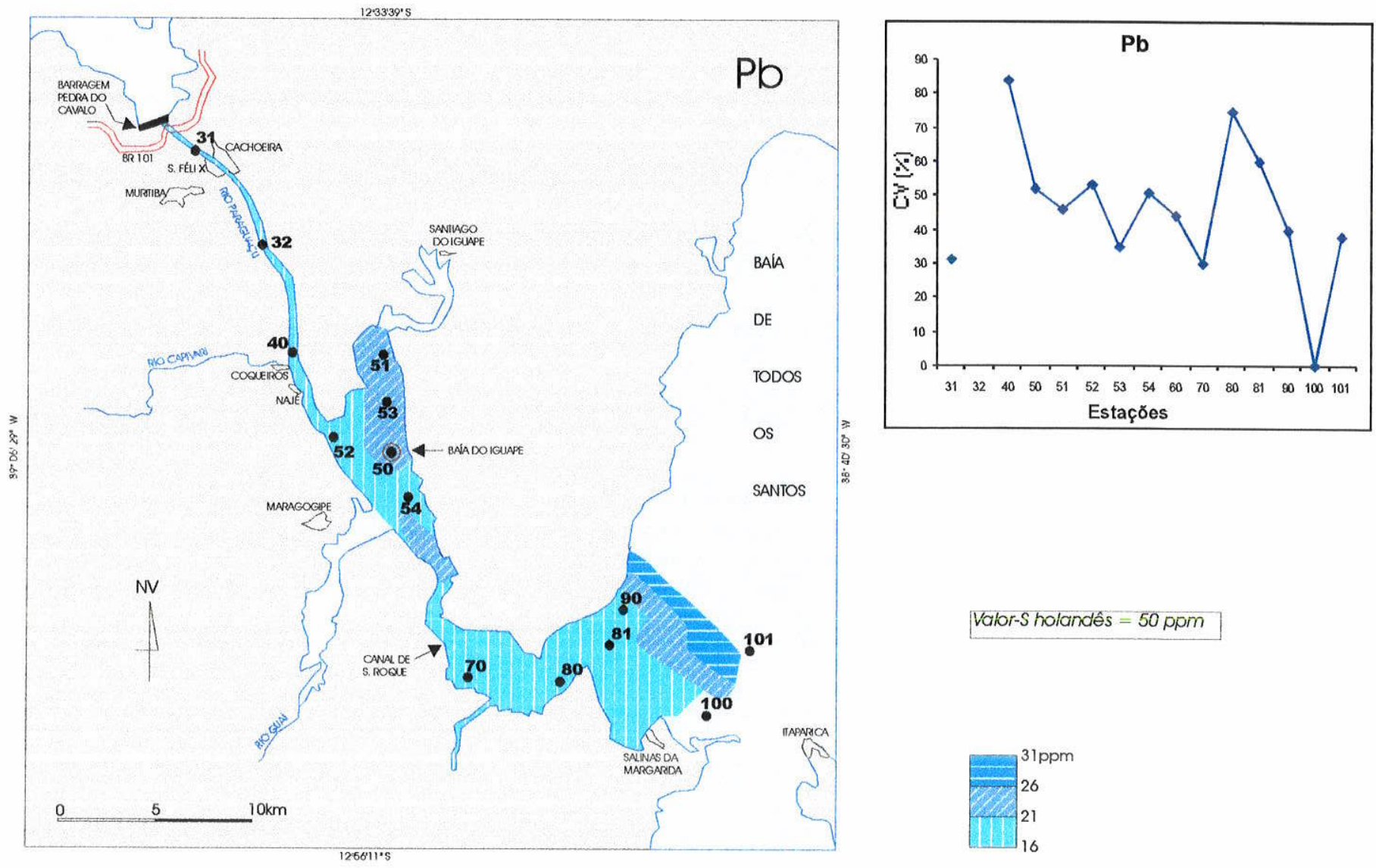

FIGURA 54 - DISTRIBUIÇÃO DO CHUMBO NO SEDIMENTO DE FUNDO NA REGIÃO ESTUARINA DO RIO PARAGUAÇU. 


\section{CAPÍTULO 5 - CONCLUSÕES}




\section{CONCLUSÕES}

A barragem de Pedra do Cavalo estabeleceu uma ruptura no trecho final da bacia do rio Paraguaçu, diminuindo a influência do aporte de água doce para sua região estuarina. Como conseqüência, efeitos significativos para as condições ecológicas locais se destacam na avaliação dos resultados obtidos neste trabalho e, conduzem a várias conclusões que, embora digam respeito a um sistema estuarino com represamento do rio, podem ser aplicadas a outros estuários, especialmente se similaridades são identificadas.

A regulação do caudal, conduz a um ecossistema estuarino com menor faixa de variação da salinidade e, permite que as correntes de marés transfiram, com maior intensidade, os impactos ambientais da baia de Todos os Santos onde estão localizadas fábricas, refinarias, terminal de petróleo, estaleiros, portos e pontos de lançamentos de esgotos urbanos da cidade de Salvador.

Durante o estudo, foi delineada proposta metodológica para o monitoramento das tendências de poluição a nível de metais pesados. A avaliação destas tendências pode se estender por décadas $e$, a confiança e comparação de dados usando procedimento adequado e similar, é de importância vital. A metodologia desenvolvida neste trabalho, pode ser considerada apropriada para monitorar as tendências espaciais e temporais relacionadas as causas antrópicas.

A circulação do material particulado em suspensão e a acumulação de metais nos sedimentos de fundo, variam de modo considerável com a dinâmica das marés. Os metais parecem ser carreados dos sedimentos de fundo os quais, atuam como reservatório semi-permanente e acumulador de metais pesados no ecossistema. $\mathrm{Na}$ maré de quadratura (marés de luas quarto crescente e minguante), existe uma menor remobilização dos metais nos sedimentos de fundo sendo provável que, nestas condições, a sua composição química parece ser mais representativa para a avaliação da qualidade ambiental, com respeito a presença de metais. Durante a maré de maior amplitude, maré de sizígia (luas nova e cheia), inversamente, o material particulado em suspensão mostra melhor as variações na composição dos metais associados. 
Portanto, na avaliação das características médias do material particulado em suspensão recomenda-se a amostragem durante a maré de sizigia, enquanto do sedimento de fundo, na maré de quadratura. O sistema não mostra modificações significantes, conforme as subidas ou descidas diárias do nivel da maré.

Para a investigar fluxos de poluentes e niveis de diluição, sugere-se monitorar o material particulado em suspensão e metais associados, nos periodos de maior estiagem, durante as marés de sizígia. Este tipo de maré promove, também, uma maior ressuspensão das partículas finas do sedimento de fundo e sua redistribuição ao longo da coluna d'água.

A avaliação da distribuição espacial e temporal da concentração dos metais pesados e, o nivel de contaminação nos sedimentos tem como diagnóstico que, a presença dos metais é influenciada pelos efluentes locais e pela circulação de água no sistema estuarino. Os valores mais altos de $\mathrm{Cu}, \mathrm{Zn}, \mathrm{Cr}$ e Fe, são encontrados próximos as cidades de Cachoeira e São Félix, enquanto na foz do rio, na baía de Todos os Santos, isto acontece para $\mathrm{Cu}, \mathrm{Cd}, \mathrm{Pb}, \mathrm{Zn}, \mathrm{Cr}$ e Fe. Estes resultados sinalizam a influência das ações antrópicas nestas áreas.

Embora a região estuarina encontre-se ainda em estado incipiente de industrialização, as condições de saneamento das cidades vizinhas são críticas e, conduzem a contaminação ambiental de metais pesados. Na margem direita do Canal de São Roque, a presença do estaleiro de plataformas submarinas, destinadas a perfuração de poços de petróleo, pode contribuir também como fonte de metais.

O fato de que, a baia de Todos os Santos é o maior receptor de efluentes do complexo estudado pode resultar, a longo e médio prazo, em aumento progressivo da concentração de metais na área estuarina.

As variações nos niveis dos metais nas diferentes fases do sedimento de fundo, estudadas por especiação química, mostram mudanças químicas no ambiente de sedimentação. $\mathrm{Zn}$ e $\mathrm{Pb}$ podem ser incorporados por processos biológicos devido a essas mudanças. $\mathrm{Cu}$ e $\mathrm{Cr}$, com alta associação na fase residual, não estão biodisponiveis. 
Com base nos valores limites para metais em solo/sedimentos aquáticos estabelecidos pelos padrão holandês (S-value) e, na ausência de valores padrões brasileiros, diante dos resultados médios obtidos neste trabalho pode-se concluir que, de modo geral, os impactos dos metais $\mathrm{Cu}, \mathrm{Cd}, \mathrm{Pb}, \mathrm{Zn}$ e $\mathrm{Cr}$ nos sedimentos da região estuarina são moderados $e$, indicam a necessidade de um monitoramento contínuo da região. Na última fase investigada (Setembro / 95), os teores de $\mathrm{Cr}$ estão acima dos valores limites ( 1 - value) que exigem intervenção ou remediação.

Os valores médios, registrados para o ano de 1995, servirão como parâmetros para acompanhar as mudanças produzidas devido a lançamentos, oriundos de atividades industriais e centros urbanos na região ou ainda, para estudos que venham a ser desenvolvidos após a implantação de medidas mitigadoras.

A metodologia utilizada pode também, ser considerada adequada para o monitoramento de zonas estuarinas similares, em ambientes tropicais, orientada para acompanhar a acumulação de metais, considerando as flutuações sazonais e diferentes condições de marés.

\subsection{SÍNTESE E RECOMENDAÇÕES}

A região estuarina do rio Paraguaçu apresenta-se de modo geral, vulnerável às atividades antrópicas, devido principalmente aos seguintes fatores:

a) Características geoambientais do sistema fluvial, onde predominam o clima semi-árido, solos frágeis e irregularidade climática das estiagens;

b) Atividades antrópicas presentes, como lançamento de esgotos e lixo diretamente nos cursos d'água, atividades industriais e portuárias na baía de Todos os Santos;

c) Represamento do rio controlando o aporte de água fluvial para o sistema. 
A adoção de medidas preventivas para evitar ou reduzir os impactos ambientais na regiäo estuarina do rio Paraguaçu é imprescindivel. Sugere-se :

- Implantação de sistema de monitoramento permanente e sistemático da qualidade das águas e dos sedimentos;

- Controle do lançamento de lixo e detritos nas margens do rio;

- Implantação de redes de esgotamento sanitários nas sedes municipais e de sistemas de tratamento de esgotos;

- Cadastramento das fontes de lançamento de efluentes nos mananciais.

Diante destas considerações, fica evidente que, no caso de maiores descargas defluentes da barragem, devem ser questionados alguns aspectos com respeito ao aporte do material particulado em suspensão e metais associados do rio Paraguaçu, oriundos do trecho à montante do reservatório de Pedra do Cavalo. Deste modo, os resultados deste trabalho se remetem a uma situação particular mas, poderão servir como base para estudos posteriores, em diferentes condições hidrodinâmicas. 
REFERÊNCIAS BIBLIOGRÁFICAS 


\section{REFERENCIAS BIBLIOGRÁFICAS}

1. AlLLON, M. P. Caracterização petroquímica e do metamorfismo das rochas granuliticas da região de Cachoeira-São Félix-Cruz das Almas, Bahia. Salvador, 1992, 165 p. Dissertação (Mestrado em Geologia) Instituto de Geociências, Universidade Federal da Bahia. 1992. Or. BARBOSA, Johildo F.S.

2. ALLOWAY, B.J. Heavy metals in soil. Glasgow and London : Blackie and Son Ltd., 1990. $340 \mathrm{p}$.

3. American Public Health Association. American Water Works Association and Pollution Control Federation. Standard methods for examination of water and wastewater. Washington, 1995, 19 ed. 1457 p.

4. ASTON, S.R.; CHESTER, R. The influence of suspended particles on the precipitation of iron in natural waters. Estuarine Coastal Marine Sciences, London, v.1, p. 25-231, 1973.

5. BAHIA Centro de Pesquisas e Desenvolvimento CEPED Estudos dos aspectos físicos e biológicos na área de influência da barragem de Pedra do Cavalo. Projeto Básico. Relatório Final. Salvador, 1980, 170p.

6. ; Centro de Recursos Ambientais - CRA. Avaliação da qualidade dos recursos ambientais. Salvador, 1982.

7. ; Secretaria de Recursos Hídricos Saneamento e Habitação, Superintendência de Recursos Hídricos - SSRH / Companhia de Desenvolvimento do Vale do Paraguaçu - DESENVALE. Aproveitamento múltiplo Pedra do Cavalo - Impactos ambientais: Publicação Sintese. Salvador, $1984.49 \mathrm{p}$. 
8. Secretaria do Planejamento, Ciência e Tecnologia. Centro de Estatística e Informações (CEI) Qualidade ambiental na Bahia - recôncavo e regiões limitrofes. Salvador, $1987.48 \mathrm{p}$.

9.

Secretaria do Planejamento, Ciência e Tecnologia. Centro de Estatística e Informações (CEI) Informações básicas dos municípios baianos. Regiões do Recôncavo sul. 1994. 92 p. Inédito.

10.

Secretaria de Recursos Hídricos Saneamento e Habitação, Superintendência de Recursos Hídricos. Plano Diretor de Recursos Hídricos. Bacia do Médio e Baixo Paraguaçu PDRH-BMBP. Salvador, 1996. v. 4, documento síntese. 200 p.

11. BAISH, P.R.M.; NIENCHESKI, L.F.H.; LACERDA, L.D. Distribution in sediments of the Patos lagoon estuary, Brazil. In : SEELIGER, O.; LACERDA; L.D.; PATCHINEELAM, S. (ed.) Metals in coastal environmental of Latin America. Berlin, New York : Springer. 1988, 297p. p. 59-63.

12. BARCELOS, C. LACERDA, L.D. Cadmium behavior in a tropical estuary . In : INTERNATIONAL CONFERENCE HEAVY METALS IN THE ENVIRONMENT, 1993, Toronto. Proceeding... Edinburgh: CEP Consultants, 1993. 2v. v.1. p.169-172.

13. BARUA, D.K. Suspended sediment environment in the estuary of GangesBachmaputra-Mughna river system. Marine Geology, Amsterdan. v. 91, p. 243-253, 1990.

14. BIFANO, C.; MONGOLL.ON J.L.Metallic contaminant profiles in sediment cores from lake Valencia, Venezuela. Environmental Geochemistry and Health. v. 17, p. 115-118, 1995.

15. BRASIL Diretoria de Hidrografia e Navegação da Marinha do Brasil. Tábuas das marés para o ano de 1994. 31 ed.: Rio de Janeiro, 1994. 187 p. 
16. ; Fundação Instituto Brasileiro de Geografia e Estatística - IBGE. Diagnóstico geoambiental e sócio-econômico da bacia do rio Paraguaçu - BA. Rio de Janeiro, 1993. 124 p.

17. ; Fundação Instituto Brasileiro de Geografia e Estatística - IBGE. Baia de Todos os Santos. Folha SD-24-X-A-IV, 1 Ed. 1972, 1 p.

18. Secretaria do Meio Ambiente CETESB. Resolução CONAMA 20/86 Legislação Federal : controle da poluição ambiental. São Paulo, 1994. p. 9-24.

19. Diretoria de Hidrografia e Navegação da Marinha do Brasil. Tábuas das marés para o ano de 1995. 32 ed.: Rio de Janeiro, 1995. 187p.

20. BRICHTA, A.A. Sedimentação na foz do Rio Paraguaçu, Bahia. Salvador, 1977, 115 p. Dissertação (Mestrado em Geologia). Instituto de Geociéncias, Universidade Federal da Bahia. 1977. Or. DI NAPOLI Enrico.

21. BUSSAB, W.O.; MIAZAKI, E.S.; ANDRADE, D.F. Introdução à análise de agrupamentos. SIMPÓSIO NACIONAL DE PROBABILIDADE E ESTATÍsTICA, 9, 1990, São Paulo : Associação Brasileira de Estatistica / Instituto de Matemática e Estatística. p. 105.

22. CARVALHO, C.E. et al. The fate of heavy metals in sediments of Northeastern and Southeastern Brazilian Continental Shelf. In : INTERNATIONAL CONFERENCE HEAVY METALS IN THE ENVIRONMENT, 1993, Toronto. Proceedings... Eindurgh : CEP Consultants. 1993. 2 v., v.1, p. 153-156.

23. CARVALHO, C.E.V. Distribuição de metais pesados em sedimentos da Plataforma Nordeste e Sudoeste do Brasil. Niterói, 1992. 85p. Dissertaçăo (Mestrado em Geociências - Geoquímica). Universidade Federal Fluminense. 1992. Or. LACERDA, Luiz Drude. 
24. CETESB Companhia de Tecnologia de Saneamento Ambiental. Guia de coleta e preservação de amostras de água. São Paulo: CETESB. 1 ed.,1988, 150 p.

25. CONCEIÇÃO, H.; BARBOSA, J.F.S.; AILLON, M.P. O maciço sienítico de São Félix - Bahia. Petrologia e implicações geodinâmicas. In : CONGRESSO BRASILEIRO DE GEOQUÍMICA, 3., 1991, São Paulo. Resumos... São Paulo : Sociedade Brasileira de Geoquímica/Sociedade Geológica de Portugal, 1991 , v. 1 , p. $134-138$.

26. DUURSMA E.K.; CARROLL J. Environmental Compartments: Equilibria and assessment of processes between air, water, sediments and biota. Berlin : Springer-Verlag, 1996. 277 p.

27. FORSTNER, U. Accumulative phases for heavy metals in limnic sediments. Hydrobiology, Dordrecht, v. 91, p. 269-284, 1982.

28. FORSTNER, U.; WITTMAN, G. Metal pollution in the aquatic environment. Berlin, Heidelberg, New York : Springer, 1981. 486 p.

29. FREIRE, G.S.S. Étude hidrologique et sédimentologique d l'estuarie du rio Pacoti (Fortaleza - Ceará - Brésil). Nantes, 1989, 232 p. These (Doctorat Sciences du la Nature), Université du Nantes, 1989.

30. ; MAIA, L.P.; BRANCO M.P.N.C. Regime hidrodinâmico do estuário do rio Pacoti. Revista de Geologia, Fortaleza. v.4, p.29-32, 1991.

31. ; MAIA, L.P.; BRANCO M.P.N.C. Frente salina e balanço do sal no estuário do rio Pacoti- Ceará. Revista de Geologia. Fortaleza , v. 4, p.33-41, 1991.

32. et al. Natureza do material em suspensão do estuário do rio Pacoti. Revista de Geologia, Fortaleza. v.4, p.13-20, 1991. 
33. HARBINSON, P. Regional variation in the distribution of trace metals in modern intertidal sediments of Norther Spencer Gulf, South Australian. Marine Geology, Amsterdan, v. 61, p. 221-247, 1984.

34. JOHNSON, R.A.; WICHERN, D.N. Applied multivariate statistical analysis. Englewood-Clifens : Prentice Hall. 3 ed., 1992, 607 p.

35. LACERDA, L.D. Biogeoquímica de metais pesados em ecosssitemas de manguezais - Niterói. Niterói, 1993, 91 p. Tese (professor titular) Departamento de Geoquímica, Universidade Federal Fluminense. 1993.

36. .; SOUZA, C.M.M.; PESTANA, M.H.D. Geochemical distribution of $\mathrm{Cd}, \mathrm{Cu}, \mathrm{Cr}, \mathrm{Pb}$ in sediments of estuarine areas along the Southeastern Brazilian coast. In : SEELIGIER, U.; LACERDA, L.D.; PATCHINEELAM, S.R. (eds.) Metal in Coastal of Latin America. Berlin : Springer-Verlag. 1988. 297p., p. 86-99.

37. et al. Bioavailability of heavy metals in sediments of two coastal lagoons in Rio de Janeiro, Brazil. Hydrobiology, Dordrecht, v. 228, p. 65-70, 1992.

38. LE DOUREC, P. L'intrusion saline dans l'estuarine interne de Loire. Éude du front de salinité et sus variantions saisonniers. Nantes, 1978, 197 p. These (Doctorat Sciences du la Nature), Université du Nantes. 1978.

39. LEVINSON, A.A. Introduction to exploration geochemistry. Chicago : Applied Publishers. 2 ed., 1980, 924 p.

40. LIMA, N.R.W. et al. Temporal and spatial variability studies of $\mathrm{Zn}, \mathrm{Cr}, \mathrm{Cd}$ and $\mathrm{Fe}$ concentrations in oyster tissue (Crassostraea brasiliana Lamarck, (1819) from Sepetiba Bay, Brasil. Environmental Technology Letters, London, v. 7 , p.453-460, 1986. 
41. LINHARES, P.S.; MESTRINHO, S.S.P.; LUZ, J.A.G. Flow of heavy metals towards the Pedra do Cavalo dom along with sediments from Paraguaçu and Jacuipe rivers, Bahia - Brazil. In : SOLUTIONS 95 INTERNATIONAL CONGRESS, 27, 1995. Alberta, Canadá. Proceedings... Alberta : Internacional Association of Hydrogeologists, 1995 (Em CD-ROM).

42. Chemical speciation of metals in the bottom sediments from Jacuipe river - Bahia, Brazil. In : INTERNATIONAL SYMPOSIUM ENVIRONMETAL GEOCHEMISTRY IN TROPICAL COUNTRIES, 2., 1996. Cartagena. Anales... Cartagena: INGEOMINAS/IDEAM, 1996. (Em CDROM).

43. LITERATHY, P. et al. The role and problems of monitoring bottom sediment for pollution assessment in the coastal marine environment. Water Science and Technology, Oxford, v. 19, p. 781-792, 1987.

44. LORING, D.H. Geochemical factors controlling the accumulation and dispersal of heavy metals in the bay of fund sediments. Canadian Journal of Sciences, Ontario, v. 19, p. 930-944, 1982.

45. LUOMA,N.; DAVIS, J.A. Requirements for modeling trace metal partitioning in oxidized estuarine sediments. Marine Chemistry, Amsterdan, v. 12, p.159$181,1981$.

46. MATTOSO, S.Q. et al. Pesquisa de métodos de Prospecção para cobre em região de clima tropical úmido, Maragogipe, BA. In : CONGRESSO BRASILEIRO DE GEOLOGIA, 24, Brasilia, 1970. Resumo... Brasilia : Sociedade Brasileira de Geologia, 1970, p. 229.

47. MESTRINHO, S.S.P. Distribution of heavy metals on the sediments of Paraguaçu river estuary, São Roque channel and Todos os Santos Bay, Bahia - Brazil. In : SOLUTIONS' 95 INTERNATIONAL CONGRESS, 2, 1995. Alberta, Canadá. Proceedings... Alberta: Internacional Association of Hydrogeologists, 1995 (Em CD-ROM). 
48. ; LINHARES, P.S.; LUZ, A. J. Metais nos sedimentos de fundo do Baixo Paraguaçu e de seu ambiente estuarino, Bahia - Brasil. In: CONGRESSO BRASILEIRO DE GEOQUIMICA, 5 E CONGRESSO GEOQUIMICA DOS PAISES DE LINGUA PORTUGUESA, 3, 1995, Niterói. Anais... Niterói: UFF/Programa de Geoquímica, 1995.

48. ; LINHARES, P.S.; LUZ, J.A.G. Variation in the distribution of heavy metals in the bottom sediments of the lower Paraguaçu river, Bahia - Brazil. In : INTERNATIONAL SYMPOSIUM ENVIRONMETAL GEOCHEMISTRY IN TROPICAL COUNTRIES, 2, 1996. Cartagena. Anales... Cartagena: INGEOMINAS/IDEAM, 1996. (Em CD-ROM).

50. et al. Behavior of heavy metals in the sediments of Paraguaçu river lagoonal estuary, Bahia - Brazil. In : SOLUTIONS' 95 INTERNATIONAL CONGRESS, 2, 1995. Alberta, Canadá. Proceedings... Alberta: Internacional Association of Hydrogeologists, 1995 (Em CD-ROM).

51. MONGOLLÓN, J.L.; BIFANO, C. Topography, weather and human activities effects on the behavior metallic elements in a tropical catchment. Chemical Geology, Amsterdan, v. 114, p. 69-82, 1994.

52. MONGOLLÓN, J.L.; RAMIREZ, A.J., BIFANO, C. Influence of sampling strategy, lithology, vegetation and rainfall on the metal background concentrations in sediment of tropical Tuy River basin, Venezuela. Chemical Geology, Amsterdan, v. 121, p. 263-272, 1995.

53. MOORE, J.W.; RAMAMOORTHY, S. Heavy metals in natural waters. Aplied monitoring and impact assessment. New York: Springer - Verlag Inc. 1983, $271 \mathrm{p}$.

54. NAIR, C.K.; BALCHAND, A.N. Speciation of trace metals in sediments of a tropical estuary. Environmental Geology, New York, v. 21, p. 96-102, 1993. 
55. NETER, J.; WASSERMAN, W. KUTNER, M.H. Applied linear statistical models: regression, analysis of variance and experimental design. Homewood : Richard D. Irwin (ed.). 3 ed., 1990, 842 p.

56. PAREDES, J.F. TOC and other hydrochemical parameters of the Paraguaçu river, Bahia, Brasil, before the building of the Pedra do Cavalo dam. Mitteilungen Geology - Palant. Inst. University of Hamburg, SCOPE-UNEP, Sonderband, v. 52, p. $383-384,1983$.

57. ; CARVALHO, V.N.; BRITO, R.R.C. Relationship between particulate organic carbon on nitrogen in estuarine mangrove area of bay of "Todos os Santos" (Bahia state, Brazil). In : Transport of carbon and minerals in major world rivers. Mitteilungen Geology - Palent. Inst., University of Hamburg. SCOPE/UNEP, v. 55, p. 203-214, 1983.

58. ; MIRANDA, M.T.S. Plano Diretor de Usos, Produção e Gestão Pesqueira no Lago Represado de Pedra do Cavalo. Salvador, Relatório CEPED - PROQUIM. 1981, 310 p.

59. ; RAMOS, M.A.S; QUEIROZ, A.F.S.; CARVALHO, I.G. Study of metals in bottom active sediments from lguape's bay - lagoon estuarine complex of Paraguaçu river, Bahia, Brazil. In : INTERNATIONAL SYMPOSIUM ON PERSPECTIVES FOR ENVIRONMENTAL GEOCHEMISTRY IN TROPICAL. COUNTRIES, 1993. Niterói. Proceedings... Niterói : UFF/Departamento de Geoquímica, 1993, p 387-389.

60. ; FIGUEIREDO G.; ROCHA, W.L.C. Hydrobiological studies of the drainage system of Bananeiras reservoir, the rivers Paraguaçu and Jacuípe. Mitteilungen Geology - Palant. Inst. University of Hamburg, SCOPE-UNEP, Sonderband, v. 52, p. 23-39, 1993. 
61. PESTANA, M.H.D.; LACERDA, L.D. Especiação geoquímica aplicada ao estudo de mobilização de metais pesados em sedimentos estuarinos dos rios Frade e da Guarda, RJ. In : CONGRESSO BRASILEIRO DE GEOQUÍMICA, 2. 1989. Rio de Janeiro. Anais... Rio de Janeiro : Sociedade Brasileira de Geoquímica/CPRM/DNPM. 1989, p. 321-328.

62. PFEIFER, W.C.; FIZMAN, M.; LACERDA, L.D. Heavy metals surveys in brazilian coastal environments. In : SEELIGER, O.; LACERDA; L.D.; PATCHINEELAM, S. (eds.) Metals in coastal environmental of Latin America. Berlin, New York : Springer. 1988, 297 p. p. 3-8.

63. PFEIFFER, W.C. et al. Chromiun in water suspended particles sediments and biota in the Irajá River estuary . Environmental pollution. London. Séries B. v.4, p. 193-205, 1982.

64. PFEIFFER, W.C. et al. Monitoring heavy metals pollution by the critical pathways analysis in the Paraiba do Sul river, Brazil. The Science of the Total Environment, Amsterdam, v. 58, n. 1/2, p. 73-79, 1986.

65. PORTO, R.L.L. Hidrologia Ambiental. São Paulo : USPIABRH. 1991, v.3, 412 p.

66. PUCCl, A. Metals in water and sediments of the Blanca Bay, Argentina. In : SEELIGER, O.; LACERDA; L.D.; PATCHINEELAM, S. (ed.) Metals in coastal environmental of Latin America. Berlin, New York : Springer. 1988, 297p. p. 9-15.

67. QUEIROZ, A.F.S. Estudo Geoquímico e sedimentológico no manguezal do estuário do rio Jacuipe, Camaçari, Bahia. Salvador, 1989, 227 p. Dissertação (Mestrado em Geociéncias) Instituto de Geociências, Universidade Federal da Bahia. 1989. Or. PATCHINEELAN, Sambasiva R. 
68. Mangroves de la Baia de Todos os Santos - Salvador - Bahia Brésil: ses caractéristiques et l'influence anthropique sur sa géochimie. Strasbourg, 1992, 148 p. Tese (Doutorado em Geoquímica Ambiental) Université Louis Pasteur de Strasbourg, França. 1992. Or. LUCAS, Jacques et MARIUS, Claude.

69. ; MOSSER C. AND SANTOS A.L.F. Heavy metals in sediments of mangrove swamps of the Todos os Santos bay - Bahia - Brazil. In : INTERNATIONAL SYMPOSIUM ON PERSPECTIVES FOR ENVIRONMENTAL GEOCHEMISTRY IN TROPICAL COUNTRIES, 1993. Niterói. Proceedings... Niterói : UFF/Departamento de Geoquímica, 1993, p 123-126.

70. RAMOS, M.A.S. Estudos geoquímicos relativamente à dinâmica de marés no estuário lagunar do rio Paraguaçu. Salvador, 1993, 81 p. Dissertação (Mestrado em Geoquímica). Instituto de Geociências, Universidade Federal da Bahia. 1993. Or. PAREDES.Jorge A.F.L.

71. ROSA, M.L.S. Magmatismo shoshonítico e ultrapotássico no sul do cinturão móvel Salvador-Curaçá, Maciço de São Félix: Geologia, Mineralogia e Geoquímica. Salvador, 1994, 240 p. Dissertação (Mestrado em Geologia). Instituto de Geociências, Universidade Federal da Bahia. 1994. Or. CONCEIÇÃO Herbet.

72. ROSE, A.W.; HAWKES H.E.; WEBB J.S. Geochemistry in mineral exploration. London: Academic Press Inc. Ltd. 1979, 2 ed, 657 p.

73. SALOMONS, W.; FORSTENER, U. Metals in the hidrocycle. New York : Springer. $1984,349 p$.

74. SERICANO, J.L.; PUCCI, A.E. Cu, Cd e $\mathrm{Zn}$ in Blanca bay surface sediments, Argentina. Marine Pollution Bulletin. New York, v. 13, n.12, p. 429-451, 1982. 
75. SOUZA, C.M.M. de; PESTANA, M.H.D.; LACERDA, L.D.de. Geochemical partitioning of heavy metals in sediments of three estuaries along the coast of Rio de Janeiro (Brazil). The Science of the Total Environment. Amsterdam, v. 58, n. $1 / 2$, p. $63-72,1986$.

76. SUBRAMANIAN, V.; JHA, P.K.; GRICKEN, R.V. Heavy metals in the Ganges estuary. Marine Pollution Bulletin, New York, v. 19, n.6, p. 290-293, 1988.

77. TALBOT, V.; CHEGWIGDDEN, A. Heavy metals in the sediments of Cocburn Sound, Western Australia, and Surrounding Areas. Environmental Pollution, London, (séries B), v. 5, p. 187-205, 1983.

78. THEELEN, R.M.C.; NIJHOF, A.G. Dutch methodology of risk assent of contaminated soil human health and ecosystem. Dutch Reference Framework (STI-values). Comunicação verbal, 1995.

79. TUREKIAN K.; WEDEPOL, P. Distribution of elements in some major units of the Earth's crust. Geology Society American Bulletin, New York, v. 12, p. 175192, 1961.

80. TURKEY, J.W. Exploratory data analysis, Reading : Addison Wesley (ed.) Software, Statistical Analysis System. 1977, 688 p.

81. VILLA, N. Spatial distribution of heavy metals in seawater and sediments from coastal areas of the southeastern Buenos Aires Province, Argentina. In : SEELIGER, O.; LACERDA; L.D.; PATCHINEELAM, S. (ed.) Metals in coastal environmental of Latin America. Berlin, New York : Springer. 1988, 297p. p. 30-44.

82. WOLANSKI, E. An evaporation divent salinity maximun gone in Australian tropical estuaries. Estuarine, Coastal and Shelf Science, London, n. 22, p. 415-424, 1986. 
TABELAS 


\section{LEGENDA PARA TABELAS}

- Valor igual ou acima do limite holandês (S-value) para solos/sedimentos aquáticos

㛀 Valor igual ou acima do limite holandês (l-value) para solos/sedimentos aquáticos poluídos

- Fração granulométrica predominante

Correlações positivas e negativas acima de $0,7(\alpha=0,05)$

n.a. Não analisado

< Inferior ao limite de deteç̧ão 
TABELA 1 - PARAMETROS MEDIDOS "IN SITU". FASE 01/94. CAMPANHAS I (SIZIGIA) E II (QUADRATURA)

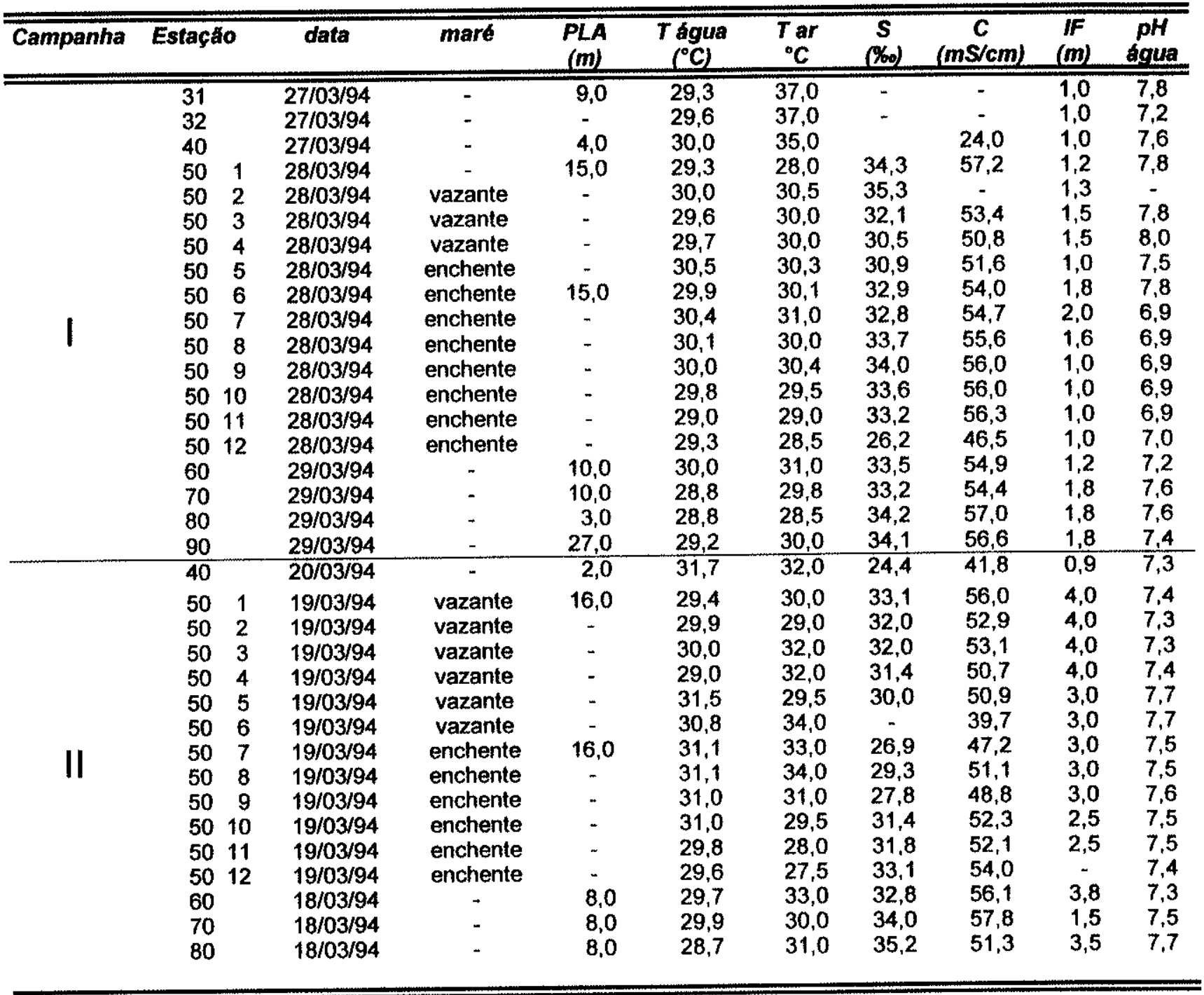

PLA - Profundidade da lâmina d'água

IF - Indice Fótico

S - Salinidade

C - Condutividade 
TABELA 2 - PARAMETROS MEDIDOS "IN SITU”. FASE 01/95, CAMPANHAS I (SIZIGIA) E I (QUADRATURA).

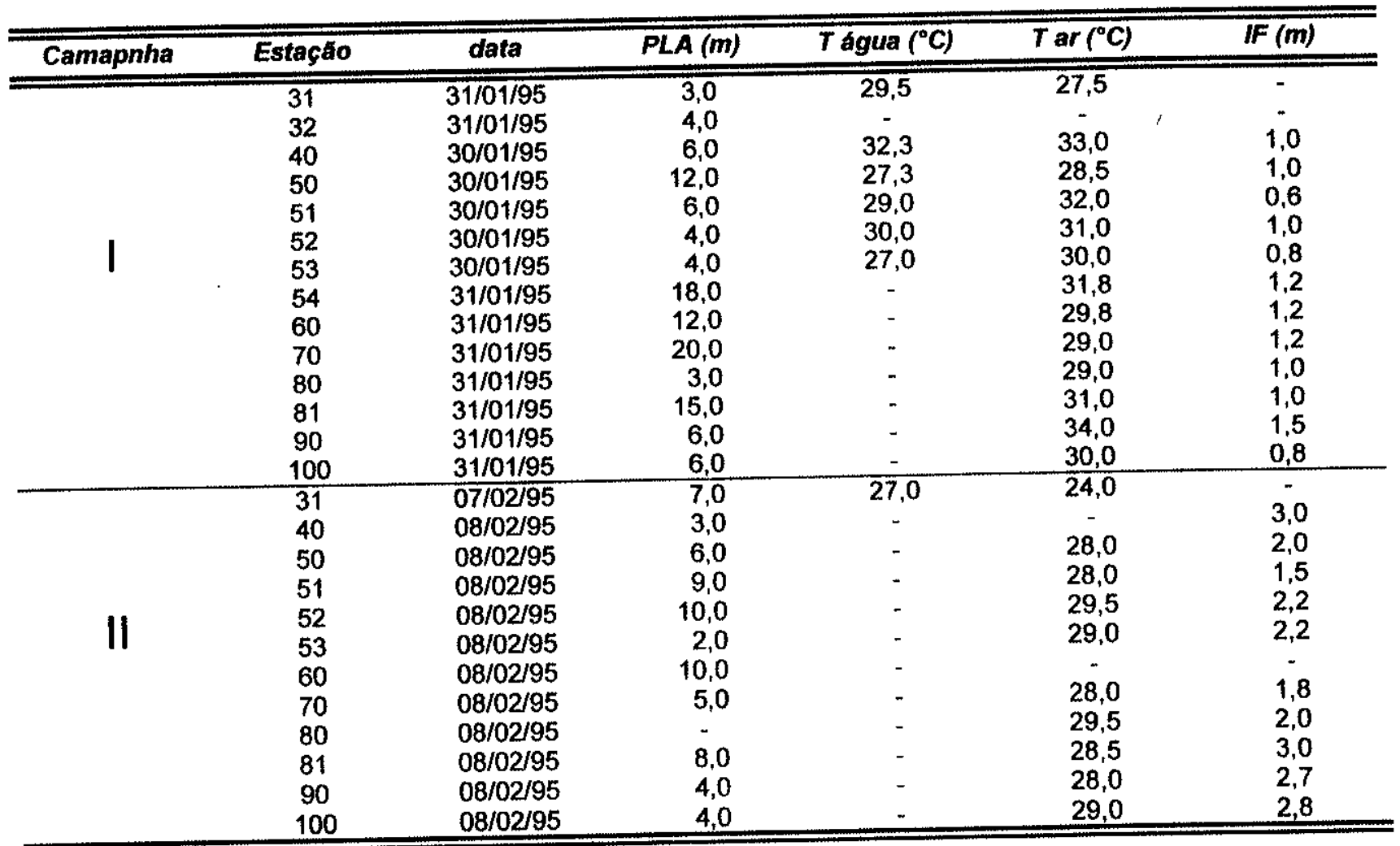

PLA - Profundidade da lâmina d'água

IF - Indice Fótico

TABELA 3 - PARAMMETROS MEDIDOS "IN SITU". FASE 02/95, CAMPANHAS I (SIZIGIA) E II (QUADRATURA).

\begin{tabular}{|c|c|c|c|c|c|c|c|}
\hline Campanha & Estacăo & data & $P L A(m)$ & $T$ água $\left({ }^{\circ} \mathrm{C}\right)$ & $\left.\operatorname{Tar}{ }^{\circ} \mathrm{C}\right)$ & $\boldsymbol{F}(\boldsymbol{m})$ & $p H$ aqua \\
\hline I & $\begin{array}{l}40 \\
50 \\
51 \\
52 \\
53 \\
54 \\
60 \\
70 \\
80 \\
81 \\
90 \\
\end{array}$ & $\begin{array}{l}12 / 06 / 95 \\
12 / 06 / 95 \\
12 / 06 / 95 \\
12 / 06 / 95 \\
12 / 06 / 95 \\
12 / 06 / 95 \\
12 / 06 / 95 \\
12 / 06 / 95 \\
12 / 06 / 95 \\
12 / 06 / 95 \\
12 / 06 / 95 \\
\end{array}$ & $\begin{array}{r}5,2 \\
8,0 \\
4,5 \\
2,3 \\
3,0 \\
21,0 \\
15,0 \\
9,0 \\
14,0 \\
7,0 \\
10,0 \\
\end{array}$ & $\begin{array}{l}23,0 \\
23,0 \\
22,0 \\
23,0 \\
23,0 \\
22,0 \\
24,0 \\
24,0 \\
23,5 \\
23,0 \\
24,0 \\
\end{array}$ & $\begin{array}{l}23,0 \\
23,0 \\
22,0 \\
22,0 \\
22,0 \\
24,0 \\
23,0 \\
23,0 \\
25,0 \\
24,0 \\
24,0 \\
\end{array}$ & $\begin{array}{l}0,7 \\
1,6 \\
0,3 \\
1,0 \\
1,2 \\
1,6 \\
1,0 \\
1,8 \\
1,6 \\
1,2 \\
1,5 \\
\end{array}$ & $\begin{array}{l}8,1 \\
7,9 \\
7,9 \\
8,0 \\
8,0 \\
8,0 \\
8,1 \\
8,1 \\
8,0 \\
8,0 \\
8,1 \\
\end{array}$ \\
\hline II & $\begin{array}{l}40 \\
50 \\
51 \\
52 \\
53 \\
54 \\
60 \\
70 \\
80 \\
81 \\
90 \\
100\end{array}$ & $\begin{array}{l}20 / 06 / 95 \\
20 / 06 / 95 \\
20 / 06 / 95 \\
20 / 06 / 95 \\
20 / 06 / 95 \\
20 / 06 / 95 \\
20 / 06 / 95 \\
20 / 06 / 95 \\
20 / 06 / 95 \\
20 / 06 / 95 \\
20 / 06 / 95 \\
20 / 06 / 95 \\
\end{array}$ & $\begin{array}{r}4,0 \\
3,0 \\
6,0 \\
2,0 \\
3,0 \\
8,5 \\
10,0 \\
8,5 \\
12,5 \\
12,0 \\
6,0 \\
3,5 \\
\end{array}$ & $\begin{array}{l}24,0 \\
25,0 \\
24,0 \\
25,0 \\
25,0 \\
25,0 \\
25,0 \\
24,0 \\
25,0 \\
24,0 \\
25,0 \\
24,0 \\
\end{array}$ & $\begin{array}{l}22,0 \\
26,0 \\
21,0 \\
24,0 \\
26,0 \\
25,0 \\
23,0 \\
23,0 \\
26,0 \\
25,0 \\
24,0 \\
25,0 \\
\end{array}$ & $\begin{array}{l}3,6 \\
2,3 \\
1,9 \\
2,0 \\
2,5 \\
1,8 \\
2,2 \\
2,5 \\
3,0 \\
3,0 \\
3,0 \\
2,5 \\
\end{array}$ & $\begin{array}{l}8,0 \\
8,0 \\
7,7 \\
8,0 \\
7,9 \\
8,0 \\
8,0 \\
8,0 \\
8,1 \\
8,1 \\
8,1 \\
8,1 \\
\end{array}$ \\
\hline
\end{tabular}

PLA - Profundidade da lâmina d'água

IF - Indice Fótico 
TABELA 4 - PARÅMETROS MEDIDOS “IN SITU”. FASE $03 / 95$, CAMPANHAS I (QUADRATURA) E II (SIZIGIA)

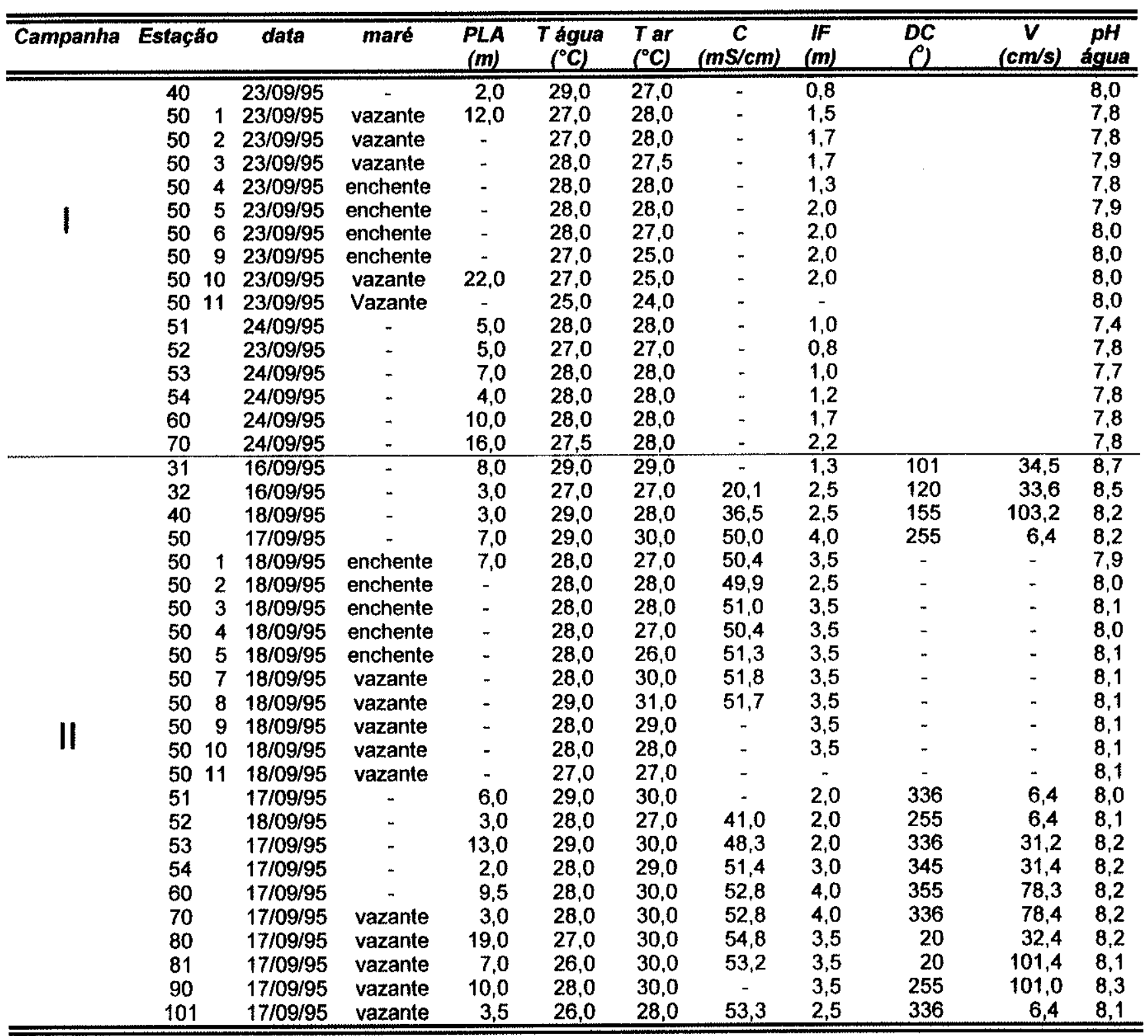

PLA - Profundidade da lâmina d'água

IF - Indice Fótico

C - Condutividade

DC - Direçăo de corrente

V - Velocidade 
TABELA 5 - CONCENTRAÇAO (mg/L) DE SOLLIDOS SUSPENSOS TOTAIS (SST), SOLIDOS SUSPENSOS VOLATEIS (SSV), MATERIAL PARTICULADO EM SUSPENSÃO (MPS) E METAIS NO MATERIAL PARTICULADO EM SUSPENSÃO . FASE 01/94, CAMPANHAS I (SIZIGIA) E II (QUADRATURA)

\begin{tabular}{|c|c|c|c|c|c|c|c|c|}
\hline Campanha & Estaçóes & $\overline{S S T}$ & ssv & MPS & $\overline{M n}$ & $\overline{F e}$ & $\overline{Z n}$ & $\overline{\overline{A l}}$ \\
\hline I & $\begin{array}{l}31 \\
32 \\
40 \\
50 \\
50 \\
50 \\
50 \\
50 \\
50 \\
50 \\
50 \\
50 \\
50 \\
50 \\
50 \\
10 \\
50 \\
11 \\
60 \\
70 \\
80 \\
90\end{array}$ & $\begin{array}{c}8 \\
25 \\
38 \\
40 \\
36 \\
33 \\
37 \\
34 \\
39 \\
34 \\
59 \\
41 \\
38 \\
42 \\
60 \\
80 \\
54 \\
49 \\
67\end{array}$ & $\begin{array}{r}5 \\
13 \\
18 \\
16 \\
16 \\
12 \\
16 \\
11 \\
15 \\
16 \\
24 \\
14 \\
16 \\
11 \\
22 \\
29 \\
20 \\
21 \\
26\end{array}$ & $\begin{array}{r}\text { n.a. } \\
18 \\
5 \\
8 \\
6 \\
6 \\
5 \\
6 \\
5 \\
5 \\
9 \\
6 \\
5 \\
9 \\
7 \\
10 \\
8 \\
8 \\
8\end{array}$ & $\begin{array}{l}12 \\
38 \\
75 \\
30 \\
19 \\
21 \\
18 \\
21 \\
21 \\
25 \\
23 \\
21 \\
35 \\
35 \\
30 \\
37 \\
35 \\
31 \\
32\end{array}$ & $\begin{array}{r}325 \\
250 \\
20 \\
296 \\
67 \\
192 \\
188 \\
158 \\
152 \\
162 \\
324 \\
290 \\
232 \\
620 \\
227 \\
562 \\
460 \\
395 \\
515\end{array}$ & $\begin{array}{r}13 \\
7 \\
4 \\
9 \\
3 \\
4 \\
4 \\
7 \\
23 \\
11 \\
7 \\
6 \\
9 \\
7 \\
9 \\
20 \\
28 \\
13 \\
36\end{array}$ & $\begin{array}{r}258 \\
258 \\
80 \\
361 \\
86 \\
258 \\
223 \\
172 \\
361 \\
206 \\
378 \\
344 \\
292 \\
585 \\
236 \\
559 \\
516 \\
451 \\
623\end{array}$ \\
\hline II & $\begin{array}{ll}40 \\
50 \\
50 \\
50 \\
50 \\
50 \\
50 \\
50 \\
50 \\
50 \\
50 & 2 \\
50 & 8 \\
50 & 9 \\
50 & 10 \\
50 & 11 \\
50 & 12 \\
60 \\
70 \\
80\end{array}$ & $\begin{array}{l}25 \\
22 \\
22 \\
20 \\
15 \\
19 \\
23 \\
30 \\
25 \\
35 \\
25 \\
25 \\
33 \\
28 \\
36 \\
46 \\
39\end{array}$ & $\begin{array}{r}16 \\
9 \\
9 \\
7 \\
12 \\
8 \\
9 \\
16 \\
12 \\
15 \\
11 \\
12 \\
15 \\
12 \\
11 \\
17 \\
16\end{array}$ & $\begin{array}{r}22 \\
\text { n.a. } \\
\text { n.a. } \\
\text { n.a. } \\
\text { n.a. } \\
\text { n.a. } \\
5 \\
\text { n.a. } \\
\text { n.a. } \\
5 \\
5 \\
5 \\
5 \\
5 \\
\text { n.a. } \\
6 \\
\text { n.a. }\end{array}$ & $\begin{array}{l}34 \\
22 \\
22 \\
18 \\
21 \\
20 \\
20 \\
22 \\
32 \\
21 \\
24 \\
22 \\
20 \\
17 \\
36 \\
39 \\
37\end{array}$ & $\begin{array}{r}220 \\
33 \\
39 \\
37 \\
\text { n.a. } \\
62 \\
54 \\
125 \\
101 \\
87 \\
77 \\
83 \\
91 \\
52 \\
42 \\
190 \\
76\end{array}$ & $\begin{array}{r}9 \\
3 \\
3 \\
1 \\
\text { n.a. } \\
4 \\
2 \\
14 \\
7 \\
4 \\
4 \\
3 \\
3 \\
3 \\
2 \\
4 \\
36\end{array}$ & $\begin{array}{r}258 \\
80 \\
80 \\
52 \\
\text { n.a. } \\
60 \\
60 \\
152 \\
129 \\
86 \\
140 \\
92 \\
75 \\
80 \\
80 \\
223 \\
80\end{array}$ \\
\hline
\end{tabular}


TABELA 6 - CONCENTRAÇAO (mg/L) DE SST, SSV, MPS E METAIS NO MATERIAL PARTICULADO EM SUSPENSAO NA FASE 01/95, CAMPANHAS I (SIZIGIA) E II (QUADRATURA)

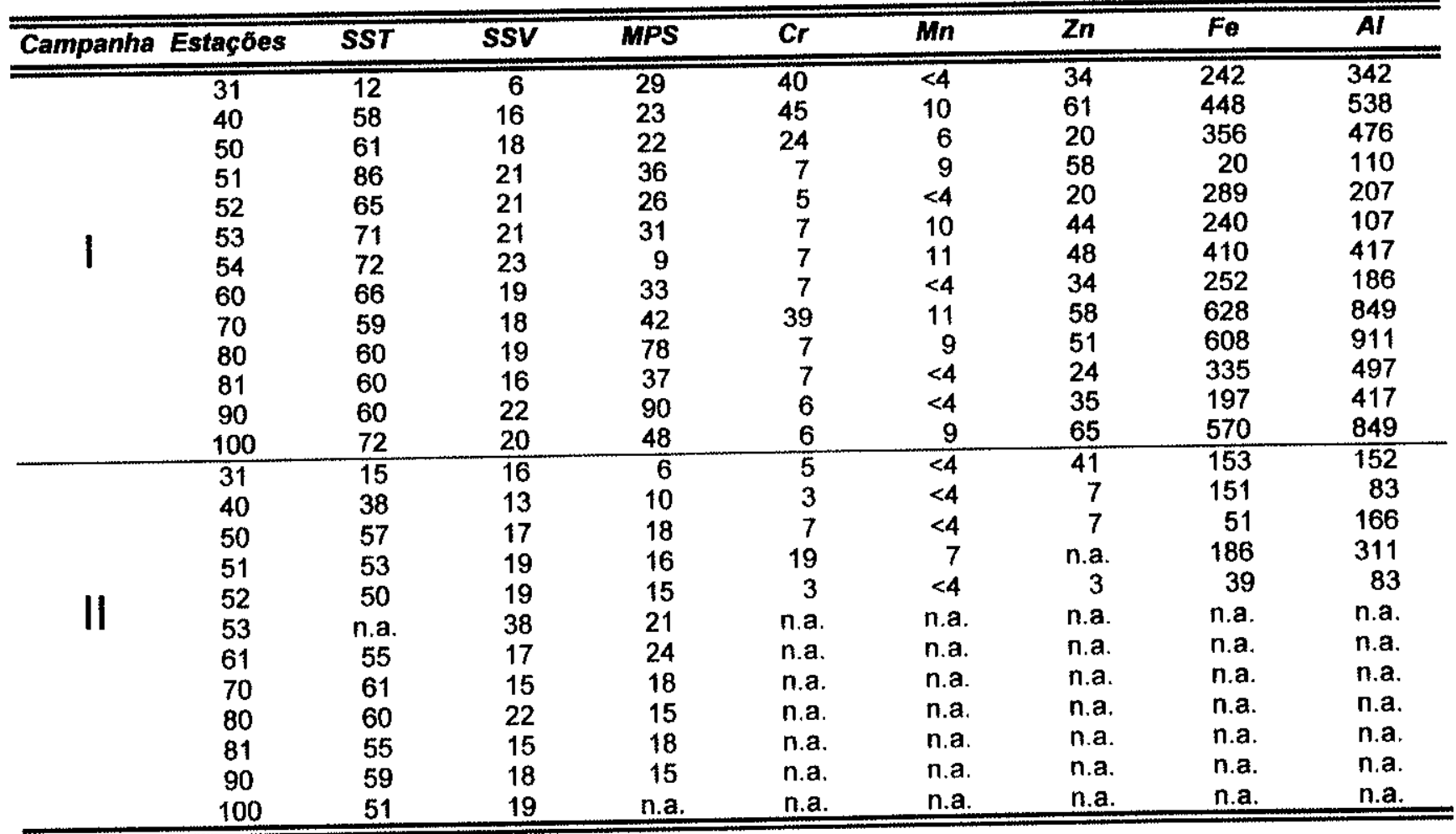

TABELA 7 - CONCENTRAÇAO (mg/L) SST, SSV, MPS E METAIS NO MATERIAL PARTICULADO EM SUSPENSAO NA FASE 02/95, CAMPANHAS I (SIZIGIA) E II (QUADRATURA).

\begin{tabular}{|c|c|c|c|c|c|c|c|c|}
\hline Campanha & Estaçסes & SST & SSV & MPS & $M n$ & $Z n$ & $\mathrm{Fe}$ & $A !$ \\
\hline \multirow{11}{*}{ I } & 40 & 27 & 9 & 23 & $<4$ & 0,3 & 81 & 52 \\
\hline & 50 & 32 & 11 & 19 & $<4$ & 0,3 & 42 & 38 \\
\hline & 51 & 38 & 10 & 40 & $<4$ & 0.3 & 142 & 99 \\
\hline & 52 & 29 & 9 & 18 & $<4$ & 0,3 & 48 & 47 \\
\hline & 53 & 28 & 9 & 18 & $<4$ & 0,8 & 43 & 47 \\
\hline & 54 & 27 & 7 & 14 & $<4$ & 0,3 & 30 & 28 \\
\hline & $\begin{array}{l}60 \\
70\end{array}$ & 36 & 11 & 27 & $<4$ & 0.6 & 90 & 109 \\
\hline & $\begin{array}{l}70 \\
80\end{array}$ & 19 & 8 & 16 & $<4$ & 0.2 & 32 & 28 \\
\hline & $\begin{array}{l}80 \\
81\end{array}$ & 27 & 7 & 19 & $<4$ & 0,3 & 27 & 15 \\
\hline & $\begin{array}{l}81 \\
90\end{array}$ & 37 & 10 & 24 & $<4$ & 0,2 & 80 & 132 \\
\hline & $\begin{array}{c}90 \\
100\end{array}$ & $\begin{array}{c}21 \\
\text { n.a. }\end{array}$ & 7 & $\begin{array}{c}21 \\
\text { n.a. }\end{array}$ & $\begin{array}{l}<4 \\
<4\end{array}$ & $\begin{array}{l}0,3 \\
0,3\end{array}$ & 43 & $\begin{array}{l}47 \\
19\end{array}$ \\
\hline \multirow{12}{*}{ II } & 40 & $\frac{\text { n.a. }}{10}$ & $\frac{\text { n.a. }}{4}$ & $\frac{\text { n.a. }}{7}$ & $\begin{array}{l}<4 \\
<4\end{array}$ & $\frac{0,3}{0,2}$ & $\frac{19}{20}$ & \\
\hline & 50 & $\begin{array}{l}10 \\
20\end{array}$ & $\begin{array}{l}4 \\
7\end{array}$ & 15 & $<4$ & 0,2 & 31 & $\begin{array}{l}15 \\
24\end{array}$ \\
\hline & 51 & $\begin{array}{l}20 \\
14\end{array}$ & 6 & 15 & $<4$ & 0,1 & 22 & $\begin{array}{l}24 \\
14\end{array}$ \\
\hline & 52 & $\begin{array}{l}14 \\
16\end{array}$ & 6 & 15 & $<4$ & 0.2 & 37 & \\
\hline & 53 & 16 & 6 & 14 & $<4$ & 0,2 & 22 & $\begin{array}{l}24 \\
15\end{array}$ \\
\hline & 54 & 18 & 6 & 14 & $<4$ & 0.2 & 21 & \\
\hline & 60 & 14 & 5 & 14 & $<4$ & 0,2 & 22 & $\begin{array}{r}15 \\
9\end{array}$ \\
\hline & & 17 & 6 & n.a. & $<4$ & 0.2 & 15 & $\begin{array}{r}9 \\
15\end{array}$ \\
\hline & & 17 & 5 & $n=$ & $<4$ & 0,2 & 16 & $\begin{array}{l}15 \\
15\end{array}$ \\
\hline & & 14 & $\begin{array}{l}5 \\
6\end{array}$ & $\begin{array}{c}\text { n.a. } \\
7\end{array}$ & $<4$ & 0,2 & 20 & $\begin{array}{l}15 \\
14\end{array}$ \\
\hline & 90 & & 6 & $\begin{array}{r}7 \\
12\end{array}$ & $<4$ & 0.1 & n.a. & $\begin{array}{l}14 \\
15\end{array}$ \\
\hline & 101 & $\begin{array}{l}16 \\
19\end{array}$ & $\begin{array}{l}6 \\
7\end{array}$ & $\begin{array}{l}12 \\
43\end{array}$ & $<4$ & 0,0 & 19 & 15 \\
\hline
\end{tabular}


TABELA 8 - CONCENTRAÇAO (mg/L) de SST, SSV, MPS E METAIS NO MATERIAL PARTICULADO EM SUSPENSAO DURANTE A FASE 03/95 CAMPANHAS I (SIZIGIA) E II (QUADRATURA)

\begin{tabular}{|c|c|c|c|c|c|c|c|c|}
\hline Campanha & Estaçסes & SST & SsV & MPS & $M n$ & $2 n$ & $F e$ & $A I$ \\
\hline I & $\begin{array}{lr}40 & \\
50 & \\
50 & 1 \\
50 & 3 \\
50 & 4 \\
50 & 5 \\
50 & 6 \\
50 & 9 \\
50 & 10 \\
50 & 11 \\
50 & 12 \\
51 \\
52 \\
53 \\
54 \\
60 \\
70 \\
\end{array}$ & $\begin{array}{l}59 \\
65 \\
59 \\
60 \\
59 \\
51 \\
59 \\
43 \\
45 \\
50 \\
47 \\
25 \\
52 \\
22 \\
30 \\
27 \\
11\end{array}$ & $\begin{array}{r}17 \\
23 \\
15 \\
21 \\
20 \\
16 \\
20 \\
15 \\
16 \\
16 \\
15 \\
8 \\
13 \\
7 \\
10 \\
8 \\
3 \\
\end{array}$ & $\begin{array}{l}16 \\
26 \\
23 \\
20 \\
20 \\
22 \\
25 \\
31 \\
18 \\
36 \\
15 \\
13 \\
18 \\
17 \\
13 \\
17 \\
24 \\
\end{array}$ & $\begin{array}{l}<4 \\
<4 \\
<4 \\
<4 \\
<4 \\
<4 \\
<4 \\
<4 \\
<4 \\
<4 \\
<4 \\
<4 \\
<4 \\
<4 \\
<4 \\
<4 \\
<4\end{array}$ & $\begin{array}{l}0,5 \\
0,4 \\
\text { n.a } \\
\text { n.a } \\
0,4 \\
0,4 \\
\text { n.a } \\
0,5 \\
0,3 \\
0,5 \\
0,5 \\
\text { n.a } \\
0,7 \\
0,8 \\
0,9 \\
0,8 \\
0,9 \\
\end{array}$ & $\begin{array}{c}57 \\
27 \\
\text { n.a. } \\
\text { n.a. } \\
27 \\
22 \\
\text { n.a. } \\
19 \\
18 \\
11 \\
47 \\
\text { n.a. } \\
51 \\
67 \\
59 \\
51 \\
21 \\
\end{array}$ & $\begin{array}{c}67 \\
63 \\
\text { n.a. } \\
\text { n.a. } \\
63 \\
26 \\
\text { n.a. } \\
30 \\
19 \\
19 \\
52 \\
\text { n.a. } \\
119 \\
104 \\
104 \\
82 \\
41 \\
\end{array}$ \\
\hline II & $\begin{array}{cc}31 \\
32 \\
40 \\
50 \\
50 & 1 \\
50 & 2 \\
50 & 3 \\
50 & 4 \\
50 & 5 \\
50 & 7 \\
50 & 8 \\
50 & 9 \\
50 & 10 \\
50 & 11 \\
51 & \\
52 \\
53 \\
54 \\
60 \\
70 \\
80 \\
81 \\
90 \\
101 \\
\end{array}$ & $\begin{array}{r}8 \\
39 \\
42 \\
40 \\
54 \\
53 \\
51 \\
47 \\
61 \\
53 \\
55 \\
50 \\
50 \\
51 \\
42 \\
52 \\
38 \\
49 \\
46 \\
59 \\
37 \\
46 \\
39 \\
41 \\
\end{array}$ & $\begin{array}{c}7 \\
14 \\
17 \\
20 \\
23 \\
24 \\
22 \\
21 \\
25 \\
19 \\
18 \\
17 \\
17 \\
15 \\
12 \\
20 \\
14 \\
17 \\
14 \\
33 \\
14 \\
13 \\
13 \\
11 \\
\end{array}$ & $\begin{array}{l}10 \\
22 \\
10 \\
19 \\
21 \\
13 \\
23 \\
17 \\
17 \\
29 \\
17 \\
23 \\
27 \\
20 \\
12 \\
17 \\
19 \\
15 \\
15 \\
14 \\
14 \\
14 \\
18 \\
15 \\
\end{array}$ & $\begin{array}{l}<4 \\
<4 \\
<4 \\
<4 \\
<4 \\
<4 \\
<4 \\
<4 \\
<4 \\
<4 \\
<4 \\
<4 \\
<4 \\
<4 \\
<4 \\
<4 \\
<4 \\
<4 \\
<4 \\
<4 \\
<4 \\
<4 \\
<4 \\
<4 \\
<4 \\
\end{array}$ & $\begin{array}{c}\text { n.a } \\
\text { n.a } \\
0,5 \\
0,5 \\
0.4 \\
\text { n.a. } \\
0,4 \\
0,7 \\
0,5 \\
0,6 \\
0,5 \\
0.5 \\
0,7 \\
\text { n.a } \\
\text { n.a } \\
0,7 \\
0,6 \\
0,4 \\
0,4 \\
\text { n.a. } \\
0,5 \\
0,5 \\
0.3 \\
\text { n.a } \\
\end{array}$ & $\begin{array}{c}\text { n.a. } \\
\text { n.a. } \\
15 \\
16 \\
16 \\
9 \\
8 \\
11 \\
8 \\
14 \\
8 \\
10 \\
12 \\
\text { n.a. } \\
\text { n.a. } \\
26 \\
16 \\
14 \\
16 \\
9 \\
16 \\
16 \\
16 \\
\text { n.a. } \\
\end{array}$ & $\begin{array}{c}\text { n.a. } \\
\text { n.a. } \\
26 \\
19 \\
19 \\
15 \\
7 \\
15 \\
15 \\
15 \\
15 \\
7 \\
15 \\
\text { n.a. } \\
\text { n.a. } \\
15 \\
15 \\
15 \\
15 \\
15 \\
15 \\
15 \\
15 \\
\text { n.a. } \\
\end{array}$ \\
\hline
\end{tabular}


TABELA 9 - ANÁLISE GRANULOMÉTRICA (\%) E MATÉRIA ORGÅNICA - MO (\%) DOS SEDIMENTOS DE FUNDO. FASE 01/95

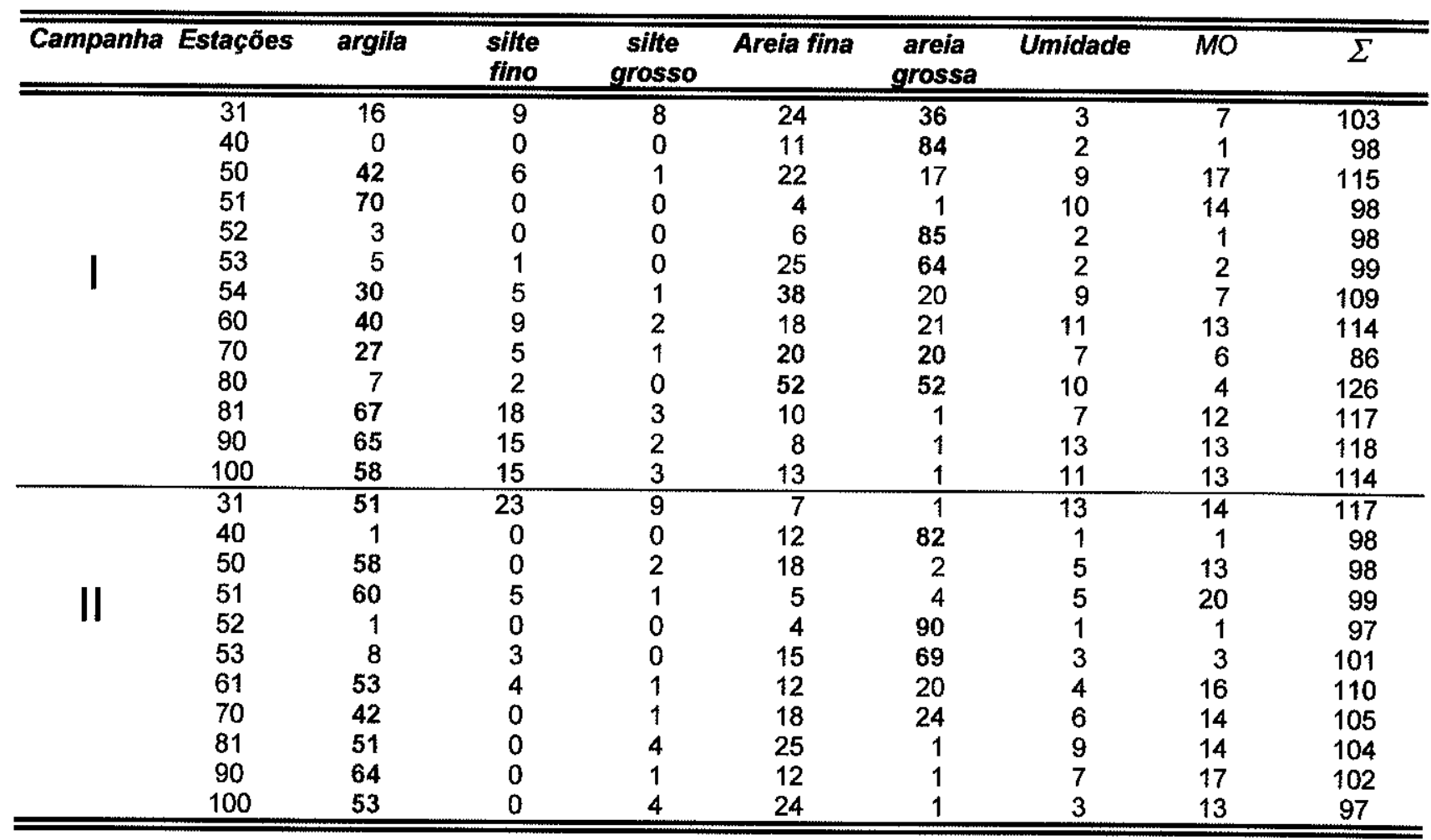


TABELA 10 - ANÁLISE GRANULOMÉTRICA (\%) E DE MO (\%) DOS SEDIMENTOS DE FUNDO. FASE 02/95

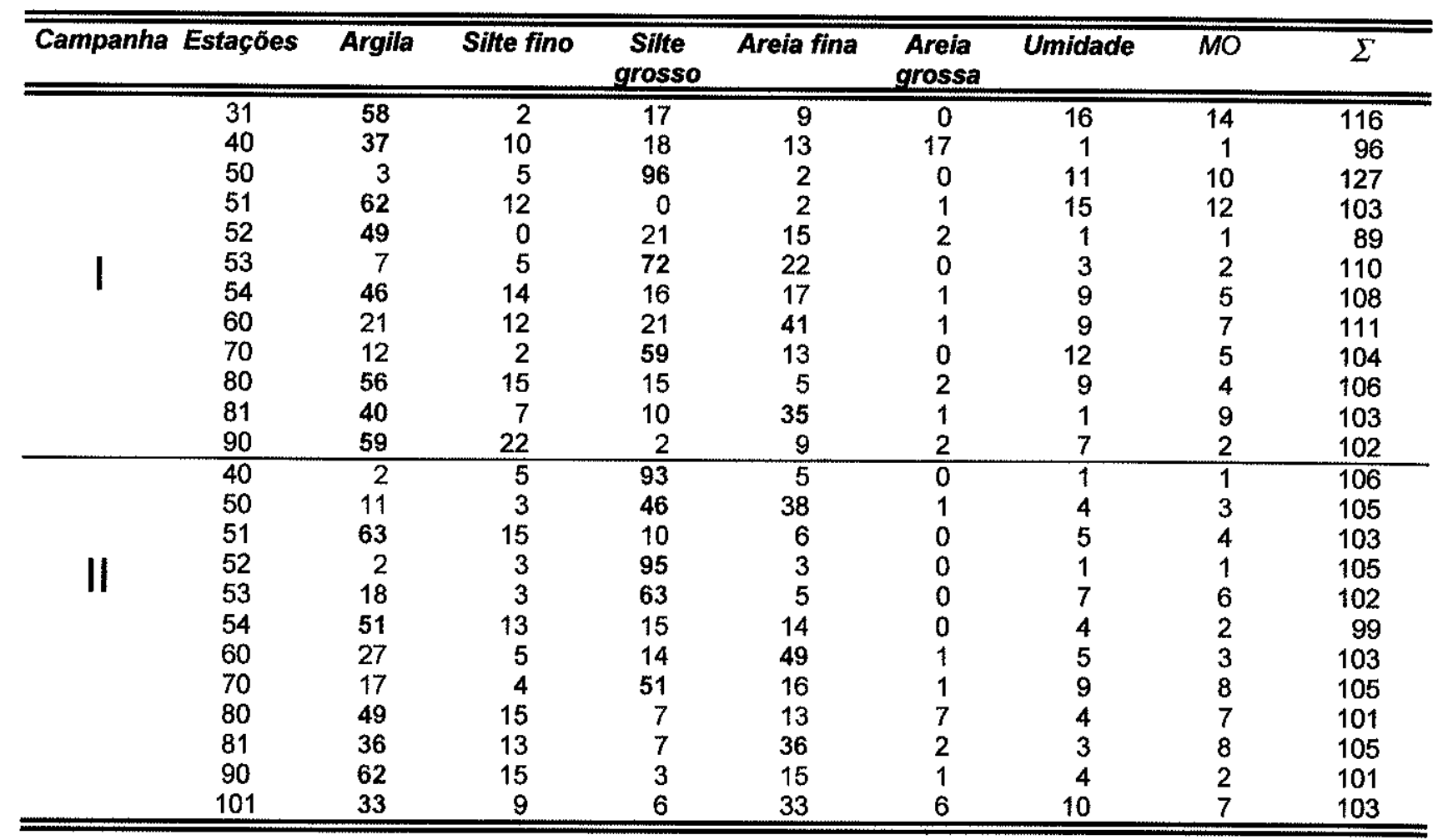

TABELA 11- ANÁLISE GRANULOMÉTRICA (\%) E DE MO (\%) DOS SEDIMENTOS DE FUNDO DURANTE A FASE 03/95 CAMPANHAS I (SIZIGIA) E II (QUADRATURA)

\begin{tabular}{|c|c|c|c|c|c|c|c|c|c|}
\hline Campanha & Estaçōes & Argila & Silte Fino & $\begin{array}{c}\text { Silte } \\
\text { Grosso }\end{array}$ & $\begin{array}{l}\text { Areia } \\
\text { Fina } \\
\end{array}$ & $\begin{array}{c}\text { Areia } \\
\text { Grossa }\end{array}$ & Umidade & $M O$ & $\Sigma$ \\
\hline \multirow{11}{*}{ | } & 40 & 39 & 12 & 10 & 11 & 23 & 2 & 3 & 99 \\
\hline & 50 & 5 & 7 & 79 & 0 & 6 & 1 & 4 & 102 \\
\hline & 51 & 64 & 14 & 8 & 0 & 7 & 7 & 4 & 102 \\
\hline & 52 & 51 & 2 & 13 & 13 & 8 & 6 & 8 & 101 \\
\hline & 53 & 9 & 7 & 54 & 20 & 6 & 5 & 3 & 103 \\
\hline & 54 & 48 & 16 & 8 & 15 & 7 & 4 & 4 & 102 \\
\hline & 60 & 23 & 14 & 13 & 39 & 7 & 6 & 4 & 104 \\
\hline & 70 & 14 & 4 & 51 & 11 & 6 & 8 & 5 & 100 \\
\hline & 80 & 58 & 17 & 7 & 3 & 8 & 6 & 6 & 104 \\
\hline & 81 & 42 & 9 & 2 & 33 & 7 & 3 & 9 & 104 \\
\hline & 90 & 60 & 24 & 6 & 7 & 8 & 2 & 2 & 109 \\
\hline \multirow{12}{*}{ II } & 40 & 4 & 6 & 85 & 3 & 6 & 1 & 1 & 106 \\
\hline & 50 & 13 & 4 & 38 & 36 & 7 & 4 & 3 & 105 \\
\hline & 51 & 65 & 16 & 2 & 4 & 6 & 6 & 2 & 102 \\
\hline & 52 & 4 & 5 & 87 & 1 & 6 & 2 & 1 & 106 \\
\hline & 53 & 20 & 5 & 55 & 3 & 6 & 8 & 5 & 102 \\
\hline & 54 & 53 & 15 & 7 & 12 & 6 & 5 & 1 & 99 \\
\hline & 60 & 29 & 7 & 6 & 47 & 7 & 6 & 2 & 103 \\
\hline & 70 & 19 & 6 & 43 & 14 & 7 & 11 & 6 & 104 \\
\hline & 80 & 51 & 17 & 1 & 11 & 13 & 5 & 5 & 103 \\
\hline & 81 & 38 & 15 & 1 & 34 & 8 & 4 & 6 & 106 \\
\hline & 90 & 64 & 17 & 6 & 13 & 7 & 6 & 0 & 112 \\
\hline & 101 & 35 & 11 & 6 & 31 & 12 & 11 & 5 & 111 \\
\hline
\end{tabular}


TABELA 12 - CONCENTRAÇÃO TOTAL DE METAIS NOS SEDIMENTOS DE FUNDO DURANTE A FASE 01/94, CAMPANHAS I (SIZÍGIA) E II (QUADRATURA)

\begin{tabular}{|c|c|c|c|c|c|c|c|c|c|}
\hline Campanha & Estações & $\begin{array}{c}\mathrm{Cu} \\
(\mathrm{ppm}) \\
\end{array}$ & $\begin{array}{c}C d \\
(p p m)\end{array}$ & $\begin{array}{c}P b \\
(p p m) \\
\end{array}$ & $\begin{array}{c}\mathrm{Cr} \\
(\mathrm{ppm})\end{array}$ & $\begin{array}{c}\mathrm{Zn} \\
(p p m) \\
\end{array}$ & $\begin{array}{c}\begin{array}{c}M n \\
(p p m)\end{array} \\
\end{array}$ & $\begin{array}{l}\mathrm{Fe} \\
(\%) \\
\end{array}$ & $\begin{array}{c}A l \\
(\%) \\
\end{array}$ \\
\hline \multirow{6}{*}{ | } & 40 & $<7$ & 2 & 40 & 9 & 13 & 117 & 0 & 2 \\
\hline & 50 & 37 & 2 & 50 & 75 & 78 & 385 & 5 & 6 \\
\hline & 60 & 9 & 2 & 40 & 31 & 36 & 245 & 2 & 4 \\
\hline & 70 & 26 & 2 & 50 & 88 & 80 & 271 & 4 & 5 \\
\hline & 80 & 13 & 2 & 40 & 21 & 30 & 167 & 1 & 3 \\
\hline & 90 & 23 & 2 & 50 & 78 & 73 & 250 & 4 & 7 \\
\hline \multirow{5}{*}{ II } & 40 & 18 & 2 & 40 & 28 & 30 & 188 & 1 & 4 \\
\hline & 50 & 30 & 2 & 40 & 75 & 75 & 438 & 4 & 4 \\
\hline & 61 & 12 & 2 & 40 & 39 & 55 & 292 & 2 & 4 \\
\hline & 70 & 18 & 2 & 60 & 43 & 75 & 479 & 7 & 6 \\
\hline & 80 & 26 & 2 & 50 & 84 & 73 & 240 & 4 & 8 \\
\hline \multicolumn{2}{|c|}{ S-value ${ }^{(a)}$} & 15 & 0,4 & 50 & 50 & 50 & & & \\
\hline
\end{tabular}

(a) - THEELEN \& NIJHOF, op. cit.

TABELA 13 - CONCENTRAÇÃO TOTAL DE METAIS NOS SEDIMENTOS DE FUNDO DURANTE A FASE 01/95 CAMPANHAS I (SIZIGIA) E II (QUADRATURA)

\begin{tabular}{|c|c|c|c|c|c|c|c|c|c|}
\hline Campanha & Estações & $\begin{array}{c}\mathrm{Cu} \\
(\mathrm{ppm})\end{array}$ & $\begin{array}{c}C d \\
(p p m)\end{array}$ & $\begin{array}{c}\mathrm{Pb} \\
(\mathrm{ppm})\end{array}$ & $\begin{array}{c}\mathrm{Cr} \\
(\mathrm{ppm})\end{array}$ & $\begin{array}{c}\mathrm{Zn} \\
(\mathrm{ppm})\end{array}$ & $\begin{array}{c}M n \\
\text { (ppm) }\end{array}$ & $\begin{array}{l}\mathrm{Fe} \\
(\%) \\
\end{array}$ & $\begin{array}{r}A l \\
(\%) \\
\end{array}$ \\
\hline \multirow{13}{*}{ | } & 31 & 26 & 1 & 25 & 65 & 59 & 115 & 1 & 2 \\
\hline & 40 & 7 & 0 & 7 & 6 & 7 & 74 & 0 & 1 \\
\hline & 50 & 11 & 0 & 16 & 48 & 36 & 75 & 1 & 1 \\
\hline & 51 & 11 & 1 & 18 & 38 & 36 & 50 & 1 & 1 \\
\hline & 52 & 9 & 1 & 12 & 8 & 10 & 30 & 0 & 1 \\
\hline & 53 & 7 & 1 & 14 & 13 & 13 & 51 & 0 & 1 \\
\hline & 54 & 8 & 1 & 12 & 21 & 19 & 168 & 1 & 1 \\
\hline & 60 & n.a. & 1 & 18 & 36 & 40 & 36 & 1 & 2 \\
\hline & 70 & 8 & 1 & 18 & 29 & 27 & 41 & 1 & 1 \\
\hline & 80 & 7 & 1 & 16 & 9 & 9 & 135 & 0 & 1 \\
\hline & 81 & 13 & $i$ & 21 & 43 & 38 & 52 & 1 & 1 \\
\hline & 90 & 11 & 1 & 18 & 43 & 32 & 62 & 1 & 1 \\
\hline & 100 & 17 & 1 & 18 & 41 & 36 & 52 & 1 & 1 \\
\hline \multirow{11}{*}{ II } & 31 & 20 & 1 & 23 & 48 & 55 & 153 & 1 & 2 \\
\hline & 40 & n.a & 1 & 9 & 8 & 11 & 193 & 0 & 1 \\
\hline & 50 & 11 & 1 & 21 & 42 & 36 & 33 & 1 & 2 \\
\hline & 51 & 13 & 1 & 18 & 50 & 45 & 37 & 1 & 1 \\
\hline & 52 & 7 & 1 & 9 & 6 & 9 & 94 & 0 & 1 \\
\hline & 53 & 6 & 1 & 16 & 15 & 14 & 46 & 0 & 2 \\
\hline & 60 & 11 & 0 & 14 & 41 & 35 & 51 & 1 & 1 \\
\hline & 70 & 11 & 1 & 16 & 37 & 26 & 27 & 1 & 1 \\
\hline & 81 & 10 & 1 & 21 & 36 & 36 & 29 & 1 & 1 \\
\hline & 90 & 29 & 1 & 23 & 56 & 48 & 50 & 1 & 1 \\
\hline & 100 & 11 & 1 & 18 & 37 & 33 & 65 & 1 & 1 \\
\hline \multicolumn{2}{|c|}{$\overline{\text { S-value }}$} & $\overline{15}$ & $\overline{\overline{0,4}}$ & $\overline{\overline{50}}$ & $\overline{\overline{50}}$ & $\overline{50}$ & & & \\
\hline
\end{tabular}

(a) - THEELEN \& NIJHOF, op. cit. 
TABELA 14 - CONCENTRAÇÃO TOTAL DE METAIS NOS SEDIMENTOS DE FUNDO DURANTE A FASE 02/95 CAMPANHAS I (SIZIGIA) E II (QUADRATURA)

\begin{tabular}{|c|c|c|c|c|c|c|c|c|}
\hline Campanha & Estações & $\overline{C u}(p p m)$ & $\overline{C d}(p p m)$ & $\overline{P b}(p p m)$ & $\overline{C r}(p p m)$ & $\overline{Z Z n(p p m)}$ & $\overline{M n}(p p m)$ & $\overline{\mathrm{Fe}(\%)}$ \\
\hline \multirow{12}{*}{1} & $\overline{40}$ & $\overline{6}$ & $\overline{1}$ & 15 & $\overline{8}$ & 15 & $\overline{181}$ & 0,5 \\
\hline & 50 & 23 & 2 & 10 & 84 & 5 & 369 & 0,5 \\
\hline & 51 & 27 & 3 & 10 & 93 & 5 & 331 & 0,5 \\
\hline & 52 & 6 & 1 & 10 & 10 & 16 & 138 & 0,6 \\
\hline & 53 & 9 & 1 & 35 & 35 & 3 & 331 & 0,2 \\
\hline & 54 & 21 & 2 & 35 & 84 & 5 & 306 & 0,5 \\
\hline & 60 & 16 & 2 & 35 & 48 & 4 & 275 & 0,4 \\
\hline & 70 & 13 & 2 & 10 & 37 & 39 & 400 & 0,3 \\
\hline & 80 & 21 & 3 & 10 & 92 & 5 & 581 & 0,5 \\
\hline & 81 & 17 & 2 & 10 & 60 & 4 & 338 & 0,4 \\
\hline & 90 & 25 & 3 & 15 & 100 & 6 & 350 & 0,5 \\
\hline & 101 & 17 & 3 & 25 & 57 & 5 & 1150 & 0,5 \\
\hline \multirow{12}{*}{ II } & 40 & 6 & 2 & 15 & 8 & 13 & 481 & 0,4 \\
\hline & 50 & 10 & 2 & 40 & 40 & 40 & 281 & 0,2 \\
\hline & 51 & 26 & 2 & 40 & 95 & 7 & 344 & 0,5 \\
\hline & 52 & 5 & 2 & 20 & 7 & 12 & 44 & 0,5 \\
\hline & 53 & 12 & 2 & 25 & 45 & 41 & 225 & 0,3 \\
\hline & 54 & 2 & 2 & 10 & 88 & 5 & 313 & 0,5 \\
\hline & 60 & 13 & 2 & 30 & 42 & 3 & 263 & 0,3 \\
\hline & 70 & 13 & 2 & 10 & 41 & 36 & 288 & 0,3 \\
\hline & 80 & 22 & 3 & 10 & 92 & 6 & 563 & 0,5 \\
\hline & 81 & 17 & 2 & 10 & 63 & 4 & 325 & 0,4 \\
\hline & 90 & 24 & 3 & 10 & 90 & 5 & 350 & 0,5 \\
\hline & 101 & 18 & 3 & 30 & 99 & 6 & 1150 & 1,4 \\
\hline \multicolumn{2}{|c|}{$\overline{\text { S-value (a) }}$} & $\overline{15}$ & $\overline{\overline{0,4}}$ & 50 & 50 & 50 & & \\
\hline
\end{tabular}

(a) - THEELEN \& NIJHOF, op. cit.

TABELA 15 - CONCENTRAÇÃO (PPM) TOTAL DE METAIS NOS SEDIMENTOS DE FUNDO DURANTE A FASE 03/95 CAMPANHAS I (SIZIGIA) E II (QUADRATURA)

\begin{tabular}{|c|c|c|c|c|c|c|c|c|}
\hline Campanha & Estações & $\mathrm{Cu}(\mathrm{ppm})$ & Cd(ppm) & $\mathrm{Pb}(p p m)$ & $\mathrm{Cr}(p p m)$ & $Z n$ (ppm) & $M n(p p m)$ & $\mathrm{Fe}(\%)$ \\
\hline \multirow{8}{*}{ I } & 40 & 10 & 1 & 0 & 94 & 46 & 298 & 3 \\
\hline & 50 & 39 & 2 & 20 & 249 & 104 & 433 & 7 \\
\hline & 51 & 26 & 2 & 30 & 236 & 90 & 316 & 6 \\
\hline & 52 & 8 & 1 & 30 & 43 & 21 & 135 & 2 \\
\hline & 53 & 4 & 1 & 20 & 18 & 8 & 135 & 12 \\
\hline & 54 & 10 & 1 & 20 & 86 & 43 & 180 & 3 \\
\hline & 60 & 9 & 1 & 20 & 66 & 24 & 144 & 2 \\
\hline & 70 & 13 & 2 & 20 & 142 & 58 & 334 & 4 \\
\hline \multirow{14}{*}{$\|$} & 31 & 26 & 1 & 40 & 188 & 81 & 450 & 6 \\
\hline & 32 & 14 & 1 & 40 & 127 & 136 & 415 & 4 \\
\hline & 40 & 10 & 1 & 40 & 107 & 122 & 289 & 3 \\
\hline & 50 & 13 & 2 & 40 & 170 & 64 & 433 & 5 \\
\hline & 51 & 19 & 1 & 20 & 137 & 46 & 280 & 4 \\
\hline & 52 & 22 & 1 & 30 & 208 & 78 & 532 & 5 \\
\hline & 53 & 19 & 2 & 30 & 183 & 64 & 704 & 5 \\
\hline & 54 & 7 & 2 & 20 & 51 & 18 & 733 & 3 \\
\hline & 60 & 7 & 2 & 10 & 58 & 35 & 244 & 0 \\
\hline & 70 & 7 & 1 & 20 & 33 & 12 & 153 & 2 \\
\hline & 80 & 19 & 1 & 40 & 160 & 70 & 361 & 4 \\
\hline & 81 & 16 & 1 & 40 & 188 & 84 & 397 & 8 \\
\hline & 90 & 23 & 2 & 30 & 226 & 84 & 262 & 5 \\
\hline & 101 & 20 & 2 & 50 & 236 & 90 & 731 & 11 \\
\hline \multicolumn{2}{|c|}{ S-value (a) } & 15 & 0,4 & 50 & 50 & 50 & & \\
\hline \multicolumn{2}{|c|}{$\overline{\text {-value }}$} & 59 & 6.1 & 312 & 190 & 257 & & \\
\hline
\end{tabular}

(a) - THEELEN \& NIJHOF, op. cit. 
TABELA 16 - TEORES DOS METAIS (PPM) OBTIDOS POR EXTRAÇAO SEQÜENCIAL PARA OS SEDIMENTOS DE FUNDO DA FASE 03/95, CAMPANHAS I (SIZIGIA) E II (QUADRATURA)

\begin{tabular}{|c|c|c|c|c|c|c|c|}
\hline Estaçбes & $\overline{C u}$ & Cd & $\overline{P b}$ & $\mathbf{C r}$ & $Z n$ & $M n$ & Fe \\
\hline \multicolumn{8}{|c|}{ FRAÇAO TROCAVEL } \\
\hline 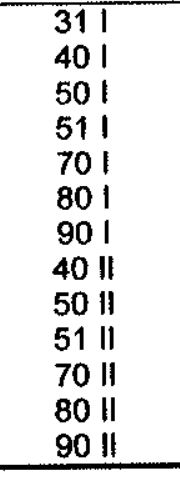 & $\begin{array}{l}<3 \\
<3 \\
<3 \\
<3 \\
<3 \\
<3 \\
<3 \\
<3 \\
<3 \\
<3 \\
<3 \\
<3 \\
<3 \\
<3 \\
<3 \\
\end{array}$ & $\begin{array}{l}<1 \\
<1 \\
<1 \\
<1 \\
<1 \\
<1 \\
<1 \\
<1 \\
<1 \\
<1 \\
<1 \\
<1 \\
<1\end{array}$ & $\begin{array}{l}<5 \\
<5 \\
<5 \\
<5 \\
<5 \\
<5 \\
<5 \\
<5 \\
<5 \\
<5 \\
<5 \\
<5 \\
<5 \\
\end{array}$ & $\begin{array}{l}<4 \\
<4 \\
<4 \\
<4 \\
<4 \\
<4 \\
<4 \\
<4 \\
<4 \\
<4 \\
<4 \\
<4 \\
<4 \\
\end{array}$ & $\begin{array}{l}<5 \\
<5 \\
<5 \\
<5 \\
<5 \\
<5 \\
<5 \\
<5 \\
<5 \\
<5 \\
<5 \\
<5 \\
<5 \\
\end{array}$ & $\begin{array}{r}39 \\
6 \\
13 \\
10 \\
5 \\
18 \\
5 \\
12 \\
19 \\
13 \\
8 \\
11 \\
6 \\
\end{array}$ & $\begin{array}{l}<1 \\
<1 \\
<1 \\
<1 \\
<1 \\
<1 \\
<1 \\
<1 \\
<1 \\
<1 \\
<1 \\
<1 \\
<1\end{array}$ \\
\hline \multicolumn{8}{|c|}{ FRAÇAO CARBONATOS } \\
\hline \begin{tabular}{l|l}
311 \\
401 \\
501 \\
511 \\
701 \\
801 \\
901 \\
$40 \|$ \\
$50 \|$ \\
5111 \\
$70 \|$ \\
$80 \|$ \\
$90 \|$ \\
\end{tabular} & $\begin{array}{l}<3 \\
<3 \\
<3 \\
<3 \\
<3 \\
<3 \\
<3 \\
<3 \\
<3 \\
<3 \\
<3 \\
<3 \\
<3 \\
<3 \\
\end{array}$ & $\begin{array}{l}<1 \\
<1 \\
<1 \\
<1 \\
<1 \\
<1 \\
<1 \\
<1 \\
<1 \\
<1 \\
<1 \\
<1 \\
<1\end{array}$ & $\begin{array}{l}<5 \\
<5 \\
<5 \\
<5 \\
<5 \\
<5 \\
<5 \\
<5 \\
<5 \\
<5 \\
<5 \\
<5 \\
<5 \\
\end{array}$ & $\begin{array}{l}<4 \\
<4 \\
<4 \\
<4 \\
<4 \\
<4 \\
<4 \\
<4 \\
<4 \\
<4 \\
<4 \\
<4 \\
<4 \\
\end{array}$ & $\begin{array}{l}<5 \\
<5 \\
<5 \\
<5 \\
<5 \\
<5 \\
<5 \\
<5 \\
<5 \\
<5 \\
<5 \\
<5 \\
<5 \\
\end{array}$ & $\begin{array}{r}42 \\
8 \\
17 \\
12 \\
4 \\
26 \\
9 \\
18 \\
1 \\
20 \\
5 \\
23 \\
8 \\
\end{array}$ & $\begin{array}{l}<1 \\
<1 \\
<1 \\
<1 \\
<1 \\
<1 \\
<1 \\
<1 \\
<1 \\
<1 \\
<1 \\
<1 \\
<1 \\
\end{array}$ \\
\hline \multicolumn{8}{|c|}{ FRAÇAO OXIDO/HIDROXIDOS DE Fe-Mn } \\
\hline $\begin{array}{l}311 \\
40 I \\
501 \\
511 \\
701 \\
801 \\
901 \\
40 \| \\
50 \| \\
51 \| \\
70 \| \\
80 \| \\
90 \| \\
\end{array}$ & $\begin{array}{l}<3 \\
<3 \\
<3 \\
<3 \\
<3 \\
<3 \\
<3 \\
<3 \\
<3 \\
<3 \\
<3 \\
<3 \\
<3 \\
<3 \\
\end{array}$ & $\begin{array}{l}<1 \\
<1 \\
<1 \\
<1 \\
<1 \\
<1 \\
<1 \\
<1 \\
<1 \\
<1 \\
<1 \\
<1 \\
<1\end{array}$ & $\begin{array}{r}10 \\
10 \\
10 \\
11 \\
10 \\
11 \\
7 \\
<5 \\
<5 \\
10 \\
<5 \\
10 \\
15 \\
\end{array}$ & $\begin{array}{r}8 \\
<4 \\
5 \\
<4 \\
<4 \\
<4 \\
<4 \\
<4 \\
<4 \\
<4 \\
5 \\
7 \\
5 \\
\end{array}$ & $\begin{array}{l}16 \\
42 \\
14 \\
16 \\
17 \\
23 \\
13 \\
12 \\
13 \\
26 \\
13 \\
13 \\
16 \\
\end{array}$ & $\begin{array}{r}360 \\
105 \\
43 \\
127 \\
114 \\
213 \\
75 \\
85 \\
26 \\
83 \\
113 \\
272 \\
108 \\
\end{array}$ & $\begin{array}{c}2300 \\
820 \\
1006 \\
1182 \\
2626 \\
788 \\
1750 \\
2130 \\
2210 \\
941 \\
2472 \\
1116 \\
2385 \\
\end{array}$ \\
\hline \multicolumn{8}{|c|}{ FRAÇĂO ORGANICA } \\
\hline 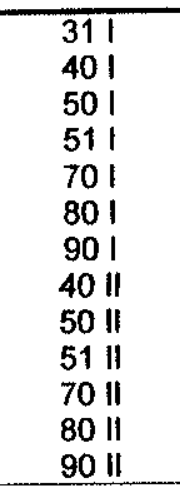 & $\begin{array}{l}<3 \\
<3 \\
<3 \\
<3 \\
<3 \\
<3 \\
<3 \\
<3 \\
<3 \\
<3 \\
<3 \\
<3 \\
<3 \\
<3\end{array}$ & $\begin{array}{l}<1 \\
<1 \\
<1 \\
<1 \\
<1 \\
<1 \\
<1 \\
<1 \\
<1 \\
<1 \\
<1 \\
<1 \\
<1\end{array}$ & $\begin{array}{r}10 \\
10 \\
8 \\
<5 \\
<5 \\
10 \\
12 \\
<5 \\
<5 \\
7 \\
<5 \\
10 \\
8 \\
\end{array}$ & $\begin{array}{l}13 \\
10 \\
11 \\
12 \\
<4 \\
12 \\
10 \\
<5 \\
<5 \\
14 \\
<5 \\
13 \\
8 \\
\end{array}$ & $\begin{array}{r}6 \\
10 \\
11 \\
10 \\
4 \\
8 \\
7 \\
3 \\
4 \\
9 \\
4 \\
9 \\
6 \\
\end{array}$ & $\begin{array}{r}240 \\
50 \\
103 \\
117 \\
27 \\
220 \\
62 \\
140 \\
142 \\
156 \\
30 \\
188 \\
48 \\
\end{array}$ & $\begin{array}{r}530 \\
2610 \\
939 \\
991 \\
2452 \\
1017 \\
574 \\
2910 \\
887 \\
1095 \\
2712 \\
991 \\
496 \\
\end{array}$ \\
\hline
\end{tabular}


Continuação

\begin{tabular}{|c|c|c|c|c|c|c|c|}
\hline Estaçöes & $\mathrm{Cu}$ & $\mathrm{Cd}$ & $P b$ & $\mathrm{Cr}$ & $Z n$ & $M n$ & $\mathrm{Fe}$ \\
\hline \multicolumn{8}{|c|}{ FRAÇAO RESIDUAL } \\
\hline 311 & 21 & $<1$ & 30 & 70 & 65 & 110 & 26500 \\
\hline 401 & 12 & $<1$ & 30 & 69 & 80 & 95 & 23000 \\
\hline 501 & 19 & $<1$ & 31 & 73 & 63 & 181 & 22029 \\
\hline 511 & 21 & $<1$ & 24 & 76 & 63 & 90 & 24841 \\
\hline 701 & 8 & $<1$ & 19 & 33 & 33 & 181 & 15233 \\
\hline 801 & 15 & $<1$ & 10 & 75 & 66 & 99 & 21326 \\
\hline 901 & 21 & $<1$ & 27 & 84 & 75 & 108 & 25779 \\
\hline $40 \|$ & 7 & $<1$ & $<5$ & 65 & 27 & 90 & 12300 \\
\hline $50 \mathrm{II}$ & 21 & $<1$ & 24 & 33 & 36 & 232 & 13592 \\
\hline $51 \|$ & 22 & $<1$ & 24 & 81 & 75 & 96 & 26247 \\
\hline $70 \|$ & 9 & $<1$ & 17 & 28 & 30 & 96 & 13358 \\
\hline $80 ॥$ & 19 & $<1$ & 24 & 74 & 66 & 90 & 21560 \\
\hline 9011 & 20 & $<1$ & 22 & 73 & 69 & 90 & 23904 \\
\hline S-value ${ }^{(a)}$ & 15 & 0,4 & 50 & 50 & 50 & & \\
\hline
\end{tabular}


TABELA 17 - MATRIZ DE CORRELAÇÃO ENTRE OS PARÂMETROS NO MATERIAL PARTICULADO EM SUSPENSÃO (MPS) E SEDIMENTOS DE FUNDO (SF). FASE 01/95 CAMPANHAS IE II.

\begin{tabular}{|c|c|c|c|c|c|c|c|c|c|c|c|c|c|c|c|c|c|c|c|}
\hline ASE & $01 / 95$ & & CAM & NHA & I & & & & & & & & & & & & & Areia & MO \\
\hline $\begin{array}{l}\text { SST } \\
\text { SSV } \\
\text { MPS }\end{array}$ & $\begin{array}{l}\text { SST } \\
1,0000 \\
0,8996 \\
0,1238\end{array}$ & $\begin{array}{l}1,0000 \\
0,1899\end{array}$ & 1,0000 & $M n_{s}$ & $\mathrm{Fe}_{3 z}$ & $\mathrm{Zn}_{38}$ & $\mathrm{Al}_{\mathbf{8 s}}$ & $\mathrm{Cu}_{8 \mathrm{f}}$ & $\mathrm{Cd}_{\mathrm{d}}$ & $\mathrm{Pb}_{\mathrm{b}_{1}}$ & $\mathrm{Cr}_{\mathbf{s t}}$ & $\mathbf{Z} \mathbf{n}_{s t}$ & $\mathrm{Mn}_{3 f}$ & $\mathrm{Fe}_{\text {st }}$ & $\mathrm{Al}_{31}$ & Argila & Silte & Arela & $\mathrm{mo}$ \\
\hline 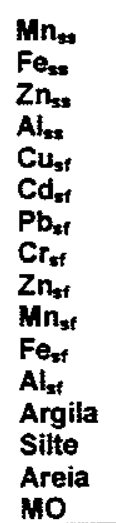 & $\begin{array}{r}0,4142 \\
-0,0749 \\
0,2896 \\
-0,1157 \\
-0,6832 \\
0,0576 \\
-0,4698 \\
-0,4502 \\
-0,4555 \\
-0,2792 \\
-0,0743 \\
-0,5967 \\
0,3258 \\
-0,4112 \\
-0,2105 \\
0,1454\end{array}$ & $\begin{array}{r}0,3313 \\
-0,0116 \\
0,1570 \\
-0,0755 \\
-0,7374 \\
0,1504 \\
-0,5186 \\
-0,5115 \\
-0,5572 \\
-0,1437 \\
-0,1269 \\
-0,6134 \\
0,2112 \\
-0,3750 \\
-0,0977 \\
0,0517\end{array}$ & $\begin{array}{r}0,3242 \\
0,5408 \\
0,4011 \\
0,6436 \\
-0,1299 \\
0,4490 \\
0,1808 \\
-0,2122 \\
-0,2056 \\
0,4843 \\
-0,1349 \\
-0,1825 \\
0,0134 \\
0,0207 \\
0,1047 \\
-0,0967 \\
\end{array}$ & $\begin{array}{r}1,0000 \\
0,4579 \\
0,8074 \\
0,3536 \\
-0,5208 \\
-0,1030 \\
-0,4771 \\
-0,4961 \\
-0,5050 \\
0,2916 \\
-0,2192 \\
-0,4921 \\
-0,2489 \\
-0,5435 \\
0,2461 \\
-0,3518 \\
\end{array}$ & $\begin{array}{r}1,0000 \\
0,3803 \\
0,9053 \\
-0,1758 \\
-0,1219 \\
-0,1986 \\
-0,3129 \\
-0,3411 \\
0,2490 \\
-0,1680 \\
-0,2673 \\
-0,3225 \\
0,0030 \\
0,3042 \\
-0,2830 \\
\end{array}$ & $\begin{array}{r}1,0000 \\
0,4234 \\
-0,1625 \\
0,0552 \\
-0,2301 \\
-0,2721 \\
-0,2363 \\
-0,0845 \\
-0,0676 \\
-0,2379 \\
-0,0310 \\
-0,2457 \\
0,0095 \\
-0,2165 \\
\end{array}$ & $\begin{array}{r}1,0000 \\
0,0053 \\
-0,0846 \\
0,0338 \\
-0,0631 \\
-0,1307 \\
0,2521 \\
0,0340 \\
-0,3055 \\
-0,0238 \\
0,2062 \\
0,0270 \\
-0,0343 \\
\end{array}$ & $\begin{array}{r}1,0000 \\
0,1713 \\
0,7523 \\
0,8223 \\
0,8708 \\
0,0900 \\
0,5309 \\
0,8270 \\
0,2661 \\
0,7061 \\
-0,3706 \\
0,3802 \\
\end{array}$ & $\begin{array}{r}1,0000 \\
0,4837 \\
0,0919 \\
0,1829 \\
-0,0225 \\
0,1777 \\
0,1818 \\
0,2022 \\
0,2563 \\
-0,2162 \\
-0,0449 \\
\end{array}$ & $\begin{array}{r}1,0000 \\
0,8422 \\
0,8678 \\
-0,0646 \\
0,6401 \\
0,5065 \\
0,4934 \\
0,7165 \\
-0,5641 \\
0,5322 \\
\end{array}$ & $\begin{array}{r}1,0000 \\
0,9734 \\
-0,0406 \\
0,8302 \\
0,4813 \\
0,6247 \\
0,7667 \\
-0,7156 \\
0,7641 \\
\end{array}$ & $\begin{array}{r}1,0000 \\
-0,0406 \\
0,8154 \\
0,6241 \\
0,5763 \\
0,7367 \\
-0,6809 \\
0,7089 \\
\end{array}$ & $\begin{array}{r}1,0000 \\
-0,0019 \\
0,0331 \\
-0,2522 \\
-0,0539 \\
0,3163 \\
-0,1521 \\
\end{array}$ & $\begin{array}{r}1,0000 \\
0,2843 \\
0,7830 \\
0,6598 \\
-0,8685 \\
0,8380 \\
\end{array}$ & $\begin{array}{r}1,0000 \\
-0,0924 \\
0,3404 \\
-0,0094 \\
0,1422 \\
\end{array}$ & $\begin{array}{r}1,0000 \\
0,5859 \\
-0,9688 \\
0,8708 \\
\end{array}$ & $\begin{array}{r}1,0000 \\
-0,6338 \\
0,5678 \\
\end{array}$ & $\begin{array}{r}1,0000 \\
-0,8597 \\
\end{array}$ & 1,0000 \\
\hline
\end{tabular}

\begin{tabular}{|c|c|c|c|c|c|c|c|c|c|c|c|c|c|c|c|c|c|c|c|}
\hline ASE & $\frac{01 / 95}{\mathrm{SST}}$ & & CAM & $\frac{\text { NHA }}{M n_{n}}$ & II & $\mathrm{Zn}_{\mathrm{n}}$ & $\mathrm{Al}_{\mathrm{st}}$ & Cuat & $\mathrm{Cd}_{n t}$ & $\mathrm{~Pb}_{b_{4}}$ & $\mathrm{Cr}_{\mathrm{sf}}$ & $Z n_{s f}$ & $\mathrm{Mn}_{\mathrm{sf}}$ & $\mathrm{F}_{\mathrm{Bst}_{\mathrm{st}}}$ & $\overline{\mathrm{Al}_{3 f}}$ & Argila & Silte & Areia & Mo \\
\hline
\end{tabular}

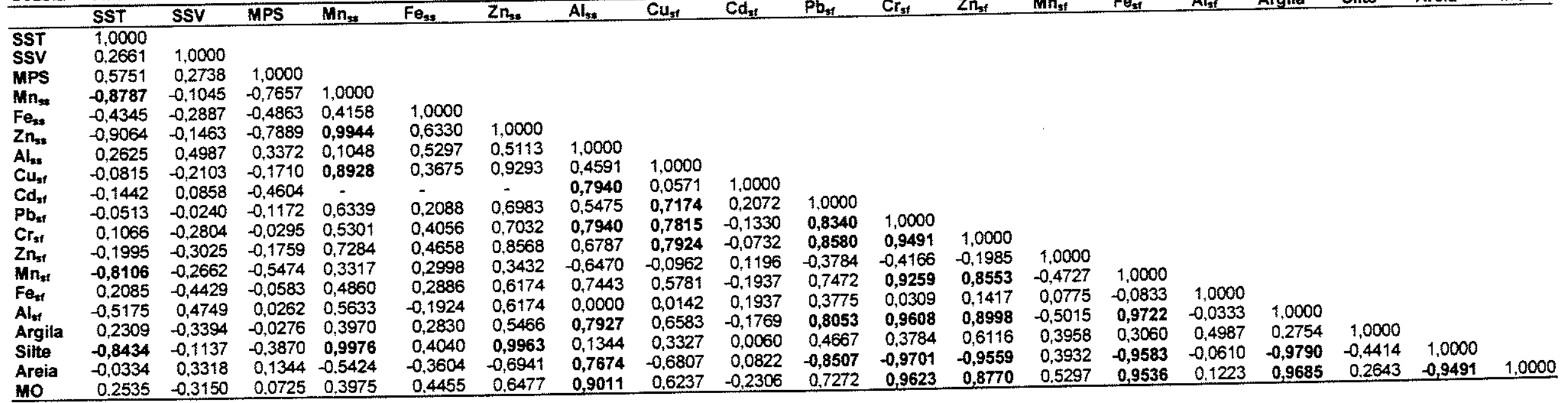


TABELA 18 - MATRIZ DE CORRELAÇÃO ENTRE OS PARÁMETROS NO MATERIAL PARTICULADO EM SUSPENSÃO (MPS) E SEDIMENTOS DE FUNDO (SF). FASE 02/95 CAMPANHAS I E II.

\begin{tabular}{|c|c|c|c|c|c|c|c|c|c|c|c|c|c|c|c|c|c|c|c|}
\hline FASE & $\frac{02 / 95}{\text { SST }}$ & SSV & $\frac{\text { CAMPA }}{\text { MPS }}$ & $\frac{\mathrm{NHA}}{\mathrm{Mn}_{\mathrm{ss}}}$ & $\mathrm{Fe}_{\mathrm{ss}}$ & $Z n_{4 s}$ & $\overline{\mathrm{Al}_{\mathrm{sz}}}$ & $\mathrm{Cu}_{\mathrm{st}}$ & $\mathrm{Cd}_{\mathrm{st}}$ & $\mathrm{Pb}_{3 t}$ & $\mathrm{Cr}_{\mathbf{s t}_{\mathrm{s}}}$ & $2 n_{s t}$ & $\mathbf{M n}_{\mathbf{3 f}}$ & $\mathrm{Fe}_{\mathrm{sf}}$ & $\mathrm{Al}_{\mathrm{st}}$ & Argila & Silte & Areia & MO \\
\hline $\begin{array}{l}\text { SST } \\
\text { SSV } \\
\text { MPS }\end{array}$ & $\begin{array}{l}1,0000 \\
0,7633 \\
0,6778\end{array}$ & $\begin{array}{l}1,0000 \\
0,4999\end{array}$ & 1,0000 & & & & & & & & & & & & & & & & \\
\hline $\begin{array}{l}\mathrm{Mn}_{\mathrm{ss}} \\
\mathrm{Fe}_{3:}\end{array}$ & $\begin{array}{c}0,6778 \\
0,7277\end{array}$ & $\begin{array}{c}0,4599 \\
- \\
0,5916\end{array}$ & $\begin{array}{l}1,0000 \\
0,9565\end{array}$ & - & 1,0000 & & & & & & & & & & & & & & \\
\hline $\begin{array}{l}\mathrm{Zn}_{58} \\
\mathrm{Al}_{53}\end{array}$ & $\begin{array}{l}0,2961 \\
0,7813\end{array}$ & $\begin{array}{l}0,3564 \\
0,6580\end{array}$ & $\begin{array}{l}0,0538 \\
0,6891\end{array}$ & - & $\begin{array}{l}0,0943 \\
0,7776\end{array}$ & $\begin{array}{l}1,0000 \\
0,2560\end{array}$ & & & & & & & & & & & & & \\
\hline $\begin{array}{l}\mathrm{Al}_{\text {ss }} \\
\mathrm{Cu}_{\mathrm{st}} \\
\mathrm{Cd}_{\text {st }}\end{array}$ & $\begin{array}{l}\mathbf{0 , 7 8 1 3} \\
0,1996 \\
0,0419\end{array}$ & $\begin{array}{r}0,6580 \\
-0,0734\end{array}$ & $\begin{array}{l}0,6891 \\
0,3655 \\
0,3818\end{array}$ & - & $\begin{array}{l}0,7776 \\
0,1696 \\
0,1473\end{array}$ & $\begin{array}{r}0,2560 \\
-0,2808 \\
-0,3191\end{array}$ & $\begin{array}{l}1,0000 \\
0,0909 \\
0,0514\end{array}$ & 1,0000 & & & & & & & & & & & \\
\hline $\begin{array}{l}\mathrm{Cd}_{\mathrm{st}} \\
\mathrm{Pb}_{\mathrm{sf}}\end{array}$ & $\begin{array}{l}0,0419 \\
0,0498\end{array}$ & $\begin{array}{l}-0,2559 \\
-0,0133\end{array}$ & $\begin{array}{r}0,3818 \\
-0,1899\end{array}$ & - & $\begin{array}{r}0,1473 \\
-0,0987\end{array}$ & $\begin{array}{r}-0,3191 \\
0,7583\end{array}$ & $\begin{array}{l}0,0514 \\
0,0316\end{array}$ & $\begin{array}{r}0,9018 \\
-0,1394\end{array}$ & $\begin{array}{r}1,0000 \\
-0,2866\end{array}$ & 1,0000 & & & & & & & & & \\
\hline $\begin{array}{l}\mathrm{Cr}_{\text {sf }} \\
\mathrm{Zn}_{\mathrm{nst}}\end{array}$ & $\begin{array}{r}0,1029 \\
-0,5940\end{array}$ & $\begin{array}{l}-0,0133 \\
-0,2212 \\
-0,2123\end{array}$ & $\begin{array}{r}-0,1899 \\
0,2163 \\
-0,2954\end{array}$ & - & $\begin{array}{r}-0,0028 \\
-0,2400\end{array}$ & $\begin{array}{r}0,2594 \\
-0,2594 \\
-0,2886\end{array}$ & $\begin{array}{r}-0,3501 \\
-0,3318\end{array}$ & $\begin{array}{r}0,9731 \\
-0,4128\end{array}$ & $\begin{array}{r}0,8887 \\
-0,2178\end{array}$ & $\begin{array}{l}-0,0831 \\
-0,3511\end{array}$ & $\begin{array}{r}1,0000 \\
-0,4749\end{array}$ & & & & & & & & \\
\hline $\begin{array}{l}2 n_{s f} \\
M n_{s f}\end{array}$ & $\begin{array}{l}-0,5940 \\
-0,1701\end{array}$ & $\begin{array}{l}-0,2123 \\
-0,3385\end{array}$ & $\begin{array}{l}-0,2954 \\
-0,0920\end{array}$ & - & $\begin{array}{l}-0,2400 \\
-0,3178\end{array}$ & $\begin{array}{l}-0,2886 \\
-0,1043\end{array}$ & $\begin{array}{l}-0,3318 \\
-0,2845\end{array}$ & $\begin{array}{r}-0,4128 \\
0,5628\end{array}$ & $\begin{array}{r}-0,2178 \\
0,6865\end{array}$ & $\begin{array}{l}-0,3511 \\
-0,1823\end{array}$ & $\begin{array}{r}-0,4749 \\
0,6592\end{array}$ & $\begin{array}{r}1,0000 \\
-0,0827\end{array}$ & 1,0000 & & & & & & \\
\hline & $-0,1053$ & $-0,3095$ & 0,0533 & - & $-0,0324$ & $\begin{array}{c}-0,6236 \\
-\end{array}$ & -0.4341 & 0,3171 & 0,2559 & $-0,3360$ & 0,3336 & $-0,2061$ & $-0,0601$ & 1,0000 & & & & & \\
\hline Argila & 0,0604 & $-0,4579$ & 0,3585 & 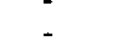 & 0,2712 & $-0,4972$ & 0,0894 & $\overline{0,3420}$ & $\overline{0,5031}$ & $-0,2914$ & 0,3566 & $-0,2328$ & $-0,4489$ & & - & & & & \\
\hline Silte & $-0,2126$ & 0,2500 & $-0,4311$ & - & $-0,4503$ & 0,2698 & $-0,4091$ & $-0,0753$ & $-0,2750$ & 0,1261 & $-0,0455$ & 0,1279 & $\begin{array}{r}-0,4489 \\
0,2131\end{array}$ & $\begin{array}{r}0,5739 \\
-0,2131\end{array}$ & 5 & $\begin{array}{r}1,0000 \\
-0,8708\end{array}$ & 1,0000 & & \\
\hline Areia & 0,2732 & 0,3018 & $-0,0133$ & - & 0,1944 & 0,5020 & 0,5646 & $-0,5263$ & $-0,4893$ & 0,4674 & $-0,5449$ & $-0,0780$ & 0.0179 & $-0,5992$ & - & $-0,2002$ & $-0,2600$ & 1,0000 & \\
\hline MO & 0,6997 & 0,5703 & 0.5614 & $=$ & 0,5093 & -0.0885 & 0,5232 & 0,6416 & 0.4677 & -0.1852 & 0.5252 & -0.2859 & 0,3060 & $-0,1131$ & - & $-0,0779$ & 0,0859 & $-0,1804$ & 1,0000 \\
\hline \multirow[t]{2}{*}{ FASE } & $02 / 95$ & & \multicolumn{2}{|c|}{ CAMPANHA } & II & & & & & & & & & & & & & & \\
\hline & SST & SSV & MPS & $\mathrm{Mn}_{\mathrm{ss}}$ & $\mathrm{Fe}_{3 x}$ & $\mathrm{Zn}_{38}$ & $A l_{s 3}$ & $\mathrm{Cu}_{31}$ & $\mathrm{Cd}_{s f}$ & $\mathrm{~Pb}_{5 f}$ & $\mathrm{Cr}_{\text {st }}$ & $\mathrm{Zn}_{31}$ & $\mathrm{Mn}_{s t}$ & $\mathrm{Fe}_{3 i}$ & $\mathrm{Al}_{\mathrm{s}}$ & Argila & Silte & Areia & MO \\
\hline $\begin{array}{l}\text { SST } \\
\text { SSV }\end{array}$ & $\begin{array}{l}1,0000 \\
0,6268\end{array}$ & 1,0000 & & & & & & & & & & & & & & & & & \\
\hline $\begin{array}{l}\text { MPS } \\
M n_{s s}\end{array}$ & 0,5206 & 0,5577 & 1,0000 & - & & & & & & & & & & & & & & & \\
\hline $\mathrm{Fe}_{43}$ & $-0,0514$ & 0,3606 & $-0,3501$ & - & 1,0000 & & & & & & & & & & & & & & \\
\hline $\mathrm{Zn}_{\mathrm{n}}$ & $\begin{array}{l}0,1771 \\
0,4810\end{array}$ & $\begin{array}{r}-0,3021 \\
0,4524\end{array}$ & $\begin{array}{l}0,4627 \\
0,2839\end{array}$ & - & $\begin{array}{r}-0,7974 \\
0,5637\end{array}$ & $\begin{array}{r}1,0000 \\
-0,0741\end{array}$ & 1,0000 & & & & & & & & & & & & \\
\hline $\mathrm{Cu}_{81}$ & $-0,3626$ & 0,1678 & 0,0690 & - & $\begin{array}{r}0,0037 \\
-0,2329\end{array}$ & $-0,1849$ & $-0,5260$ & 1,0000 & & & & & & & & & & & \\
\hline $\mathrm{Cd}_{\text {st }}$ & $\begin{array}{l}0,2797 \\
0,0432\end{array}$ & $\begin{array}{l}0,0000 \\
0,3293\end{array}$ & $\begin{array}{r}0,6062 \\
-0,4713\end{array}$ & - & $\begin{array}{r}-0,5742 \\
0,3872\end{array}$ & 0,2955 & $-0,3459$ & 0,5420 & 1,0000 & & & & & & & & & & \\
\hline $\begin{array}{l}\mathrm{Pb}_{3 t} \\
\mathrm{Cr}_{\mathrm{st}}\end{array}$ & $\begin{array}{r}0,0432 \\
-0,1047\end{array}$ & $\begin{array}{r}0,3293 \\
-0,2059\end{array}$ & $\begin{array}{l}-0,4713 \\
-0,0731\end{array}$ & - & $\begin{array}{r}0,3872 \\
-0,5739\end{array}$ & $\begin{array}{r}-0,1055 \\
0.2290\end{array}$ & $\begin{array}{r}0,3524 \\
-0,5561\end{array}$ & $\begin{array}{l}0,8246 \\
0,5901\end{array}$ & $\begin{array}{r}-0,3162 \\
0,4446\end{array}$ & 1,0000 & 10000 & & & & & & & & \\
\hline $\begin{array}{l}\mathrm{Cr}_{\mathbf{s t}} \\
\mathrm{Zn}_{3 t}\end{array}$ & 0,3931 & 0,3629 & $-0,1149$ & - & $\begin{array}{r}-0,5739 \\
0,5247\end{array}$ & $\begin{array}{r}0.2290 \\
-0,5134\end{array}$ & $\begin{array}{r}-0,5561 \\
0,3830\end{array}$ & $\begin{array}{r}0,5901 \\
-0,2911\end{array}$ & $\begin{array}{r}0,4446 \\
-0,3921\end{array}$ & $\begin{array}{l}0,5390 \\
0,2607\end{array}$ & $\begin{array}{r}1,0000 \\
-0,4634\end{array}$ & 1.0000 & & & & & & & \\
\hline $\mathrm{Mn}_{* f}$ & $\begin{array}{l}0,4022 \\
0,3537\end{array}$ & $\begin{array}{l}0,3372 \\
0,0000\end{array}$ & $\begin{array}{l}0,8956 \\
0,4118\end{array}$ & - & $-0,5670$ & 0.4898 & 0,0215 & 0,3572 & $\begin{array}{r}-0,7035 \\
0,708\end{array}$ & $-0,0045$ & 0,3141 & $-0,3036$ & 1,0000 & 10000 & & & & & \\
\hline $\begin{array}{l}\mathrm{Fe}_{\mathrm{st}} \\
\mathrm{Al}_{\mathrm{sf}}\end{array}$ & & $\begin{array}{c}0,0000 \\
-\end{array}$ & $\begin{array}{c}0,4118 \\
-\end{array}$ & - & $-0,3816$ & $-0,5071$ & $-0,0446$ & $-0,0808$ & 0,6708 & 0,3872 & $\begin{array}{l}0,2292 \\
-\end{array}$ & $\begin{array}{c}-0,5071 \\
-\end{array}$ & $\begin{array}{l}0,3614 \\
-\end{array}$ & 1,0000 & - & & & & \\
\hline Argila & $-0,2623$ & $-0,2460$ & $-0,0640$ & - & $-0,5756$ & 0,2257 & $-0,6546$ & 0,6316 & 0,4469 & $-0,1916$ & 0,9628 & $-0,6160$ & 0,2860 & 0,2692 & - & 1,0000 & & & \\
\hline Silte & 0.1050 & 0,1355 & $-0,1853$ & - & 0,7611 & $-0,4919$ & 0,5706 & $-0,5681$ & $-0,4752$ & 0,0851 & $-0,7542$ & 0,5749 & $-0,5718$ & $-0,0564$ & - & $-0,7610$ & $\begin{array}{r}1,0000 \\
-0,5388\end{array}$ & & \\
\hline $\begin{array}{l}\text { Areia } \\
\text { MO }\end{array}$ & $\begin{array}{r}0,1152 \\
-0,0153\end{array}$ & $\begin{array}{l}0,0802 \\
0.0119\end{array}$ & $\begin{array}{l}0,2332 \\
0.2771\end{array}$ & - & $\begin{array}{r}-0,3416 \\
-0,1747\end{array}$ & $\begin{array}{r}0,4370 \\
-0,0408\end{array}$ & $\begin{array}{r}-0,0263 \\
0,0486\end{array}$ & $\begin{array}{l}0,0369 \\
0.3458\end{array}$ & $\begin{array}{l}0,1048 \\
0,1622\end{array}$ & $\begin{array}{r}0,1875 \\
-0,2391\end{array}$ & $\begin{array}{r}-0,1016 \\
0.1039\end{array}$ & $\begin{array}{r}-0,1888 \\
0.1968\end{array}$ & $\begin{array}{l}0,3848 \\
0,4527\end{array}$ & $\begin{array}{l}-0,2335 \\
-0,3262\end{array}$ & - & $\begin{array}{l}-0,1083 \\
-0,0195\end{array}$ & $\begin{array}{r}-0,5388 \\
-0,2540\end{array}$ & $\begin{array}{l}1,0000 \\
0,2109\end{array}$ & 1,0000 \\
\hline
\end{tabular}


TABELA 19 - MATRIZ DE CORRELACCÃO ENTRE OS PARÂMETROS NO MATERIAL PARTICULADO EM SUSPENSÃO (MPS) E SEDIMENTOS DE FUNDO (SF). FASE 03/95 CAMPANHAS IE II.

\begin{tabular}{|c|c|c|c|c|c|c|c|c|c|c|c|c|c|c|c|c|c|c|c|}
\hline FASE & $\frac{03 / 95}{\text { SST }}$ & & $\frac{\text { CAMP }}{\text { MPS }}$ & $\frac{\text { NHA }}{M n_{s s}}$ & $\frac{I}{F e_{s 3}}$ & $\mathrm{Zn}_{\mathrm{n}_{8}}$ & $A l_{58}$ & $\mathrm{Cu}_{s t}$ & $\mathrm{Cd}_{\text {st }}$ & $\mathrm{Pb}_{\mathrm{sf}}$ & $\mathrm{Cr}_{5 f}$ & $2 n_{s f}$ & $\mathrm{Mn}_{\mathrm{gf}}$ & $\mathrm{Fe}_{\text {st }}$ & $\mathrm{Al}_{\text {si }}$ & Argila & Silte & Areia & MO \\
\hline $\begin{array}{l}\text { SST } \\
\text { SSV } \\
\text { MPS }\end{array}$ & $\begin{array}{l}1,0000 \\
0,9350 \\
0,4140\end{array}$ & $\begin{array}{l}1,0000 \\
0,3982\end{array}$ & 1,0000 & & & & & & & & & & & & & & & & \\
\hline 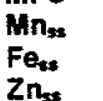 & $-\overline{0}, 0152$ & $\begin{array}{r}- \\
-0,1019 \\
-0,7489\end{array}$ & $\begin{array}{r}-0,8955 \\
-0,6971\end{array}$ & - & $\begin{array}{l}1,0000 \\
0,5312\end{array}$ & & & & & & & & & & & & & & \\
\hline $\begin{array}{l}\mathrm{Zn}_{\mathrm{ss}} \\
\mathrm{Al}_{\mathrm{sz}} \\
\mathrm{Cu}_{\mathrm{st}}\end{array}$ & $\begin{array}{r}-0,5791 \\
0,0788 \\
0,1799\end{array}$ & & $\begin{array}{r}-0,6971 \\
-0,6588 \\
0,1768\end{array}$ & - & $\begin{array}{r}0,5312 \\
\mathbf{0 , 7 5 6 0} \\
-0,6724\end{array}$ & $\begin{array}{r}1,0000 \\
0,3163 \\
-0,9727\end{array}$ & $\begin{array}{r}1,0000 \\
-0,4646\end{array}$ & 1,0000 & & & & & & & & & & & \\
\hline $\begin{array}{l}C_{u} u_{s t} \\
C_{d s t}\end{array}$ & $\begin{array}{r}0,1799 \\
-0,0047\end{array}$ & $\begin{array}{l}0,4301 \\
0,0393\end{array}$ & $\begin{array}{r}0,1768 \\
0,4597 \\
-0,2016\end{array}$ & - & $\begin{array}{l}-0,6724 \\
-0,9429 \\
-0,1014\end{array}$ & $\begin{array}{r}-0,9727 \\
-0,6455 \\
0,0000\end{array}$ & $\begin{array}{r}-0,4646 \\
-0,7614 \\
0,5422\end{array}$ & $\begin{array}{l}1,0000 \\
0,6389 \\
0,2568\end{array}$ & $\begin{array}{r}1,0000 \\
-0,1184\end{array}$ & 1,0000 & & & & & & & & & \\
\hline $\begin{array}{l}\mathrm{Pb}_{s f} \\
\mathrm{Cr}_{s f}\end{array}$ & $\begin{array}{r}-0,3338 \\
0,0308\end{array}$ & $\begin{array}{r}-0,1759 \\
0,2567\end{array}$ & $\begin{array}{r}-0,2016 \\
0,1284\end{array}$ & & $\begin{array}{l}-0,1014 \\
-0,8017\end{array}$ & $\begin{array}{r}0,0000 \\
-0,8579\end{array}$ & $\begin{array}{r}0,0422 \\
-0,6812 \\
-0,6470\end{array}$ & $\begin{array}{l}0,2568 \\
0,9431 \\
0,6853\end{array}$ & $\begin{array}{r}-0,1184 \\
0,7351 \\
0,3864\end{array}$ & $\begin{array}{l}1,0000 \\
0,2759\end{array}$ & 1,0000 & & & & & & & & \\
\hline $\begin{array}{l}\mathrm{Zn}_{\mathrm{n}} \\
\mathrm{Mn}_{\mathrm{n}} \\
\mathrm{Fe}_{\mathrm{nt}}\end{array}$ & $\begin{array}{r}0,1208 \\
0,0167 \\
-0,2144\end{array}$ & $\begin{array}{r}0,3572 \\
0,2879 \\
-0,0814\end{array}$ & $\begin{array}{l}0,2829 \\
0,2242 \\
0,0187\end{array}$ & - & $\begin{array}{r}-0,7533 \\
-0,7689 \\
0,1586\end{array}$ & $\begin{array}{l}-0,8429 \\
-0,7294 \\
-0,0098\end{array}$ & $\begin{array}{r}-0,6470 \\
-0,8072 \\
0,0558\end{array}$ & $\begin{array}{l}0,6853 \\
0,7608 \\
0,1876\end{array}$ & $\begin{array}{l}0,3864 \\
0,4180 \\
0,1743\end{array}$ & $\begin{array}{l}0,5410 \\
0,4164 \\
0,0188\end{array}$ & $\begin{array}{l}\mathbf{0 , 7 6 4 4} \\
\mathbf{0 , 8 1 5 3} \\
0,1006\end{array}$ & $\begin{array}{r}1,0000 \\
0,8769 \\
-0,0098\end{array}$ & $\begin{array}{l}1,0000 \\
0,0919\end{array}$ & 1,0000 & & & & & \\
\hline $\begin{array}{l}\mathrm{Fe}_{\mathrm{nt}} \\
\mathrm{Al}_{\mathrm{si}}\end{array}$ & & $-0,0814$ & 0,0187 & - & $\begin{array}{c}0,1586 \\
-\end{array}$ & $-0,0098$ & - & $\begin{array}{l}0,1876 \\
-\end{array}$ & & & - & - & & & - & & & & \\
\hline $\begin{array}{l}\text { Argila } \\
\text { Silte }\end{array}$ & $\begin{array}{l}0,0226 \\
0,0759\end{array}$ & $\begin{array}{r}-0,1034 \\
0,2659\end{array}$ & $\begin{array}{r}-0,7534 \\
0,7921\end{array}$ & - & $\begin{array}{r}0,4458 \\
-0,5392\end{array}$ & $\begin{array}{r}0,5207 \\
-0,7485\end{array}$ & $\begin{array}{r}0,5461 \\
-0,4813\end{array}$ & $\begin{array}{r}-0,1166 \\
0,5166\end{array}$ & $\begin{array}{r}-0,1466 \\
0,5070\end{array}$ & $\begin{array}{l}-0,1184 \\
-0,2188\end{array}$ & $\begin{array}{l}0,0337 \\
0,3751\end{array}$ & $\begin{array}{l}0,0332 \\
0,3809\end{array}$ & $\begin{array}{l}0,0215 \\
0,5344\end{array}$ & $\begin{array}{r}-0,4618 \\
0,6331\end{array}$ & - & $\begin{array}{r}1,0000 \\
-0,8587 \\
-0,1055\end{array}$ & $\begin{array}{r}1,0000 \\
-0,4006\end{array}$ & & \\
\hline $\begin{array}{l}\text { Areia } \\
\text { no }\end{array}$ & $\begin{array}{r}-0,0908 \\
0,1435\end{array}$ & $\begin{array}{r}-0,2016 \\
-0,0100\end{array}$ & $\begin{array}{r}-0,2950 \\
0,1778\end{array}$ & - & $\begin{array}{r}0,5618 \\
-0,1738\end{array}$ & $\begin{array}{l}0,6506 \\
0.0775\end{array}$ & $\begin{array}{l}0,1703 \\
0,4356\end{array}$ & $\begin{array}{r}-0,7199 \\
-0,1237 \\
\end{array}$ & $\begin{array}{r}-0,7748 \\
-0,0755 \\
\end{array}$ & $\begin{array}{r}-0,4885 \\
0,6533 \\
\end{array}$ & $\begin{array}{r}-0,7367 \\
-0,2122 \\
\end{array}$ & $\begin{array}{r}-0,7404 \\
-0,2130\end{array}$ & $\begin{array}{r}-0,6254 \\
-0,2951 \\
\end{array}$ & $\begin{array}{r}-0,3454 \\
-0,3597 \\
\end{array}$ & & $\begin{array}{r}-0,1055 \\
0,2487 \\
\end{array}$ & $\begin{array}{r}-0,4000 \\
-0,2307 \\
\end{array}$ & $\begin{array}{r}1,1816 \\
\end{array}$ & 1,0000 \\
\hline
\end{tabular}

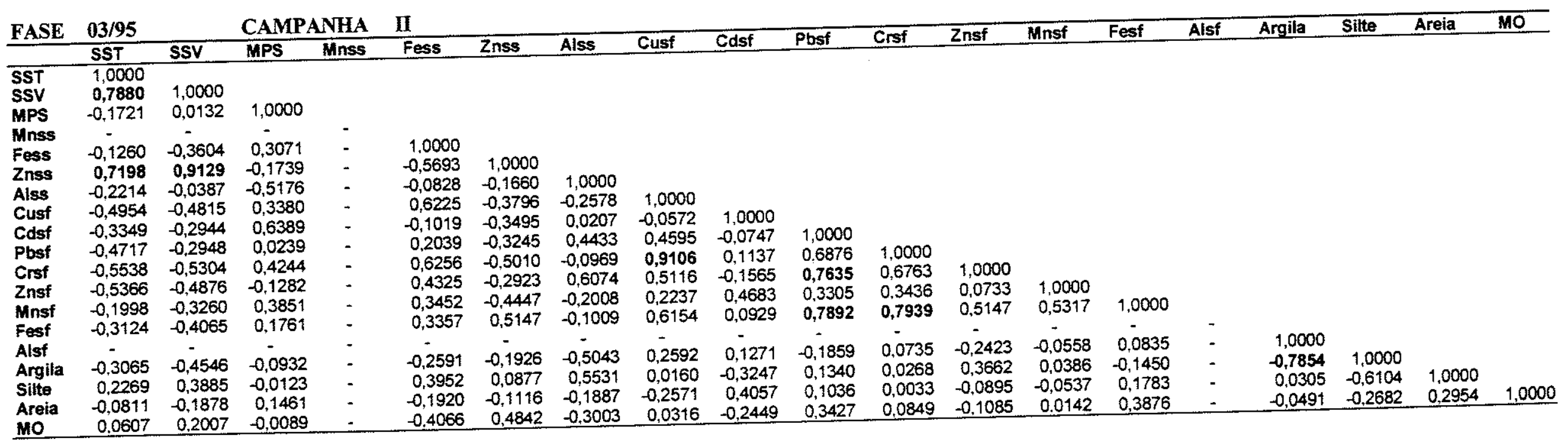


TABELA 20 - PARAMETROS ESTATISTICOS PARA OS DADOS (mg/L) DO MATERIAL PARTICULADO EM SUSPENSAO DURANTE AS FASES 01/95, 02/95 E 03/95.

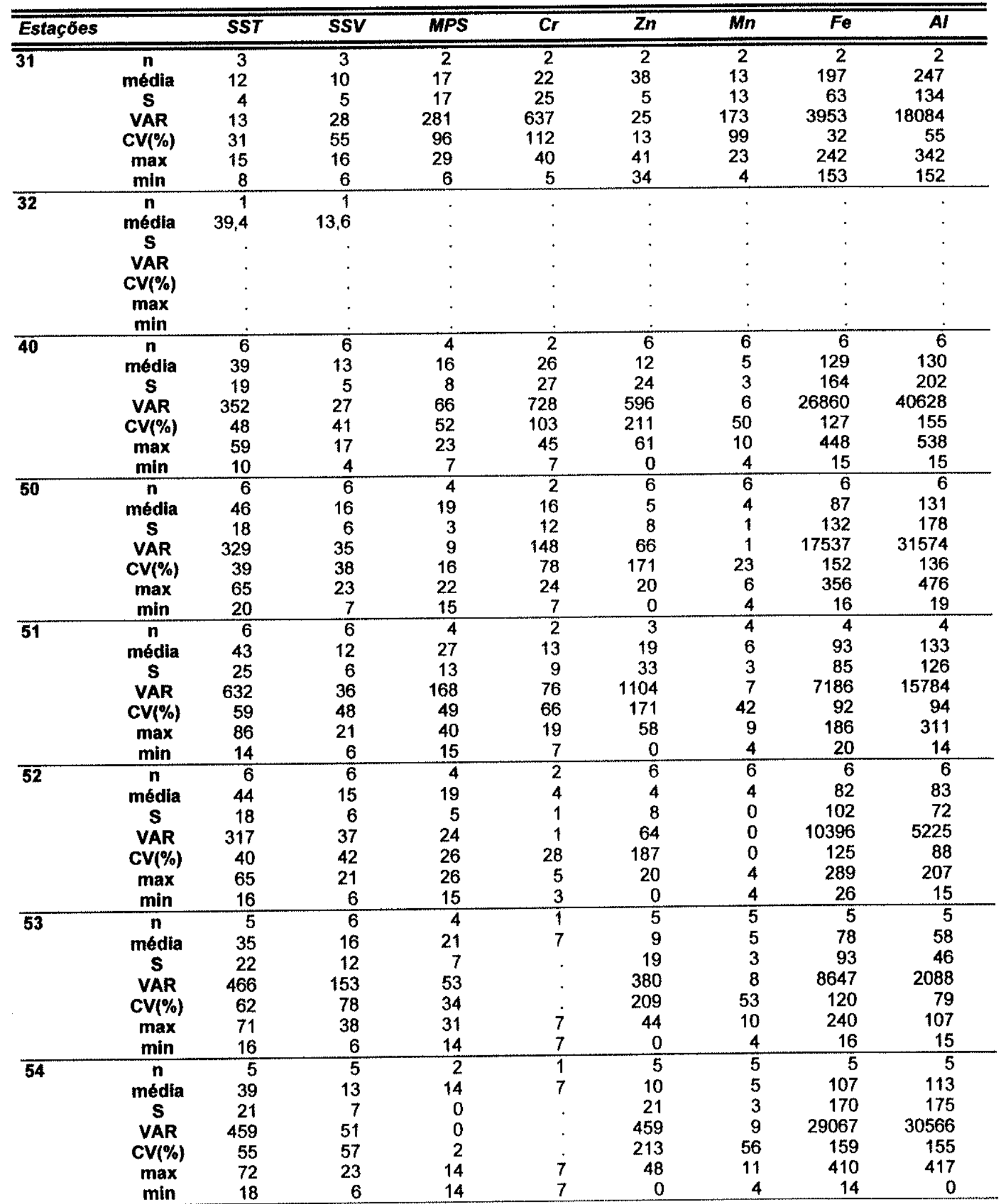


Cont...

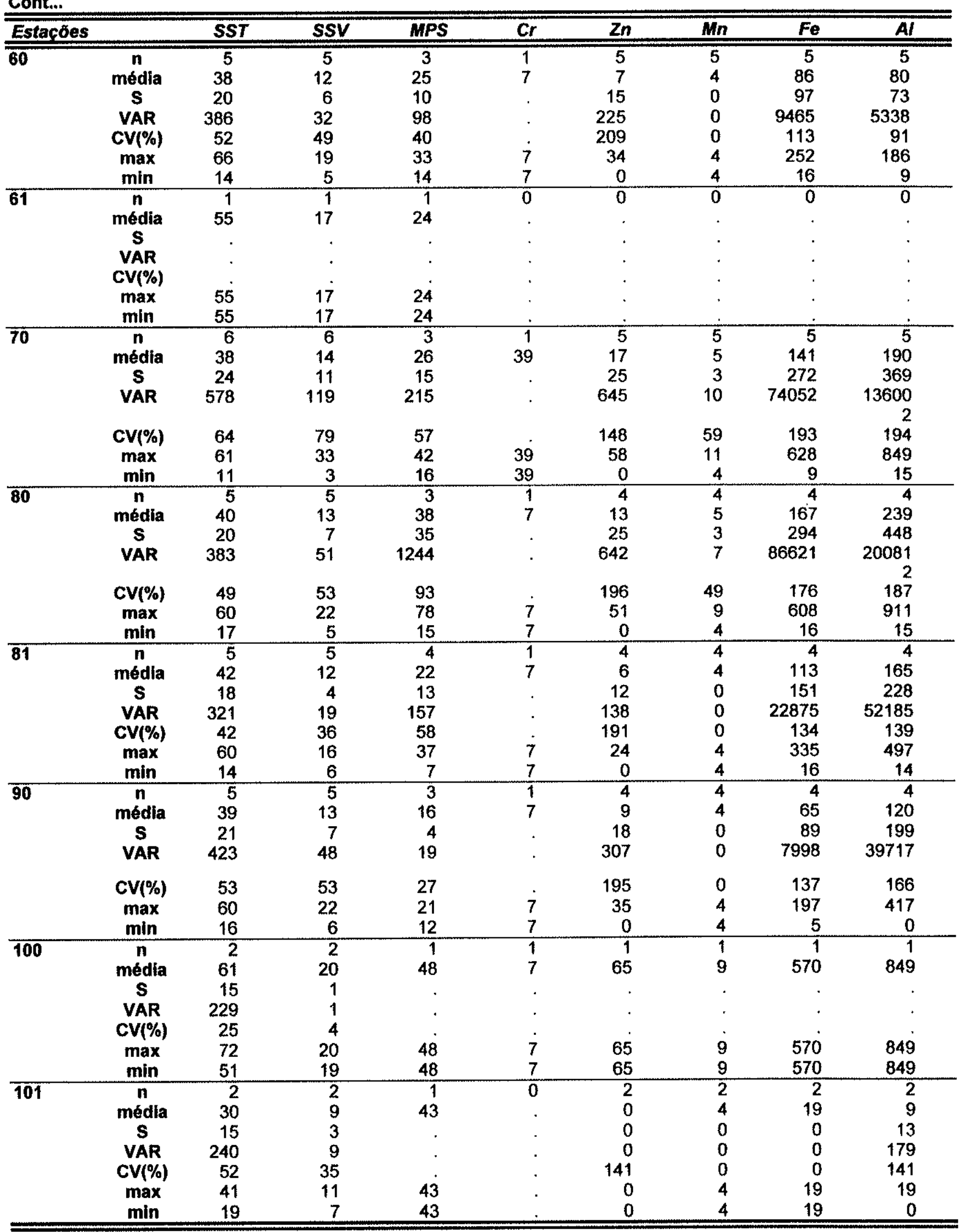


TABELA 21 - PARÅMETROS ESTATÍSTICOS PARA OS DADOS DOS SEDIMENTOS DE FUNDO NAS FASES 01/95, 02/95 E 03/95

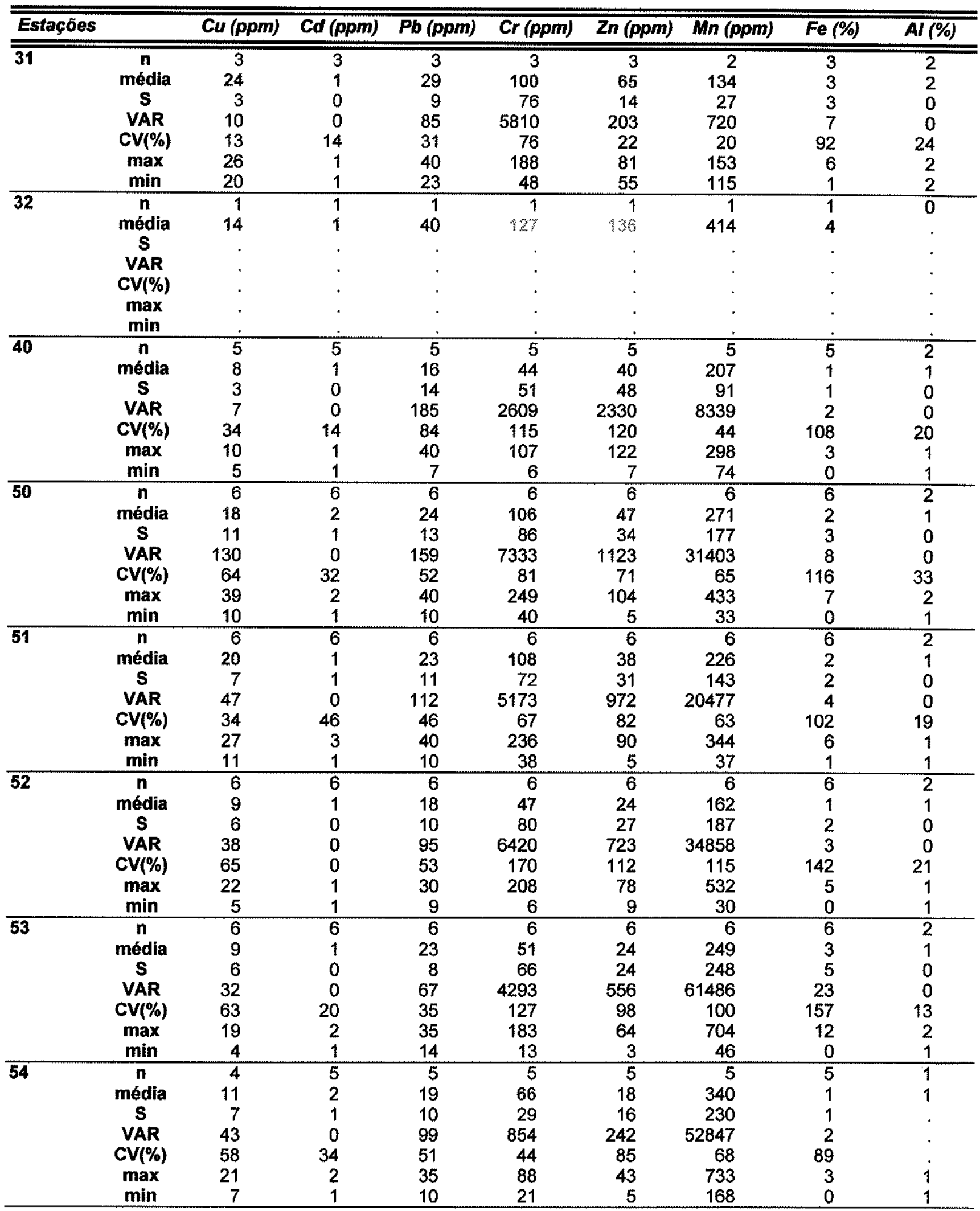


Cont...

\begin{tabular}{|c|c|c|c|c|c|c|c|c|c|}
\hline \multicolumn{2}{|c|}{ Estações } & $\mathrm{Cu}(\mathrm{ppm})$ & Cd (ppm) & $\mathrm{Pb}(p p m)$ & $\operatorname{Cr}(p p m)$ & $Z n(p p m)$ & $M n(p p m)$ & $\mathrm{Fe}(\%)$ & $A I(\%)$ \\
\hline \multirow[t]{7}{*}{60} & $\mathbf{n}$ & 4 & 5 & 5 & 5 & 5 & 5 & 5 & 1 \\
\hline & média & 11 & 1 & 23 & 50 & 21 & 192 & 1 & 2 \\
\hline & $\mathbf{S}$ & 4 & 0 & 10 & 12 & 17 & 101 & 1 & . \\
\hline & VAR & 17 & 0 & 98 & 146 & 296 & 10251 & 1 & . \\
\hline & CV(\%) & 38 & 22 & 44 & 24 & 81 & 53 & 95 & . \\
\hline & $\max$ & 16 & 2 & 35 & 66 & 40 & 275 & 2 & 2 \\
\hline & $\min$ & 7 & 1 & 10 & 36 & 3 & 36 & 0 & 2 \\
\hline \multirow[t]{7}{*}{70} & $\mathbf{n}$ & 6 & 6 & 6 & 6 & 6 & 6 & 6 & 2 \\
\hline & média & 11 & 1 & 16 & 53 & 33 & 207 & 1 & 1 \\
\hline & S & 3 & 0 & 5 & 44 & 16 & 157 & 1 & 0 \\
\hline & VAR & 8 & 0 & 22 & 1922 & 242 & 24516 & 2 & 0 \\
\hline & CV(\%) & 27 & 23 & 30 & 83 & 47 & 76 & 108 & 4 \\
\hline & $\max$ & 13 & 2 & 20 & 142 & 58 & 400 & 4 & 1 \\
\hline & $\min$ & 7 & 1 & 10 & 29 & 12 & 27 & 0 & 1 \\
\hline \multirow[t]{7}{*}{80} & $\mathbf{n}$ & 4 & 4 & 4 & 4 & 4 & 4 & 4 & 1 \\
\hline & média & 17 & 2 & 19 & 88 & 22 & 410 & 1 & 1 \\
\hline & S & 7 & 1 & 14 & 62 & 32 & 209 & 2 & . \\
\hline & VAR & 49 & 1 & 204 & 3826 & 997 & 43592 & 4 & . \\
\hline & CV(\%) & 41 & 52 & 75 & 70 & 142 & 51 & 144 & . \\
\hline & $\max$ & 22 & 3 & 40 & 160 & 70 & 581 & 4 & 1 \\
\hline & $\min$ & 7 & 1 & 10 & 9 & 5 & 135 & 0 & 1 \\
\hline \multirow[t]{7}{*}{81} & $\mathbf{n}$ & 5 & 5 & 5 & 5 & 5 & 5 & 5 & 2 \\
\hline & média & 14 & 1 & 20 & 78 & 33 & 228 & 2 & 1 \\
\hline & S & 3 & 1 & 12 & 62 & 33 & 173 & 3 & 0 \\
\hline & VAR & 9 & 0 & 150 & 3895 & 1083 & 30096 & 10 & 0 \\
\hline & CV(\%) & 20 & 43 & 60 & 80 & 99 & 76 & 153 & 3 \\
\hline & $\max$ & 17 & 2 & 40 & 188 & 84 & 397 & 8 & 1 \\
\hline & $\min$ & 10 & 1 & 10 & 36 & 4 & 29 & 0 & 1 \\
\hline \multirow[t]{7}{*}{90} & n & 5 & 5 & 5 & 5 & 5 & 5 & 5 & 2 \\
\hline & média & 22 & 2 & 19 & 103 & 35 & 215 & 2 & 1 \\
\hline & $\mathbf{S}$ & 7 & 1 & 8 & 73 & 33 & 150 & 2 & 0 \\
\hline & VAR & 45 & 1 & 59 & 5273 & 1073 & 22354 & 4 & 0 \\
\hline & CV(\%) & 30 & 47 & 40 & 71 & 93 & 70 & 122 & 12 \\
\hline & $\max$ & 29 & 3 & 30 & 226 & 84 & 350 & 5 & 1 \\
\hline & $\min$ & 11 & 1 & 10 & 43 & 5 & 50 & 1 & 1 \\
\hline \multirow[t]{7}{*}{100} & $\mathbf{n}$ & 2 & 2 & 2 & 2 & 2 & 2 & 2 & 2 \\
\hline & média & 14 & 1 & 18 & 39 & 34 & 58 & 1 & 1 \\
\hline & S & 4 & 0 & 0 & 3 & 2 & 9 & 0 & 0 \\
\hline & VAR & 20 & 0 & 0 & 11 & 4 & 87 & 0 & 0 \\
\hline & CV(\%) & 33 & 0 & 0 & 9 & 6 & 16 & 7 & 8 \\
\hline & $\max$ & 17 & 1 & 18 & 41 & 36 & 65 & 1 & 1 \\
\hline & $\min$ & 11 & 1 & 18 & 37 & 33 & 52 & 1 & 1 \\
\hline \multirow[t]{7}{*}{101} & $\mathbf{n}$ & 3 & 3 & 3 & 3 & 3 & 3 & 3 & 0 \\
\hline & média & 19 & 3 & 35 & 130 & 34 & 1010 & 4 & . \\
\hline & S & 1 & 0 & 13 & 94 & 49 & 242 & 6 & . \\
\hline & VAR & 2 & 0 & 175 & 8794 & 2366 & 58613 & 34 & . \\
\hline & $\mathrm{CV}(\%)$ & 7 & 11 & 38 & 72 & 144 & 24 & 135 & . \\
\hline & $\max$ & 20 & 3 & 50 & 236 & 90 & 1150 & 11 & . \\
\hline & $\min$ & 17 & 2 & 25 & 57 & 5 & 731 & 1 & . \\
\hline \multicolumn{2}{|c|}{ S-value (a) } & $\overline{15}$ & $\overline{0,4}$ & 50 & 50 & 50 & & & \\
\hline \multicolumn{2}{|c|}{ l-value (बiा } & 59 & 6,1 & 312 & 190 & 257 & & & \\
\hline
\end{tabular}


TABELA 22 - PARÂMETROS ESTATÍSTICOS PARA A GRANULOMETRIA (\%) DOS SEDIMENTOS DE FUNDO EM CADA ESTAÇÃO DURANTE AS FASES 01/95, 02/95 E 03/95.

\begin{tabular}{|c|c|c|c|c|c|c|c|c|}
\hline Estaçסes & & Argila & Silte Fino & $\begin{array}{c}\text { Silte } \\
\text { Grosso }\end{array}$ & Areia Fina & $\begin{array}{c}\text { Areia } \\
\text { Grossa }\end{array}$ & Umidade & MO \\
\hline \multirow[t]{7}{*}{31} & $n$ & $\overline{2}$ & 2 & 2 & 2 & 2 & 2 & 2 \\
\hline & média & 33 & 16 & 9 & 15 & 19 & 8 & 11 \\
\hline & $\mathbf{s}$ & 25 & 10 & 0 & 12 & 25 & 7 & 5 \\
\hline & VAR & 627 & 101 & 0 & 145 & 603 & 43 & 22 \\
\hline & CV (\%) & 75 & 63 & 4 & 80 & 132 & 81 & 43 \\
\hline & $\max$ & 51 & 23 & 9 & 24 & 36 & 13 & 14 \\
\hline & $\min$ & 16 & 9 & 8 & 7 & 1 & 3 & 7 \\
\hline \multirow[t]{7}{*}{40} & $n$ & 6 & 6 & 6 & 6 & 6 & 6 & 6 \\
\hline & média & 14 & 6 & 35 & 9 & 35 & 1 & 1 \\
\hline & $\mathbf{S}$ & 19 & 5 & 43 & 5 & 38 & 0 & 1 \\
\hline & VAR & 347 & 24 & 1835 & 20 & 1440 & 0 & 1 \\
\hline & CV (\%) & 135 & 89 & 124 & 49 & 107 & 45 & 70 \\
\hline & $\max$ & 39 & 12 & 93 & 13 & 84 & 2 & 3 \\
\hline & $\min$ & 0 & 0 & 0 & 3 & 0 & 1 & 1 \\
\hline \multirow[t]{7}{*}{50} & $\mathrm{n}$ & 6 & 6 & 6 & 6 & 6 & 6 & 6 \\
\hline & Média & 22 & 4 & 44 & 20 & 6 & 6 & 8 \\
\hline & $\mathbf{s}$ & 23 & 3 & 39 & 16 & 6 & 4 & 6 \\
\hline & VAR & 519 & 6 & 1502 & 262 & 41 & 14 & 36 \\
\hline & CV (\%) & 105 & 61 & 89 & 83 & 115 & 66 & 71 \\
\hline & $\max$ & 58 & 7 & 96 & 38 & 17 & 11 & 17 \\
\hline & $\min$ & 3 & 0 & 1 & 0 & 0 & 1 & 3 \\
\hline \multirow[t]{7}{*}{51} & $n$ & 6 & 6 & 6 & 6 & 6 & 6 & 6 \\
\hline & média & 64 & 10 & 4 & 3 & 3 & 8 & 9 \\
\hline & $\mathbf{S}$ & 4 & 6 & 4 & 2 & 3 & 4 & 7 \\
\hline & VAR & 12 & 41 & 18 & 5 & 8 & 14 & 48 \\
\hline & CV (\%) & 6 & 63 & 116 & 63 & 98 & 49 & 76 \\
\hline & $\max$ & 70 & 16 & 10 & 6 & 7 & 15 & 20 \\
\hline & $\min$ & 60 & 0 & 0 & 0 & 0 & 5 & 2 \\
\hline \multirow[t]{7}{*}{52} & $\mathbf{N}$ & 6 & 6 & 6 & 6 & 6 & 6 & 6 \\
\hline & Média & 18 & 2 & 36 & 7 & 32 & 2 & 2 \\
\hline & $\mathbf{S}$ & 25 & 2 & 44 & 6 & 43 & 2 & 3 \\
\hline & VAR & 608 & 4 & 1892 & 36 & 1882 & 4 & 8 \\
\hline & CV (\%) & 135 & 113 & 121 & 86 & 136 & 79 & 138 \\
\hline & $\max$ & 51 & 5 & 95 & 15 & 90 & 6 & 8 \\
\hline & $\min$ & 1 & 0 & 0 & 1 & 0 & 1 & 1 \\
\hline \multirow[t]{7}{*}{53} & $n$ & 6 & 6 & 6 & 6 & 6 & 6 & 6 \\
\hline & média & 11 & 4 & 41 & 15 & 24 & 5 & 4 \\
\hline & $\mathbf{s}$ & 6 & 2 & 32 & 9 & 33 & 2 & 2 \\
\hline & VAR & 38 & 4 & 1022 & 87 & 1075 & 6 & 3 \\
\hline & CV (\%) & 56 & 56 & 79 & 63 & 135 & 53 & 45 \\
\hline & $\max$ & 20 & 7 & 72 & 25 & 69 & 8 & 6 \\
\hline & $\min$ & 5 & 1 & 0 & 3 & 0 & 2 & 2 \\
\hline \multirow[t]{7}{*}{54} & $\bar{n}$ & 5 & 5 & 5 & 5 & 5 & 5 & 5 \\
\hline & média & 45 & 13 & 9 & 19 & 7 & 6 & 4 \\
\hline & $\mathbf{S}$ & 9 & 5 & 6 & 11 & 8 & 3 & 3 \\
\hline & VAR & 84 & 21 & 40 & 111 & 60 & 7 & 7 \\
\hline & CV (\%) & 20 & 36 & 69 & 55 & 112 & 41 & 68 \\
\hline & $\max$ & 53 & 16 & 16 & 38 & 20 & 9 & 7 \\
\hline & $\min$ & 30 & 5 & 1 & 12 & 0 & 4 & 1 \\
\hline \multirow[t]{7}{*}{60} & $\mathbf{n}$ & 5 & 5 & 5 & 5 & 5 & 5 & 5 \\
\hline & média & 28 & 9 & 11 & 39 & 7 & 7 & 6 \\
\hline & s & 7 & 4 & 8 & 12 & 8 & 3 & 5 \\
\hline & VAR & 54 & 13 & 57 & 149 & 70 & 6 & 21 \\
\hline & CV (\%) & 27 & 40 & 68 & 32 & 112 & 34 & 81 \\
\hline & $\max$ & 40 & 14 & 21 & 49 & 21 & 11 & 13 \\
\hline & $\min$ & 21 & 5 & 2 & 18 & 1 & 5 & 2 \\
\hline
\end{tabular}


Cont...

\begin{tabular}{|c|c|c|c|c|c|c|c|c|}
\hline Estaçóes & & Argila & Sitte Fino & $\begin{array}{c}\text { Silte } \\
\text { Grosso }\end{array}$ & Areia Fina & $\begin{array}{c}\text { Areia } \\
\text { Grossa }\end{array}$ & Umidade & $M O$ \\
\hline \multirow[t]{6}{*}{61} & $\begin{array}{c}\mathbf{n} \\
\text { média }\end{array}$ & $\begin{array}{r}1 \\
53\end{array}$ & $\begin{array}{l}1 \\
4\end{array}$ & $\begin{array}{l}1 \\
1\end{array}$ & $\begin{array}{r}1 \\
12\end{array}$ & $\begin{array}{r}1 \\
20\end{array}$ & $\begin{array}{l}1 \\
4\end{array}$ & $\begin{array}{r}1 \\
16\end{array}$ \\
\hline & $\mathbf{S}$ & . & . & . & . & . & . & . \\
\hline & VAR & . & . & . & . & . & . & . \\
\hline & CV (\%) & & & . & & & & \\
\hline & $\max$ & 53 & 4 & 1 & 12 & 20 & 4 & 16 \\
\hline & $\min$ & 53 & 4 & 1 & 12 & 20 & 4 & 16 \\
\hline \multirow[t]{7}{*}{70} & $\mathbf{n}$ & 6 & 6 & 6 & 6 & 6 & 6 & 6 \\
\hline & média & 22 & 3 & 34 & 15 & 9 & 9 & 7 \\
\hline & $\mathbf{S}$ & 11 & 2 & 27 & 3 & 10 & 2 & 4 \\
\hline & VAR & 125 & 4 & 702 & 11 & 99 & 5 & 14 \\
\hline & CV $(\%)$ & 51 & 58 & 77 & 21 & 105 & 26 & 50 \\
\hline & $\max$ & 42 & 6 & 59 & 20 & 24 & 12 & 14 \\
\hline & $\min$ & 12 & 0 & 1 & 11 & 0 & 6 & 5 \\
\hline \multirow[t]{7}{*}{80} & $n$ & 5 & 5 & 5 & 5 & 5 & 5 & 5 \\
\hline & média & 44 & 13 & 6 & 17 & 16 & 7 & 5 \\
\hline & & 21 & 7 & 6 & 20 & 20 & 3 & 1 \\
\hline & VAR & 448 & 43 & 33 & 405 & 411 & 7 & 2 \\
\hline & CV $(\%)$ & 48 & 49 & 96 & 121 & 125 & 41 & 27 \\
\hline & $\max$ & 58 & 17 & 15 & 52 & 52 & 10 & 7 \\
\hline & Min & 7 & 2 & 0 & 3 & 2 & 4 & 4 \\
\hline \multirow[t]{7}{*}{81} & $\mathbf{N}$ & 6 & 6 & 6 & 6 & 6 & 6 & 6 \\
\hline & média & 46 & 10 & 4 & 29 & 3 & 4 & 10 \\
\hline & $\mathbf{S}$ & 12 & 6 & 4 & 10 & 3 & 3 & 3 \\
\hline & VAR & 140 & 40 & 13 & 98 & 11 & 8 & 8 \\
\hline & CV $(\%)$ & 26 & 63 & 80 & 35 & 103 & 64 & 29 \\
\hline & $\max$ & 67 & 18 & 10 & 36 & 8 & 9 & 14 \\
\hline & $\min$ & 36 & 0 & 1 & 10 & 1 & 1 & 6 \\
\hline \multirow[t]{7}{*}{90} & n & 6 & 6 & 6 & 6 & 6 & 6 & 6 \\
\hline & média & 62 & 15 & 3 & 11 & 3 & 7 & 6 \\
\hline & $\mathbf{S}$ & 2 & 8 & 2 & 3 & 3 & 4 & 7 \\
\hline & VAR & 6 & 72 & 4 & 10 & 10 & 14 & 52 \\
\hline & CV (\%) & 4 & 55 & 64 & 30 & 92 & 57 & 122 \\
\hline & $\max$ & 65 & 24 & 6 & 15 & 8 & 13 & 17 \\
\hline & $\min$ & 59 & 0 & 1 & 7 & 1 & 2 & 0 \\
\hline \multirow[t]{7}{*}{100} & $\mathbf{n}$ & 2 & 2 & 2 & 2 & 2 & 2 & 2 \\
\hline & média & 55 & 7 & 3 & 18 & 1 & 7 & 13 \\
\hline & $\mathbf{S}$ & 4 & 10 & 0 & 8 & 0 & 5 & 0 \\
\hline & VAR & 14 & 107 & 0 & 57 & 0 & 29 & 0 \\
\hline & CV (\%) & 7 & 141 & 6 & 41 & 32 & 74 & 2 \\
\hline & $\max$ & 58 & 15 & 4 & 24 & 1 & 11 & 13 \\
\hline & $\min$ & 53 & 0 & 3 & 13 & 1 & 3 & 13 \\
\hline \multirow[t]{7}{*}{101} & $n$ & 2 & 2 & 2 & 2 & 2 & 2 & 2 \\
\hline & médía & 34 & 10 & 6 & 32 & 9 & 10 & 6 \\
\hline & $\mathbf{S}$ & 1 & 1 & 0 & 1 & 4 & 1 & 1 \\
\hline & VAR & 2 & 2 & 0 & 2 & 18 & 1 & 1 \\
\hline & $\operatorname{CV}(\%)$ & 4 & 12 & 0 & 4 & 48 & 9 & 21 \\
\hline & $\max$ & 35 & 11 & 6 & 33 & 12 & 11 & 7 \\
\hline & $\min$ & 33 & 9 & 6 & 31 & 6 & 10 & 5 \\
\hline
\end{tabular}

